\title{
Innovation in manufacturing from product variety and labor productivity growth to economic development in Chile
}

Citation for published version (APA):

Lauterbach, R. (2012). Innovation in manufacturing from product variety and labor productivity growth to economic development in Chile. [Doctoral Thesis, Maastricht University]. Datawyse / Universitaire Pers Maastricht. https://doi.org/10.26481/dis.20121204rl

Document status and date:

Published: 01/01/2012

DOI:

10.26481/dis.20121204rl

Document Version:

Publisher's PDF, also known as Version of record

\section{Please check the document version of this publication:}

- A submitted manuscript is the version of the article upon submission and before peer-review. There can be important differences between the submitted version and the official published version of record.

People interested in the research are advised to contact the author for the final version of the publication, or visit the DOI to the publisher's website.

- The final author version and the galley proof are versions of the publication after peer review.

- The final published version features the final layout of the paper including the volume, issue and page numbers.

Link to publication

\footnotetext{
General rights rights.

- You may freely distribute the URL identifying the publication in the public portal. please follow below link for the End User Agreement:

www.umlib.nl/taverne-license

Take down policy

If you believe that this document breaches copyright please contact us at:

repository@maastrichtuniversity.nl

providing details and we will investigate your claim.
}

Copyright and moral rights for the publications made accessible in the public portal are retained by the authors and/or other copyright owners and it is a condition of accessing publications that users recognise and abide by the legal requirements associated with these

- Users may download and print one copy of any publication from the public portal for the purpose of private study or research.

- You may not further distribute the material or use it for any profit-making activity or commercial gain

If the publication is distributed under the terms of Article $25 \mathrm{fa}$ of the Dutch Copyright Act, indicated by the "Taverne" license above, 


\section{Innovation in \\ Manufacturing,}

From Product Variety and Labor Productivity Growth to Economic Development in Chile 
(C) Copyright R Lauterbach, Maastricht 2012 ISBN 9789461591845

Published by Universitaire Pers Maastricht

Printed in The Netherlands by Datawyse Maastricht 


\title{
Innovation in Manufacturing From Product Variety and Labor Productivity Growth to Economic Development in Chile
}

\author{
DISSERTATION \\ to obtain the degree of doctor at Maastricht University, \\ on the authority of the Rector Magnificus Prof. Dr. L.L.G. Soete, \\ in accordance with the decision of the Board of Deans, \\ to be defended in public on Tuesday December $4^{\text {th }} 2012$ at 10:00 hours
}

by

Rodolfo Lauterbach

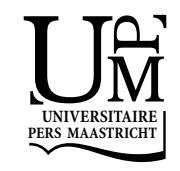


Supervisor:

Prof. Dr. Jacques Mairesse

Prof. Dr. Bronwyn Hall

Assesment Committee:

Prof. Dr. Pierre Mohnen (chair)

Prof. Dr. Jose Miguel Benavente (Universidad Adolfo Ibañez)

Prof. Dr. Can Huang 


\section{Acknowledgements}

This project would not have been feasible without the participation of all the people who made me believe it possible. On the way to my doctorate studies, there were many people who challenged, encouraged and inspired me. I would not have achieved my $\mathrm{PhD}$ in Economics without the love and support of my family. The perseverance of my mother and the hard working example of my father made me become an economist on the first place. My wife has provided me with the inspiration to pursue what I want in my life and my son has taught me about the things that truly matter.

The two people who truly made my graduation possible were Bronwyn Hall and Jacques Mairesse. To them my gratitude is endless. I owe them for their wisdom and their patience but also for challenging me to use my best qualities and struggle against my weaknesses during these four years of research. They supported me in every moment and not only shared the joy of my small achievements but also recognized my mistakes with honesty.

My experience as a researcher would not have been the same without the passion for empirical economics that I learned at the Economics and Business Faculty of the University of Chile. I had the fortune to be a student of Jose Miguel Benavente in a research environment that opened my mind in a way I did not expect. I was invited to collaborate in the research of Manuel Agosin and Ricardo Paredes, to both of whom I am grateful for teaching me discipline and research methods. My research at Intelis Centre for Innovation and Entrepreneurial studies greatly benefited from the interaction with Jocelyn Olivari, Cintia Külzer, Pablo Hernandez, Jose Zubizarreta, Gustavo Crespi, Jose Luis Contreras, Jose Luis Lima, Claudio Bravo, Roberto Alvarez, Andres Zahler, Oscar Landerreche and Jorge Katz.

Since my arrival to Maastricht, I have enjoyed unprecedented hospitality from its inhabitants. Having the fortune of coexisting with people from the community of the United Nations has made my days in Maastricht an experience that I will never forget. My first year in The Netherlands was spent on the company of Iman Rajabzadeh and Ying Zhang, with whom I shared experiences that expanded the reach of my understanding. In the surroundings of my classmates from the United Nations University Maastricht Economic and Social Research Center on Innovation and Technology (UNU-MERIT) I learned some of the most important aspects of teamwork and friendship. Many thanks to my co-workers and friends Lilia Stubrin, Asel Doranova, Flavia Carvalho, Nico Rasters, Luciana Marins, Ezequiel Tacsir, Daniel Vertesy, Shuan SadreGhazi, Conrad SchmidtBens, Muhammad Shafique, Tina Saebi, Lina Sonne, Semih Akçomak, Nora Engel, Luciana Cingolani, Cheng Ong, Salih Cevikarslan, Jun Hou, Alexis Habiyaremye, Ibrahim Bolat, Anant Kamath, Baseer A. Qazi, Bilal Mirza, Zakaria 
Babutsidze, Sergey Filippov, Kirsten Wiebe, and Than Le Phuoc. At the United Nations University (UNU), they taught me how to be a $\mathrm{PhD}$ researcher.

While conducting the data analysis that was part of this research, I had the chance to work with Sabien Dobbelaere, who shared a tremendous amount of knowledge with me. Thanks to her for showing me the way toward truly careful data analysis. During my PhD, I had the priviledge of learning economics and innovation policy from various professors. Pierre Mohnen, Bart Verspagen, Luc Soete, Robin Cowan, Adam Szirmai, Théophile Azomahou, and Anthony Arundel are some of the best team leaders I have ever seen. They have helped develop the real knowledge that makes possible the mission of the UNU.

During the past four years, the UNU-MERIT community has been enlightened by the minds of researchers including Michiko Iizuka, Jojo Jacob, Ionara Costa, Can Huang, Mulu Gebreeyesus, Micheline Goedhuys, Maha Ahmed, Rossitza Rousseva, and many others who contributed their research to the common prosperity goals of the United Nations. I am indebted to Samyukta Bhupatiraju, François Lafond, Alejandro Lavopa, Hibret Maemir, Daniel Opolot, Tatevik Poghosyan, Giorgio Triulzi, Jennifer Taborda, Andrea Medina, Charlotte Guillard, Ilire Agimi, Simone Sasso, Craig Loschmann, Andrea Franco-Correa, Francesca Guadagno, and many others who have more recently joined the $\mathrm{PhD}$ program at the Economics and Policy Studies of Technical Change. They fill our workspace and environment with challenging ideas and sincere emotions. Without them, I would not believe that it is possible to make this planet a better place to share with everyone.

The joint PhD program from Maastricht University and UNU-MERIT would not be the same in the absence of Eveline in de Braek, who was always there to care for the problems of each student, Eric Engelen, who organized and cared for our building and workspace, Herman Pijpers and Mourik Jan Heupink, who built and sustained our informatics system, and Ad Notten, who maintains and updates an unprecedentedly specialized library on Innovation and Technical Change.

During these four years of research, I have traveled to Paris on repeated occasions as a visiting researcher to Centre de Recherche en Èconomie et Statistique (CREST) that is part of the French National Statistical and Economic Studies Office (INSEE). I am grateful to Nadine Guedj, Paul-antoine Chevalier, Maxime To, Yilin Wu, Caroline Paunov, and Eduardo Rodriguez, who welcomed me to France and shared their moments with me. Many thanks also to Anja Schmiele, Diego Ubfal, Alessandro Maffioli, Lucas Navarro, Jaan Masso, and many others who participated in the MEIDE conferences in Maastricht, Rio do Janeiro, and Tartu.

Part of my research was also done at the University of California at Berkeley (UCB), where I greatly benefited from knowledge spillovers from many people. Many thanks to Chantal Toledo, Gianmarco León, Jessica Rider, Anna Spurlock, Alex Solís, Charles Séguin, Di Zeng, and Catie Almirall from the Agricultural and Resource Economics (ARE) Department for making me feel like one more of 
your outstanding PhD cohort. Thanks to Francois Gerard, Mauricio Larrain, Willa Friedman, Issi Romen, Omar Nayeem, Josh Hausman, James Zuberi, Miguel Almunia, Carlos Noton, Rosario Macera, and Gabriel Chodorow-Reich from the Economics Department of UCB for sharing their knowledge, their workspace, and their friendship with me.

My PhD research was funded by the United Nations and my research-related travel was supported by the European Commission Research and Innovation $7^{\text {th }}$ Framework Program on Science and Technology. Intelis Centre at the Department of Economics of the University of Chile has given me access to valuable data to carry out this research. The surveys that have been used for most of this study have been carried out by the Chilean statistical office, Instituto Nacional de Estadisticas (INE). 


\section{Table of Contents}

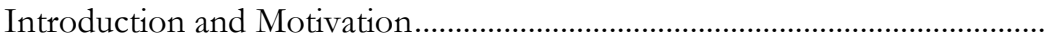

Chapter 1 Democratic Institutions, Industrial Development, and Economic Growth in Chile 5

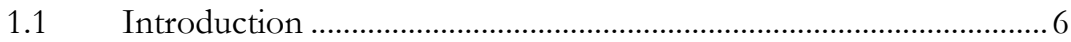

1.2 Towards the Establishment of a Dependable Democracy .............. 7

1.3 Institutions, Industrial Development, and Growth in Chile ..........10

1.3.1 Economic Growth in the Past Three Decades 10

1.3.2 Recent Economic Development Experience in Chile 14

1.3.3 Education Effort and Education Quality 19

1.3.4 R\&D and the National Innovation System 20

1.3.5 Dutch Disease, the Role of Copper and Exports on Chilean Development 25

1.3.6 Productivity, Industrial Policy, Economic Sectors and Convergence $\quad 30$

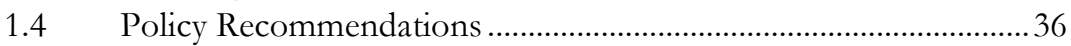

1.4.1 Chilean Strengths that have Supported Growth and Development 36

1.4.2 Weaknesses and Challenges for Future Development 38

1.4.3 Recommendations for Modern Economic Growth in Chile 39

1.5 Concluding Remarks ..................................................................... 42

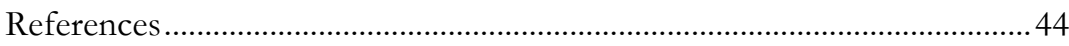

Chapter 2 Cooperation on Innovative Investments: The Role of Information Flows 49

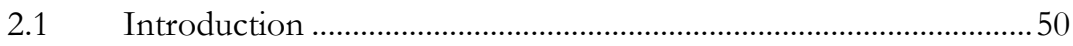

2.2 Previous Literature on R\&D Cooperation Determinants..............51

2.3 Knowledge Spillovers Econometric Model ......................................53

2.4 Chilean Fourth Innovation Survey Data .............................................56

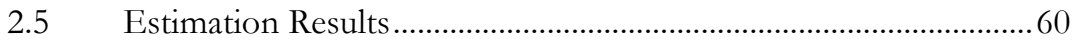

2.5.1 Preliminary Probit Regressions $\quad 60$

2.5.2 Two-Step Endogeneity Test Results 62

2.5.1 CML with Instrumental Variables Results 62

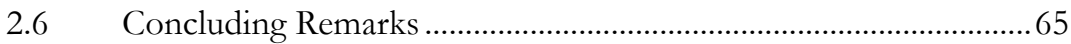

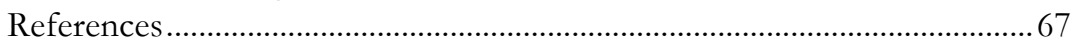

Chapter 3 Product Innovation, Price Growth, and Labor Productivity 69

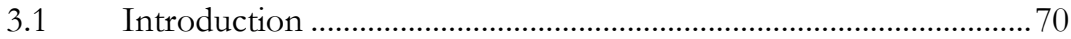

3.2 Previous Literature on Production Function Estimation ............... 71

3.3 Productivity and Innovation Empirical Strategy …..........................75

3.4 Chilean Manufacturing Industry Data ............................................. 78

3.4.1 A Measure of Product Innovation $\quad 78$

3.4.2 Correlation between the Main Product Innovation Indicators 85 
3.4.3 Correlation between New Price Growth and Innovation Indicators 86

3.4.4 Basic Descriptive Statistics 88

3.5 Estimation Results ........................................................................... 91

3.5.1 OLS Preliminary Estimates 91

3.5.1 Instrumental Variable Estimates 95

3.5.2 Products Added or Dropped and the Proportion of Innovative Sales 98

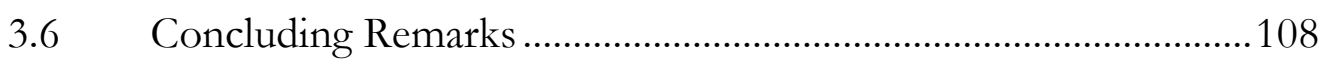

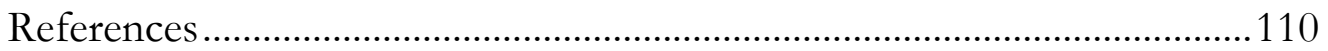

Chapter 4 Markup and Rent Sharing in Manufacturing: New Evidence from Chilean Firms $\quad 113$

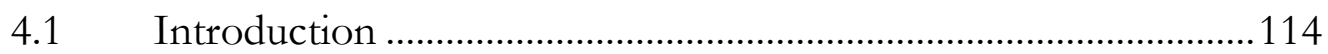

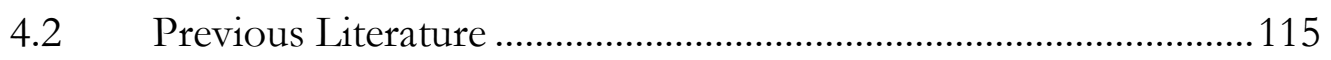

4.2.1 The Empirical Study of Market Power 115

4.2.2 Market Power and Rent Distribution 116

4.2.3 Mark-up and Rent sharing in the Manufacturing Industry 117

4.2.4 Managerial Efforts, Innovation, and Market Power 119

4.3 Markup and Rent Sharing Econometric Model ...........................120

4.3.1 Markup of Prices over Marginal Costs 120

4.3.2 Labor Force Market Power 122

4.4 Chilean Manufacturing Industry Data .......................................... 124

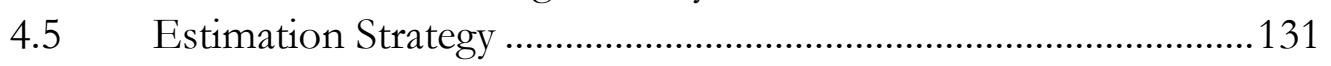

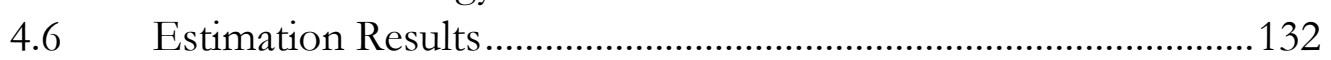

4.6.1 Manufacturing Level Results 132

4.6.2 Industry Level Analysis 137

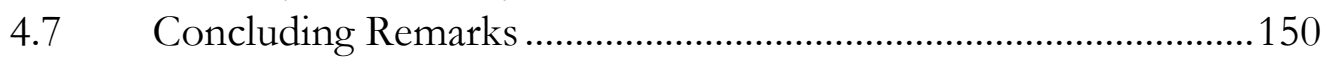

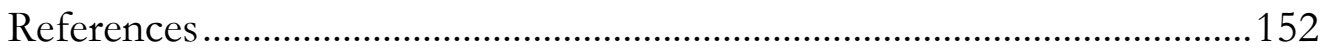

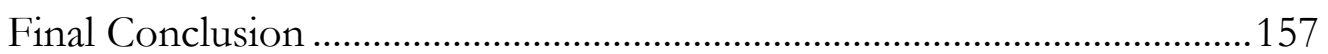

Appendix 1 Statistics of Growth and Development in Chile .....................161

Appendix 2 R\&D Cooperation Determinants Model Variable

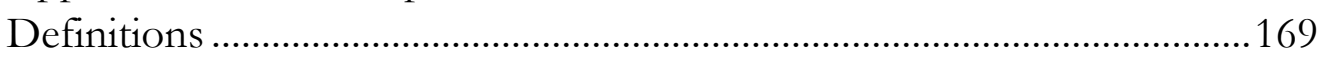

Appendix 3 Chilean Survey Data on Manufacturing and Innovation ......171

A3.1 Introduction to the Data 171

A3.2 Panel Data from Different Surveys 172

A3.3 Creation of a Firm-Level Panel Database 174

A3.4 Measurement of Book Value of Capital 175

A3.5 Generating Production Function Variables 175

A3.6 Basic Data Cleaning 176

A3.7 Summary of Main Variables and Production Variables

$\begin{array}{ll}\text { Definitions } & 176\end{array}$

A3.8 Preliminary Panel Data Production Function Regression 179 
Appendix 4 Firm-Level Price Growth ..........................................................181

A4.1 Constructing Firm-level Price Growth Rates 181

A4.2 Computation of the Industry-level Price Index 184

A4.3 Correlation between Firm and Industry-level Price Changes 186

A4.4 Deflated Output and Input Variables at Firm and Industrylevel 187

A4.5 Using Industry-level and Firm-level Output Deflators 187

A4.6 Input Deflators 190

Appendix 5 Computation of Product Innovation Variables ......................193

Appendix 6 Innovation and Productivity with Constant Returns .............196

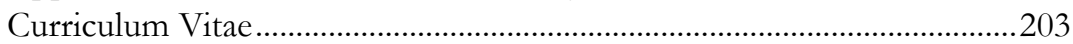

UNU-MERIT Dissertation Series .............................................................205 


\section{List of Figures}

Figure 1.1 Yearly Total GDP and GDP growth in Chile (1980-2010) ...................13 Figure 1.2 Average Per Capita Income and GINI Index in Chile (1980-2010)......15 Figure 1.3 Interest Rate, Inflation Rate and Unemployment Rate in Chile (19802010) 16

Figure 1.4 Chilean Consolidated Public Debt (1990-2008) .......................................17

Figure 1.5 Labor market Development Indicators in Chile (1980-2010) .................18

Figure 1.6 Development Indicators in Chile (1980-2010) .......................................19

Figure 1.7 Education Expenditure in Chile (1990-2008) ............................................20

Figure 1.8 Manufactured Exports, Copper Exports and GDP in Chile (1980-2010)

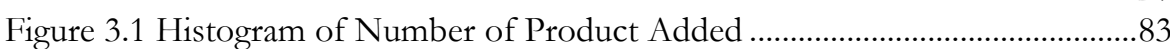

Figure 3.2 Histogram of Number of Products Dropped ..........................................83

Figure 3.3 Histogram of Added Products Share on Sales .........................................84

Figure 3.4 Histogram of Dropped Products Share on Sales over 2 years................85

Figure 3.5 Correlation of New Price and Innovation Variables with $4^{\text {th }}$ Innovation

Survey (IS) Product and Process Innovation .............................................................89

Figure A4.1 Firm-level Deflated Output and INE ISIC Rev.2 3-digit Deflated Output 190 


\section{List of Tables}

Table 1.1 EIU Democracy Index 2010 ........................................................................

Table 1.10 Sector Shares on Chilean Exports 1996-2007 ………………………......29

Table 1.11 Evolution of Aggregate TFP Growth in Chile 1981-2003......................31

Table 1.12 TFP Growth in Chilean Economic Sectors 1996-2001............................31

Table 1.13 Productive Structures of Chilean Regions in 2000......................................34

Table 1.14 Per capita GDP PPP across Regions of Chile (constant 2005 US\$) ....35

Table 1.15 Sector Shares in Value Added, the Chilean Productive Structure 2003-

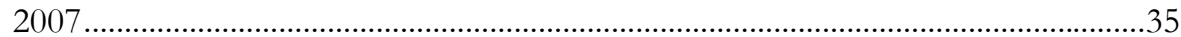

Table 1.2 GDP and GDP per capita in Chile 1974-2011 .......................................12

Table 1.3 Decade Average GDP per capita Growth of Selected Country Groups 1981-2009

Table 1.4 Standard Deviation of GDP per capita Growth of Selected Countries 1981-2009.

Table 1.5 Patents Filed under the Patent Co-operation Treaty (PCT) 2003-2008.22

Table 1.6 R\&D Spending across Selected Countries (Percentage of Total GDP).23

Table 1.7 Productive Composition of Chile 1980-2007 …………………………....24

Table 1.8 Evolution from 2005 to 2007 of Technological Innovation by

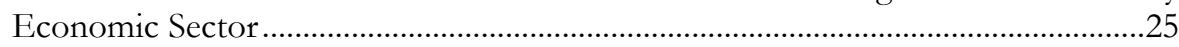

Table 1.8 Participation of Metallic Mining Sector in Total Exports (\% of year

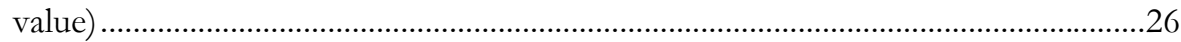

Table 1.9 Exports and Imports of Goods and Services, Chile 1970-2009..............28

Table 2.1 Fourth Chilean Innovation Survey Basic Sample Statistics.........................57

Table 2.2 Descriptive Statistics.....................................................................................57

Table 2.3 Correlation Matrix of Cooperation with Different Partners.....................59

Table 2.4 Correlation Matrix of the Dependent Variable with the Main Explanatory Variables................................................................................................5

Table 2.5 Results of Probit Preliminary Regressions .................................................61

Table 2.6 Testing for Endogeneity, Results of 2SCML .............................................63

Table 2.7 Results of CML with Instrumental Variables................................................64

Table 3.1 Number of Products Added and Dropped over a Single-year Period ..79, 80

Table 3.10 IV regressions with Constant Returns to Scale …………………………...97

Table 3.11 OLS regressions with Products Added and Products Dropped ...........99

Table 3.12 OLS regressions with Number of Products Added............................... 101

Table 3.13 OLS regressions with Number of Products Dropped .......................... 102

Table 3.14 OLS regressions with Products Added and Dropped Sales Proportions

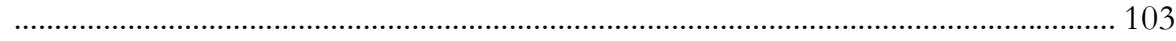

Table 3.15 OLS regressions, with Products Added Sales Proportion ................... 104

Table 3.16 OLS regressions with Products Dropped Sales Proportion ................ 105

Table 3.17 OLS regressions with Four Product Innovation Dummies................. 107

Table 3.2 Number of Products Added and Dropped over a Two-year Period......82

Table 3.3 Correlation Matrix of Product Innovation Variables..................................86

Table 3.4 Correlations between Innovation Survey Product and Process Innovation, Product Innovation Indicators and Firm-level price growth ...............87

Table 3.5 Descriptive Statistics of Main Variables .........................................................90 
Table 3.6 Correlation Matrix of Main Variables in First Differences

Table 3.7 OLS Production Function regressions with Non-Constant Returns to

Scale

Table 3.8 OLS Production Function regressions assuming Constant Returns to

Scale

Table 3.9 IV regressions with Non-Constant Returns to Scale .96

Table 4.1 Number of Observations by Industrial Sector 124

Table 4.10 Basic Metal, Fabricated Metal Products, Machinery and Equipment Industries...... 130

Table 4.11 All Manufacturing Industries Estimates with Constant Returns to Scale 134

Table 4.12 All Manufacturing Industries Estimates with Non-Constant Returns to Scale 136

Table 4.13 Manufacture of Food, Beverages and Tobacco Industries Estimates 138 Table 4.14 Textile, Wearing Apparel and Leather Industries Estimates .............. 140 Table 4.15 Wood, Wood Products and Furniture Industries Estimates ............... 141 Table 4.16 Paper and Paper Products, Printing and Publishing Industries Estimates . 143

Table 4.17 Manufacture of chemicals and chemical, petroleum, coal, rubber and plastic products 144

Table 4.18 Non-metallic Mineral Products and Other Manufacturing Industries Estimates . 145

Table 4.19 Basic Metal, Fabricated Metal Products, Machinery and Equipment Industries Estimates. 146

Table 4.2 Unbalanced Panel Summary ........................................................................... 125

Table 4.20 Summary of Seven Industrial Sectors OLS Estimates in Levels ........ 148

Table 4.21 Summary of Seven Industrial Sectors GMM SYS Estimates ............. 149

Table 4.3 All Manufacturing Industries Descriptive Statistics .............................. 125

Table 4.4 Manufacture of Food, Beverages and Tobacco Industries .................... 126

Table 4.5 Textile, Wearing Apparel and Leather Industries Descriptive Statistics 127

Table 4.6 Manufacture of Wood and Wood Products and Furniture Industries Descriptive Statistics 128

Table 4.7 Manufacture of Paper and Paper Products, Printing and Publishing Industries 128

Table 4.8 Chemicals and Chemical Petroleum, Coal, Rubber and Plastic Products Industries. 129

Table 4.9 Non-metallic Mineral Products and Other Manufacturing Industries 130 Table A1.1 Yearly total GDP and GDP growth in Chile 1960-2009 ................... 161

Table A1.2 Average Per capita Income and GINI Index in Chile 1980-2009 .... 162 Table A1.3 Interest Rate, Inflation Rate and Unemployment rate in Chile (19802009) 163

Table A1.4 Chilean Consolidated Public Debt (1990-2008) .................................. 164

Table A1.5 Labor Market Development Indicators in Chile (1980-2009) ............ 165

Table A1.6 Development Indicators in Chile 1980-2009 ......................................... 166

Table A1.7 Education Expenditure in Chile 1990-2008 (\% of current GDP) .... 167 
Table A1.8 Manufacture Exports, Copper Exports and GDP in Chile (1980-2009)

Table A3.1 Number of Observations in Firm-level and Product-firm level Data

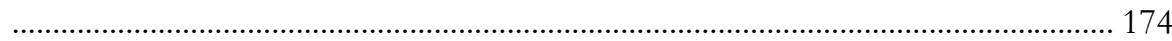

Table A3.2 Average Industry-level Yearly Growth of Capital Book Value ......... 175

Table A3.3 Average Industry-level Yearly Capital Investment............................. 175

Table A3.4 Descriptive Statistics of Basic Production Variables .......................... 177

Table A3.5 Descriptive Statistics of Basic Production Variables Expressed in

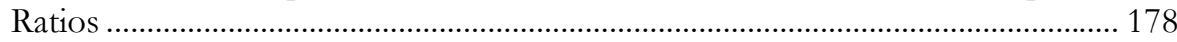

Table A3.6 Preliminar Productivity Regressions using Nominal Sales and Inputs 180

Table A4.1 Descriptive Statistics of Product-level data Coverage over Total Sales 182

Table A4.2 Descriptive Statistics of Firm-level Price Growth Rates .................... 184 Table A4.3 Industry-level (ISIC Rev. 2) Price Growth Rates at 2, 3 and 4-digit level 185

Table A4.4 Correlation of Firm-level Price Growth Rates and Industry-level

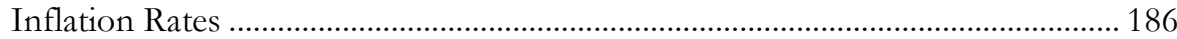

Table A4.5 Comparison between Firm-level Deflated Output ............................. 188

Table A4.6 Comparison between 2, 3 and 4-digit Industry-level Deflated Output

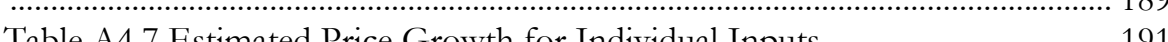

Table A4.7 Estimated Price Growth for Individual Inputs .................................... 191

Table A4.8 Descriptive Statistics of Deflated Input Variables ............................... 192

Table A5.1 Descriptive Statistics of Product Innovation Indicators ..................... 194

Table A6.1 Ordinary Least Square estimation with Number of Products Added and Dropped and constant returns to scale............................................................. 196

Table A6.2 Instrumental Variable estimation with Number of Products Added and Dropped and constant returns to scale.......................................................... 197

Table A6.3 Ordinary Least Square estimation with Number of Products Added and constant returns to scale 198

Table A6.4 Instrumental Variable estimation with Number of Products Added and constant returns to scale 199

Table A6.5 Ordinary Least Square estimation with Number of Products Dropped and constant returns to scale 200

Table A6.6 Instrumental Variable estimation with Number of Products Dropped and constant returns to scale 


\section{INTRODUCTION AND MOTIVATION}

As a result of the current economic situation in Chile where it seems that a full employment phenomenon is taking place, economists have awakened their interest in productivity. This work starts from the basis that manufacturing is one of the main engines for exports and thus economic growth. Therefore the main target of this book is to study productivity dynamics in the manufacturing sector giving specific attention to the innovative process, the effects of the introduction of new products and the labor and final product market outcomes and their relation with labor productivity growth.

The manufacturing industry is the manifestation of the level of technology and knowledge of a country. Manufacturing may be defined as the capacity to change materials into goods that are later transformed into consumption and ultimately into welfare. Improving market efficiency and increasing productivity in the manufacturing industry is therefore an objective of the social planner in her search for economic growth and development. The case of Chilean industry is of specific interest because it is a relatively successful experience, in which natural resources such as copper have been extracted, promoting economic growth and positive current account balances. A share of these revenues is being invested in knowledge, infrastructure, and financial assets. This work is also based on the idea that growth in the long term cannot be based on the extraction of exhaustible natural resources but requires a more diversified industrial production.

Measuring productivity dynamics in the manufacturing industry is important because productivity reflects the effects of all the forces of economic life: technical progress, accumulation of productive factors, managerial inputs and the institutional trend of the economy. Even though it represents a relatively small proportion of the economy, the manufacturing sector provides basic goods such as elaborated materials, electronics, foods, and medicines that are indispensable for the generation of value added and growth in all sectors of the economy. In the context of goods that are essential for life, such as food, economists have been interested for decades in understanding productivity growth and how it is affected by the uses of inputs and knowledge, as well as by market conditions.

Understanding production growth and market outcomes in the manufacturing sector is relevant also because industrial production has embedded in humans the knowledge and the ability to build and transform materials. From the construction of buildings to small utensils and electronic equipment, a great deal of cultural knowledge and creativity has been transmitted through the production of manufactures. 
Different approaches have been used since the 1970s to measure the role of innovation, own R\&D, and R\&D spillovers as sources of knowledge affecting productivity at the firm-level. When the level of knowledge available in an economy increases, the industry improves its productivity. Achieving high productivity should also be understood from a long-term perspective, since what we ultimately care about is sustainable economic growth. Increasing knowledge may also expand the variety of products in the manufacturing industry. The case of Chile is highly interesting from the long-term perspective because its industry is based on the extraction of exhaustible natural resources. When natural resources are exhausted, a diversified manufacturing industry may lead to further economic success if the necessary investment in diversified knowledge and infrastructure has been previously made.

The Chilean economy has recently been distinguished as a relatively successful case of rapid growth. The main factors contributing to this success have been its democratic institutions, foreign trade based on copper exports, and macroeconomic stability. The first chapter of this work analyzes the economic growth and development that has taken place in Chile during the past three decades. The Chilean economy is studied in light of data collected by several national and international organizations, including the Chilean Statistical Office (INE), the Central Bank of Chile, the World Bank, and the OECD. An evaluation and international comparison of the recent success of Chilean democracy is made. This work proposes that international trade based on manufacture and export diversification, increasing human capital through public investment in education, and innovative activities, which imply R\&D investment, are some of the aspects that can contribute to sustainable economic growth for the coming decades.

The second chapter studies the determinants of R\&D cooperation among innovative firms using data from the $4^{\text {th }}$ version of the Chilean Innovation Survey, which covered the years 2003 and 2004. The empirical model applied in this work defines the probability of R\&D cooperation for the innovating firms as a function of the technology of information flows. The findings show that firms that have declared in surveys that they benefit from incoming information spillovers, those that have declared that they benefit from cost-risk sharing, and those that make use of legal protection of their knowledge are more likely to commit to R\&D agreements with other firms, such as consultants, universities, competitors, and customers. Firm size also affects positively and significantly the probability of cooperating among Chilean firms. Among the factors that are associated with a smaller probability of engaging in $\mathrm{R} \& \mathrm{D}$ agreements are lack of information and firms' perception of the ease with which their own inventions could be imitated by others. Information flows seem to have a larger impact on cooperation with universities and consulting agents. After finding that incoming spillovers are endogenous, the empirical estimations used the industry-level data about incoming spillovers and basic nature of $\mathrm{R} \& \mathrm{D}$ as instrumental variables in the context of a conditional maximum likelihood estimation method.

The third chapter of this thesis develops a set of new measures for firm-level product innovation based on product-firm-level information. It then evaluates the impact of innovation on manufacturing productivity at the firm level. Because the absence of 
individual firm data on price growth was one of the main restrictions on the empirical study of production functions in previous work, this work also takes advantage of price information at the level of products within firms. The problem of absent price data occurs when observed nominal output growth cannot be separated into unobserved real production growth and price changes. This chapter develops a new strategy to estimate annual firm-level price growth and product innovation indicators. It uses a panel containing detailed firm-level and product-firm level information provided by the Chilean Statistical Office (INE) for the period 1996-2003. It compares different ways in which firm-level price data may be incorporated into the econometrics of production. The findings show that incorporating new products is associated with productivity growth while dropping products is related to decreases in productivity, probably due to the rigidity of the labor market. It also finds that estimating a production function using nominal or real output makes very little difference to the estimated input and scale elasticities.

This fourth and last chapter estimates price-cost markups and workers' bargaining power using input elasticities and shares of input cost over sales. Real output and productivity growth were calculated using firm-level price information, thanks to new product-firm level data from the Chilean manufacturing industry between 1996 and 2003. The Chilean manufacturing industry was divided and compared across seven sectors. The Paper, Printing, and Publishing industry was found to have the lowest mark-ups, measured by the estimations in levels, followed by the Textile industry. The Food and Beverages industry appears to have the highest average mark-up of price over marginal cost and also the highest extent of rent sharing between workers and firm owners. The Textile industry was found to be the sector where workers get the smallest share of rents. In general, firm rents are distributed between capital owners and employees, allowing for different labor market outcomes across sectors of the manufacturing industry. This analysis also found that deflating output at the firm level or at the industry level does not change the estimated parameters significantly, even though some differences may be found in the estimated standard deviations.

In summary, using the experience of the Chilean economy and its manufacturing industry, this work considers the manufacturing industry as the main source of providing an economy with physical goods and capacity to transform materials into consumption and welfare. It proposes that diversification of manufactures and the development of knowledge-based industries constitute a sustainable path toward economic development and growth. One of the main objectives of this study is to estimate the manufacturing production function using real output instead of nominal or industry-level deflated output as proxies. Using estimated production function input elasticities, this study measures average manufacturing mark-ups of output price over marginal cost and rent sharing between workers and firm owners. Additionally, the estimation of $\mathrm{R} \& \mathrm{D}$ cooperation determinants allows disentangling part of the incentive mechanisms that operate in the process of developing knowledge. 



\title{
Chapter 1 DEMOCRATIC INSTITUTIONS, INDUSTRIAL DEVELOPMENT, AND ECONOMIC GROWTH IN CHILE
}

\section{RECENT EXPERIENCE AND FUTURE OPPORTUNITIES}

\begin{abstract}
This chapter studies the main forces that have driven economic growth and development in Chile since in the past three decades. The recent experience and the present of the Chilean economy are reviewed using several datasets that facilitate comparison to other countries around the world. The effects of reestablishing democracy in 1990 are evaluated. In the economics literature during the past decades, Chile has been characterized as an open and growing country. However, determining how it can continue on the same path requires study and discussion. Democratic institutions, foreign trade, and macroeconomic stability counted among the main advantages that helped to achieve growth in previous decades. Diversification of manufactures and exports, increasing human capital, innovative activities (implying R\&D investment) and domestic reinvestment of mining industry revenues are among the biggest challenges for the following decades.
\end{abstract}




\subsection{Introduction}

This work analyzes the strengths and weaknesses of the economic growth and development process of Chile. The main objective is to evaluate the opportunities and threats that the economy faces for the coming decades, giving special attention to the importance of knowledge creation and to industry composition in domestic production. A distinction is made between the forces that drove past growth and the forces that may lead growth in the future. This work evaluates the Chilean economy as a whole, with special attention to macroeconomic characteristics that can be compared throughout the Latin American region and with other countries around the world. Two main questions are discussed. The first of them is what are the forces that have determined the recent high economic growth and strong development performance in Chile? The second question is what are the forces on which we should now rely on for continuing this process in the future?

From the starting point of the Chilean economy during the past three decades, we propose a future development strategy based on an open economy that can innovate to take advantage of its strengths and diversify its risks. We base these proposals on the ideas of several experts who have previously published work analyzing Chilean macroeconomics, social development, institutions, innovation, educational systems, and export diversification.

International data comparisons may allow a comparative analysis of a country in terms of institutional value, innovation capacity, economic development, and GDP growth. Nevertheless it may be a difficult or impossible task to evaluate objectively the level of well-being of an entire society. This paper uses local data from the Central Bank of Chile and the National Institute of Statistics as well as data collected by international organizations like the World Bank to compare measures of well-being and GDP growth, as well as innovation efforts, financial stability and development measures. With this material, and in the light of previous literature, the Chilean case is viewed in perspective and compared with other countries around the world.

Institutions play a big role in growth and development. The extent to which a democratic system is in place determines how much the population's needs are addressed in public policy. Even though Chile has been evaluated positively in terms of its democratic institutions, it is important to give ongoing attention to this essential aspect of the economy.

Exports have been one of the main engines of growth in Chile. However, Chile has focused on the production of copper, which represents more than $50 \%$ of exports, while knowledge-intensive goods do not represent a significant share of Chilean exports. The extent to which the growing income from copper exports has affected the exchange rate and the fact that the copper industry has absorbed a huge amount of human capital complicate the emergence and growth of other exporting industries. This situation has been compared to the Dutch Disease phenomena that occurred in the sixties' after the discovery of huge natural gas reserves in the Northern Seas of Holland. If economic stability is desirable for growth, it is important to analyze the sector composition of the 
Chilean manufacturing industry and the extent to which Chilean export markets may be vulnerable to foreign and local shocks. For a small and open economy that is based on the extraction of natural resources developing a comparative advantage in manufacturing can constitute a powerful and sustained engine of growth for the future. Appropriate diversification of product and export markets may lead to sustained economic growth if a dynamic industrial sector can compete in foreign markets. Thus, sector composition of industry must be carefully studied by the social planner in order to promote private development.

The Chilean government has recently exerted major effort to promote local innovation through a series of programs offering research grants, R\&D subsidies, and seed capital to attract entrepreneurs. Nevertheless, a comprehensive National Innovation System for Market Competition was not in place until 2006. Previous literature has analyzed the impact of some of these programs on local research efforts in Latin America and around the world. ${ }^{1}$ Innovation expenditures in Chile are the lowest of the OECD. Innovation is an essential factor in economic development, especially for a country that is trying to diversify its export markets. Even though total educational spending has greatly increased in the past two decades, the quality of education varies a good deal across income levels. A high-quality educational system is one of the main challenges for the near future and possibly the main factor that will contribute to a more equal income distribution.

The rest of this chapter is structured as follows. Section 2 discuses the fact that Chile reformulated its democracy in 1989 and compares the Chilean case to other countries around the world. Section 3 analyzes the economic performance of Chile in the past three decades, including development issues, the national innovation system, educational efforts, and the sector composition of manufactures and exports. Section 4 discusses some of the strengths and weaknesses of Chile's recent economic performance. Section 5 mentions policy recommendations based on previous literature and international organizations' reports. Section 6 concludes and discusses possible ideas for further research on development and growth in the Latin American context.

\subsection{Towards the Establishment of a Dependable Democracy}

This section analyzes the evolution of Chilean democracy over the past few decades. It follows relevant variables over time and compares those variables with other countries. A democratic state has a government that represents the will of all its citizens instead of using coercion to impose the visions of a few. The work by the Economist Intelligence Unit $^{2}$ (EIU) in 2010 measured the extent to which democratic principles are applied at the level of countries. But we must be aware that we cannot observe in an objective way

\footnotetext{
${ }^{1}$ See, for example, Benavente, Crespi, and Maffioli (2007) or Lach (2001).

2 The Economist Intelligence Unit is an independent business within The Economist Group where The Economist

2 The Economist Intelligence Unit is an independent business within The Economist Group where The Economist Magazine is also included.
} 
some of the most important aspects of democracy, such as the extent to which decisions are made in the best interests of the represented population or whether basic human rights are respected.

After 17 years of a military government, presidential elections were held in Chile in 1989. In 1990, the military gave up power in a peaceful process, with no further political violence. From that time, the country has enjoyed a stable and widespread state of peace. Basic human rights have been respected by the state and a number of legal proceedings were conducted to clarify and to punish some of the previous government's crimes, although most of them were forgiven. Since democracy was reestablished, no person has been executed, and the death penalty was legally abolished during the nineties. Violence and crime persist, as in most other countries, and vary across regions, generating fears that affect people in different ways. ${ }^{3}$ Nevertheless, it is clear that in the past two decades the Chilean population has lived relatively free of concerns about terrorism and war. Chile has chosen to step aside from global violence and to focus its public policy on growth, development, and income distribution.

Chile has not engaged in foreign armed conflict in many decades. Nevertheless, a high investment in trained military institutions and defensive equipment has been made in the past decades due to a regulation imposed by the military government that forces a share of copper revenues to be allocated to armed forces investment. However, there is also very low concern that armed conflict will reach the region, because the country enjoys relatively good relations with its neighbor countries.

Table 1.1 shows the results of the EIU index that ranks countries in terms of the success of their democracies. Chile has been evaluated on this international democracy index and was ranked $34^{\text {th }}$ on a group of 167 countries. The study was conducted by the EIU in 2010. Two versions of the same study were done in 2006 and 2008, showing similar results. All three reports from the Economist Intelligence Unit are divided into five categories for analysis.

In general terms, Chile appears to be a relatively successful case, but it was classified by the index as a "flawed democracy." It is outstanding in terms of "electoral process and pluralism," "functioning of government," and "civil liberties." In terms of "political participation," the Chilean democracy still has some flaws. Once an adult is registered for voting, participation in all elections becomes mandatory; this is not considered valid as a high participation rate under the EIU index. As a result, Chile gets a 0 score on this important aspect of the index. Because voluntary voting was legislated in 2012, the Chilean democracy will probably have a higher score on the next version of the EIU Democracy Index. Furthermore, women's participation in Congress is low and, as a result, Chile gets an even poorer score in terms of political participation. Another aspect that, according to the EIU, keeps Chile as a flawed rather than a full democracy is its "democratic culture." Public opinion surveys show that a large part of the population would prefer a strong government, even if that would mean they would enjoy less

3 A program through which crime can be reduced to improve the most important mission of a democratic government was evaluated in the paper by Benavente, Contreras, Melo and Montero (2010). 
freedom. This reflects the controversy and division during the Chilean experience with a military government in the seventies and eighties; the conservative political model imposed during that era was not democratic but it allowed reasonable prosperity to those who did not oppose it.

Northern European countries (Norway, Iceland, Denmark, and Sweden) appear to have the most successful democracies in the world. Some very high scores are also seen in other European countries, as well as New Zealand, Australia, Canada, and the US. Most of the developed nations but also some developing and fast-growing countries appear to be ranked high.

These international comparisons are not able to consider the fact that some highly ranked countries suffer from war and from restriction of civil liberties. These acts may be conducted under military secrecy and cannot be considered easily in an international index. These countries are defined as democratic according to the information filled on a general form by an international news agency. They are also considered developed in accordance with a measure of GDP per capita and other straightforward variables, regardless of whether basic human rights are respected by the state authority.

Table 1.1 EIU Democracy Index 2010

\begin{tabular}{|c|c|c|c|c|c|c|c|}
\hline & Rank & $\begin{array}{l}\text { Overall } \\
\text { Score }\end{array}$ & $\begin{array}{l}\text { Elections and } \\
\text { Pluralism }\end{array}$ & $\begin{array}{l}\text { Functioning } \\
\text { Government }\end{array}$ & $\begin{array}{c}\text { Political } \\
\text { Participation }\end{array}$ & $\begin{array}{c}\text { Political } \\
\text { culture }\end{array}$ & $\begin{array}{c}\text { Civil } \\
\text { Liberties }\end{array}$ \\
\hline Norway & 1 & 9.8 & 10 & 9.64 & 10 & 9.38 & 10 \\
\hline Iceland & 2 & 9.65 & 10 & 9.64 & 8.89 & 10 & 9.71 \\
\hline Denmark & 3 & 9.52 & 10 & 9.64 & 8.89 & 9.38 & 9.71 \\
\hline Sweden & 4 & 9.5 & 9.58 & 9.64 & 8.89 & 9.38 & 10 \\
\hline New Zealand & 5 & 9.26 & 10 & 9.29 & 8.89 & 8.13 & 10 \\
\hline Australia & 6 & 9.22 & 10 & 8.93 & 7.78 & 9.38 & 10 \\
\hline Finland & 7 & 9.19 & 10 & 9.64 & 7.22 & 9.38 & 9.71 \\
\hline Switzerland & 8 & 9.09 & 9.58 & 9.29 & 7.78 & 9.38 & 9.41 \\
\hline Canada & 9 & 9.08 & 9.58 & 9.29 & 7.78 & 8.75 & 10 \\
\hline Netherlands & 10 & 8.99 & 9.58 & 8.93 & 8.89 & 8.13 & 9.41 \\
\hline Luxembourg & 11 & 8.88 & 10 & 9.29 & 6.67 & 8.75 & 9.71 \\
\hline Ireland & 12 & 8.79 & 9.58 & 7.86 & 7.78 & 8.75 & 10 \\
\hline Austria & 13 & 8.49 & 9.58 & 7.86 & 7.78 & 8.13 & 9.12 \\
\hline Germany & 14 & 8.38 & 9.58 & 7.86 & 7.22 & 8.13 & 9.12 \\
\hline Malta & 15 & 8.28 & 9.17 & 8.21 & 5.56 & 8.75 & 9.71 \\
\hline Czech Republic & 16 & 8.19 & 9.58 & 7.14 & 6.67 & 8.13 & 9.41 \\
\hline US & 17 & 8.18 & 9.17 & 7.86 & 7.22 & 8.13 & 8.53 \\
\hline Spain & 18 & 8.16 & 9.58 & 8.21 & 6.11 & 7.5 & 9.41 \\
\hline UK & 19 & 8.16 & 9.58 & 7.86 & 6.11 & 8.13 & 9.12 \\
\hline South Korea & 20 & 8.11 & 9.17 & 7.86 & 7.22 & 7.5 & 8.82 \\
\hline Uruguay & 21 & 8.1 & 10 & 8.57 & 4.44 & 7.5 & 10 \\
\hline Japan & 22 & 8.08 & 9.17 & 8.21 & 6.11 & 7.5 & 9.41 \\
\hline Belgium & 23 & 8.05 & 9.58 & 8.21 & 5.56 & 7.5 & 9.41 \\
\hline Mauritius & 24 & 8.04 & 9.17 & 8.21 & 5 & 8.13 & 9.71 \\
\hline Costa Rica & 24 & 8.04 & 9.58 & 8.21 & 6.11 & 6.88 & 9.41 \\
\hline
\end{tabular}

Source: Economist Intelligence Unit (2010). 
Table 1.1 (Continued) EIU Democracy Index 2010

\begin{tabular}{|c|c|c|c|c|c|c|c|}
\hline & Rank & $\begin{array}{l}\text { Overall } \\
\text { Score }\end{array}$ & $\begin{array}{l}\text { Elections and } \\
\text { Pluralism }\end{array}$ & $\begin{array}{l}\text { Functioning } \\
\text { Government }\end{array}$ & $\begin{array}{c}\text { Political } \\
\text { Participation }\end{array}$ & $\begin{array}{l}\text { Political } \\
\text { Culture }\end{array}$ & $\begin{array}{c}\text { Civil } \\
\text { Liberties }\end{array}$ \\
\hline Portugal & 26 & 8.02 & 9.58 & 7.5 & 6.11 & 7.5 & 9.41 \\
\hline Cape Verde & 27 & 7.94 & 9.17 & 7.86 & 6.67 & 6.88 & 9.12 \\
\hline Greece & 28 & 7.92 & 9.58 & 6.43 & 6.67 & 7.5 & 9.41 \\
\hline Italy & 29 & 7.83 & 9.58 & 6.79 & 6.11 & 8.13 & 8.53 \\
\hline South Africa & 30 & 7.79 & 8.75 & 8.21 & 7.22 & 6.25 & 8.53 \\
\hline France & 31 & 7.77 & 9.58 & 7.14 & 6.11 & 7.5 & 8.53 \\
\hline Slovenia & 32 & 7.69 & 9.58 & 7.14 & 6.67 & 6.25 & 8.82 \\
\hline Estonia & 33 & 7.68 & 9.58 & 7.5 & 5 & 7.5 & 8.82 \\
\hline Chile & 34 & 7.67 & 9.58 & 8.57 & 3.89 & 6.88 & 9.41 \\
\hline Botswana & 35 & 7.63 & 9.17 & 7.14 & 5.56 & 6.88 & 9.41 \\
\hline Taiwan & 36 & 7.52 & 9.58 & 7.14 & 5.56 & 5.63 & 9.71 \\
\hline Israel & 37 & 7.48 & 8.75 & 7.5 & 8.33 & 7.5 & 5.29 \\
\hline Slovakia & 38 & 7.35 & 9.58 & 7.5 & 5.56 & 5 & 9.12 \\
\hline Cyprus & 39 & 7.29 & 9.17 & 6.43 & 6.11 & 5.63 & 9.12 \\
\hline India & 40 & 7.28 & 9.58 & 8.57 & 4.44 & 4.38 & 9.41 \\
\hline Lithuania & 41 & 7.24 & 9.58 & 5.71 & 5.56 & 6.25 & 9.12 \\
\hline Timor-Leste & 42 & 7.22 & 8.67 & 6.79 & 5.56 & 6.88 & 8.24 \\
\hline Hungary & 43 & 7.21 & 9.58 & 6.07 & 5 & 6.88 & 8.53 \\
\hline Jamaica & 43 & 7.21 & 9.17 & 6.79 & 5 & 6.25 & 8.82 \\
\hline Trinidad and Tobago & 45 & 7.16 & 9.58 & 7.14 & 6.11 & 5 & 7.94 \\
\hline Panama & 46 & 7.15 & 9.58 & 6.79 & 5.56 & 5 & 8.82 \\
\hline Brazil & 47 & 7.12 & 9.58 & 7.5 & 5 & 4.38 & 9.12 \\
\hline Poland & 48 & 7.05 & 9.58 & 6.07 & 6.11 & 4.38 & 9.12 \\
\hline Latvia & 48 & 7.05 & 9.58 & 5.36 & 5.56 & 5.63 & 9.12 \\
\hline Mexico & 50 & 6.93 & 8.75 & 7.14 & 6.11 & 5 & 7.65 \\
\hline
\end{tabular}

Source: Economist Intelligence Unit (2010).

Basic respect for human rights through the enforcement of the Universal Declaration of Human Rights should be taken into account when evaluating a country's democracy, but this is not defined as essential to the EIU index. In this regard, since 1990 Chile has complied with the United Nations foundational act signed in San Francisco in 1945 and the Universal Declaration of Human Rights adopted in $1948 .^{4}$

\subsection{Institutions, Industrial Development, and Growth in Chile}

\subsubsection{Economic Growth in the Past Three Decades}

In Chile, even before the seventies, foreign investors slowly developed a copper industry to extract the mining resources that exist underground in the Andes Mountains. In the late sixties and early seventies, governments developed widespread agrarian reforms, imposed many economic regulations, and fixed commodity prices, generating confusion that later led to armed rivalry among social classes. The copper industry was

\footnotetext{
${ }^{4}$ See United Nations (1948) for the full text of this international agreement.
} 
confusion that later led to armed rivalry among social classes. The copper industry was nationalized in 1971 with the intention of directing the profits from non-renewable mineral resources to the state as their only legal owner.

After a military coup d'état in 1973, the executive power started undoing the socialist reforms in order to reestablish a capitalist economy. The government initiated freemarket economic policies, including deregulation of business and privatization of stateowned firms. To accomplish these objectives, the government abolished the minimum wage, removed artificially lowered commodity prices, eliminated trade union rights, privatized the pension system, privatized state-owned industries and banks, and lowered taxes on income and profits. The copper industry was also partially privatized in this process, resulting in a large flow of foreign investment to the private industry of copper extraction.

Table 1.2 is based on World Development Indicators data published by World Bank (2012). The data in Table 1.2 compares the path of total GDP with per capita GDP as well as their growth rates in Chile from 1980 to 2011. In late 1981 a foreign crisis triggered the massive exit of foreign capitals from the Chilean financial system. An internal crisis developed in which domestic product was strongly reduced in 1982 and 1983. After this crisis the economy entered a path of rapid growth that lasted at least until 1998, when Asian markets affected Chilean domestic financial system again, this time having much milder effects but still resulting in negative GDP growth in 1999. After 2000 growth rates have been positive and persistent but of smaller magnitude that on the previous periods.

In an attempt to control inflation during the late 1970s, the Chilean government took several steps that, by 1982, led the country into the worst financial crisis of the past decades. These steps included fixing the exchange rate and removing barriers to capital mobility. At the same time, domestic interest rates were liberalized. The result was a huge increase in external private debt, which at the moment was much cheaper than domestic loans. Nevertheless, the fixed exchange rate became unsustainable when external capital was removed from the region, starting in 1981. Banks went into bankruptcy and had to be bought by the state, while many firms and individuals were not able to honor their loan payments, which increased at the same time that a huge devaluation took place. The 1981 international financial crisis may have been one of the reasons for the reforms that led to the current path of sustained GDP growth in Chile.

Chile regained its democracy at the end of the 1980s. During the eighties, Chilean exports of mining products resulted in healthy current account balances and high levels of economic growth. The renewed democracy and the growing exports were accompanied by a very responsible monetary policy. The success of lowering inflation rates during the nineties is attributable mainly to the independence of the Central Bank authority, which was granted by constitutional law in December 1989. The main result of this law was a controlled inflation, as well as a reasonable floating band for the exchange rate. Another aspect of the new democratic government was a conservative and careful fiscal policy oriented to social spending as well as to stability and growth. 
Table 1.2 GDP and GDP per capita in Chile 1974-2011

\begin{tabular}{|c|c|c|c|c|}
\hline Year & $\begin{array}{l}\text { GDP (constant } \\
2000 \text { US\$) }\end{array}$ & $\begin{array}{l}\text { GDP growth } \\
\text { (annual \%) }\end{array}$ & $\begin{array}{l}\text { GDP per } \\
\text { capita } \\
\text { (constant } \\
2000 \text { US\$) }\end{array}$ & $\begin{array}{l}\text { GDP per } \\
\text { capita } \\
\text { growth } \\
(\text { annual \%) }\end{array}$ \\
\hline 1980 & $27,950,035,375$ & 8.15 & 2,500 & 6.60 \\
\hline 1981 & $29,274,115,494$ & 4.74 & 2,580 & 3.17 \\
\hline 1982 & $26,252,080,505$ & -10.32 & 2,277 & -11.71 \\
\hline 1983 & $25,258,026,490$ & -3.79 & 2,156 & -5.32 \\
\hline 1984 & $27,271,935,216$ & 7.97 & 2,290 & 6.22 \\
\hline 1985 & $29,213,486,581$ & 7.12 & 2,413 & 5.36 \\
\hline 1986 & $30,848,376,502$ & 5.60 & 2,506 & 3.85 \\
\hline 1987 & $32,882,584,739$ & 6.59 & 2,627 & 4.82 \\
\hline 1988 & $35,286,696,752$ & 7.31 & 2,771 & 5.50 \\
\hline 1989 & $39,013,086,690$ & 10.56 & 3,011 & 8.66 \\
\hline 1990 & $40,455,626,742$ & 3.70 & 3,068 & 1.88 \\
\hline 1991 & $43,679,935,489$ & 7.97 & 3,253 & 6.03 \\
\hline 1992 & $49,042,927,669$ & 12.28 & 3,585 & 10.23 \\
\hline 1993 & $52,469,207,193$ & 6.99 & 3,767 & 5.06 \\
\hline 1994 & $55,464,212,029$ & 5.71 & 3,913 & 3.88 \\
\hline 1995 & $61,358,713,993$ & 10.63 & 4,258 & 8.83 \\
\hline 1996 & $65,907,537,053$ & 7.41 & 4,505 & 5.79 \\
\hline 1997 & $70,261,111,897$ & 6.61 & 4,735 & 5.10 \\
\hline 1998 & $72,531,163,202$ & 3.23 & 4,823 & 1.86 \\
\hline 1999 & $71,979,306,357$ & -0.76 & 4,726 & -2.01 \\
\hline 2000 & $75,210,511,780$ & 4.49 & 4,878 & 3.21 \\
\hline 2001 & $77,750,400,228$ & 3.38 & 4,983 & 2.16 \\
\hline 2002 & $79,448,554,863$ & 2.18 & 5,033 & 1.02 \\
\hline 2003 & $82,560,485,563$ & 3.92 & 5,173 & 2.77 \\
\hline 2004 & $87,548,035,975$ & 6.04 & 5,427 & 4.91 \\
\hline 2005 & $91,287,855,656$ & 4.27 & 5,600 & 3.19 \\
\hline 2006 & $96,486,092,629$ & 5.69 & 5,859 & 4.62 \\
\hline 2007 & $101,465,571,562$ & 5.16 & 6,100 & 4.12 \\
\hline 2008 & $104,806,280,194$ & 3.29 & 6,240 & 2.29 \\
\hline 2009 & $103,720,034,589$ & -1.04 & 6,117 & -1.97 \\
\hline 2010 & $110,041,983,987$ & 6.10 & 6,430 & 5.12 \\
\hline 2011 & $116,631,547,327$ & 5.99 & 6,754 & 5.03 \\
\hline
\end{tabular}

Source: World Bank (2012).

With an average per capita GDP growth of $4.8 \%$ per year, the 1990 s were by far the fastest-growing decade in the history of Chile. This was true even though GDP growth was almost zero in 1998 and 1999 as a result of an international financial crisis. In the last decade, growth has been a sustained characteristic of the Chilean economy. After more than 20 years of democracy and high rates of growth, it is important to study these phenomena in order to learn the lessons that will allow the country to continue its development in the future. 
Figure 1.1 uses data from the World Bank (2012) and contrasts the total annual GDP with GDP growth in Chile, expressed in constant 2000 US dollars. In the middle of the 1980s, there clearly appears to be a change, with a tendency toward higher rates of growth and lower instability. The size of the Chilean economy grew from $\$ 24$ billion in 1980 to $\$ 116$ billion in 2011, expressed in constant US\$ for the year 2000. The economy grew at high rates during the 1990s, and even though by the end of the decade it staggered for two years, the first decade of the twenty-first century also came along with positive rates of growth.

Figure 1.1 Yearly Total GDP and GDP growth in Chile (1980-2011)

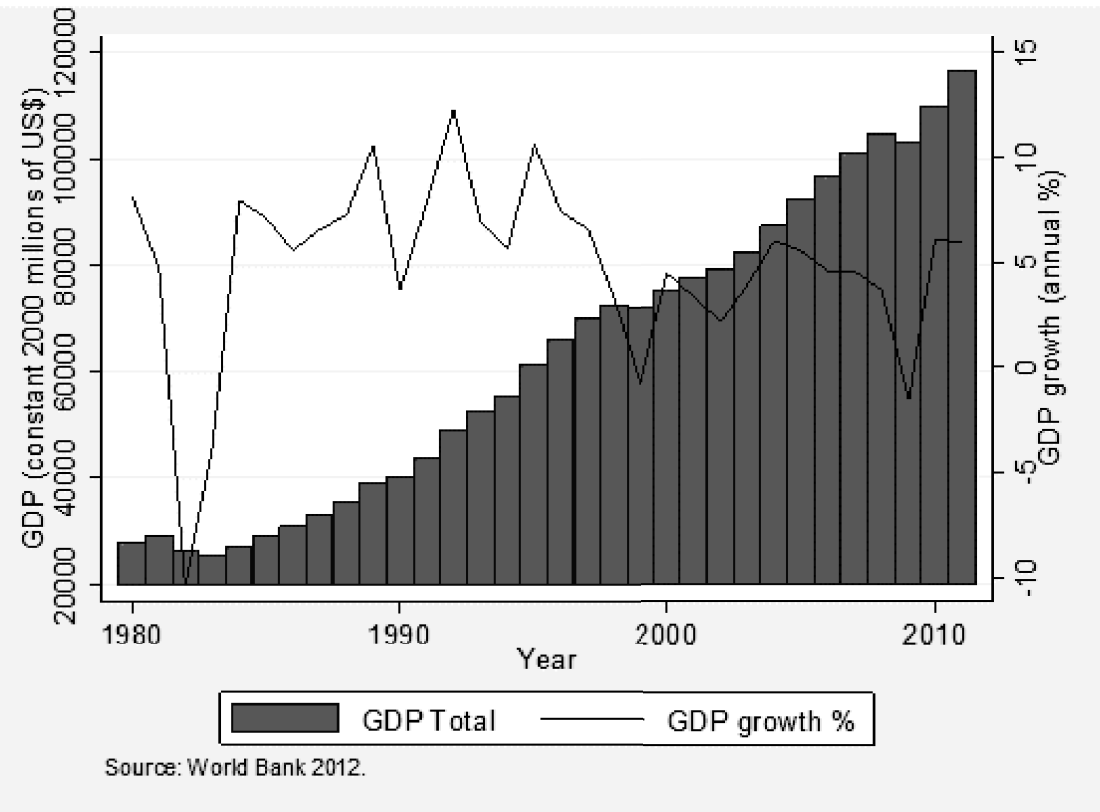

In summary, after a deep financial crisis in 1981 caused by an unsustainable exchange rate, in the middle of the 1980s Chile emerged as the fastest growing country in Latin America during a decade that had almost no GDP per capita growth for most of the region's countries. Starting in the second half of the 1980s, the Chilean economy initiated a sustained growth path that continues to the present, with growth rates that surpassed 10\% in 1989, 1992 and 1995.

Table 1.3 contains data from the World Bank (2010) and shows per capita real GDP growth rates, summarized from 1970 to 2009. During the seventies, per capita growth of the Chilean economy was relatively poor compared to the Latin American average and also low compared to per capita GDP growth of Asia, Europe and North America. After 1983, Chile became a much faster-growing country than the average of its neighbors and was actually much closer to the pattern developed by the fast-growing Asian countries. The nineties were by far the decade in which Chile's GDP per capita grew the most. With 
an annual average growth rate of $4.8 \%$, the Chilean economy expanded more than twice as much as Europe and North America and three times the average growth of Latin America and the world.

Table 1.3 Decade Average GDP per capita Growth of Selected Country Groups 1981-

\begin{tabular}{|c|ccc|}
\hline \multicolumn{4}{|c}{2009} \\
\hline Chile & $1981-1990$ & $1991-2000$ & $2001-2009$ \\
\hline Latin America \& Caribbean & 2.24 & 4.80 & 2.51 \\
East Asia \& Pacific & -0.71 & 1.59 & 1.81 \\
European Union & 3.57 & 1.90 & 2.63 \\
North America & 2.14 & 2.02 & 0.89 \\
World & 2.23 & 2.17 & 0.62 \\
& 1.49 & 1.42 & 1.17 \\
\hline
\end{tabular}

Source: Author's calculation using World Bank (2010) data.

When comparing the growth paths of different countries and regions, it is important not only to analyze how much an economy can grow but also how stable this process can be. Volatility rates of GDP growth may reflect the ability of an economy to interact with exogenous shocks. Low volatility implies an ability to prevent internal financial crises and low growth rate periods. Table 1.4 shows that volatility rates were relatively high in 1982 , as an international financial crisis caught the country with a rigid exchange rate that became unsustainable and that ended in an exchange rate adjustment that drove down consumption and moved unemployment up to more than $27 \%$. In relation to other regions of the world, volatility rates in Chile became much lower in the past two decades. It is clear from Tables 1.3 and 1.4 that, after the return of the state of law and democracy in 1989, Chile achieved its highest per capita GDP growth and its lowest GDP volatility rates, showing a better performance than most of the other countries of its region and catching up fast with respect to the developed world.

Table 1.4 Standard Deviation of GDP per capita Growth of Selected Countries 1981-

\begin{tabular}{|c|ccc|}
\hline \multicolumn{4}{|c}{2009} \\
\hline Chile & $1981-1990$ & $1991-2000$ & $2001-2009$ \\
Latin America \& Caribbean & 6.14 & 3.45 & 2.21 \\
East Asia \& Pacific & 1.17 & 1.59 & 3.01 \\
European Union & 1.16 & 1.30 & 1.85 \\
North America & 2.34 & 1.58 & 2.21 \\
World & 1.28 & 0.95 & 1.90 \\
\hline
\end{tabular}

Source: Author's calculation using World Bank (2010) data.

\subsubsection{Recent Economic Development Experience in Chile}

Countries are typically classified as developed, developing, or underdeveloped according to a measure of per capita GDP that simplifies most of the complexities and subjectivity of measuring the level of well-being and development. Some other variables that we present here may be useful to evaluate the evolution of Chilean economic 
development, distinguishing which advances come along with GDP growth and which do not. Figures 1.2 and 1.3 identify the paths of some variables that are related to this fast growth process.

Figure 1.2 shows the level of per capita GDP in terms of purchasing power parity and a measure of income inequality. Per capita GDP has persistently increased, and reached levels over US\$13,000 in 2009. Income distribution inequality has also diminished simultaneously with this growth process but still remains at a high level. Greater equality in income distribution is essential to achieve a long-term stable democracy and a high level of development for the twenty-first century.

Figure 1.2 Average Per Capita Income and GINI Index in Chile (1980-2010) ${ }^{5}$

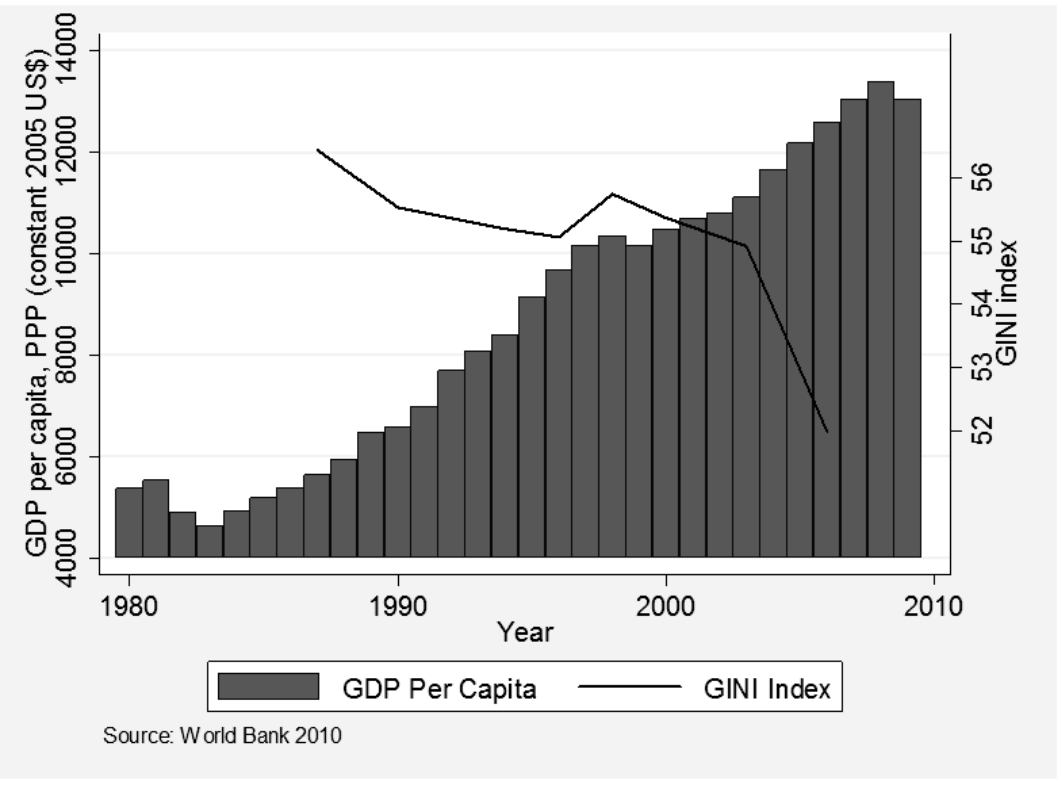

Figure 1.3 shows the evolution of interest, inflation and unemployment rates in the past decades. Interest rates have decreased as a result of better-developed financial systems. Inflation rates converged during the nineties and by 1998 were at the levels of a healthy and stable economy. Lower interest rates imply an easier access to capital and a healthy financial system, while controlled inflation rates widen the use of currency and allow agents to adjust their future expectations. But adequate financial and monetary policy are only part of the elements that allow economic growth. Economists are usually also concerned with employment levels, not only from the perspective of providing economic opportunities for every agent but also from the point of view of efficiency.

Unemployment decreased during the nineties but showed a sudden increase at the end of the decade, responding to the impact of an international financial crisis. Unemployment rates have also been relatively high, reaching almost $10 \%$ during the first

\footnotetext{
${ }^{5}$ More detail about the data used to draw Figures 1.2 through 1.8 can be found in Appendix 1.
} 
decade of the twenty-first century. Some economists would argue that the high unemployment rates are due to regulations that have decreased labor market flexibility in the Chilean economy. ${ }^{6}$

Figure 1.3 Interest Rate, Inflation Rate, and Unemployment Rate in Chile (1980-2010)

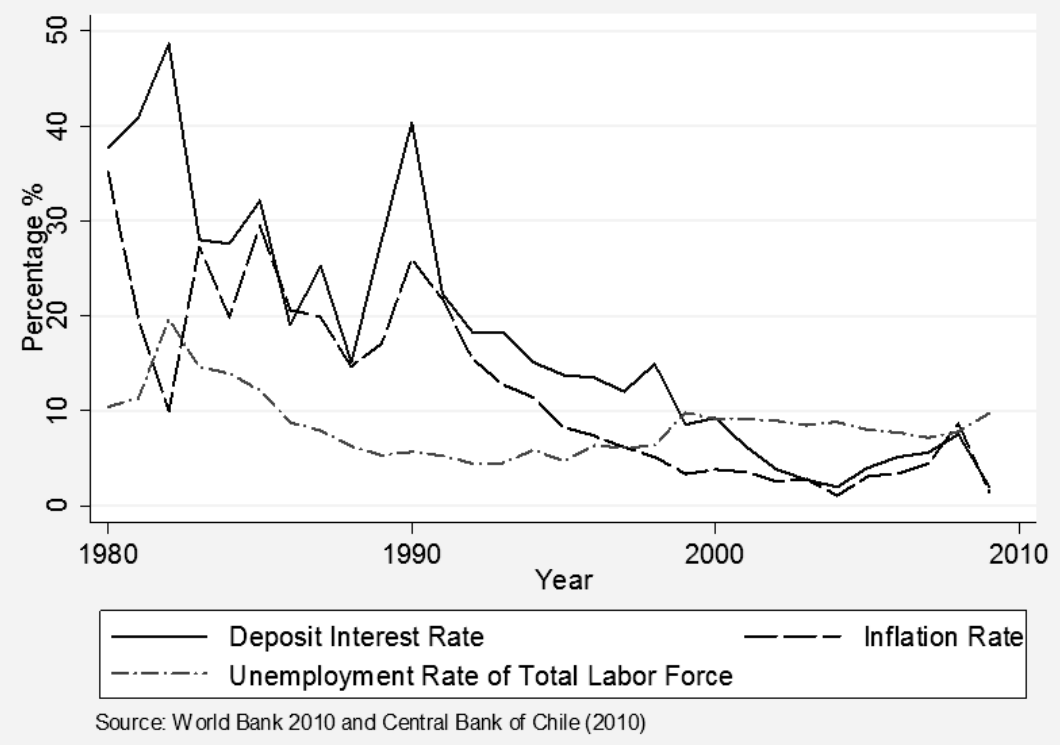

One of the public policies that have contributed to economic stability in Chile is the decreasing level of public debt. A country's public debt path over time is the result of yearly fiscal balances. When a specific level of structural surplus is embraced as the target of the fiscal rule, a desired path for public debt is being designed. The optimal path depends on two factors: intergenerational transfers and sustainability. Accumulation of debt increases the risk of a financial crisis and also compromises the possibility of incurring further deficit. In contrast, reducing the level of debt is equivalent to a wealth transfer to future generations, which could also be done by investing in loans to improve human capital and future production capacities.

When designing an optimal fiscal rule, policy makers must consider that international financial markets are less tolerant of public debt in developing than in developed economies. In Chile, the fiscal rule of a $1 \%$ structural surplus is applied to the central government. This rule means that the government should spend as if the country was producing up to its structural capacity every year and generating a surplus equivalent to $1 \%$ of the structural GDP. When national production decreases due to a temporary financial crisis, the rule should result in public deficit. When production increases over the structural capacity due to a higher value of the exported commodity, the rule should

\footnotetext{
${ }^{6}$ See, for example, the analysis by Albagli, Garcia, and Restrepo (2005).
} 
result in a surplus higher than 1\% of actual GDP. (Public enterprises are excluded from this rule because they have independent management linked to their own objectives and are not used as instruments of fiscal policy.) Under this fiscal rule, once other factors influencing fiscal accounts are considered, such as social security liabilities and state guarantees for infrastructure contracts, the consolidated balance is close to zero. The result is that the consolidated public debt is constant in the medium term.

The levels of Chilean public debt may be seen in Figure 1.4. In practical terms, public structural surplus of " $1 \%$ of GDP" means that the transitory incomes from copper extraction are not taken as current income but rather as a non-permanent positive flow that must be administered conservatively, with its spending accounted for over a reasonable period of time. Therefore, Chile presents a negative public debt of nearly $15 \%$ of GDP in 2007 and 24\% of GDP in 2008. At the present moment, when a financial crisis due to over-spending by rich economies threatens to stagnate growth in most of the developing world, Chile is likely to stand in a relatively protected position with respect to the world economy. This data also shows the strength of Chilean democracy and the importance of learning lessons from the developed world but not copying its weaknesses.

There are some common patterns that can be observed throughout the world as countries develop. As specialization occurs in varied areas of knowledge, a population tends to group in cities rather than in rural areas. A modern and efficient society also offers women and men a similar chance of developing higher human capital and participating equally in the labor force.

Figure 1.4 Chilean Consolidated Public Debt (1990-2008)

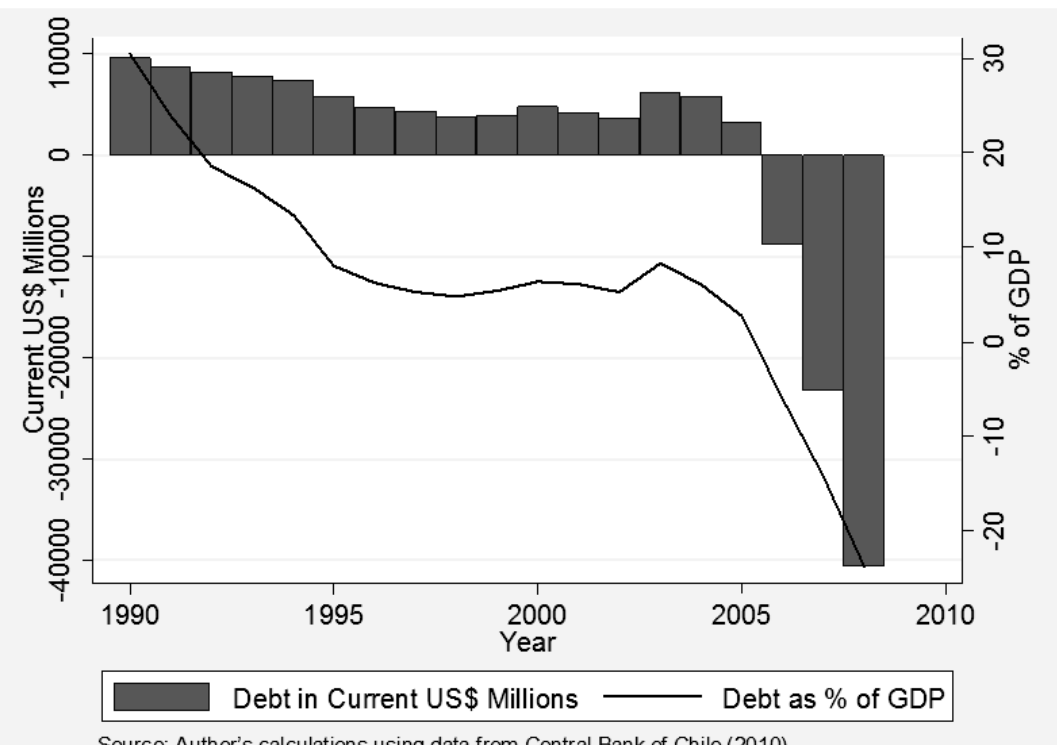

Source: Author's calculations using data from Central Bank of Chile (2010) 
Figure 1.5 summarizes these concepts. In keeping with the first trend, the percentage of urban population has increased. People are moving to the cities. More than one third of the population is concentrated in Santiago (located in the central Metropolitan region). Female labor participation has also increased at a slow but relatively constant rate. This variable is related not only to improvements in social integration but also to economic growth because it expands the total labor available for production, stimulating per capita GDP growth. Enrollment in secondary education has risen to over $90 \%$ in 2009 and the proportion of women enrolled in higher education in 2009 was higher than the number of men.

As development takes place, family planning becomes accessible for everyone and fertility rates stabilize in a way that allows a population to stop growing. In a developing society that takes good care of its members, life expectancy should increase over time as a result of better and more accessible health care. In a similar way, in a society that is incrementally achieving economic development access to communication technologies should expand.

Figure 1.5 Labor Market Development Indicators in Chile (1980-2010)

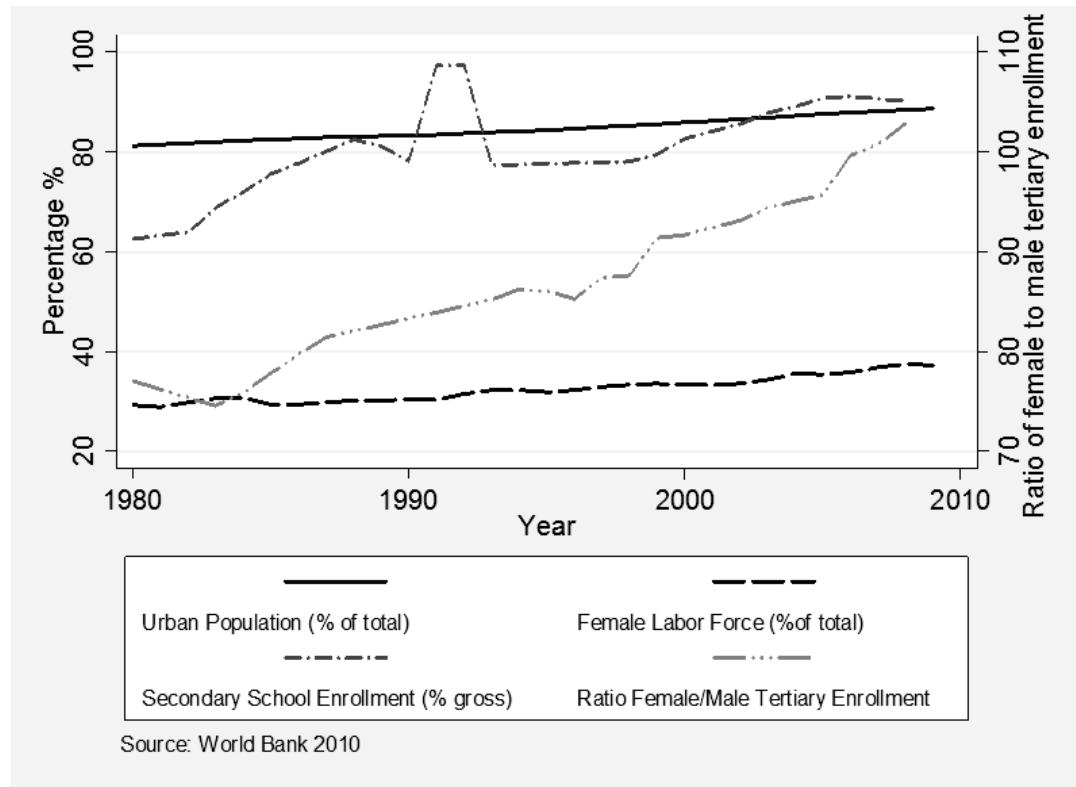

Figure 1.6 shows indicators of these developments in Chile. Fertility rate decreased from 2.7 children per woman in 1980 to less than one child per woman in 2003. Similarly life expectancy at birth was situated at around 70 years in 1980 and it has increased to almost 80 years in 2009, following a worldwide tendency that goes along with advances in health care and medicine. Finally, mobile phones have fully penetrated the Chilean market, with almost one phone per person in 2009, while internet connections are growing quickly. 
Figure 1.6 Development Indicators in Chile (1980-2010)

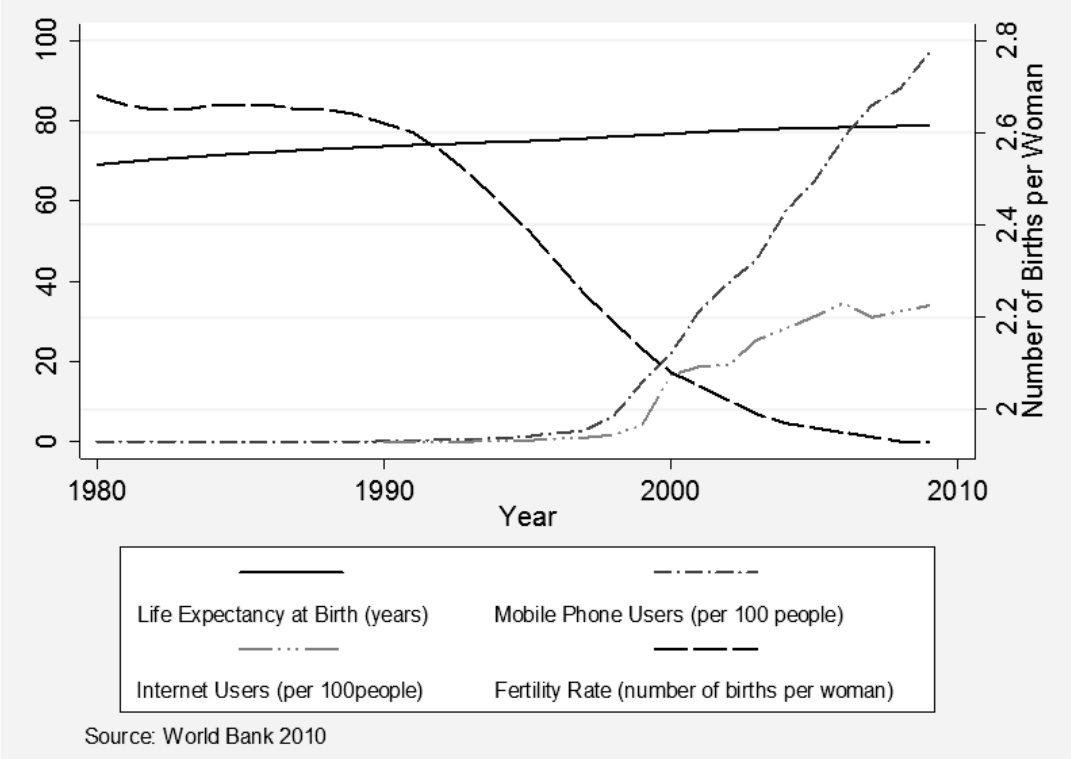

\subsubsection{Education Effort and Education Quality}

The amount of state effort in education is an essential factor in determining income distribution and creating equal opportunity. Education is the key to accessing the knowledge that allows people to take active part in the transformation of markets and production processes. Figure 1.7 shows data on education expenditure collected and published by the Chilean Ministry of Education. In the past 20 years, the total expenditure on education in Chile as a percentage of GDP has increased from $3.9 \%$ to 6.9\%. According to MINEDUC (2010) the public effort in education represented almost $19 \%$ of total government expenditures in 2008 . However, most of the increase in the percentage of GDP allocated to education is not due to a government effort but to private effort.

The implications of the shift from public schools to privately subsidized education are analyzed in the paper by Paredes and Pinto (2009). They showed that public school enrollment decreased 13\% from 2000 to 2006 while voucher schools increased their enrollment by $38 \%$ in the same period. They conclude that, because private voucher schools provide on average better education quality than public schools, it is likely that increases in income result in a demand-side substitution of public school education for private voucher school education. They also argued that, because public schools are decentralized and managed by municipalities, it is likely that some local municipal administrations opt for giving more support to private schools and lower priority to public schools.

Manzi et al. (2008) evaluate the quality of Chilean school education in an international context using the results of the Chilean Education Quality Measuring 
System (SIMCE) national census, the International Adult Literacy Survey (IALS) and the Program for International Student Assessment (PISA). They studied the fact that, among the three main kinds of schools that exist in Chile, there is a persistent and significant difference in education quality. Private schools perform the best. Private that are publicly subsidized (voucher schools) obtain lower scores in the quality measures. Students from public schools obtain on average the lowest scores on learning tests. They found that in Chile most of the between-school variance in education quality is explained by individual and school socioeconomic factors. Nevertheless, according to the results of PISA 2000 and PISA 2006, overall educational quality in Chile has increased.

Figure 1.7 Education Expenditure in Chile (1990-2008)

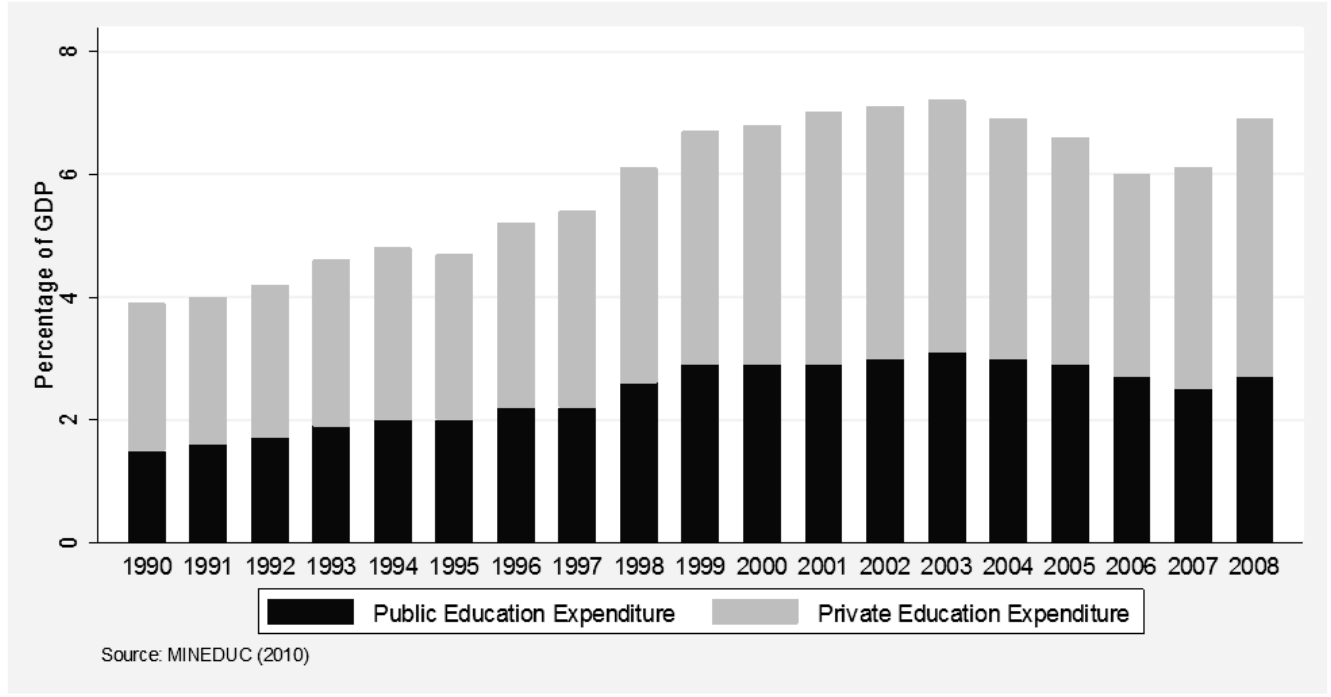

Access to higher education and greater educational quality has been widely discussed in Aequalis (2011). A group of 100 Chilean academics contributed to this book and developed concrete policy proposals in order to improve quality and universal access to higher education. Policy recommendations include the creation of new administrative units within the state that can promote quality and monitor the actions of higher education institutions. The forum also proposed to modify selection tests and a redefinition of professional-academic degree and license structures. Finally, the forum concludes that a better system can only be achieved by investing more resources and it proposes some specific areas for increases in the educational budget.

\subsubsection{R\&D and the National Innovation System}

From an economic production perspective, education is a system to transfer knowledge to younger generations so that they can continue and enlarge the present production capacities. The acquisition of new knowledge is also very important for an 
economy that is open to competitive international markets. In order to provide a better understanding of the innovation system and the requirements of knowledge creation for the Chilean economy, a book published by Chile Innova (2005) gathered expert opinions and analyzed different innovation funds in Chile. The effect of these efforts and investments on innovation activities in Chile is analyzed by Benavente (2006). His work was intended to gather and publish information that could guide a national policy for innovation and new technologies. He discussed the importance of innovation activities for economic growth and analyzed why and how the state should have a role in promoting R\&D activities and innovations. Later, Aninat et al. (2010) expressed concerns about how appropriate are the existing incentives in the public and private sectors, when the main objective of the social planner is to develop new technologies that expand productivity in a way that benefits the whole economy.

Benavente et al. (2009) describe how the Chilean National Innovation System has developed over the past two decades. A National Innovation System, organizing and encompassing all or most of the state efforts to promote R\&D, did not effectively exist in Chile before 2006. After 1990, some support was given to innovative firms through the Ministry of Economics, but these state efforts were neither initiated by a centralized process nor targeted to specific areas of development. Only after 2000 were some incentives directed to specific areas such as biotechnology, cleaner production, and information technologies. In 2004, there were three major state agencies responsible for promoting innovation efforts in Chile. CONICYT was focused on scientific research and the development of specialized human capital. CORFO implemented innovation and entrepreneurship policy. The Ministry of Economics operated as a supervising entity through its Program of Development and Technological Innovation (PDIT), but its influence as a supervising agency was limited. As a consequence, state efforts to promote innovation were not organized into a National Innovation System with explicit, clear, and agreed-on goals.

In 2005, some major steps changed this decentralized innovation policy. The first was legislation imposing a royalty tax on the mining industry, based on the provision in the Chilean constitution that all non-renewable mining resources are the property of the state. The second was the creation of the Innovation for Competitiveness Fund (FIC) that uses the resources collected by the mining royalty tax. This law also stipulated a National Strategy for Innovation and Competitiveness and created a National Council of Innovation for Competitiveness (CNIC). By late 2005, CNIC was created with a 12-year target horizon that made it less linked with the political cycle. In 2006, FIC was initiated to fund initiatives to improve Chilean competitiveness in accordance with the National Innovation System.

Intellectual Property Rights (IPR) legislation is another factor related to innovation. Patents and IPRs can promote inventions and innovations, but nevertheless restrict the contemporaneous transfer of technological knowledge. Therefore, careful analysis must be exercised in the design and modification of IPR legislation. A recent work by Cimoli et al (2011) showed that all cases of economies successfully "catching up" happened in the absence of IPRs. International patent applications are often used as an indicator of 
technological innovation within a region, because they represent innovation outputs that are completely new to the market and can be granted a patent. The Patent Co-operation Treaty (PCT) registered almost 150,000 patent applications in 2008.

Table 1.5 shows that the number of Chilean patents filed under the PCT has increased but remains a very small number in relation to other countries. The total number of patents filed by Chilean organizations grew from 13 in 2003 to 47 in 2008 . While most of the world patent applications are filed in OECD countries, the United States, the European Union, Japan, and the United Kingdom are those with the largest number of yearly patent applications. China increased the number of patent applications by nearly 400\% from 2003 to 2008, which is consistent with an expansion of technological knowledge that has boosted their recent high levels of GDP growth.

Table 1.5 Patents Filed under the Patent Co-operation Treaty (PCT) 2003-2008

\begin{tabular}{|c|cccccc|}
\hline & 2003 & 2004 & 2005 & 2006 & 2007 & 2008 \\
\hline Chile & 13 & 24 & 27 & 25 & 40 & 47 \\
Australia & 1,898 & 2,046 & 2,093 & 2,070 & 2,029 & 1,791 \\
Belgium & 835 & 973 & 1,018 & 1,096 & 1,160 & 1,040 \\
Canada & 2,325 & 2,494 & 2,789 & 3,011 & 3,010 & 2,525 \\
France & 5,308 & 5,922 & 6,360 & 6,489 & 6,787 & 6,712 \\
Germany & 15,012 & 15,967 & 16,728 & 17,591 & 18,639 & 16,311 \\
Hungary & 175 & 190 & 196 & 202 & 245 & 206 \\
Japan & 19,352 & 24,187 & 26,156 & 26,731 & 27,749 & 27,019 \\
Korea & 3,389 & 4,248 & 5,207 & 6,436 & 7,239 & 7,034 \\
Mexico & 135 & 158 & 188 & 204 & 211 & 205 \\
Netherlands & 3,057 & 3,214 & 3,387 & 3,571 & 3,551 & 3,461 \\
New Zealand & 363 & 386 & 369 & 399 & 387 & 302 \\
Spain & 866 & 1,162 & 1,295 & 1,395 & 1,524 & 1,539 \\
Switzerland & 1,743 & 1,974 & 2,071 & 2,146 & 2,454 & 2,196 \\
Turkey & 119 & 188 & 257 & 326 & 374 & 362 \\
United Kingdom & 5,912 & 5,958 & 5,976 & 6,555 & 6,386 & 5,672 \\
United States & 42,187 & 45,565 & 49,338 & 52,442 & 49,818 & 42,470 \\
China & 1,703 & 2,336 & 3,856 & 5,245 & 6,462 & 6,792 \\
India & 952 & 932 & 1,087 & 1,187 & 1,293 & 1,248 \\
EU27 Total & 39,850 & 42,829 & 45,291 & 48,416 & 50,439 & 46,146 \\
OECD Total & 113,279 & 126,299 & 136,245 & 144,806 & 146,420 & 132,341 \\
World & 118,596 & 132,359 & 144,383 & 154,848 & 159,328 & 144,944 \\
\hline
\end{tabular}

Source: OECD (2011)

Looking at Research and Development (R\&D) efforts, Table 1.6 shows research and development spending as a percentage of GDP for a number of countries. The average $\mathrm{R} \& \mathrm{D}$ investment in OECD countries is around 2.2\% of GDP. Table 1.6 shows that Chile has the lowest rate of OECD countries. Between 2003 and 2008, the lowest R\&D investment in Chile took place in 2005 and was only $0.23 \%$ of GDP. The highest R\&D investment made by Chile was $0.4 \%$ of GDP in 2008. France, Germany, Japan, South Korea, and the United States are among the countries with the highest R\&D investment as a share of GDP. Other Latin American countries, such as Brazil with nearly 1\% of 
GDP dedicated to R\&D and Mexico with $0.4 \%$ of GDP spent on R\&D, have relatively low innovative investments but still outperform Chile in terms of their innovation efforts.

Table 1.6 R\&D Spending across Selected Countries (Percentage of Total GDP)

\begin{tabular}{|c|c|c|c|c|c|c|}
\hline & 2003 & 2004 & 2005 & 2006 & 2007 & 2008 \\
\hline Chile & 0.28 & 0.31 & 0.23 & 0.25 & 0.33 & 0.40 \\
\hline Australia & & 1.78 & & 2.06 & & \\
\hline Belgium & 1.88 & 1.86 & 1.83 & 1.86 & 1.9 & 1.92 \\
\hline Brazil & 0.96 & 0.9 & 0.97 & 1 & 1.1 & 1.13 \\
\hline Canada & 2.04 & 2.07 & 2.05 & 1.97 & 1.9 & 1.84 \\
\hline France & 2.17 & 2.15 & 2.1 & 2.1 & 2.04 & 2.02 \\
\hline Germany & 2.52 & 2.49 & 2.49 & 2.53 & 2.53 & \\
\hline Hungary & 0.93 & 0.87 & 0.94 & 1 & 0.97 & \\
\hline Japan & 3.2 & 3.17 & 3.32 & 3.4 & 3.44 & \\
\hline Korea & 2.49 & 2.68 & 2.79 & 3.01 & 3.21 & \\
\hline Mexico & 0.4 & 0.4 & 0.41 & 0.39 & 0.37 & \\
\hline Netherlands & 1.76 & 1.81 & 1.79 & 1.78 & 1.71 & \\
\hline New Zealand & 1.19 & & 1.16 & & 1.21 & \\
\hline Russian Federation & 1.28 & 1.15 & 1.07 & 1.07 & 1.12 & 1.03 \\
\hline South Africa & 0.8 & 0.86 & 0.92 & 0.95 & & \\
\hline Spain & 1.05 & 1.06 & 1.12 & 1.2 & 1.27 & 1.35 \\
\hline Switzerland & & 2.9 & & & & \\
\hline Turkey & 0.48 & 0.52 & 0.59 & 0.58 & 0.72 & \\
\hline United Kingdom & 1.75 & 1.69 & 1.73 & 1.76 & 1.82 & 1.88 \\
\hline United States & 2.61 & 2.54 & 2.57 & 2.61 & 2.66 & 2.77 \\
\hline China & 1.13 & 1.23 & 1.34 & 1.42 & 1.44 & \\
\hline India & 0.8 & 0.79 & 0.84 & 0.88 & 0.87 & 0.88 \\
\hline EU27 Total & 1.75 & 1.73 & 1.74 & 1.76 & 1.77 & \\
\hline OECD Total & 2.2 & 2.17 & 2.21 & 2.24 & 2.28 & \\
\hline
\end{tabular}

Source: for Chile, Ministerio de Economia (2009, 2010); for all other countries OECD (2010).

Investment in R\&D and knowledge creation clearly has been left aside in the recent development of the Chilean economy. In a country that is small and largely dependent on the export of mineral commodities, it is very important to promote innovation activities that will help the economy be sustainable in the future. If newer technologies are developed for production of a wider variety of manufactured exports, growth can be less dependent on the price of copper and the amount extracted, and can be sustainable without reliance on this exhaustible resource.

As economies grow and educational systems allow a larger variety of labor specialization patterns, societies show a change in the shares of labor allocated to the main three economic activities: agriculture, industry, and services. As labor productivity increases, the share of employment working in agriculture is first reduced to increase the share of labor dedicated to industry. In further stages of development, we expect an increase in the share of people working in services and a decline of the share working in both industry and agriculture. Table 1.7 shows the evolution of the shares of employment 
dedicated to different activities in Chile. In the past 20 years, the share of people working in agriculture has gradually decreased, while the share of the labor force working in services has increased.

Table 1.7 Productive Composition of Chile 1980-2007

\begin{tabular}{|c|c|c|c|}
\hline $\begin{array}{l}\text { Chile } \\
\text { Year }\end{array}$ & $\begin{array}{l}\text { Employment in services } \\
(\% \text { of total employment) }\end{array}$ & $\begin{array}{l}\text { Employment in industry } \\
\text { (\% of total employment) }\end{array}$ & $\begin{array}{c}\text { Employment in agriculture } \\
\text { (\% of total employment) }\end{array}$ \\
\hline 1980 & 59.8 & 23.7 & 16.3 \\
\hline 1981 & 60.7 & 23.7 & 15.5 \\
\hline 1982 & 65.4 & 18.2 & 16.2 \\
\hline 1983 & 66 & 18.1 & 15.8 \\
\hline 1984 & 63.7 & 20.2 & 16 \\
\hline 1985 & 59.6 & 20.2 & 20.2 \\
\hline 1986 & 58.2 & 21.2 & 20.6 \\
\hline 1987 & 56 & 23 & 20.9 \\
\hline 1988 & 54.8 & 24.9 & 20.3 \\
\hline 1989 & 54.1 & 26.5 & 19.4 \\
\hline 1990 & 55.5 & 25.2 & 19.3 \\
\hline 1991 & 54.6 & 26.3 & 19.1 \\
\hline 1992 & 55.5 & 26.5 & 18 \\
\hline 1993 & 56.2 & 27.2 & 16.6 \\
\hline 1994 & 57.7 & 26.1 & 16.2 \\
\hline 1995 & 58.2 & 26.1 & 15.7 \\
\hline 1996 & 58 & 26.6 & 15.4 \\
\hline 1997 & 58.3 & 27.3 & 14.4 \\
\hline 1998 & 60 & 25.5 & 14.4 \\
\hline 1999 & 62.1 & 23.4 & 14.4 \\
\hline 2000 & 62.2 & 23.4 & 14.4 \\
\hline 2001 & 62.5 & 23.9 & 13.6 \\
\hline 2002 & 67.2 & 22.1 & 10.7 \\
\hline 2003 & 63 & 23.4 & 13.6 \\
\hline 2004 & 63 & 23.6 & 13.4 \\
\hline 2005 & 63.9 & 23 & 13.2 \\
\hline 2006 & 63.9 & 23.3 & 12.8 \\
\hline 2007 & 64.3 & 23.4 & 12.3 \\
\hline
\end{tabular}

Source: World Bank 2010.

In different economic sectors the use of knowledge for production varies. Innovation of products and processes occur in different intensities across sectors and evolves in a particular way for each economic activity. For the effects of this research it becomes especially relevant to understand the sectorial taxonomy of knowledge allocations comparing the knowledge dynamics in natural resource based sectors, manufacturing industry and service sectors. Table 1.8 shows the percentage of firms that performed technological innovations across economic sectors according to the 2005 and 2007 Chilean Innovation Surveys. The Mining Industry performed less product innovations than the average of the Chilean economy but much more process 
innovations than the average Chilean firm. The Manufacturing Industry performs above the average in both product and process innovations according to 2005 and 2007 Innovation Surveys. Agriculture, Fishing and Financial Services are the sectors with the lowest levels of Technological Innovations in the economy.

Table 1.8 Evolution from 2005 to 2007 of Technological Innovation by Economic Sector

\begin{tabular}{|c|ccc|ccc|}
\hline \multicolumn{3}{|c|}{ (\% of firms) } \\
Economic Sectors / Kind of Innovation & \multicolumn{3}{|c|}{ 2005 Survey } & \multicolumn{3}{c|}{2007 Survey } \\
\cline { 2 - 7 } & Product & Process & Total & Product & Process & Total \\
\hline Agriculture & 22,8 & 25,3 & 27,9 & 10,9 & 18,9 & 20,8 \\
Fishing & 17,0 & 19,7 & 21,3 & 6,8 & 8,8 & 13,0 \\
Mining & 18,8 & 56,3 & 57,8 & 10,6 & 36,2 & 36,2 \\
Manufacturing & 27,6 & 35,0 & 38,3 & 20,2 & 26,4 & 29,0 \\
Electricity, Gas, Water & 22,7 & 46,7 & 48,0 & 10,8 & 33,8 & 33,8 \\
Construction & 23,5 & 25,2 & 29,7 & 17,9 & 21,4 & 27,2 \\
Transport and Communications & 34,5 & 26,3 & 35,6 & 11,6 & 11,8 & 14,8 \\
Financial Services & 28,9 & 24,3 & 29,6 & 12,3 & 13,3 & 15,4 \\
Real estate, Informatics, R\&D & 28,7 & 28,7 & 32,3 & 45,5 & 41,1 & 51,0 \\
Teaching & 46,1 & 30,2 & 50,7 & & & \\
Social Services and Health & 30,3 & 33,4 & 39,1 & 23,7 & 25,7 & 34,9 \\
Other Services (in 2007 includes Teaching) & 46,3 & 20,1 & 51,7 & 20,9 & 19,1 & 24,7 \\
Total & 27,3 & 28,2 & 33,3 & 16,2 & 19,9 & 23,7 \\
\hline
\end{tabular}

Source: Ministerio de Economía (2009)

\subsubsection{Dutch Disease, the Role of Copper and Exports on Chilean Development}

Economists usually see the recent Chilean experience as a case of a successful economy moving toward development faster than other countries in the same region. It is true that institutions have become stronger, that democracy allows organizing the country in the best interest of its people, and that the moderated economic model developed in recent decades has allowed the existence of private incentives and the redistributive role of the state. Nevertheless, the main industry supporting growth has not been the manufacture of innovative products but the extraction of mining resources. If we are interested in sustainability, we should be aware not only of the Chilean dependence on copper but also whether the profits of this sector are being used for building up industrial capacity that will last beyond the extraction of the non-renewable resource.

The concept of "Dutch Disease" was first used by The Economist magazine to describe the situation generated by the discovery of natural gas in the Northern Seas of Holland during the 1960's. The Dutch Government and a group of private firms moved rapidly into the newly discovered resource generating large profits in a relatively short period of time. Nevertheless the abundance of foreign currency affected the terms of trade making all other Dutch exports less competitive. The result was a decline in the production of all other export oriented manufacturing industries. The fact that international prices of Copper have been increasing since the eighties in addition to large 
investments that have accumulated in Chile during the past three decades implies that Chile is now one of the countries affected by the Dutch Disease. Giarda and Landerretche (2011) analyzed this problem and measured the impact of the terms of trade in different Chilean exporting industries. They found Agriculture, Food, Fishing, Paper and Chemicals among the industries that have lost growth potential as a result of becoming less competitive in relation to the worsening terms of trade.

Table 1.8 shows the participation of the mining sector in total exports in Chile from 2000 to 2009. All mining as a share of exports has increased during the past ten years and was near $60 \%$ in 2009. The great importance of copper for Chilean trade is clear from this table. The annual variation in the share of copper in total exports depends on three factors. First is the exogenous change in copper price determined by international markets based on a demand-supply interaction. Secondly, this variation depends on the level of extraction, which increases with time due to the increase of known reserves, investment, and improvements in extraction efficiency. Third, the share of copper in total exports depends negatively on the growth of non-mineral goods exports.

In the past decade, the importance of copper in total exports has increased because of a high commodity price, accompanied by an increase on copper extraction, mainly by private companies, but also by the publicly owned company CODELCO.

Table 1.8 Share of Metallic Mining Sector in Total Exports (\% of year value)

\begin{tabular}{|c|cccccccccc|}
\hline Year & 2000 & 2001 & 2002 & 2003 & 2004 & 2005 & 2006 & 2007 & 2008 & 2009 \\
\hline Total Mining & $\mathbf{4 3 . 6}$ & $\mathbf{4 1 . 0}$ & $\mathbf{4 0 . 0}$ & $\mathbf{4 1 . 5}$ & $\mathbf{5 3 . 1}$ & $\mathbf{5 6 . 7}$ & $\mathbf{6 5 . 1}$ & $\mathbf{6 5 . 6}$ & $\mathbf{6 1 . 2}$ & $\mathbf{5 7 . 7}$ \\
Copper & 37.9 & 35.5 & 34.1 & 35.4 & 45.2 & 44.5 & 56.8 & 56.3 & 52.2 & 50.2 \\
Molybdenum & 1.0 & 1.1 & 1.4 & 1.8 & 4.6 & 8.7 & 5.1 & 6.0 & 5.2 & 2.6 \\
Gold & 1.8 & 1.5 & 1.4 & 1.4 & 1.0 & 0.9 & 0.9 & 0.9 & 1.1 & 1.7 \\
Iron & 0.7 & 0.7 & 0.8 & 0.6 & 0.5 & 0.8 & 0.6 & 0.6 & 0.8 & 1.1 \\
Iodine & 0.8 & 0.7 & 0.7 & 0.7 & 0.5 & 0.6 & 0.5 & 0.5 & 0.5 & 0.7 \\
Silver & 0.5 & 0.5 & 0.5 & 0.4 & 0.4 & 0.3 & 0.6 & 0.8 & 0.6 & 0.6 \\
Other & 0.9 & 1.0 & 1.1 & 1.2 & 0.9 & 0.9 & 0.6 & 0.5 & 0.8 & 0.8 \\
\hline
\end{tabular}

Source: Central Bank of Chile (2010), except copper. Cochilco (2009), copper.

Growth has been due not only to mining, because exports of non-mineral goods have also grown, as we see in figure 1.8. The idea that manufactured exports are highly correlated with GDP growth is explained by Agosin (1999) and Agosin and Bravo-Ortega (2007). Figure 1.8 shows that, in the case of Chile, GDP is not only correlated with manufactured exports but also with copper exports. In fact, it seems to be that adding up the rates of growth of manufactured and mining exports would yield an approximate GDP growth rate. The Chilean economy is highly vulnerable because it is dependent on a single commodity that represents almost $50 \%$ of total exports. If these resources are not administered properly, the economy could end up in a situation where the reliance on a natural resource damages the capacity to develop other industries. 
Figure 1.8 Manufactured Exports, Copper Exports and GDP in Chile (1980-2010)

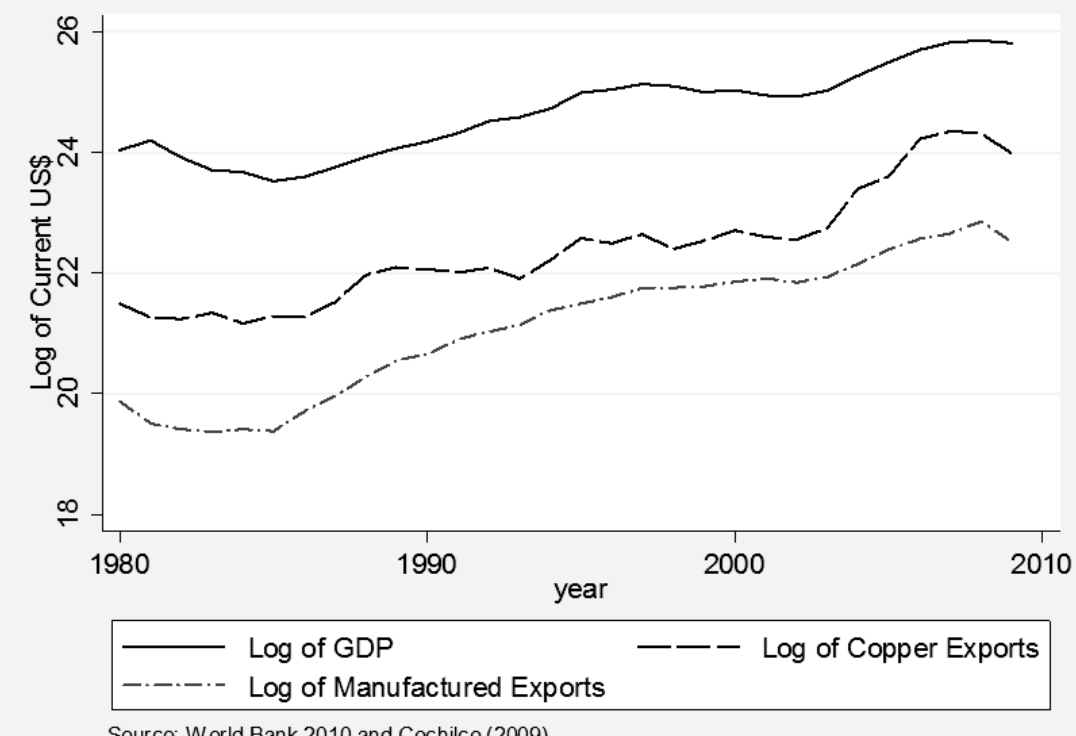

Source: World Bank 2010 and Cochilco (2009)

Agosin (2009) developed a model in which evidence could be found to support the idea that widening the comparative advantage by exporting a larger variety of products is one of the main forces that explain GDP growth. According to Agosin (1999), it is very clear that the expansion of Chilean manufactures and exports, which began in the mid1970s but took on a decisive role in development as from the mid-1980s, was one of the most important factors contributing to the growth of the Chilean economy during the past three decades.

Nevertheless, the next stage of export-oriented development will be much more difficult than the previous one. To maintain high GDP growth rates, Chile now needs to diversify manufactures. Chile needs to go beyond copper and develop industries capable of manufacturing goods that incorporate a high level of value added and that are not all as sensitive as copper to international demand shocks. Exporting a wisely designed basket of goods would mean that, when demand for some exports diminishes, demand for other exports increases or at least is not reduced as much, resulting in a relatively stable exchange rate.

According to the model of Agosin (2009), non-mining manufactured exports are one of the main drivers of development based on international trade. The experience of several Asian countries in previous decades shows that, when value added from diversified manufactured products is placed into international markets, employment and productivity increase. For the study of Chilean economic growth and development, the structure of non-mining exports must be placed on the center of the academic discussion, not only from the point of view of private profit but also from a public policy 
perspective. This table shows that the products exported most contain relatively low value added and technological knowledge.

Table 1.9 Exports and Imports of Goods and Services, Chile 1970-2009

\begin{tabular}{|c|c|c|}
\hline Year & $\begin{array}{l}\text { Exports of goods and } \\
\text { services }(\% \text { of GDP) }\end{array}$ & $\begin{array}{l}\text { Imports of goods and } \\
\text { services (\% of GDP) }\end{array}$ \\
\hline 1980 & 22.82 & 26.98 \\
\hline 1981 & 16.42 & 26.75 \\
\hline 1982 & 19.37 & 21.25 \\
\hline 1983 & 24.01 & 21.32 \\
\hline 1984 & 24.23 & 25.34 \\
\hline 1985 & 28.15 & 25.71 \\
\hline 1986 & 29.09 & 26.03 \\
\hline 1987 & 30.13 & 27.22 \\
\hline 1988 & 34.25 & 27.25 \\
\hline 1989 & 35.39 & 30.65 \\
\hline 1990 & 33.99 & 30.55 \\
\hline 1991 & 32.40 & 27.77 \\
\hline 1992 & 29.81 & 28.17 \\
\hline 1993 & 26.62 & 28.62 \\
\hline 1994 & 28.24 & 26.57 \\
\hline 1995 & 29.30 & 27.10 \\
\hline 1996 & 27.28 & 28.97 \\
\hline 1997 & 27.08 & 29.20 \\
\hline 1998 & 26.30 & 29.57 \\
\hline 1999 & 29.60 & 27.33 \\
\hline 2000 & 31.60 & 29.73 \\
\hline 2001 & 33.31 & 31.77 \\
\hline 2002 & 34.04 & 31.62 \\
\hline 2003 & 36.52 & 32.41 \\
\hline 2004 & 40.76 & 31.58 \\
\hline 2005 & 41.33 & 32.81 \\
\hline 2006 & 45.77 & 30.71 \\
\hline 2007 & 47.25 & 33.24 \\
\hline 2008 & 44.78 & 40.89 \\
\hline 2009 & 38.14 & 30.36 \\
\hline
\end{tabular}

Source: World Bank 2010

The orientation of Chile to foreign trade and its evolution in the past decades is summarized in Table 1.9. Exports as a percentage of GDP increased from 23\% in 1980 to $45 \%$ in 2008 . Imports also increased from $27 \%$ in 1980 to $41 \%$ in 2008 . The balance of the current account has been increasingly positive in the past nine years.

Table 1.10 describes the participation of different economic sectors in exports in Chile. Raw materials including copper accounted for $34.4 \%$ of exports in 2007, while simple manufactures based on a single material, including copper products, represented $42.6 \%$ of exports in the same year. Food products including wine and seasonal fruits account for the third most important exporting sector, with $13.6 \%$ in 2007. 


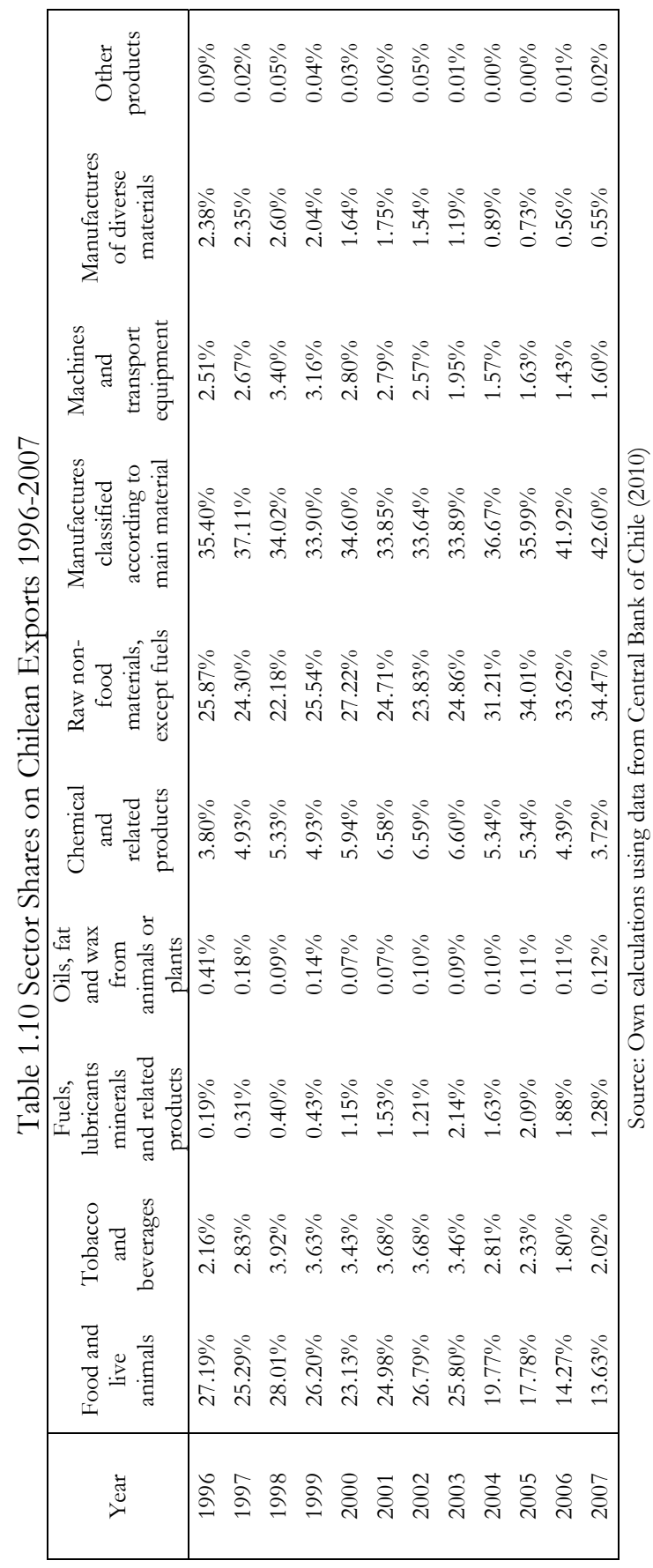


In summary, copper represents nearly half of total Chilean exports. The income resulting from this activity depends to a high extent on exogenous and unpredictable international price variations. These fluctuations have a large impact on the exchange rate, which in turn affects the competitiveness of Chilean firms. In order to achieve high rates of per capita GDP growth, as well as stability in the future, the expansion of production must be sustained by knowledge-intensive diversified exporting industries rather than on exhaustible natural resources.

\subsubsection{Productivity, Industrial Policy, Economic Sectors and Convergence}

Economists have discussed about productivity growth and its sectorial composition during many decades. The work by Salter (1960) provided a framework and an empirical analysis of productivity growth in the United States. In a full-employment scenario like the one that happened after World War II, labor productivity growth became an essential part of the economic discussion. At different stages, governments have declared their intentions to raise productivity growth in the manufacturing industry. Nevertheless understanding the causes of productivity gains is the first necessary step in order to lead any successful policy to promote productivity growth. According to Salter (1960), "behind productivity lie all the dynamic forces of economic life: technical progress, accumulation, enterprise, and the institutional pattern of society."

The work by Katz (1969) analyzed productivity in the Argentine industry and gave a precedent of economic research and empirical analysis of Productivity in Latin American economies. According to his work there was a stage on the economy during the post-war period when productivity growth was driven by Foreign Direct Investment (FDI). He also showed that this situation happened in the absence of public policy to regulate capital flows, market power, employment, income distribution and generation of domestic industrial technology among others. This situation resembles the recent history of Chile in which the Copper Industry stands for FDI and detailed regulations to this industry and other related markets to advance in productivity growth are still missing.

The paper by Leung et al (2008) discussed the relation of firm size and productivity growth among firms from Canada and the United States. They found a positive relationship between firm size and both labor productivity and TFP for both manufacturing and non-manufacturing sectors.

The work by Vergara and Rivero (2005) estimated a measure for Total Factor Productivity (TFP) growth in Chile from 1981 to 2003. Table 1.11 describes the evolution of aggregate TFP growth during this period. It appears that from the mideighties to the mid-nineties aggregate productivity experienced growth to a large extent. This pattern was discontinued after the foreign financial crisis hit the Chilean markets in 1998, even though GDP growth rates remained positive. In the period until 1995 the absence of accurate sectorial values of capital growth made the sectorial analysis hard to evaluate. Nevertheless from 1996 to 2001 Vergara and Rivero (2005) proposed a measure of Total Factor Productivity (TFP) growth that divided the economy in nine sectors and showed very interesting results from the point of view of this research. Table 1.12 
contains the summary of their findings. Most of TFP growth is related to Agriculture and Mining while the Manufacturing Industry has a negative TFP growth between 1996 and 2001.

During the decades after the Great Depression, Latin American economies turned inward as protection from external crises. Katz (2001) shows that, in Chile during the seventies, the first effort was made to open the economy toward deregulation and foreign markets. This change in economic paradigm brought about great macro-, meso- and microeconomic changes. These pro-competitive structural reforms, in combination with international financial turbulence and volatility in the environment of the historical features of each Latin American economy, triggered a Schumpeterian episode of creative destruction that gave birth to the current technological and economic paradigm.

Table 1.11 Evolution of Aggregate TFP Growth in Chile 1981-2003

\begin{tabular}{|c|cccc|}
\hline & GDP & \multicolumn{3}{c|}{ Contribution of } \\
& Growth & Labor & Capital & TFP \\
\hline $1981-1985$ & -0.7 & 2.3 & 0.3 & -3.4 \\
$1986-1990$ & 6.7 & 2.6 & 2.2 & 1.9 \\
$1991-1995$ & 8.7 & 2.9 & 2.2 & 3.5 \\
$1996-2000$ & 4.2 & 1.2 & 2.8 & 0.2 \\
$2000-2003$ & 2.5 & 0.8 & 1.8 & -0.1 \\
\hline \multicolumn{5}{|c}{ Source: Vergara and Rivero (2005) } \\
\hline
\end{tabular}

Table 1.12 TFP Growth in Chilean Economic Sectors 1996-2001

\begin{tabular}{|c|cccc|}
\hline & GDP & \multicolumn{3}{c|}{ Contribution of } \\
& Growth & Labor & Capital & TFP \\
\hline Farming, forestry and fishing & 4.12 & -2.76 & 0.95 & 5.92 \\
Mining & 8.09 & -1.45 & 3.2 & 6.34 \\
Manufacturing Industry & 1.51 & -1.66 & 3.43 & -0.26 \\
Electricity, gas and water & 3.58 & -1.79 & 4.19 & 1.18 \\
Construction & -0.1 & -1.64 & 2.98 & -1.44 \\
Commerce restaurants and hotels & 2.54 & 0.38 & 2.5 & -0.34 \\
Transport and communications & 6.78 & 2.1 & 5.22 & -0.54 \\
Financial services & 4.13 & 1.88 & 3.74 & -1.49 \\
Non-financial Services & 3.59 & -0.37 & 1.51 & 2.45 \\
\hline
\end{tabular}

Source: Vergara and Rivero (2005)

Katz (2001) describes how a new technological paradigm introduced a pattern of specialization that was biased in favor of low-knowledge industry with almost no R\&D. Latin American economies found themselves trapped in low growth rates due to a stagnation of productivity. This last problem was explored by Cimoli and Katz (2002), who concluded that an institutionalism promoting innovation activities was an essential condition for faster productivity growth. In Chile, a National Innovation System was created in 2006 as a response to the call made by this and other studies to implement an Innovation Policy that could meet this challenge in an integrated way. 
The idea of the state fostering a specific sector of the economy with the intention of promoting innovation and growth has been on the mind of industrial economists for a long time. A recent analysis of this practice was done by Aghion et al (2011), who took the experience of some European countries and compared it with other regions of the world. The work by Aghion et al (2011) found that, when state aid is focused on a particular industry, success depends largely on market competition in that particular industry. If the sector is competitive and the resources are made available to all the firms in the sector, then aid promotes growth and innovation. If, on the other hand, aid is given to a monopolistic firm or assigned to a closed subgroup of firms in a competitive market, then the impact is small or even inexistent.

A case in which the state promoted an industry that later developed into a growing economic sector was the salmon industry in the south of Chile starting in the 1980s. Iizuka and Katz (2011) have documented the rise and decline of this industry in a situation described as the problem of the commons.

Iizuka and Katz (2011) explained how the Chilean state originally put the administration of sea coastline water and terrain for the production of salmon into private hands. International demand for the commodity grew and the Chilean salmon industry registered 2-digit growth rates during two decades. In this case, clean sea water was a public good that no particular firm was willing to protect at its own cost. Eventually, pathogens contaminated the fish. In 2008, an outbreak of an infectious salmon anemia and the decreased quality of water overpopulated by salmon contributed to the massive deaths of salmon. As a result, the production of the industry decreased enormously.

In response to situations such as this, there have been recent developments in the analysis of industrial policy that promotes environmentally friendly and sustainable growth. Acemoglu et al. (2012) developed a growth model with endogenous and directed technical change in which they introduced environmental constraints. Assuming the existence of "clean" and "dirty" inputs, they obtained several practical conclusions from the model.

They found that, when inputs can be substituted, sustainable growth can be achieved by the use of temporary taxes and subsidies that redirect innovation efforts towards clean inputs. They showed that an optimal policy should include both carbon emission taxes and research subsidies but that carbon emission taxes should not be so high as to restrict the growth of efficient industries before alternative production methods can be developed. When intervention is not made timely to promote sustainable industry, the cost of introducing clean technologies will become much higher, as industries have already developed with dirty technologies. In this case, the transition will take a longer time and will include a period of slow growth. The salmon industry provides an example of what policy makers should be cautious with when promoting sustainable industries. The discussion of clean and dirty inputs in state-directed innovation efforts should be taken into account in the design of such policies.

To promote production that can be traded internationally, it is important to focus on those sectors that use Chile's advantages relative to other countries. Diaz, Meller and 
Pardo (2002) conclude that the different regions of Chile are highly specialized in certain economic activities, and that these correspond to the sectors that lead their growth. In addition, they observed that there has been no important economic restructuring in the Chilean regions in recent decades (except for the southern region XII of Magallanes).

Table 1.13 presents the main economic activities of each region of Chile during the nineties. Mining is prevalent, mainly copper, with other metallic extraction in the north (regions II, III and IV) and with oil extraction in the south (region XII). Agriculture is an important activity in several regions, mainly in the central and southern regions. Commerce, services, and industry are most developed in urban areas such as Santiago (Metropolitan Region) and Concepcion (region VIII).

In the absence of proper incentives for developing other industries, it is likely that this structure will remain unchanged in the future, because the regional development of the economic sectors is related to the endowment of natural resources and conditions of infrastructure that are not likely to be changed in a short period of time. The sector structure of each region is probably an important determinant of the regional per capita product differences that may be explored in detail from the information offered in Table 1.14. Per capita GDP apparently decreases over the 2003-2006 period but this effect is the result of the change in the Purchase Power Parity (PPP) adjustment factor we used, which went from 0.45 in 2003 to 0.69 in $2006 .{ }^{7}$

In Chile, there is no clear tendency toward reduction of the inter-regional gaps in per capita GDP. The evidence does not show a process of long run regional convergence in Chile over recent decades. On the contrary, the evidence shows that, in the long run, regions tend to stay near the same relative per capita GDP levels. A possible explanation has to do with a relatively neutral industrial policy that has not been capable of developing new productions beyond those related to natural resources and lowknowledge industries.

Reinforcing this situation, endowments of natural resources and infrastructure may drive national and foreign investments. According to Cimoli and Katz (2002), the technological paradigm that was created after 1970 in Latin America introduced a pattern of specialization that favored low-knowledge industries, and therefore the R\&D efforts were low.

The main disaggregation of the gross domestic product made by the Central Bank of Chile includes the following nine economic sectors: Farming, Forestry and Fishing (AGR), Mining (MIN), Manufacturing Industry (IND), Construction (CON), Electricity, Gas and Water (EGA), Transport and Communications (TYC), Commerce, Restaurants and Hotels (COM), Financial Services (SFI), and non-Financial Services (SNF).

\footnotetext{
${ }^{7}$ PPP correction factors were obtained from World Development Indicators, World Bank (2010).
} 


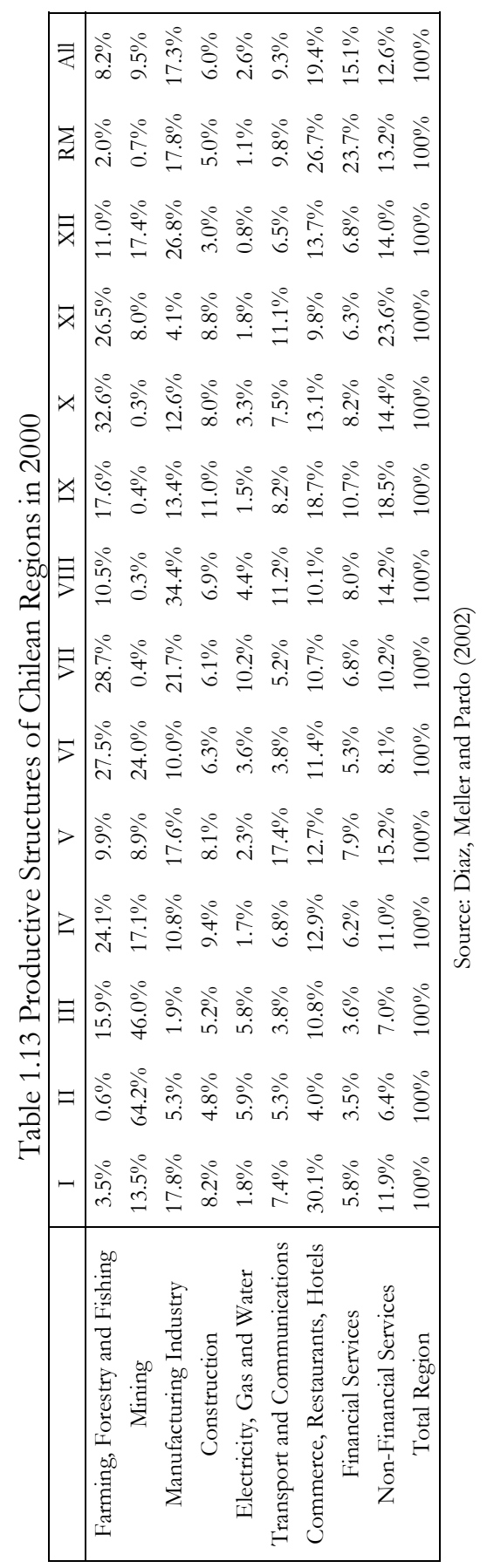


Table 1.14 Per capita GDP PPP across Regions of Chile (constant 2005 US\$)

\begin{tabular}{|c|cccc|}
\hline Region & 2003 & 2004 & 2005 & 2006 \\
\hline I & 16,145 & 16,840 & 16,657 & 17,911 \\
II & 26,488 & 27,655 & 28,199 & 29,024 \\
III & 13,221 & 13,324 & 13,643 & 15,114 \\
IV & 7,024 & 7,376 & 7,673 & 8,051 \\
V & 9,772 & 10,367 & 10,877 & 11,664 \\
VI & 8,816 & 9,603 & 10,166 & 10,539 \\
VII & 7,179 & 7,594 & 8,234 & 8,831 \\
VIII & 9,411 & 9,985 & 10,689 & 11,074 \\
IX & 5,054 & 5,346 & 5,720 & 5,984 \\
X & 7,922 & 8,472 & 8,769 & 9,141 \\
XI & 12,286 & 13,044 & 14,601 & 14,191 \\
XII & 20,726 & 20,589 & 21,497 & 22,596 \\
RM & 13,012 & 13,847 & 14,681 & 15,394 \\
\hline
\end{tabular}

Source: Own calculations using Central Bank of Chile (2010) and World Bank (2010).

Using this broad classification of economic sectors, Diaz and Meller (2004) made a convergence sector analysis in Chile, concluding that there are sectors that converge (CON, EGA, TYC, COM, SFI, SNF) and sectors that do not converge (MIN, AGR, IND). In addition, we can see from the sector analysis that a very significant part of the evolution in the differences of regional per capita GDP is due to unequal performances in the non-convergent sectors: Mining, Farming, Forestry and Fishing, and Manufacturing Industry.

The general structure of value added across sectors is summarized in Table 1.15. Financial services, manufacturing industry, and non-financial services together account for about $50 \%$ of total value added, while construction represents approximately $13.3 \%$ of total value added.

Table 1.15 Sector Shares in Value Added, the Chilean Productive Structure 2003-2007

\begin{tabular}{|c|ccccccccc|}
\hline Year & $\begin{array}{c}\text { Farming, } \\
\text { forestry } \\
\text { and } \\
\text { fishing }\end{array}$ & Mining & $\begin{array}{c}\text { Manufac- } \\
\text { turing } \\
\text { Industry }\end{array}$ & $\begin{array}{c}\text { Electrici- } \\
\text { ty, gas } \\
\text { and water }\end{array}$ & $\begin{array}{c}\text { Cons- } \\
\text { truction }\end{array}$ & $\begin{array}{c}\text { Commerce } \\
\text { restaurants } \\
\text { and hotels }\end{array}$ & $\begin{array}{c}\text { Transport } \\
\text { and } \\
\text { communi- } \\
\text { cations }\end{array}$ & $\begin{array}{c}\text { Financial } \\
\text { services }\end{array}$ & $\begin{array}{c}\text { Non- } \\
\text { financial } \\
\text { Services }\end{array}$ \\
\hline 2003 & $5.08 \%$ & $8.89 \%$ & $17.28 \%$ & $3.01 \%$ & $13.39 \%$ & $10.19 \%$ & $9.69 \%$ & $15.74 \%$ & $16.72 \%$ \\
2004 & $5.33 \%$ & $8.92 \%$ & $17.47 \%$ & $2.92 \%$ & $13.03 \%$ & $10.33 \%$ & $9.67 \%$ & $16.05 \%$ & $16.29 \%$ \\
2005 & $5.41 \%$ & $8.12 \%$ & $17.54 \%$ & $2.85 \%$ & $13.21 \%$ & $10.62 \%$ & $9.79 \%$ & $16.49 \%$ & $15.97 \%$ \\
2006 & $5.28 \%$ & $7.79 \%$ & $17.43 \%$ & $2.94 \%$ & $13.12 \%$ & $10.89 \%$ & $9.99 \%$ & $16.70 \%$ & $15.84 \%$ \\
2007 & $5.19 \%$ & $7.71 \%$ & $17.06 \%$ & $2.51 \%$ & $13.31 \%$ & $11.07 \%$ & $10.28 \%$ & $17.18 \%$ & $15.69 \%$ \\
\hline
\end{tabular}

Source: Author's calculations using data from Central Bank of Chile (2010) 


\subsection{Policy Recommendations}

\subsubsection{Chilean Strengths that have Supported Growth and Development}

Barro (1991) provides a theoretical framework for analyzing the factors that contribute to modern economic growth. This type of analysis allows quantifying the effect of the factors that promote or slow down a growth process. This work has particular importance at the time of designing public policies for development. The expansion of an economy may be seen as a result of investments in capital and alternatively as an expansion or improvement of the labor force. The economy will also grow as a result of technological change that can increase total factor productivity, as has been well documented for the Chilean case in the work by Bitran and Gonzalez (2010).

An inclusive analysis highlighting the strengths of the Chilean economy and explaining why these characteristics are likely to be some of the most important factors contributing to Chilean growth may be found in Schmidt-Hebbel (2006). His work mentions institutions, inflation control, exchange rate flotation scheme, international trade, fiscal policy, and financial liberalization as the main factors contributing to growth after 1990. He shows that recent growth was not due only to factor accumulation but also to productivity growth. Fuentes et al. (2006) made a more complete analysis of Chilean production factors and productivity growth, concluding that, even though TFP growth has behaved in a pro-cyclical way, it has contributed more than half of the economic growth in Chile after 1990. The work carried out by De Gregorio (2007) summarizes the strengths of the Chilean economy. According to him, the most important strengths of the Chilean economy are its openness to international trade, macroeconomic stability, strong institutions, and a stable and deep financial sector.

One of the most important characteristics accompanying Chilean economic growth has been the openness of the economy to the outside world. The importance of trade for the Chilean case has been described in Agosin (1999, 2009), where it has been shown that exports have driven Chilean growth to a large extent. His work shows that the Chilean economy progressively opened to international trade in the nineties and that commercial agreements since 1990 have increased the degree of commercial integration even more. Import tariffs have decreased from an average of around $9 \%$ in the middle of the $1990 \mathrm{~s}$ to rates that range below $2 \%$ by the end of the decade.

Besides the development of international product markets, Chile has opened financially and has eliminated most of the controls to capital flows. The exchange rate policy is based on a flotation scheme, coherent with the financial integration of a country that is small and open to international trade. Although the exchange flotation scheme has induced major fluctuations of the nominal exchange rate in the short term, this system has brought a greater degree of stability in the long term.

The importance of macroeconomic stability in Chile during the past two decades has been extensively discussed by De Gregorio $(2005,2007)$. The scheme of policies and macroeconomic stability is important not only from the point of view of the economic cycle, but also from the point of view of growth potential. A system of macroeconomic policies that is responsible and coherent offers enormous benefits for growth and 
development. This positive effect can be reflected in a healthy and more stable economy. Some of the greatest achievements in the case of Chile during the nineties had to do with the control of inflation and product volatility. Low and stable inflation promotes growth, allowing the economy to adjust prices without discouraging the use of money. A scheme of flexible inflation goals has consolidated in Chile during the nineties. This scheme was designed for a context in which it is desired to reduce simultaneously the costs of inflation deviations and the fluctuations of GDP. With respect to these aims, the Central Bank of Chile is committed credibly to an inflation goal using policies that assure a suitable balance between both concerns.

Chilean fiscal policy in the past two decades has been characterized by its responsibility, in the sense of controlling public deficit in such a way that there exists dynamic efficiency in the public investment process. This way, public spending has been coherent with the permanent income. The transitory incomes produced by the fluctuations of the value of copper have been used to pay public debt and accumulate investment or saved to be spent over a longer period of time. Since 2000, this policy has become fortified by the use of the rule of $1 \%$ of structural GDP fiscal surplus. ${ }^{8}$

Institutional strength is also a very important driver of growth. Chilean institutions are described by multinational organisms in a very positive way. Within the main Chilean institutions that have gone through profound modernization processes after 1990, we find the central bank authority, the judicial system, the tax system, and a democracy based on citizen participation and the state of law. There is no evidence that the institutional quality has deteriorated in recent years in perceivable magnitudes. On the contrary, there has been progress in institutional development, for example concerning transparency in the selection of public directives, the creation of the competition court, and the recent development of a public information law by which every citizen has the right to be provided with financial and performance information from every public agency that operates in Chile.

A very important support for growth has been to maintain a deep and stable financial sector. The financial system has deepened during the past two decades. New instruments have emerged that have given medium- and low-income people access to stock markets and competitive savings interest rates. Part of this progress is due to the action of the state owned bank "Banco Estado" that allows every person 18 years of age or older with a tax identification number to have a current account with an ATM card. Capital market reforms, including those regulating corporate governance, have also increased the efficiency and capacity of capital markets.

The financial system is an important tool that allows the efficient allocation of capital. Most of it is controlled by private owners who can contribute to improving efficiency as a result of their rent seeking process. Nevertheless, in Latin America, we have seen many situations in which the private banks have collapsed, risking the environment in which manufacturing firms operate. Therefore, a financial regulatory framework under government supervision is essential.

\footnotetext{
${ }^{8}$ Since 2000 , this rule has the force of law, a sign of a relatively democratic political context.
} 


\subsubsection{Weaknesses and Challenges for Future Development}

One of the main disadvantages of Chile in terms of international competitiveness is the low level of innovation, as measured by innovation inputs and outputs. Research and Development expenditures are the lowest of the OECD. The Chilean government is studying how to stimulate R\&D activities in order to increase innovation of products and processes. As shown in Table 1.5, there were less than 50 patent applications by Chilean firms under the Patent Co-operation Treaty in 2008. This indicates the number of innovations introduced that were new to the market. It is quite clear that Chile is a country that has obtained most of its productive knowledge by developing absorptive capacities and facilitating technology diffusion rather that developing novel processes within Chilean firms.

The impact of innovation on economic growth has been widely discussed in the literature. The measurement of the innovative process, the importance of innovation, and the relation between innovation and productivity has been studied in Mairesse and Mohnen (2001), Crepon, Duguet and Mairesse (1998), and a rich literature that followed these studies. There is also evidence of a link between innovation and competitiveness (see Geroski 1995). The impact of innovation on employment in Chile has been discussed recently in Benavente and Lauterbach (2008) and positive and important rates of return to R\&D in Chile have been found in Benavente, De Gregorio and Nuñez (2006).

In addition to extending the public infrastructure in areas such as education, transport, and communications, it can be very effective to involve the private sector in the innovative process. To achieve this goal, several subsidies are being developed to promote $R \& D$ and entrepreneurship. Some of these programs are being funded with the recently created royalty tax on the extraction of non-renewable resources. These subsidies aim for the adoption and generation of technology on the part of private companies, universities, and research centers.

While maintaining a liberal attitude towards foreign direct investment, the Chilean authorities do not make a great effort to attract multinational corporations with desirable technological or management assets and with access to markets for manufactures. A special effort could be made to avoid tax evasion by large enterprises, especially the larger multinational companies that in some cases try to use local natural resources to produce a benefit in foreign markets without paying taxes in the country of origin of those resources. A successful FDI policy could stimulate international transfer of knowledge in favor of Chile. This kind of policy may help develop innovation capabilities and stimulate private R\&D investment. Association with Common Southern Market (MERCOSUR) could be important for attracting investment to the Chilean manufacturing sector in the near future.

In both developed and developing countries, high quality education that is accessible to all populations is one of the most important ways to both achieve economic growth and decrease income inequality. Although Chile has appropriate levels of schooling, the quality of education is still deficient; see, for example, Paredes and Paredes (2007) or Paredes and Garcia (2008). Consequently, improving the quality of education provides 
ample potential for gains in growth. Nevertheless, improvements in the quality of education normally have a lagged impact on growth, which will take a long time in materializing.

Even though Chile has seen high levels of growth, one of the biggest challenges it faces in the following years is the high level of income inequality. Inequality is a very serious problem when the lowest income does not allow a family to cover basic necessities. Inequality also undermines the development of a more integrated society. Decreasing inequality is also important to maintain sustainable high rates of growth and economic efficiency. People in the lower income levels have smaller participation in the economy and contribute less than they would if they participated in higher productivity and better paid jobs. Inequality limits the chances of many economically active citizens with lower income to access productive jobs that can result in greater growth.

Some authors have argued that flexibility in the labor market is needed to reduce unemployment and to promote growth and efficiency. Instead of forcing employers to pay high amounts of compensation when dismissing people from their jobs, unemployment insurance can be improved so that workers who lose their jobs can receive money to provide themselves the means to find a new job. Care should be exercised in the design of these policies because, when taken to an extreme, they may invert workers' incentives. This may result in increasing unemployment rates to high levels, as occurred during previous decades in some European Union countries.

In the same line of thought about giving the proper incentives to economic agents, De Gregorio (2007) proposed that the law of bankruptcy can be improved. In Chile, bankruptcy processes recover about $20 \%$ of the assets of bankrupt firms, while, in countries with better procedures, the rates of recovery reach to more than $50 \%$, and in many cases they surpass $80 \%$. A law of bankruptcy that allows investors high rates of recovery would facilitate the access of firms to financing.

\subsubsection{Recommendations for Modern Economic Growth in Chile}

The Central Bank of Chile performed a research project during 2004 on the economic growth of Chile. From this project arose several empirical and analytical works discussing the policies, perspectives, and challenges of economic growth in Chile. Fuentes and Schmidt-Hebbel (2004) summarized this research and identified four areas of policy recommendations. Their conclusions are also related to the findings of other authors in terms of the weaknesses and strengths of the Chilean economy.

In the first place, the importance of educational quality is the central subject in Tokman (2005). This work addresses the importance of improving human capital levels in Chile as one of the driving engines of development. In addition, it suggests modifying government subsidies for public and private primary and secondary education; to improve university degree programs in pedagogy; to reinforce the evaluation of teachers as a common practice; and to increase state subsidies for the preschool education. This last aspect acquires high importance when considering the participation of women in the labor market, which in turn has high distributional consequences. Secondly, Benavente (2005) is based on the foundations of modern economic growth and aims at 
demonstrating that long-run economic growth does not depend so much on the increase of productive factors but rather on the increase of productivity. His work studies the way in which it is possible to spur innovation and technological development through public policy. His study also includes a complete international comparative description in which the innovative effort of Chile is placed among other countries. The third subject has to do with the efficiency of the labor market. Albagli (2005) analyzed the rigidities of the Chilean labor market from a neoclassical point of view. He suggested replacing the present payments of indemnifications for dismissal based on years of service by an insurance system that pays a comparable amount of money to people who lose their jobs. He also proposed eliminating restrictions on part-time work and subsidizing day-care centers for the children of working mothers. Aguirre et al. (2004) suggested improving the efficiency of the public and private sectors, adopting enterprise practices, and performing evaluations in the government similar to those in the private sector. They also proposed modifying the law of bankruptcy; extending the reform of the judicial system; and improving the ongoing reform in the health sector.

There is an ample range of reports issued by international institutions that describe Chilean economic development and make proposals to stimulate economic growth. The "Economic Survey of Chile by the Organization of Economic Cooperation and Development" (OECD, 2005) concentrates directly on the long-term challenges. The report identifies key areas for reforms that would have an important impact on economic growth. In regard to the educational system, it concludes that long-term gains would be obtained by improving human capital. The report indicates that this is the factor of weakest performance in Chile. Because the educational coverage in Chile is relatively high, the proposal consists of raising the present educational standards and improving the quality of the labor training programs. The second proposal is to promote competition for the network industries (electricity, telecommunications, and transport infrastructure). In relation to innovation and $\mathrm{R} \& \mathrm{D}$, the report also proposes promoting of innovation based on efficient use of the mining tax revenue, assigning this revenue by means of competitive contests and in a transparent way. Finally, the OECD proposes to improve the efficiency of the labor markets, a subject in which it agrees with Albagli (2005).

The International Monetary Fund (IMF, 2005) also recognized the importance of increasing human capital to increase long-run growth rates. The quality of education is a persistent subject in the literature of development in Chile. The IMF report also discusses the importance of preschool education. It recommends improving the quality of primary and secondary education; improving the access of low-income students to higher education; and providing professors the right incentives through wage differentiation in accordance with their productivity. The IMF report also suggested developing innovation capabilities and flexibility for labor markets.

The World Bank (World Bank, 2002) also encouraged a change in the present growth based on the accumulation of factors to growth founded on the increase of productivity. This perspective is shared by the OECD and diverse authors including Benavente (2005). In order to achieve this objective, the World Bank suggests policies that aim to increase the quality of human resources and knowledge, including adult 
education as well as labor mobility. They also recommended improving the investment climate and reinforcing governmental modernization.

A report by the Inter-American Development Bank (IADB, 2001) included a deep analysis of economic development in Chile. It proposes the development of competitiveness to increase the potential of growth in Chile. The competitiveness principle must be present in the development of policies that spur the adoption of clean technologies. Other general recommendations were a greater integration with international trade, infrastructure improvements, and development of human capital.

The work by Agosin (1999) proposes that Chile should also reinvent development banks. Such banks should be designed to provide long-term credit at market interest rates to firms with good export projects but no access to private capital markets. These institutions could also be used to channel funds to loans for higher and technical education and for financing expenditure on applied research. Development banks do not need to intervene directly in the provision of loans for firms or individuals; they can function as second-tier banks, making credit lines available to private financial institutions for specific purposes. According to Agosin (1999) this is the most efficient way of supporting infant industries, and moreover it is not prohibited by the rules of the World Trade Organization. It could in fact become the main instrument for promoting specific sectors and activities. By providing long-term credit for new, non-traditional activities, development banks would help developing industries and would promote exports. This would stimulate long-term growth and give opportunities to small-scale entrepreneurs to achieve success, thus helping to reduce inequality.

A recent approach by Aequalis (2011) argued that access to higher education should be equal for all persons in the society. It proposed policy recommendations to improve the quality of the Chilean higher education system, including the creation of new administrative state units to promote and monitor the actions of higher education institutions. This work proposed several measures to modify the selection of students and graduation systems. Aequalis (2011) implied that there is a great need to invest more state resources in higher education.

Chile and its citizens are rich in natural resources, can profit greatly from them, and can rely on them if they are used properly. Copper is the mineral that is currently allowing the country to have a positive current account balance. One century ago the saltpeter industry was providing a comparable commodity and causing a similar effect. This industry ended when a chemical substitute for saltpeter was invented. If Chileans manage to care for and conserve the natural resources that lie in their territory, they will most likely be able to allow future generations to enjoy this wealth. Mineral resources can be a sustainable advantage for the economy if their profits are reinvested in a way that allows alternate industries to develop and eventually replace mineral exports when mineral resources become exhausted or substituted by other commodities.

Smart decisions must be made to re-invest the current revenues of the copper industry. All minerals in Chile are a public resource own and managed by the state, but private extraction of copper and other minerals is allowed. The practical application of the Chilean copper constitutional law relies on a series of laws that should reasonably 
change over time in order to adapt to the evolving reality of the nation. In recent years, the share of copper extracted by the state-owned CODELCO has greatly decreased, and private extraction has increased, while the price of the commodity has greatly increased. As the value of copper increases in foreign markets, a larger share of the value of Chilean copper is being captured by private and foreign firms and a relatively smaller share is received by the state (COCHILCO, 2009). This poses a large challenge for Chilean society, especially for its politicians and economists.

This is the reason that the mining royalty tax was legislated in 2005. The tax requires the largest mining companies to pay a tax of no more than $4.5 \%$ of the value of their sales, as compensation for the resource that they extract and commercialize. But the importance of this tax depends completely on how this revenue is spent by the state. A significant share of the revenue is being invested in the National Innovation Policy. Because copper is a non-renewable resource, the yields of this industry must be reinvested into other industries within the same economy. R\&D, start-ups, infant industries, higher education, and knowledge transfers from abroad are examples of how to use this revenue wisely. When new industries boosted by copper revenues become independent and profitable, the natural resources will have been transformed into sustainable economic growth.

\subsection{Concluding Remarks}

A comprehensive analysis of the Chilean growth process and development performance has been made, considering the perspectives of several authors and international organizations. Data from different sources has been gathered to evaluate the arguments, not only in terms of growth and development but also in terms of other aspects such as exports, innovation and education, which are the most relevant determinants of the long-term growth path.

Chile has developed an outstanding advantage with respect to most developed countries, building peaceful relations not only with its close neighbors but also with countries from other regions. At least since 1990, when democracy was reestablished, Chile has focused its foreign policy on trade, basing the solution to all international conflicts on international referees such as the UN and WTO. Chile has increasingly become safe, not only for doing business but also for its low risk of armed conflicts and the absence of deadly terrorist attacks.

Even though Chile has been described as a country that has achieved a stable democracy, with an open economy, good macroeconomic policies, and reasonable institutional quality, challenges for the future remain. Innovations, public education, export market diversity, inequality of income, and allocation of mining exports revenue are some of the most important issues of which economists and politicians should take care in the near future.

In many ways, Chilean policy since the second half of the seventies has adhered to the policies recommended by the Washington Consensus, both in its positive aspects, 
such as macroeconomic stability, and its more negative aspects, such as the absence of a national innovation policy promoted by the state. A Chilean national innovation system was established only in 2006. As discussed in the literature, besides having good macroeconomic stability, credible institutions, and a deep financial sector, Chile has among its advantages for growth its openness to trade and international markets. This implies greater growth opportunities but it is not alone going to generate the growth potential that Chile needs for the future. Becoming internationally competitive in diversified manufactured goods and services requires innovation and the development of other strengths that were not needed for the export of primary commodities like copper. The most important challenge related to competitiveness for the Chilean economy in the near future is achieving structural differentiation in manufactured production and exports.

The development of human capital and R\&D investment appear without doubt as some of the most important aspects of development for the present and future. Both of these aspects are closely related and rely also on the creation of country and industry level absorptive capacities. Important aspects of this process are the development of improved business capabilities, the acquisition of information, greater applied research efforts by local firms, and improvements in the country's ports, highways, and tunnels. In this context, the role of the government in providing the proper incentives to the private sector is crucial.

Special attention must be given to the role of copper in the Chilean economy. Exogenous fluctuations in the price of this commodity have a huge impact on exchange rates, creating distortions in other markets and threatening the stability of other exporting industries. It is important that the state ensures that the profits of the mining industry, or at least a significant share of them, stay within the country and contribute to investment that will allow the creation and sustainable development of other industries. The need for more diversification of production and exports emerges as an important conclusion from the previous analysis. Stimulating industrial investment, facilitating the import of capital goods, improving the educational system, and promoting R\&D appear to be some of the state's most important roles for the next decades. 


\section{References}

Aequalis (2011). "Propuestas para la Educacion Superior, Foro Aequalis y las Transformaciones Necesarias.” Edited by M. Jimenez de la Jara, F. Lagos Rojas and F. Duran del Fierro. Published by INACAP in Santiago.

Acemoglu, D., Aghion, P., Bursztyn, L., Hemous, D. (2012). "The Environment and Directed Technical Change.” American Economic Review, 102(1): 131-66

Aghion P., Dewatripont, M., Du, L., Harrison, A., and Legros, P. (2011). "Industrial Policy and Competition.” European Commission GRASP Project Working paper No 17.

Agosin M. (2009). "Export diversification and growth in emerging economies." Cepal Review, Vol. 97, pp. 115 - 131, Abril, 2009

Agosin, M. and C. Bravo-Ortega (2007). "The Emergence of New Successful Export Activities in Latin America: The Case of Chile." Department of Economics, Universidad de Chile. Working Paper Number 236, April 2007.

Agosin, M. (1999). “Trade and Growth in Chile.” Cepal Review Vol. 68 August 1999.

Aguirre, A., E. Albagli and D. Rappaport. (2004). "Eficiencia del sector público y crecimiento." Manuscrito, Banco Central de Chile.

Albagli, E. (2005). "Mercado laboral y crecimiento económico: Recomendaciones de política para Chile.” Estudios Públicos 99: 135-64.

Albagli, E., Garcia, P., and Restrepo J. E. (2005). "Assessing the Flexibility of the Labor Market in Chile: an International Perspective.” Labor markets and Institutions, Edited by Jorge E. Restrepo and Andrea Tokman R. Santiago Chile, Central bank of Chile.

Aninat, C., Benavente, J.M., Briones, I., Eyzaguirre, N., Navia, P., Olivari, J. (2010). “The Political Economy of Productivity: The Case of Chile.” Inter-American Development Bank, Working Papers Series No. IDB-WP-105

Barro, R. (1991). "Economic Growth in a Cross-Section of Countries." Quarterly Journal of Economics, Vol. 106, No. 2, pp. 407-443.

Benavente, J.M. (2005). "Innovación Tecnológica en Chile: Dónde estamos y qué se puede hacer.” Economía Chilena 8(1): 53-74. 
Benavente, J.M. (2006). "Antecedentes para el diseño de una Política Tecnológica Nacional." Serie Documentos de Trabajo N 229. Departamento de Economía, Universidad de Chile.

Benavente, J.M., De Gregorio, J., and Nuñez, M. (2006). "Rates of Return for Industrial R\&D in Chile," Serie Documentos de Trabajo Número 220. Departamento de Economia, Universidad de Chile.

Benavente, J.M., Crespi, G., and Maffioli, A. (2007). “The Impact of National Research Funds: An Evaluation of the Chilean FONDECYT." Inter-American Development Bank Office of Evaluation and Oversight, OVE Working Paper: OVE/WP-03/07

Benavente, J.M., Price, J.J., and Olivari, J. (2009). "Sistemas Públicos de Apoyo a la Innovación.” Economía y Administración (157): 60-67. Junio-Julio.

Benavente, J.M. and Lauterbach, R., (2008). "Technological Innovation and Employment: Complements or Substitutes?" The European Journal of Development Research (vol 20, issue 2).

Bitran E., and González, C.M. (2010). "Productividad Total de Factores, Crecimiento e Innovacion." Documento de Referencia Consejo Nacional de Innovacion y Copetitividad CNIC. www.cnic.cl .

Braun, J., Braun, I., Briones, I., and Diaz, J., (2000). "Economia Chilena 1810-1995, Estadisticas Historicas." Instituto de Economia Pontificia Universidad Catolica de Chile. Working paper n 187. ISSN 0717-7593.

Central Bank of Chile (2010). "Base de datos Estadisticos." Gerencia de Informacion Estadistica, (C) Banco Central de Chile.

Cimoli, M. and Katz, J. (2002) "Structural Reforms, Technological Gaps and Economic Development, A Latin American Perspective." Cepal- Serie Desarrollo Productivo No 129.

Cimoli, M., Dosi, G., Mazzoleni, R., and Sampat, B. (2011). "Innovation, technical change and patents in the development process: A long term view." LEM Papers Series 2011/06, Laboratory of Economics and Management (LEM), Sant'Anna School of Advanced Studies, Pisa, Italy.

Chile Innova (2005). "Innovar en Chile, Programa de desarrollo e Innovacion tecnologica 2001-2006." Subsecretaría de Economía, Fomento y Reconstrucción, Ministerio de Economía 
Crepon, B., Duguet, E., and Mairesse, J., (1998). "Research, Innovation, and Productivity: an Econometric Analysis at the Firm Level." NBER Working Papers number 6696. National Bureau of Economic Research, Inc.

COCHILCO (2009). "Yearbook: Copper and Other Mineral Statistics." Comision Chilena del Cobre, Gobierno de Chile.

De Gregorio, J. (2005). "Crecimiento económico en Chile: Evidencia, fuentes y perspectivas.” Estudios Públicos 98: 19-86.

De Gregorio, J. (2007). “Algunas Reflexiones sobre el Crecimiento Económico de Chile.” Economic Policy Papers N 20, Central Bank of Chile.

Díaz, R., Meller, P., and Pardo, A. (2002). "Análisis Económico-Descriptivo de las Regiones Chilenas." Documentos de Trabajo no 133, Centro de Economía Aplicada, Universidad de Chile.

Díaz, R., and Meller, P. (2004). "Crecimiento Económico Regional Chile: Convergencia?” Documentos de Trabajo n 180, Centro de Economía Aplicada, Universidad de Chile.

Economist Intelligence Unit (2010). "Democracy index 2010 Democracy in retreat." The Economist Intelligence Unit Limited 2010.

Fuentes, R. and K. Schmidt-Hebbel. (2004). "Las bases del crecimiento económico de Chile: Resumen y conclusiones de un proyecto de investigación.” Manuscrito, Banco Central de Chile.

Fuentes, R., M. Larraín y K. Schmidt-Hebbel. (2006). "Sources of Growth and Behavior of TFP in Chile." Cuadernos de Economía, 41: 5-48.

Geroski, P.A., (1995). "Innovation and Competitive Advantage." OECD Economic Department Working Paper No. 159. OECD.

Giarda, M., and Landerretche, O., (2011) "El Efecto Holandes en Chile: Heterogeneidad en Competitividad y Dinamica Macroeconomica”. Departamento de Economia, Universidad de Chile. Serie Documentos de Trabajo N 343, Santiago, Mayo de 2011.

IADB. (2001). “Chile: Country Paper." Washington, DC: Banco Interamericano de Desarrollo

IMF. (2005). "Chile: Article IV Consultation -- Staff Report; Public Information Notice on the Executive Board Discussion; and Statement by the Executive Director for Chile." IMF Country Report No. 05/315. Washington, DC International Monetary Fund. 
Izuka, M., and Katz, J. (2011). "Natural Resource Industries, 'Tragedy of the Commons' and the Case of Chilean Salmon Farming." International Journal of Institutions and Economies, Vol. 3, No. 2, July 2011, pp. 259-286

Katz, J. (1969). "Production Functions, Foreign Investment and Growth, A Study based on the Argentine Manufacturing Sector 1946-1961". North-Holland Publishing Company, Amsterdam-London.

Katz, J. (2001). "Structural Reforms, Productivity and Technological Change in Latin America." Cepal- Libros de la Cepal No 64.

Lach, S. (2001). "Are the Public Subsidies to R\&D Complement or Substitute to the Private R\&D? The Israeli Empirical Evidence.” NBER Working Paper Series, 7943.

Leung, D., Meh, C. and Terajima, Y. (2008) "Firm Size and Productivity" Bank of Canada Working Paper 2008-45

Mairesse, J. and Mohnen, P. (2001). "To Be or Not To Be Innovative, An Exercise in Measurement.” NBER Working Papers 8644, National Bureau of Economic Research.

Manzi, J., Strasser, K., San Martín, E., and Contreras, D. (2008). "Quality of Education in Chile." Centro Medicion MIDE UC.

MINEDUC (2010). "Indicadores de la Educación en Chile 2007-2008.” Departamento de Estudios y Desarrollo de la División de Planificación y Presupuesto, ded.mineduc.cl.

Ministerio de Economia (2009). "Informe 5ta Encuesta de Innovacion Tecnologica." Division de Innovacion, Ministerio de economia de Chile.

Ministerio de Economia (2010). "Resultados de las Encuestas de Innovación e I+D 2007-2008.” Division de Innovacion, Ministerio de economia de Chile.

OECD (2004). "Compendium of Patent Statistics.” OECD: Paris.

OECD (2005). “OECD Economic Survey of Chile.” OECD, París.

OECD (2010). "Factbook 2010: Economic, Environmental and Social Statistics." OECD, Paris.

OECD (2011). "Patents by main technology and by International Patent Classification (IPC)." OECD Patent Statistics (database). 
Paredes, R. and García, C. (2008). "Reducing the Educational Gap: Good Results in Vulnerable Groups.” Journal of Development Studies, Volume 46, Issue 3.

Paredes, R.; Pinto, J.I. (2009). “¿El Fin de la Educación Pública en Chile?” Estudios de Economía, Santiago, v. 36, n. 1, jun. 2009.

Salter, W.E.G, (1960). "Productivity and Technical Change". The Syndics of Cambridge University Press, London.

Schmidt-Hebbel, (2006). "El Crecimiento Economico de Chile.” Working Paper N 365, Central Bank of Chile.

Tokman, A. (2005). "Diagnóstico y Propuestas para la Educación Chilena." Economía Chilena 8(1): 53-74.

United Nations (1948). "Universal Declaration of Human Rights.” G.A. res. 217A (III), U.N. Doc A/810 at 71 (1948).

Vergara, R., and Rivero, R. (2006). "Productividad Sectorial en Chile: 1986-2001," Latin American Journal of Economics-formerly Cuadernos de Economía, Instituto de Economía. Pontificia Universidad Católica de Chile., vol. 43(127), pages 143-168.

World Bank. (2002). “Country Assistance Strategy for Chile 2002-2006.” Washington, DC: World Bank.

World Bank. (2005) “World Development Indicators.” Washington, DC: World Bank.

World Bank. (2007). “World Development Indicators.” Washington, DC: World Bank.

World Bank. (2010). “World Development Indicators.” Washington, DC: World Bank 


\title{
Chapter 2 COOPERATION ON INNOVATIVE INVESTMENTS: THE ROLE OF INFORMATION FLOWS
}

\begin{abstract}
This chapter studies the determinants of $R \& D$ cooperation among innovative firms using data from the $4^{\text {th }}$ Chilean Innovation Survey. It follows the empirical model developed by Cassiman and Veugelers (2002) in which cooperation is allowed to be a function of the technology of the information flows. Results show that incoming information spillovers, cost-risk sharing, use of legal protection, and firm size positively and significantly affect the probability of cooperation among Chilean firms, while lack of information about innovation has a negative impact on the same variable. In the empirical approach, information flows seem to have a larger impact than cooperation with universities and consulting agents. Endogeneity problems present in the model have been addressed using a two-stage conditional maximum likelihood test (2SCML) based on Rivers and Vuong (1988). After finding that incoming spillovers are endogenous, the model used the industry-level of incoming spillovers and basic nature of R\&D as instrumental variables for the first stage estimates of incoming spillovers.
\end{abstract}




\subsection{Introduction}

The need to promote sustainable industries, with diversification of products that allows knowledge to accumulate and grow, has been one of the main ideas about Latin America that economists have discussed during the past decade. ${ }^{9} \mathrm{R} \& \mathrm{D}$ activities have a very important impact on the development of new products and productive processes, as shown in Crepon, Duguet, and Mairesse (1995). When we study the innovative process of firms, it is very important to analyze not only the incentives for a firm to allocate financial resources to $\mathrm{R} \& \mathrm{D}$ but also how these innovative firms are able to share the knowledge and capacities of other organizations with the intention of together developing research activities that will later result in a process or product innovation.

Cooperation in an innovative process is an efficient manner of developing innovative products and processes for various reasons. One reason is that cooperation may avoid duplicate innovative efforts by two or more firms. In particular, duplication can be avoided when cooperation takes place among competitors. Avoiding R\&D duplication can lead to an important cost reduction for all firms participating in the cooperative process. Additionally, because of the possibility that the knowledge available in two organizations is complementary, cooperation may result in the development of a new process or product that would not have been possible with the information available to only one of the firms. However, more R\&D collaboration does not necessarily lead to better innovation performance. R\&D collaboration may present some disadvantages, such as risk of IP leakage, risk of management failure and high coordination cost. Cooperation may promote knowledge creation and diffusion and is therefore a phenomenon that should be studied in order to understand and promote development through innovation in Chile and Latin America.

Following the paper by Cassiman and Veugelers (2002), this work uses a model that investigates the determinants of the likelihood of having cooperated with other firms on an innovative process. The possible endogeneity of the variables was tested using a twostage conditional maximum likelihood method. It was found that incoming spillovers is an endogenous factor; therefore, it was instrumented with industry-level incoming spillovers and basic nature of R\&D. A probit conditional maximum likelihood method with instrumental variables was applied in order to correct for the specification problem of the model caused by the endogenous variable detected in the first stage.

This work uses a sample of 3,122 firms from the manufacturing and services sectors that replied to the Fourth Chilean Innovation Survey carried out in 2005 by the Chilean Statistical Office (INE). The survey refers to the innovative activities of firms from all Chilean regions during 2003 and 2004.

We find that incoming spillovers affect the probability of cooperating positively and very significantly. This result has been robust in all the estimation procedures. Two factors that positively affect the probability of cooperating are the existence of legal

\footnotetext{
${ }^{9}$ This idea is developed in the work by Katz (2001). An analysis of the challenges and opportunities for industrial development in Latin America can be found also in Benavente et al (2007).
} 
protection and an indicator of whether cost and risk sharing are perceived as a benefit. On the other side, lack of information negatively affects the probability of cooperating for innovative purposes, and this impact is very significant in all the estimations. Finally, larger firms cooperate significantly more than smaller firms, a finding that is also in accordance with the previous literature.

The rest of this document is structured as follows. In section 2.2, we briefly comment on some conceptual antecedents and previous empirical findings. Section 2.3 explains the econometric model. Section 2.4 refers to the data of the $4^{\text {th }}$ Chilean Innovation Survey. Section 2.5 shows our main results and section 2.6 concludes.

\subsection{Previous Literature on R\&D Cooperation Determinants}

The literature on $R \& D$ cooperation determinants focuses mainly on the importance of information flows to stimulate firms to engage or not in cooperative $R \& D$ activities. Recent empirical strategies have discussed a distinction between incoming information flows and outgoing information flows. These studies show how firms have more propensity to cooperate when they have enough absorptive capacity to receive and use external public knowledge, and when they can incorporate the knowledge generated by their own innovative activities.

One of the most important inputs for a firm's innovative activities is knowledge. A firm that is capable of successfully incorporating information flows is probably more capable of, and willing to, engage in cooperative behavior for its innovative activities. On the other side, firms that can't incorporate the results of their innovative activities will tend not only to practice less cooperation but also to engage less in R\&D activities.

Laursen and Salter (2005) studied the link between the way firms search for new ideas with innovative performance. In order to better understand how firms draw knowledge from external sources they introduced the concepts of "external search breadth" and "external search depth". They found that searching widely and deeply has an inverted U-shape relation with firm innovative performance. As firms search more widely and deeply they are more likely to have a better innovation performance. Nevertheless search can be expensive and laborious so after a tipping point is reached more breadth and depth affect innovation performance negatively.

Cassiman and Veugelers (2002) developed a model in which they studied separately the effects of incoming spillovers and the ability to incorporate knowledge on the probability of participating in cooperative R\&D agreements. They developed a very simple and intuitive empirical model and tested it using a sample of 411 firms. They used data from the Belgian Community Innovation Survey (CIS). They concluded that incoming spillovers and ability to incorporate knowledge have important and separately identifiable effects on R\&D cooperation. Furthermore, they found differences in the size of the effect of these variables on cooperation with different types of partners.

López (2004) used a similar approach to that developed by Cassiman and Veugelers (2002) and studied the determinants for R\&D cooperation among Spanish manufacturing 
firms. Results showed a positive effect of the importance of external information sources and the ability of the firm to appropriate the returns from innovations on the probability of $\mathrm{R} \& \mathrm{D}$ cooperation.

Mark and Graversen (2004) discussed the rationale for firms' choices of cooperative R\&D partners, which can be public research institutions or private firms. They used micro data from the Danish Center for Studies in Research and Research Policy collected for the year 2001. The determinants for R\&D cooperation included absorptive capacity and R\&D time horizon. They found heterogeneity in the cooperation determinants for different kinds of partners.

Atallah (2005) considered an R\&D cooperation model with asymmetric firms. The study focused on cooperation among firms with different levels of efficiency. The results suggested that firms' preferences for choice of partners in cooperation depend on spillovers and on cost differences among firms. With low (high) spillovers, a firm prefers to cooperate with the most (least) efficient among the remaining firms. As the cost differential between firms increases, efficient (inefficient) firms prefer to cooperate with the most (least) efficient firm more often.

Schmidt (2005) analyzed the determinants of R\&D cooperation among German manufacturing firms. Using data from the Third Community Innovation Survey (CIS3), the paper focused on the effect of information flows over cooperation for R\&D activities. He found a positive relationship between knowledge flows and cooperative activities. Moreover, evidence showed that firms with high intramural R\&D budgets are more likely to cooperate with universities and research institutions than with suppliers and customers.

Vencatachellum and Vesaevel (2006) studied the effects of spillovers on R\&D cooperation using French data. They found that a firm which benefits from higher spillovers from its rivals is more likely to cooperate horizontally in R\&D. Furthermore, the impact of incoming spillovers on R\&D cooperation is positive and significant only when the spillovers are above a certain threshold. That is to say, the value and precision of the estimates increased with the information flows that firms reported receiving from their competitors.

In Latin American countries some evidence has been gathered by economists in regard to the determinants of the probability of engaging in R\&D cooperation agreements. Primi and Rovira (2011) made a comparison of R\&D cooperation determinants among five Latin American countries (Argentina, Brazil, Chile, Mexico, and Uruguay). They found a small number of firms that engage in cooperative agreements and Chile is the country with the lowest rate of $\mathrm{R} \& \mathrm{D}$ cooperation (5.7\%). In Chile, Brazil and Mexico firms tend to cooperate more with other firms (clients or suppliers) while in Argentina and Uruguay the preferred partners are S\&T research centers and institutions. The paper by Alvarez, Benavente and Crespi (2010) discussed organizational change in Chile in relation to the economic cycle. They found that firms tend to engage more in $R \& D$ contracts during an economic crisis when final output demand is lower. Benavente and Contreras (2011) suggested that in Chile technical cooperation is inversely related 
with firm size, probably because larger firms tend to vertically integrate their R\&D activities.

\subsection{Knowledge Spillovers Econometric Model}

The model used in this work is based on the idea that information flows are one of the most important aspects determining R\&D cooperation. Cassimann and Veugelers (2002) separate information flows between those that come from outside and increase firm's knowledge, and those that come from the firm and allow other agents to benefit from the firm's experience and knowledge.

Cooperation in the knowledge production process depends on the opportunities and risks associated with the cooperative strategy. It is expected that the more important the incoming knowledge flows or spillovers, the more likely it is that the firm will be able to benefit from R\&D agreements. When public information sources are important for the firm's knowledge development, it is expected that the return to cooperating will be greater, because partners are more capable of transmitting useful information.

Additionally, the level of ability to incorporate the knowledge that has been generated inside a firm or within a cooperation agreement could have a positive impact on the level of cooperation. Therefore, in our empirical model we consider a variable that measures the use of legal protection of knowledge, as declared by the firm, to capture this effect. When a firm is capable of protecting its knowledge by legal means, that is to say, when a firm has patents or know-how agreements, it may be more likely that it will cooperate.

We also include other variables in the binary dependent variable model that may be likely to affect $R \& D$ cooperation agreements. Lack of information as a constraint for innovating is a variable that takes value 1 if lack of information is declared by the firm as an important restraint on innovating. If lack of information is important for innovative firms, that could mean that they do not have yet information about what is being done by competitors in their associated research topic, so they are not in a good position to cooperate with other firms or institutions. Thus, we expect this variable to affect the probability of cooperating in a negative way.

We consider the possibility of sharing the risks and the costs of innovative activities when the risks and costs are high, as declared by the firms. When the costs and risks of innovative activities are perceived as high by the firms, it is more likely that they will tend to cooperate in order to produce process and product innovations in a less expensive way. This study has constructed a cost and risk sharing variable based on the following firm-level information: difficulty in finding sources of finance; high cost of innovating; perception of high risk; and too long a payback period for innovating activities.

Finally, as shown in the previous empirical literature, firm size and R\&D intensity may be $\mathrm{R} \& \mathrm{D}$ cooperation determinants. We have included the log of number of employees and its squared value, as well as $R \& D$ intensity and industry level of 
cooperation, in order to control for size and unobservable industry level characteristics that may affect firms' decision to cooperate with other firms or institutions.

Under the assumption of no endogeneity problems, the model may be properly estimated as:

$$
y^{*}=\alpha+x \beta+\varepsilon \quad \text { with } \quad \varepsilon \sim N(0,1)
$$

Where $y^{*}$ is the expected value for a firm of choosing to have cooperation agreements, $X$ is a vector of independent variables, $\alpha, \beta$ are parameters and $\varepsilon$ is an error term. But the dependent variable is a latent variable and we do not observe $y^{*}$ directly; instead we observe $y$ as follows:

$$
\begin{aligned}
& y=1 \text { if } y^{*}>0 \\
& y=0 \text { if } y^{*} \leq 0
\end{aligned}
$$

with $y=1$ if the firm chooses cooperates in $R \& D$ activities and 0 in other case.

Because in our data the dependent variable $\mathrm{R} \& \mathrm{D}$ Cooperation is a binary variable taking only values 1 or 0 , we need our econometric specification to be defined as a probit equation. The $X$ variables are incoming spillovers, easy imitation, lack of information, cost and risk sharing, legal protection, industry level, legal protection at industry level, R\&D intensity, firm size (log of employees), and the square of firm size. ${ }^{10}$

As shown in previous literature, some of the variables included in this model may be endogenous. According to Cassiman and Veugelers (2002), incoming and outgoing information flows may be endogenous variables. Because firms that cooperate may also try to control information flows with their R\&D agreements, the fact of cooperating may also be a determinant of the incoming information flows or spillovers. Moreover, an R\&D agreement may also be used by firms to control the outgoing information flows to both partner firms and non-partner firms.

Other studies, such as Veugelers (1997) and Colombo and Gerrone (1996), have found reasons to believe that R\&D intensity may also be an endogenous regressor in this empirical model. We also consider these studies in this paper. Cost-risk has also been treated as an endogenous variable in Lopez (2004) because the effects of cooperating may also affect the degree to which firms consider the variables used to build this regressor to be obstacles to innovation.

In order to approach the model in a more consistent way, we test for the presence of endogeneity. We perform a test on the four variables that have been referred to as endogenous in previous work that consider the determinants of $\mathrm{R} \& \mathrm{D}$ agreements. We first estimate the model using a two-stage conditional maximum likelihood method that has been described by Wooldrige (2002). This model, which was previously considered in Heckman and MaCurdy (1985) and Rivers and Vuong (1988), and has been used by a series of empirical studies, provides a simple way to test for the endogeneity of some of

\footnotetext{
10 The detailed definition of each variable in the model can be found in Appendix 2.
} 
the variables in the model. In the first step of this procedure, all the variables that are possibly endogenous are regressed one by one on all the variables that are assumed to be exogenous. The test is performed in the second step of this procedure, where we consider the residuals of each of the first step equations as independent variables of our main equation, which has $R \& D$ cooperation as dependent variable.

We can now define a model that considers the presence of endogenous explanatory variables. We assume that the endogenous explanatory variables $\left(y_{2}\right)$ are a function of the other exogenous explanatory variables described in our previous equation $(X)$ and that they also depend on a set of instruments $(Z)$.

Therefore, we can write the model as follows:

with:

$$
\begin{gathered}
y^{*}=\beta_{1} z_{1}+\beta_{2} y_{2}+u_{1} \\
y_{2}=\beta_{3} z_{1}+\beta_{4} z_{2}+v_{2}=\beta_{5} z+v_{2}
\end{gathered}
$$

where $z_{1}, z_{2}$ are $k \times n$ and $p \times n$ matrices respectively while $y_{2}$ is a $n \times j$ matrix. Then $\beta_{1}$ and $\beta_{3}$ are both $1 \times k, \beta_{4}$ is $1 \times p, \beta_{2}$ is $1 \times j$, and $\beta_{5}$ is a $1 \times(k+p)$ vector. And we define that $u_{1}$ and $v_{2}$ have a joint normal distribution with a zero and finite positive covariance matrix:

$$
\Omega=\left[\begin{array}{cc}
\sigma_{\mathrm{u}_{1}}^{2} & \sum \mathrm{u}_{1} \mathrm{v}_{2} \\
\sum \mathrm{v}_{2} \mathrm{u}_{1} & \sum \mathrm{v}_{2} \mathrm{v}_{2}
\end{array}\right]
$$

We can write the normalization imposed by Wooldridge (2002):

$$
\sigma_{u_{1}}^{2}=\operatorname{Var}\left(u_{1}\right)=1
$$

And under joint normality of $\left(u_{1}, v_{2}\right)$, we can write

$$
u_{1}=v_{2} \theta_{1}+e_{1}
$$

Where $\theta_{1}=\sum_{v_{2} v_{2}}^{-1} \sum v_{2} u_{1}$

Because of the joint normality of $\left(u_{1}, v_{2}\right)$ which implies that $e_{1}$ is also normally distributed with $E\left(e_{1}\right)=0$ and $\operatorname{Var}\left(e_{1}\right)=\operatorname{Var}\left(u_{1}\right)-\theta_{1}^{\prime} \sum v_{2} v_{2} \theta_{1}=1-$ $\theta_{1}^{\prime} \sum v_{2} v_{2} \theta_{1}$, we can derive the following expression: 


$$
\begin{aligned}
f\left(y, y_{2} \mid z\right)= & \left\{\Phi\left(w_{i}\right)\right\}^{y}\left\{1-\Phi\left(w_{i}\right)\right\}^{1-y}(2 \pi)^{-\frac{m}{2}}\left|\sum v_{2} v_{2}\right|^{-\frac{1}{2}} \exp \left\{-\frac{1}{2}\left(y_{2}\right.\right. \\
& \left.\left.-z \beta_{5}\right) \sum_{v_{2} v_{2}}^{-1}\left(y_{2}-z \beta_{5}\right)^{\prime}\right\}
\end{aligned}
$$

This way the $\log$ likelihood for observation $i$ is:

$$
\begin{aligned}
y_{i} \log \Phi\left(w_{i}\right)+ & \left(1-y_{i}\right) \log \left[1-\Phi\left(w_{i}\right)\right]-\frac{n}{2} \log (2 \pi)-\frac{1}{2} \log \left|\sum v_{2} v_{2}\right| \\
& -\frac{1}{2}\left[\left(y_{i 2}-z_{i} \beta_{5}\right) \sum_{v_{2} v_{2}}^{-1}\left(y_{i 2}-z_{i} \beta_{5}\right)^{\prime}\right]
\end{aligned}
$$

Where $w_{i}=\frac{z_{i 1} \beta_{1}+y_{i 2} \beta_{2}+\left(y_{i 2}-z_{i} \beta_{5}\right) \theta_{1}}{\left(1-\theta_{1}^{\prime} \Sigma v_{2} v_{2} \theta_{1}\right)^{1 / 2}}$

And so we know that $w_{i}$ depends on the parameters $\left(\beta_{1}, \beta_{2}, \beta_{5}, \theta_{1}\right)$. Summing the $\log$ likelihood across all $i$ and maximizing with respect to all parameters gives the MLEs of $\left(\beta_{1}, \beta_{2}, \beta_{5}, \sum_{v_{2} v_{2}}, \theta_{1}\right)$. The estimate of $\theta_{1}$ is what Rivers and Vuong (1988) used to test for endogeneity of $y_{2}$.

\subsection{Chilean Fourth Innovation Survey Data}

The data used in this paper has been obtained from the Fourth Chilean Innovation Survey, collected by the National Institute of Statistics (INE) during the year 2005. The data refers to firm innovative activities during the years 2003 and 2004.

Table 2.1 describes the database that has been used for this work. The sample is composed of 3,122 firms, of which 1,494 firms (48\%) have reported that they innovated in the two-year period before the survey. The survey considered firms from the manufacturing, mining, energy, and services sectors. The most innovative enterprises in Chile are those from the mining sector, with $58 \%$ of innovative firms. The sector in which the smallest proportion of firms carries out some type of innovation is the services sector, with $43 \%$ of innovative firms.

Of all innovating firms included in the sample, only $12.4 \%$ have cooperated with other firms in performing R\&D activities. 106 firms cooperated with universities, representing $7.1 \%$ of innovating firms, while 96 firms cooperated with competitors, representing $6.2 \%$ of total innovative firms. The 93 firms that cooperated with consultant professionals represent $6.2 \%$ of innovative firms. Finally, the 166 firms that cooperate with customers represent $11 \%$ of innovating firms. 
Table 2.1 Fourth Chilean Innovation Survey Basic Sample Statistics

\begin{tabular}{|c|cc|}
\hline & All firms & Innovating firms \\
\hline All Sample Firms & $3,122(100 \%)$ & $1,494(48 \%)$ \\
Manufacturing Firms & $1,269(41 \%)$ & $640(20 \%)$ \\
Energy Firms & $150(5 \%)$ & $72(2 \%)$ \\
Mining Firms & $64(2 \%)$ & $37(1 \%)$ \\
Services Firms & $1,412(45 \%)$ & $613(20 \%)$ \\
\hline Innovating but Not-Cooperating Firms & & $1,309(42 \%)$ \\
Innovating and Cooperating Firms & & $185(6 \%)$ \\
Firms Cooperating with Universities & & $106(3 \%)$ \\
Firms Cooperating with Competitors & & $93(3 \%)$ \\
Firms Cooperating with Consultants & & $93(3 \%)$ \\
Firms Cooperating with Customers & & $166(5 \%)$ \\
\hline
\end{tabular}

Note: Innovating and Cooperating Firms: percentage of firms that innovated and cooperated on innovative activities with any other agent (suppliers, clients, competitors, consultants, universities, research institutes). Firms

Cooperating with Universities: number (percentage) firms that cooperated on innovative activities with universities. Firms Cooperating with Competitors: number (percentage) of firms that cooperated on innovative activities with competitors. Firms Cooperating with Consultants: number (percentage) of firms that cooperated on innovative activities with consultants. Firms Cooperation with Customers: number (percentage) of firms that cooperated on innovative activities with clients.

Table 2.2 Descriptive Statistics

\begin{tabular}{|c|ccccccc|}
\hline & $\begin{array}{c}\text { Sample } \\
\text { mean } \\
\mathrm{N}=3,122\end{array}$ & $\begin{array}{c}\text { Mean non- } \\
\text { coopera- } \\
\text { ting firms } \\
\mathrm{N}=1,309\end{array}$ & $\begin{array}{c}\text { Mean } \\
\text { coopera- } \\
\text { ting firms } \\
(\mathrm{N}=185)\end{array}$ & $\begin{array}{c}\text { Mean } \\
\text { coopera- } \\
\text { tion with } \\
\text { universities } \\
(\mathrm{N}=106)\end{array}$ & $\begin{array}{c}\text { Mean } \\
\text { coopera- } \\
\text { tion with } \\
\text { competitors } \\
\text { (N=93) }\end{array}$ & $\begin{array}{c}\text { Mean } \\
\text { coopera- } \\
\text { tion with } \\
\text { consultants } \\
(\mathrm{N}=93)\end{array}$ & $\begin{array}{c}\text { Mean } \\
\text { coopera- } \\
\text { tion with } \\
\text { customers } \\
\text { (N=166) }\end{array}$ \\
\hline $\begin{array}{c}\text { Incoming } \\
\text { Spillovers }\end{array}$ & 0.655 & 0.653 & 0.686 & 0.707 & 0.741 & $0.752^{* *}$ & 0.698 \\
$\begin{array}{c}\text { Lack of Info } \\
\text { Cost-Risk } \\
\text { Legal } \\
\text { Protection }\end{array}$ & 0.283 & 0.289 & $0.183^{* *}$ & $0.160^{*}$ & $0.182^{* *}$ & $0.150^{* *}$ & $0.174^{* *}$ \\
$\begin{array}{c}\text { Employees } \\
\begin{array}{c}\text { R\&D } \\
\text { Intensity }\end{array}\end{array}$ & 0.198 & 0.189 & $0.340^{* *}$ & $0.405^{* *}$ & $0.333^{* *}$ & $0.408^{* *}$ & $0.349^{* *}$ \\
\hline
\end{tabular}

Note: Cooperation: takes the value 1 if the firm has cooperated on innovative activities with any other agent (suppliers, clients, competitors, consultants, universities, research institutes) and 0 otherwise. Cooperation with

Universities: takes the value 1 if the firm has cooperated on innovative activities universities and 0 otherwise.

Cooperation with Competitors: takes the value 1 if the firm has cooperated on innovative activities with competitors and 0 otherwise. Cooperation with Consultants: takes the value 1 if the firm has cooperated on innovative activities consultants and 0 otherwise. Cooperation with Customers: takes the value 1 if the firm has cooperated on innovative activities with clients and 0 otherwise. Incoming Spillovers: takes values between 1 (low) and 4 (high) if innovation ideas are originated by professional conferences, exhibitions, meetings, and journals, and 0 otherwise. Lack of Information: takes values between 1 (low importance) and 4 (high importance) when the lack of information is an obstacle for innovating and 0 otherwise. Cost-Risk: Sum of the scores of importance of the

following declared obstacles to innovating (values between 0 (not relevant) and 4 (very important obstacle)):

Difficulty in finding sources of finance; High cost of innovating; High risk perceived; Payback period too long. Rescaled between 0 (not relevant) and 1 (high). Legal Protection: takes the value 0 if the firm has no patents or know-how agreements and takes the value 1 otherwise. Employment: Log of number of employees of the firm.

R\&D Intensity: Ratio between intramural R\&D expenditures and turnover. The difference in means between cooperating and non-cooperating firms that is significant at $5 \%$ is noted by **; at $10 \%$, noted by $*$. 
Table 2.2 presents the mean values of the most important variables of our model. Incoming Spillovers has a sample mean of 0.655 and is significantly higher for firms that cooperate with consulting professionals. Easy Imitation has a sample mean of 0.727 and presents no significant mean difference between cooperating and non-cooperating firms. Lack of Information has a sample mean of 0.283 and has a significantly lower mean value for firms that cooperate with any kind of partner. Cost-Risk has a sample mean of 0.223. This variable has a mean that is not significantly different between cooperating and noncooperating firms. Legal Protection has a sample mean of 0.198 and has a significantly higher mean value for firms that cooperate with any kind of partner. There are 236 employees per firm on average. The number of employees is significantly higher for firms that cooperate, regardless of what kind of partner. R\&D Intensity has a mean of 0.012 for innovative firms and is significantly higher for firms that cooperate with at least one kind of partner and for firms that cooperate with universities.

Table 2.3 contains the correlation matrix of different types of cooperation agreements. All kinds of cooperation are highly correlated. The highest correlation is between cooperation with Suppliers or Customers and Cooperation with Consultants while the lowest correlation level is between cooperation with Universities and cooperation with Competitors.

Table 2.4 shows the correlation matrix of the dependent variable the main explanatory variables in the model. The detailed definition of each variable in the model can be found in Appendix 2. This first approach shows that R\&D cooperation agreements are positively correlated with incoming spillovers and legal protection but negatively related with lack of information as declared by firms on the innovation survey. This is likely explained by the model developed by Cssiman and Veugelers (2002) in which incoming information flows stimulate cooperation while information losses relate to less $R \& D$ cooperation. $R \& D$ intensity and the basic nature of $R \& D$ also have positive correlations with cooperation agreements which is compatible to a system in which more $\mathrm{R} \& \mathrm{D}$ increases the probability of participating in $\mathrm{R} \& \mathrm{D}$ agreements. The industry level of cooperation has also a relatively high correlation with firm-level cooperation. Incoming spillovers has a negative but low correlation with lack of information and easy imitation, it relates positively to legal protection, size and basic nature of R\&D. Legal protection relates negatively with easy imitation and positively with R\&D intensity, export intensity and basic nature of R\&D. Lack of information correlates positively with the perceived possibility to share elevated costs and risks and it relates negatively with easy imitation. Elevated perception of cost and risk associated with innovation investments is negatively correlated with easy imitation and firm size and positively correlated with R\&D intensity and export intensity. Easy imitation correlates positively with firm size and export intensity and negatively with basic nature of R\&D and R\&D intensity. 

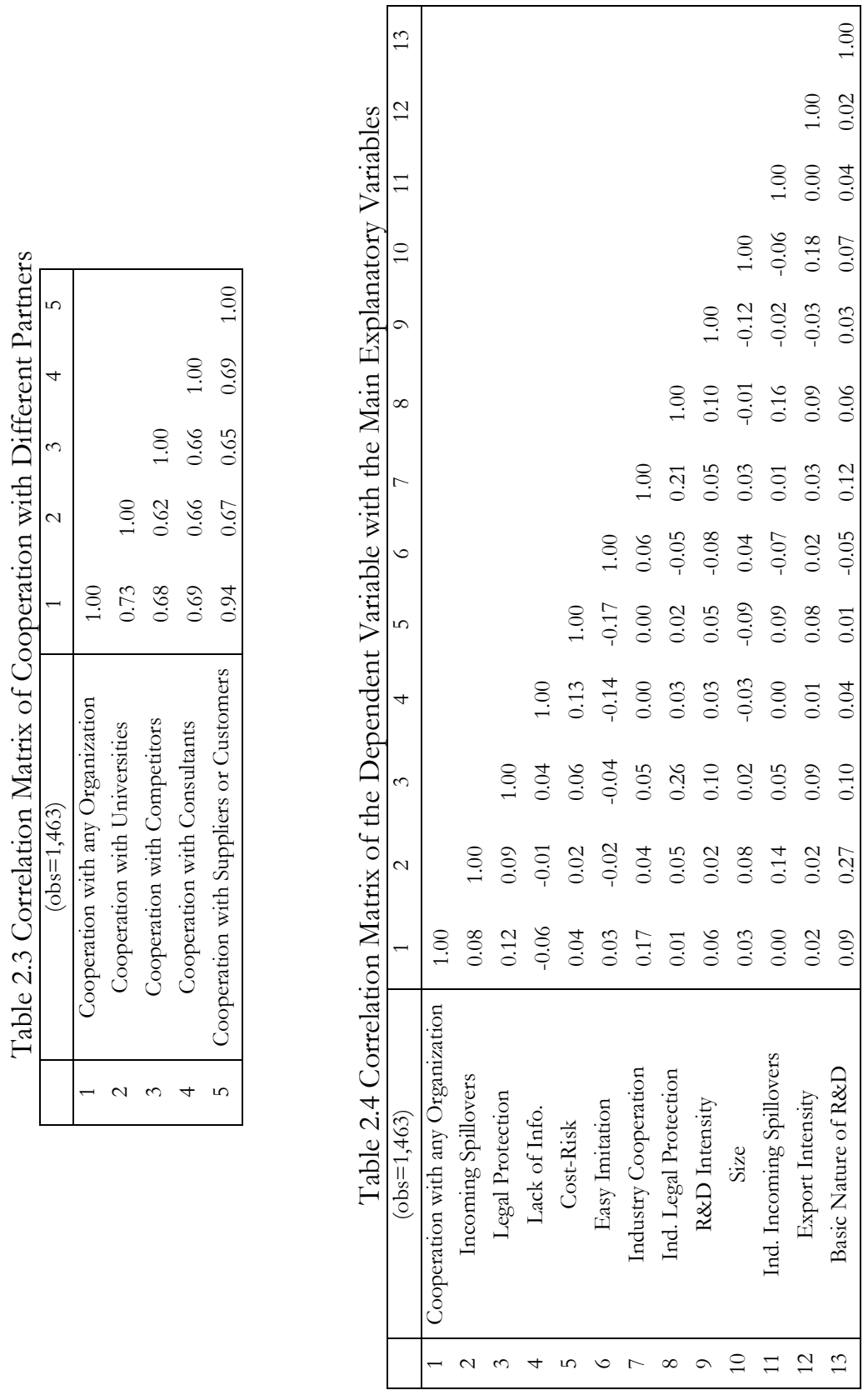


\subsection{Estimation Results}

\subsubsection{Preliminary Probit Regressions}

Results shown in Table 2.5 suggest that there is evidence to believe that incoming information flows determine a greater likelihood of performing $\mathrm{R} \& \mathrm{D}$ cooperation within our sample. This result is robust for all regressions, no matter which kind of partner is being considered. The highest impact of incoming spillovers is on cooperation agreements with consultants and competitors. Cooperation with suppliers and customers and cooperation with universities seem to be affected in a smaller magnitude by the existence of incoming spillovers.

The use legal protection affects positively and significantly the probability of engaging in R\&D agreements. This is consistent with the empirical model previously specified. We have found that, for Chilean firms, the greatest impact of this variable is on cooperation with universities.

Lack of Information affects negatively and significantly the probability of having R\&D cooperation agreements inside of the Chilean firms. This parameter takes a higher absolute value when the dependent variable is cooperation with universities and cooperation with consultants. This result may be because firms that declare that they have a lack of information do not know what is being done by others in their research area. Thus, they are not prepared for cooperating with other firms on innovating activities.

The Cost-Risk variable seems to affect cooperation agreements in a positive way. This result is consistent in all our specific-partner estimations but appears with a low significance in the regression that considers all kinds of cooperation together. The value of the parameter is higher for the dependent variables cooperation with competitors and cooperation with consultants.

This specification also controls by Industry Level of Cooperation, Industry Level of Legal Protection, R\&D Intensity during the period, Size, and Size Squared. All controls are always significant, except for $R \& D$ Intensity, which is only significant for cooperation with all partners and cooperation with universities. 
Table 2.5 Results of Probit Preliminary Regressions ${ }^{11}$

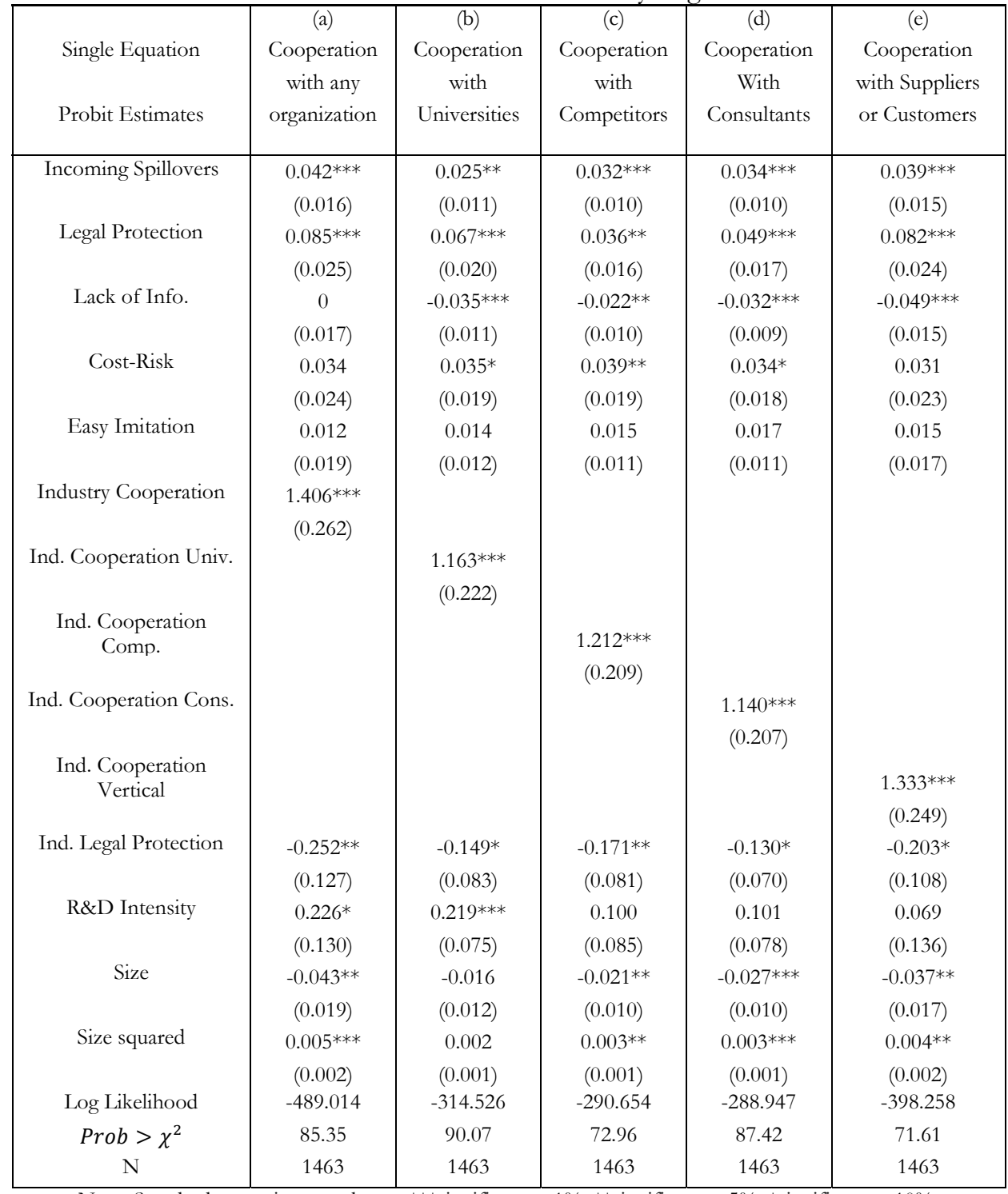

Note: Standard errors in parentheses, ***significant at $1 \%$, ** significant at $5 \%$, *significant at $10 \%$. Prob $>\chi^{2}$ refers to the Wald test of joint parameter significance.

\footnotetext{
11 This set of regressions is reporting the marginal effects.
} 


\subsubsection{Two-Step Endogeneity Test Results}

We have used for our estimations a two-step endogeneity test that can be found in Heckman and MaCurdy (1985) and Rivers and Vuong (1988). This allows us to state the direction of the causality relationships for all the variables that we believe may be endogenously determined. In this case, we have tested the endogeneity of four of the independent variables included in our model. These variables are incoming spillovers, legal protection, R\&D intensity, and cost-risk.

In the first step of our test, we regress each of the allegedly endogenous regressors on all the assumed independent variables of the model. Then we use the predicted value of the latent variable in the second step of the estimation procedure. The second equation has $R \& D$ cooperation as dependent variable. It includes the residuals of each of the first step equations as regressors. We check the significance of these regressors in order to see if there are endogeneity problems.

As shown in Table 2.6, we find that only Incoming Spillovers is endogenous for the regression of cooperation with all kinds of partners. Because some of the residuals may not be significant when included with other residuals, this test has also been performed for each potentially endogenous variable separately. The logic behind this test is that the residual of the regression that determines Incoming Spillovers affects significantly the probability of cooperation. The endogeneity tests for the regressions of cooperation with specific partners give the same result and therefore we have assumed the endogeneity of Incoming Spillovers in all our further estimations. The results of the final estimation procedure with instrumented incoming spillovers are documented in the following subsection.

\subsubsection{CML with Instrumental Variables Results}

Table 2.7 contains the instrumental variable results. The Conditional Maximum Likelihood method was used with a set of instrumental variables for incoming spillovers. The instruments that were used are industry level of incoming spillovers ${ }^{12}$, basic nature of $\mathrm{R} \& \mathrm{D}^{13}$ and export intensity ${ }^{14}$.

Results show that the presence of incoming spillovers implies a higher probability of $R \& D$ cooperation. This result is seen on all regressions, independently of which kind of partner is being considered. Thus, we have reduced a negative bias of the incoming spillovers parameter related to endogeneity problems. The highest impact of incoming spillovers is on cooperation agreements with universities and consultants. Cooperation with suppliers and customers and cooperation with competitors seem to be affected at a smaller magnitude by the existence of incoming spillovers.

Legal Protection affects positively and significantly the probability of engaging in $R \& D$ agreements. In accordance with the preliminary probit regressions, we have found that, for Chilean firms the greater impact of this variable is on cooperation with

\footnotetext{
${ }^{12}$ The correlation between Incoming Spillovers and Industry Level of Incoming Spillovers is 0.14

${ }^{13}$ The correlation between Incoming Spillovers and Basic Nature of R\&D is 0.27

${ }^{14}$ The correlation between Incoming Spillovers and Export Intensity is 0.02
} 
universities. We conclude that legal protection has a higher impact on cooperation with universities, consultants, and vertically related firms, compared to the impact it has on cooperation with competitors.

Table 2.6 Testing for Endogeneity, Results of 2SCML

\begin{tabular}{|c|c|c|c|}
\hline $\begin{array}{c}\text { Two Stages } \\
\text { Conditional ML }\end{array}$ & $\begin{array}{c}\text { (a) } \\
\text { Cooperation } \\
\text { with all Partners }\end{array}$ & $\begin{array}{c}\text { (b) } \\
\text { Cooperation } \\
\text { with all Partners }\end{array}$ & $\begin{array}{c}\text { (c) } \\
\text { Cooperation } \\
\text { with all Partners }\end{array}$ \\
\hline Incoming Spillovers & $\begin{array}{l}0.163 * * \\
(0.098)\end{array}$ & $\begin{array}{l}0.163^{*} \\
(0.098)\end{array}$ & $\begin{array}{l}0.168^{*} \\
(0.098)\end{array}$ \\
\hline Lack of Info & $\begin{array}{c}-0.447 * * \\
(0.176)\end{array}$ & $\begin{array}{c}-0.444 * * * \\
(0.157)\end{array}$ & $\begin{array}{c}-0.399 * * * \\
(0.169)\end{array}$ \\
\hline Cost-Risk & $\begin{array}{l}-0.023 \\
(0.194)\end{array}$ & $\begin{array}{l}-0.023 \\
(0.194)\end{array}$ & $\begin{array}{c}0.059 \\
(0.177)\end{array}$ \\
\hline Legal Protection & $\begin{array}{l}0.304 * * \\
(0.122)\end{array}$ & $\begin{array}{l}0.305^{* *} \\
(0.120)\end{array}$ & $\begin{array}{l}0.266^{* *} \\
(0.177)\end{array}$ \\
\hline Easy Imitation & $\begin{array}{c}0.063 \\
(0.152)\end{array}$ & $\begin{array}{c}0.059 \\
(0.118)\end{array}$ & $\begin{array}{c}0.106 \\
(0.146)\end{array}$ \\
\hline Industry Cooperation & $\begin{array}{c}7.623 * * * \\
(1.579)\end{array}$ & $\begin{array}{c}7.627 * * * \\
(1.576)\end{array}$ & $\begin{array}{c}6.916 \\
(1.409)\end{array}$ \\
\hline R\&D Intensity & $\begin{array}{l}-4.362 \\
(5.277)\end{array}$ & $\begin{array}{l}-4.370 \\
(5.276)\end{array}$ & $\begin{array}{c}1.118 \\
(0.732)\end{array}$ \\
\hline Size & $\begin{array}{c}-0.293 * * * \\
(0.113)\end{array}$ & $\begin{array}{c}-0.293 * * * \\
(0.112)\end{array}$ & $\begin{array}{c}-0.243 * * \\
(0.102)\end{array}$ \\
\hline Size squared & $\begin{array}{c}0.030 * * * \\
(0.010)\end{array}$ & $\begin{array}{c}0.030 * * * \\
(0.010)\end{array}$ & $\begin{array}{c}0.027 * * * \\
(0.010)\end{array}$ \\
\hline$\theta$ Incoming Spillovers & $\begin{array}{l}0.410 * * \\
(0.192)\end{array}$ & $\begin{array}{l}0.410^{* *} \\
(0.192)\end{array}$ & $\begin{array}{l}0.402 * * \\
(0.192)\end{array}$ \\
\hline${ }_{\theta}$ Legal Protection & $\begin{array}{l}-0.995 \\
(0.807)\end{array}$ & $\begin{array}{l}-0.997 \\
(0.806)\end{array}$ & $\begin{array}{l}-0.590 \\
(0.711)\end{array}$ \\
\hline$\theta$ R\&D Intensity & $\begin{array}{c}5.666 \\
(5.403)\end{array}$ & $\begin{array}{c}5.673 \\
(5.402)\end{array}$ & \\
\hline${ }_{\theta}$ Cost-Risk & $\begin{array}{c}0.026 \\
(0.625)\end{array}$ & & $\begin{array}{c}0.042 \\
(0.623)\end{array}$ \\
\hline Constant & $\begin{array}{l}-0.571 \\
(0.846)\end{array}$ & $\begin{array}{l}-0.563 \\
(0.825)\end{array}$ & $\begin{array}{l}-1.125^{*} \\
(0.668)\end{array}$ \\
\hline Log Likelihood & -488.252 & -488.253 & -488.831 \\
\hline $\begin{array}{c}\text { Prob }>\chi^{2} \\
\mathrm{~N}\end{array}$ & $\begin{array}{l}86.87 \\
1463\end{array}$ & $\begin{array}{l}86.87 \\
1463\end{array}$ & $\begin{array}{l}85.71 \\
1463\end{array}$ \\
\hline
\end{tabular}

Note: Standard errors in parenthesis, ***significant at $1 \%$, ** significant at $5 \%$, *significant at $10 \%$.

Prob $>\chi^{2}$ refers to the Wald test of joint parameter significance.

Lack of information affects negatively and significantly the probability of having R\&D cooperation agreements among Chilean firms. As in the previous probit regressions from table 3, this parameter takes a relatively higher absolute value when the dependent variable is cooperation with consultants. 
Table 2.7 Results of CML with Instrumental Variables

\begin{tabular}{|c|c|c|c|c|c|}
\hline $\begin{array}{l}\text { Instrumental Variables } \\
\text { Probit Estimates }\end{array}$ & $\begin{array}{c}\text { (a) } \\
\text { Cooperation } \\
\text { with any } \\
\text { organization }\end{array}$ & $\begin{array}{c}\text { (b) } \\
\text { Cooperation } \\
\text { with } \\
\text { Universities }\end{array}$ & $\begin{array}{c}\text { (c) } \\
\text { Cooperation } \\
\text { with } \\
\text { Competitors }\end{array}$ & $\begin{array}{c}\text { (d) } \\
\text { Cooperation } \\
\text { with } \\
\text { Consultants }\end{array}$ & $\begin{array}{c}\text { (e) } \\
\text { Cooperation } \\
\text { with Suppliers } \\
\text { or Customers }\end{array}$ \\
\hline Incoming Spillovers & $\begin{array}{l}0.602 * * \\
(0.273)\end{array}$ & $\begin{array}{l}1.000 * * * \\
(0.260)\end{array}$ & $\begin{array}{l}0.813 * * \\
(0.318)\end{array}$ & $\begin{array}{c}1.056 * * * \\
(0.282)\end{array}$ & $\begin{array}{c}0.735 * * * \\
(0.285)\end{array}$ \\
\hline Legal Protection & $\begin{array}{c}0.306^{* * *} \\
(1.340)\end{array}$ & $\begin{array}{c}0.338 * * * \\
(0.123)\end{array}$ & $\begin{array}{c}0.197 \\
(0.133)\end{array}$ & $\begin{array}{l}0.292 * * \\
(0.128)\end{array}$ & $\begin{array}{c}0.338 * * * \\
(0.115)\end{array}$ \\
\hline Lack of Info & $\begin{array}{c}-0.302 * * * \\
(0.114)\end{array}$ & $\begin{array}{c}-0.366^{* * *} \\
(0.142)\end{array}$ & $\begin{array}{l}-0.272 * \\
(0.145)\end{array}$ & $\begin{array}{c}-0.417 * * * \\
(0.154)\end{array}$ & $\begin{array}{c}-0.286^{* *} \\
(0.125)\end{array}$ \\
\hline Cost-Risk & $\begin{array}{c}0.166 \\
(0.116)\end{array}$ & $\begin{array}{l}0.261 * * \\
(0.131)\end{array}$ & $\begin{array}{l}0.328 * * \\
(0.139)\end{array}$ & $\begin{array}{l}0.299 * * \\
(0.138)\end{array}$ & $\begin{array}{c}0.201 \\
(0.125)\end{array}$ \\
\hline Easy Imitation & $\begin{array}{c}0.078 \\
(0.108)\end{array}$ & $\begin{array}{l}-0.008 \\
(0.129)\end{array}$ & $\begin{array}{l}0.009 \\
(0.14)\end{array}$ & $\begin{array}{c}0.231 \\
(0.141)\end{array}$ & $\begin{array}{c}0.009 \\
(0.029)\end{array}$ \\
\hline Industry Cooperation & $\begin{array}{c}6.448 * * * \\
(1.340)\end{array}$ & & & & \\
\hline Industry Cooperation Univ. & & $\begin{array}{c}8.638 * * * \\
(1.964)\end{array}$ & & & \\
\hline Ind. Cooperation Comp. & & & $\begin{array}{c}11.315^{* * *} \\
(2.240)\end{array}$ & & \\
\hline Ind. Cooperation Cons. & & & & $\begin{array}{c}10.753^{* * *} \\
(2.276)\end{array}$ & \\
\hline Ind. Cooperation Vertical & & & & & $\begin{array}{c}8.656^{* * *} \\
(2.021)\end{array}$ \\
\hline R\&D Intensity & $\begin{array}{c}1.111 \\
(0.720)\end{array}$ & $\begin{array}{l}1.799 * * \\
(0.722)\end{array}$ & $\begin{array}{c}1.061 \\
(0.897)\end{array}$ & $\begin{array}{c}0.802 \\
(0.884)\end{array}$ & $\begin{array}{c}1.042 \\
(0.766)\end{array}$ \\
\hline Size & $\begin{array}{c}-0.248^{* *} \\
(0.100)\end{array}$ & $\begin{array}{l}-0.183^{*} \\
(0.110)\end{array}$ & $\begin{array}{c}-0.250^{* *} \\
(0.112)\end{array}$ & $\begin{array}{c}-0.332 * * * \\
(0.111)\end{array}$ & $\begin{array}{c}-0.227^{* *} \\
(0.104)\end{array}$ \\
\hline Size squared & $\begin{array}{c}0.027 * * * \\
(0.010)\end{array}$ & $\begin{array}{c}0.017 \\
(0.011)\end{array}$ & $\begin{array}{c}0.028^{* * *} \\
(0.011)\end{array}$ & $\begin{array}{c}0.037 * * * \\
(0.011)\end{array}$ & $\begin{array}{c}0.024^{* *} \\
(0.010)\end{array}$ \\
\hline Constant & $\begin{array}{c}-1.590^{* * *} \\
(0.279)\end{array}$ & $\begin{array}{c}-2.152^{* * *} \\
(0.301)\end{array}$ & $\begin{array}{c}-2.218^{* * *} \\
(0.317)\end{array}$ & $\begin{array}{c}-2.158^{* * *} \\
(0.310)\end{array}$ & $\begin{array}{c}-1.886^{* * *} \\
(0.293)\end{array}$ \\
\hline Log Likelihood & -1452.901 & -1275.436 & -1254.715 & -1251.228 & -1361.570 \\
\hline Prob $>\chi^{2}$ & 81.51 & 108.30 & 71.50 & 95.85 & 70.80 \\
\hline $\mathrm{N}$ & 1463 & 1463 & 1463 & 1463 & 1463 \\
\hline
\end{tabular}

Note: Conditional Maximum Likelihood Regression, standard errors in parentheses, ${ }^{* * *}$ significant at $1 \%$, $* *$ significant at $5 \%$, *significant at 10\%. Incoming Spillovers was instrumented with Industry Level of Incoming Spillovers and Basic Nature of R\&D. The instruments have $14 \%$ and $27 \%$ correlation with the instrumented variable, respectively. Prob $>\chi^{2}$ refers to the Wald test of joint parameter significance.

The Cost-Risk variable affects cooperation agreements in a positive way. This result is significant in all cases, with the exception of the regression in which the dependent variable is cooperation with all kinds of partners. Cost-Risk has a more intensive impact on cooperation with competitors and cooperation with consultants.

In general, after controlling for the presence of endogeneity, we find that our results are robust and that the differences in the parameters with respect to the simple probit regressions are in accordance with the presence of a bias that has been successfully 
addressed in the regressions shown in Table 2.7. This model also controls by industry level of cooperation, industry level of legal protection, $\mathrm{R} \& \mathrm{D}$ intensity during the period, size, and size squared.

\subsection{Concluding Remarks}

This chapter presented the results of evaluating R\&D cooperation determinants among Chilean firms during the years 2003-2004. The data used for this study was obtained from the Fourth Chilean Innovation Survey (2005). This data has the characteristic of distinguishing among different kind of R\&D partners with which firms cooperate. The empirical model relates the probability of $\mathrm{R} \& \mathrm{D}$ cooperation to information flows and innovation restrictions among firms that have innovated.

In order to take into account the existence of endogeneity problems in our preliminary probit regressions, the empirical model was estimated using Instrumental Variables and Conditional Maximum Likelihood Methods. Following previous literature on $\mathrm{R} \& \mathrm{D}$ cooperation determinants, we have also tested the existence of endogeneity on incoming and outgoing information flows and also on R\&D intensity and cost-risk variables. Our findings show that incoming spillovers is the only endogenous regressor in the model. By instrumenting incoming spillovers with the industry average and with basic nature of $\mathrm{R} \& \mathrm{D}$, we obtained a considerable reduction in the bias of the parameters produced by endogeneity problems.

Results show that incoming spillovers determine a significantly greater probability of $\mathrm{R} \& \mathrm{D}$ cooperation. This is seen in all regressions, independently of which kind of partner is considered. Using Instrumental Variables increased the value of the incoming spillover parameter. Incoming information flows affect cooperation with universities and with consulting agents to a larger extent than they affect cooperation with competitors, suppliers, and customers.

This finding shows that one important channel for promoting innovation is to improve access to information flows that are public but do not always find their way to the minds of those who can use them in innovation. Information spillover could be promoted through the collection and sharing of data relevant to markets, such as prices and product characteristics. Information flows are also stronger if the know-how in many industries can be made easily accessible to everyone who wants to learn.

On the other side, legal protection has a higher effect on cooperation with universities and consultants but also effects cooperation along the vertical chain that connects the firm to suppliers and customers.

Lack of Information impacts negatively and significantly the probability of having R\&D cooperation agreements for the Chilean firms, while cost-risk seems to affect cooperation agreements in a positive way. This result is significant in most of our regressions.

Our results add to the literature by confirming the main findings of Cassiman and Veugelers (2002) and the literature that follows. We find similar results using a larger 
sample of 1463 innovating firms, even though our data is from a developing country in which overall R\&D performance is lower than in the developed world.

These empirical findings have important policy implications. In the first place, we conclude that facilitating public information flows should be a policy tool to promote innovation. Improvements in legal protection of knowledge may also have a positive impact on the level of cooperation among firms, by protecting property rights or patents for future inventions.

Further work should consider evaluating these results using a panel of innovation surveys over a period of several years. Lagged variables could also be added as additional instruments for the endogenous explanatory variables if panel data was available. 


\section{References}

Alvarez, R., Benavente, J.M., Crespi, G. (2010). "Economic Crisis and Organizational Change in Developing Countries: evidence from Chile". International Journal of Technological Learning, Innovation and Development, Volume 3, Number 1/2010.

Atallah, G. (2005). "Partner Selection in R\&D Cooperation." CIRANO Scientific Series.

Benavente, J.M., Crespi, G., Katz, J., Stumpo, G. (2007). "New problems and opportunities for industrial development in Latin America." Oxford Agrarian Studies Vol. 25, Iss. 3, 2007.

Benavente J.M., and Contreras, C. (2011). "Cooperation Partnerships in Manufacturing: Evidence from Chile" in "National Innovation Surveys in Latin America: Empirical Evidence and Policy Implications" Project Document of the Economic Commission for Latin America and the Caribbean (ECLAC) Edited by Mario Cimoli, Annalisa Primi and Sebastian Rovira.

Cassiman, B. and Veugelers, R. (2002). "R\&D Cooperation and Spillovers: Some Empirical Evidence from Belgium." American Economic Review, 92(4), pp. 1169-1184.

Cohen, W.M. and Levinthal, D.A., (1989). "Innovation and Learning: The Two Faces of R\&D." Economic Journal, 99(397).

Colombo, M. and Gerrone, P. (1996). "Technological Cooperative Agreements and Firm's R\&D intensity. A note on causality relations." Research Policy, September 1996, 25(6), pp. 923-32.

Geroski, P. A. (1995). "Do Spillovers Undermine the Incentives to Innovate?" in Steven Dowrick, ed., Economic approaches to innovation. Aldershot, U.K.: Elgar, 1995, pp. 7697.

Griliches, Z. (1992)."The Search for R\&D Spillovers." Scandinavian Journal of Economics, Supp. 1992, 94, pp. 29-47.

Hagenhoff, S. (2008). "Innovationsmanagement für Kooperationen: eine instrumenorientierte Betrachtung”, Universitätsverlag Göttingen. http://univerlag.unigottingen.de

Heckman, J. and MaCurdy, T. (1985). "A Simultaneous Equations Linear Probability Model." Canadian Journal of Economics, February 1985, 18(1), pp. 28-37. 
Katz, J. (2001). "Structural Reforms, Productivity and Technological Change in Latin America." Cepal- Libros de la Cepal No 64.

Laursen, K. and Salter, A. (2005). "Open for Innovation: The Role of Openness in Explaining Innovation Performance Among U.K. Manufacturing Firms" Strategic Management Journal, 27: 131-150 (2006)

López, A. (2004). "Determinants for R\&D Cooperation: Evidence From Spanish Manufacturing Firms." Universidad Carlos III de Madrid, part of the research project: "Innovation and Employment in European Firms: Microeconometric Evidence."

Mark, M. and Graversen, E. (2004). "Determinants of Danish Firms' choice of R\&Dcooperation partners." The Danish Centre for Studies in Research and Research Policy, University of Aarhus, Working Paper 2004/6

Primi, A. and Rovira, S. (2011). "Innovation and Cooperation in Latin America: Evidence from National Innovation Surveys in a Comparative Perspective" in "National Innovation Surveys in Latin America: Empirical Evidence and Policy Implications" Project Document of the Economic Commission for Latin America and the Caribbean (ECLAC) Edited by Mario Cimoli, Annalisa Primi and Sebastian Rovira.

Rivers, D. and Vuong, Q. H., (1988). "Limited Information Estimators and Exogeneity Tests for Simultaneous Probit Models."

Schmidt, T. (2005). "Knowledge Flows and R\&D Cooperation: Firm-level Evidence from Germany." Zentrum für Europäische Wirtchaftsforschung (ZEW), Discussion Paper 05-22.

Vencatachellum, D. and Versaevel, B. (2006). "Horizontal R\&D Cooperation and Spillovers: Evidence from France." Centre National de la Recherche Scientifique, Working Paper 06-12.

Veugelers, R.(1997). "Internal R\&D Expenditures and External Technology Sourcing." Research Policy, 26(3), pp. 303-316.

Wooldridge, J. M., (2002). "Econometric Analysis of Cross Section and Panel Data". MIT Press. 


\title{
Chapter 3 PRODUCT INNOVATION, PRICE GROWTH, AND LABOR PRODUCTIVITY
}

\begin{abstract}
This chapter develops a new measure for product innovation based on product-firmlevel information and evaluates the impact of innovation on manufacturing productivity at the firm level. The absence of individual firm data on price growth is one of the main restrictions of the empirical study of production functions. This problem occurs when observed nominal output growth cannot be separated into unobserved real production growth and price changes. We develop a novel strategy to estimate annual firm-level price growth and product innovation indicators. We use a panel containing detailed firm-level and product-firm level information provided by the Chilean Statistical Office (INE) for the period 1996-2003. Following the work of Mairesse and Jaumandreu (2005) we compare the outcome of different ways in which firm-level price data may be incorporated in the econometrics of production. We find that incorporating new products is associated with productivity growth, while dropping products is related to decreases in productivity. We also find that estimating a production function using nominal or real output makes very little difference to the estimated input and scale elasticities.
\end{abstract}




\subsection{Introduction}

Independently of how welfare is supposed to be distributed, economists are usually involved with the ideal of maximizing the benefits that may be obtained from a given flow or process. This paper studies empirically the maximization process in the manufacturing industry where firms choose optimally how to allocate production factors to different products across markets in order to maximize a utility function.

The efficiency of labor in the manufacturing industry is a way to measure the level of success of the industry. When average labor productivity is increasing, a nation can produce the same value with less effort from its labor force. Otherwise, keeping the labor effort constant, it could produce a growing amount of value. Because economists are interested in achieving economic development for nations, this work will estimate average manufacturing productivity growth as a measure of how added welfare is growing and allowing further development to take place.

When studying manufacturing production, innovation, and productivity, Chilean industry is of specific interest as a case of a small and open economy. Previous studies of growth in the context of the Chilean economy have pointed out the importance of manufactured exports and the widening of the comparative advantage as an engine of economic growth. In Chile, the extraction of non-renewable natural resources represents a high share of total exports. If the governing agents are interested in a sustainably growing economy, then an important share of mining industry revenues should be reinvested in knowledge, infrastructure, and physical capital.

The main objective of this study is to understand the effect of innovations on productivity at the level of firms. With this objective in mind, we used product level data to develop several novel measures of product innovation, including the number of products added and dropped from production and the proportion of innovated sales at the firm-level. Using this new information, we estimated separated production functions with different product innovation measures to estimate the effect of innovation on productivity.

An innovative feature of the present study is that we succeed in estimating productivity growth in real terms using an individual firm-level price deflator. We are aware that a large number of studies have already explored the relationship between knowledge, R\&D investment, innovation, and productivity or firm success. Therefore, in this paper, we introduce new measures of product innovation based on product-firm level panel data that describes the product mix changes inside firms over a period of eight years. We also measure innovation in a way that is comparable with the Oslo Manual framework.

There are two main possible sources of bias when we estimate production functions using firm-level data. On one side, a bias may arise from the fact that price levels are not observed and are likely to be correlated with the levels of output. The second bias is caused by the fact that inputs may be chosen simultaneously with output. This paper proposes a particularly innovative solution for the first bias by incorporating information 
on prices into the productivity equations. However, if we assume that there is serial correlation between input choice and the residuals, then our parameters may still be considered biased, even though the first bias was accounted for and corrected.

We compared production function estimation made with non-deflated, industry-level deflated, and firm-level deflated output. The main objective of this exercise was to evaluate whether the factor elasticity parameters and the scale elasticities are biased in the case of the production function estimation using non-deflated or industry level deflated output per employee measures. We estimated revenue and production functions in levels and in first differences using Ordinary Least Squares and Instrumental Variables. From these estimations, the evidence can be directly analyzed by comparing the regression parameters, coefficients, and significance levels. The assumption of constant returns to scale was also evaluated in a set of regressions.

In this study, we have combined data from manufacturing industry surveys, innovation surveys, and manufacture products surveys. One of the advantages of merging different databases is that we can combine the information at the firm level with specific details on quantities and prices of products within firms and across markets. We analyze the evidence using an unbalanced panel of 2,439 firms that was provided by the Chilean Statistical Office (INE) for the period 1996-2003. From product-firm level data, we were able to construct a firm-level price growth variable and a set of product innovation indicator variables. This data was merged with the Annual Industrial Survey (ENIA) from which the rest of the production variables were obtained.

The rest of the paper is structured as follows. Section 2 contains a summary of the achievements, difficulties and challenges that may be found in the previous literature regarding the specification of the production function. Section 3 explains the empirical strategy and a simple model that allows comparing the estimation of production functions with and without individual firm-level prices. Section 4 gives details on the database that was used for this study. Results are shown in section 5 , and section 6 concludes.

\subsection{Previous Literature on Production Function Estimation}

The estimation of labor productivity functions in the manufacturing industry has been for many years a topic of interest for economists. One of the most fundamental econometric approaches was the well-known contribution of Cobb and Douglas (1928). The literature that follows has included a rich discussion focused on two main sources of bias that appear from the original functional form. The first source of bias arises from the correlation between observed input choices and unobserved productivity shocks. Marschak and Andrews (1944) proposed a two-equation model of producer behavior that contains a Cobb-Douglas production function and variable input demand functions. Griliches (1957) proposed a formal framework by which empirical researchers could at least have an idea of the sign and size of this specification bias on the estimated 
parameters. His contribution was important for clarifying that the marginal productivity of observed inputs was biased upward by the omission of managerial input variables.

A second source of bias arises because of the absence of data that reports the change of prices at the firm level. This problem was analyzed by Klette and Griliches (1996). They showed that a common price deflator across firms is likely to bias the estimations of the production function. This problem originates in manufacturing firms that operate in imperfectly competitive markets. When individual firms are capable of setting the price at a wider range, the firm-level dispersion of price growth makes it unreasonable to deflate sales using the industry average price growth. Non-deflated or industry average deflated production variables may lead to a downward bias in the scale parameters obtained from production function regressions. This bias is affected by the magnitude of the parameters and the amount of variation in the different shocks.

The present paper offers an alternative method to empirically evaluate this theoretical model. If the estimates obtained using firm-level deflators are significantly different, that would support the theoretical model developed in Klette and Griliches (1996). On the other hand, and as the evidence found by Mairesse and Jaumandreu (2005) suggests, if there is no significant variation in the parameters when using deflated or non-deflated output, we could conclude that firm-level price dispersion is not large enough to generate a bias on the elasticity parameters when estimating labor productivity using non-deflated output as a proxy for real output.

A famous contribution was made by Olley and Pakes (1996). They proposed a methodology by which they used investment as an instrument for input demand. Their method also considered the fact that some firms enter and exit the market as a result of their own levels of productivity causing a bias in the panel estimates.

$$
\begin{gathered}
y_{i t}=\beta_{l} l_{i t}+\phi\left(i_{i t}, a_{i t}, k_{i t}\right)+\eta_{i t} \\
\phi\left(i_{i t}, a_{i t}, k_{i t}\right)=\beta_{0}+\beta_{a} a_{i t}+\beta_{k} k_{i t}+h_{t}\left(i_{i t}, a_{i t}, k_{i t}\right)
\end{gathered}
$$

where $y, l$ and $k$ stand for output, labor and capital while $i$ and $a$ stand for investment and firm age respectively. They define $\phi$ as a function of observables that allows controlling for unobservable productivity. Levinsohn and Petrin (2003) extended the previous model considering intermediate inputs to control for correlation between input levels and the unobserved firm-specific productivity process. They show an advantage of this extended model for the case in which the investment proxy has too few non-cero values.

A significant contribution to the empirical methods for the estimation of production functions was made by Arellano and Bond (1991). They developed a model for the estimation of production functions by the generalized method of moments (GMM). For this purpose they used individual effects, lagged dependent variables, and no strictly exogenous variables in order to obtain the different distribution moments of the estimated functions. They also used specification tests that they could apply after estimating a GMM model. Their experiments were performed by using both generated 
and real data. They proposed a test for serial correlation based on the GMM residuals as an alternative to Sargan tests of over-identifying restrictions and Haussman specification tests. The paper by Blundell and Bond (2000) proposed that first-differences GMM estimations are subject to large finite sample bias. Therefore they proposed a dynamic GMM specification that includes also the level moments as instruments.

A survey of empirical work with a review of the methods and criticisms of production function estimation was made by Griliches and Mairesse (1998). Their work shows how the production function estimation shifted its focus from the use of macro aggregated data in the 1930s to industrial and firm-level data between the 1970s and 1990s. They also summarized some of the most important contributions that were made to the production function estimation literature, showing why and how researchers have made continuous efforts to develop estimation methods that are robust to the simultaneity problem. A relatively recent and complete review of the production function estimation literature may be found in Ackerberg, Benkard, Berry, and Pakes (2005).

In general the literature that refers to the empirical estimation of the production function has two limitations. The first is regarding the endogeneity of inputs which has been addressed with several methodologies summarized here. In second place the literature has found a problem in estimating the production function in the absence of firm-level price information that can allow distinguishing nominal output growth from real production increases. It is in this regard that the present chapter gives a contribution to the literature. We provide firm-level price growth with which our production function is based on real output instead of nominal output or industry-level deflated output growth.

Taking the models and the empirical evidence of product level price dispersion into account, some attempts have been made to estimate production functions using firmlevel price growth to deflate output. The first published paper that was able to control for firm-level price changes in the context of production functions estimation was Abbott (1991). The computation of firm-level price change was made by observing directly the quantities of different cement varieties together with the data on shipments obtained from three years of the U.S. Census of Manufacturing. Among Abbott's conclusions, he found that there exists real price variation across manufacturing producers that goes beyond product quality differences and is caused by local conditions in both the input and the output markets.

Because lack of individual firm information on output prices is a major problem in the econometrics of production, Mairesse and Jaumandreu (2005) use Spanish data that includes a self-reported inflation index at the firm level. They developed a model to compare production function estimates using non-deflated output as well as industrylevel and firm-level deflated output. They found that different ways to deflate output do not make a significant difference in the results of their production function estimates. They conclude that there are other biases which are probably more important and may be due to other sources of specification errors.

Taking advantage of the data, and following the results of the previous work, Jaumandreu and Mairesse (2006) then used French and Spanish data with firm-level 
average price changes to formalize a system of equations in which output demand and input demands were taken into consideration at the same time that a production function was estimated.

In a different approach, Foster, Haltiwagner, and Syverson (2008) used 11 groups of firms that produced "homogeneous goods" and computed the prices, dividing total sales by total physical output at the firm level. They found that there are important differences between revenue and physical productivity. They show that physical productivity is inversely related to price, while revenue productivity is positively correlated with price. They also found that young producers charge on average lower prices than incumbents.

There are several research questions in which econometric studies with industrial surveys have been limited because of the absence of firm-level price growth or real output growth data. Based on a line of research started by Hall (1988), the studies by Crepon et al. (1999) and Dobbelaere and Mairesse (2008) estimated price-cost margins, scale economies, and workers' bargaining power at the firm level. Other work studied the impact of innovative sales and process innovation on employment and found a limitation in their models as well, because of having non-observed firm-level price dispersion. Some examples are Harrison et al. (2008), Benavente and Lauterbach (2008) and Hall et al. (2008).

Different approaches have been used at least from the 1970s to measure the role of innovation, own $\mathrm{R} \& \mathrm{D}$, and $\mathrm{R} \& \mathrm{D}$ spillovers as sources of knowledge of productivity at the firm level. The work by Mairesse and Mohnen (1994) and Hall, Mairesse, and Mohnen (2010) contain a complete review of previous work and empirical strategies that evaluated the impact of R\&D investment on productivity. They concluded that increasing knowledge and higher levels of R\&D investment are associated not only with labor productivity growth but also with expansions in the variety of products produced by the manufacturing industry.

The paper of Crepon et al. (1998) used French manufacturing firms data and developed a structural model that explained productivity by innovation output, and innovation output by research investment. In their productivity equation they found that firm productivity correlates positively with a higher innovation output, even when controlling for the skill composition of labor as well as for physical capital intensity. Benavente (2006) studied this model using data from 488 Chilean firms. He found that the effects of innovative output over Chilean firms' productivity are not significant at least contemporaneously.

The work by Alvarez et al (2012) uses the same data to the one in the present paper to study the relation of Chilean firms' product mix changes with productivity during the period 1996-2000. Their results suggest a positive and increasing impact of product mix changes on total factor productivity and labor productivity after two years of the introduction of product mix changes.

The varied evidence in previous literature makes it interesting to use a group of new product innovation definitions to introduce firm-level productivity estimates. The present paper incorporates new innovation measures and firm-level price growth estimates that 
provide much more accurate information on new products, old products, the proportion of innovative sales, and real output growth.

\subsection{Productivity and Innovation Empirical Strategy}

This research is focused on factor elasticities of the production function and on the effects of product innovation on productivity. We have created a new measure for product innovation based on the product-mix changes within firms across time. From product-firm level data, we observe which products are introduced and when they are introduced and dropped from firms' production. We computed a set of variables that describe firms' product-mix change behavior. From this information, we have also obtained the value in the present year of the proportion of sales that corresponds to the products that were introduced in the previous two years. Similarly, the proportion of sales of products that were dropped during the previous two years is represented by the share of total sales that these products had before being dropped. The model in this paper was used to test the productivity effects of product innovation in two different ways. First, it evaluated whether the behaviors of adding and dropping products over a period of two years have an impact on firms' labor productivity. Secondly, the empirical strategy also tested the effects of the rate of innovative sales on firms' labor productivity.

While this paper evaluates the effects of innovation on productivity, these results are not directly comparable with previous studies that evaluate the effect of innovation on productivity. This is because innovation indicators in this paper were constructed based on product-firm level information and not on self-reported innovation levels. The correlation between the number of products added over a two-year period and product innovation level from the $4^{\text {th }}$ Innovation Survey is approximately 0.2 for the year 2003 . In this study, we measure the inclusion and exclusion of products and not the degree of innovativeness that these products represent for a firm. Furthermore, our measure of product innovation does not intend to define the degree of innovation of products that remain into the firm's product mix but only those that were added or dropped during a specific period. Therefore, even though we focus on the measurement of innovation at the firm level, this approach actually evaluates the effects on productivity of the number of products that were added and dropped from the firm's production function.

Additionally, this research focuses on the difficulties that have been found in previous production function studies, and will apply a new empirical strategy based on the availability of product-firm level information to overcome some of these problems. The literature that focuses on the estimation of production functions has directed its attention to two main biases that arise from the estimation of a Cobb-Douglas production function.

One source of bias that is potentially present in the estimation of production functions is related to the endogeneity that arises from the correlation between observed input choices and unobserved productivity shocks. Marschak and Andrews (1944) commented that this difficulty arises because the researcher can observe the levels of 
inputs associated with a certain level of final output but he cannot see the market information and technological changes that are being taken into account by the manager who decides the input levels. The identification of IV and GMM equations using valid instruments for the input levels is very difficult. To try to solve this problem, this paper considers the use of external instruments that account for inputs cost. An alternative that has been widely used in previous literature is the use of lagged values of the variables in first differences to instrument the equations in levels and lagged values of the variables in levels to include as instruments for the equations in first differences.

The second source of bias in the estimation of the production function is associated with the fact that the level of prices is typically not observed and therefore a revenue function is used instead of a production function. In imperfectly competitive markets, a manager's price decision is related to both market conditions and technological changes. Therefore, if imperfect competition is the predominant market structure in which firms operate, there is intra-industry price growth dispersion that reflects market power and differentiation of products within markets. In this context, ignoring firm-level price dispersion when there is a correlation between firms' price behavior and their own input decision will result in biased input and scale elasticities estimates.

The analysis in Klette and Griliches (1996) explains the bias that arises from the absence of firm-level prices in production functions. Following their idea, which is also explained in the work of Mairesse and Jaumandreu (2005), we assume that the production function is represented by a Cobb-Douglas function for every firm $i$ in each year $t$. We can write an expression in the form of the standard (log) linear regression as follows,

$$
q_{i t}=a_{t}+\alpha k_{i t}+\beta l_{i t}+\lambda i n n_{i t}+u_{i t} \quad \text { with } i=1, \ldots, N \text { and } t=1, \ldots, T
$$

where $q, k$ and $l$ are the levels of the values of output, capital and labor expressed in logs, inn contains information on the changes to the specific products made within the firm, $u$ denotes the error or disturbance term, $a_{t}$ is the $\log$ of autonomous technicalprogress coefficients (or log average total factor productivity), and $\alpha, \beta$ and $\mu=\alpha+\beta$ are the capital, labor, and scale elasticities, respectively.

One of the essential assumptions for this model is that we use a real or volume measure of output at the individual firm level. As we usually lack firm information on the prices of output at the individual level, the real or volume value of output is approximated by the observed nominal output deflated by an industry average price growth index. Therefore, instead of estimating equation (1), what we estimate in this case is:

$$
\left(y_{i t}-p_{S t}\right)=q_{i t}+\left(p_{i t}-p_{S t}\right)=a_{t}+\alpha k_{i t}+\beta l_{i t}+\lambda i n n_{i t}+v_{i t}
$$

where $p_{i t}$ and $p_{S t}$ are, respectively, the (log) price index of firm $i$ and the (log) price index of industry $S$ to which firm $i$ belongs. Equation (2) shows that the firm (log) price deviation from the industry (log) price is a part of the disturbance term:

$$
v_{i t}=\left(p_{i t}-p_{S t}\right)+u_{i t}
$$

In summary there are two conditions under which the factor and scale elasticities will be biased. The first is that there must be significant output price dispersion within 
industries. The second is that output prices must be significantly correlated with the level values of inputs. It can be shown that both input and scale elasticities will be underestimated under these conditions. The underestimation of production function parameters is inversely proportional to the markup and is larger for a smaller absolute price elasticity of demand.

This study proposes a method to take into account this bias source using information on price levels and price growth at the level of firms. The empirical strategy is based on replicating traditional production function estimation with newly available data using firm-level price deflators instead of nominal output growth as a proxy for real output, or industry-level price deflators as a second best solution. One of the main objectives of this research is to measure the biases on the parameters produced by the unobserved within-sectors price dispersion. We want to test whether there are differences in the estimated parameters of input elasticities and scale economies using new price deflators that we can obtain at the firm level as well as at the three-digit industry level of disaggregation.

There are nevertheless at least two cases in which not observing individual firms output prices becomes irrelevant. The first is the case in which demand price elasticity is very high, markup has a value near zero, and firms' price dispersion is negligible. In this case, dispersion of price growth across firms would essentially reflect random measurement errors. This could be the case of a few highly competitive industries or also if we were considering the long run. The second case is one in which the correlation between real output growth and the change in prices is low relative to the relation between price change and other shocks. If the correlation between price change and output volume change is small, then the transmitted correlation between output prices and inputs will be also small.

These estimations use OLS and IV methods as their main empirical strategies. For our IV estimations, we rely on external instruments. That is to say, we prefer to instrument production factors with variables that reflect their respective costs rather using only past values of the same instrumented variables in levels or first differences. The main instruments used for materials, capital, and number of employees are the user cost of capital, the number of hours worked, and the value of wages paid. As an additional instrument, the first differences of intermediates per employee were used on the estimates in levels, while the levels of intermediates per employee were used on the first differences estimates. All equations were estimated in levels and in first differences. We also evaluate the imposition of constant returns to scale by excluding the number of employees from the equations.

This work has the advantage of having information on firm capacity utilization rates to include in the regressions. Capacity utilization rates are usually ignored in this kind of study, and we believe this causes a serious source of bias in time-series-type estimates if the utilization rates are dispersed across sectors. In this paper, we use the log of total number of days worked during the year in order to consider capacity utilization in our estimated equations. The non-observable firm-level prices and capacity utilization rates produce similar biases but reflect different kinds of economic behaviors. Therefore, 
taking both into consideration at the same time will allow us to assess the specific impact of the dispersion of output price changes without confusing this effect with the impact of the variability of capacity utilization.

\subsection{Chilean Manufacturing Industry Data}

The data used for this work corresponds to the Annual National Manufacturing Survey (ENIA) carried out by the Chilean Statistical Unit (INE). A group of firm-level and product firm-level datasets were combined to obtain an ideal dataset for production function estimation. ${ }^{15}$ In what follows, only the unbalanced panel of firms that reported both firm-level and product-firm level data is used. Observations with leaps and those that were observed less than three consecutive times over the 8-year period were deleted from the database. After merging the information from all databases, the result was an unbalanced panel of 8 periods from 1996 to 2003 that contains 2,439 plants and 15,839 observations.

This section discusses the characteristics of the dataset, the variables that were created, and the basic statistics for all the estimating variables from the econometric model. In the first place, it describes how a set of product innovation indicators was defined based on the annual manufacturing industry survey data from ENIA that was provided from 1996 to 2003 at the level of products inside firms. Some correlation measures are offered afterward in order to compare the behavior of the new product innovation measures among themselves, as well as with data from the Fourth Chilean Innovation Survey. From yearly information about product prices inside each firm, it was possible to calculate firm-level average price growth in order to distinguish the difference between real output growth and nominal output growth. How these firm-level price growth measures were obtained is explained in Appendix 4.

\subsubsection{A Measure of Product Innovation}

Using as a starting point a product-level database that can be combined with the traditional industrial firm-level survey, we can provide yearly information on price growth and product innovation at the firm level. The product data has been provided by the Chilean National Institute of Statistics (INE) and was collected together with the National Annual Industrial Survey (ENIA) using an annex form (Formulario 3) that collected information on each product line inside firms. The original version of the product-firm level data contained 123,548 observations. Products were originally disaggregated using a seven-digit standard industry code.

A preliminary analysis of the product-firm level data and an approximation of how product innovation can be estimated can be found in Appendix 5. In what follows, a description is given of how the innovation indicators were obtained based on the

${ }^{15}$ A detailed explanation of the origin of the Chilean industrial firm-level and product-firm level datasets and how they were handled and merged can be found in Appendix 3. 
information provided at the product-firm level. Because we observe a panel of products within firms, we have information that shows whenever a product was added or dropped from a particular firm's product mix. From the data at hand, we can think of several ways to approximate the concept of product innovation.

Table 3.1 refers in detail to the number of products added and dropped during a one-year period. A product is considered added in any given period $t$ if it was not present in year t- 1 but it is produced in year t. Similarly, a product is counted as dropped during a given period $t$ if it is still produced in that year but not in the following year. In the first column, the total number of products is presented. In the balanced panel, the average number of products in year $t$ is equivalent to the average number of products reported in $\mathrm{t}-1$, minus the average number of products dropped in $\mathrm{t}-1$, plus the number of products added in year t. In this table, the unbalanced panel is used, and therefore this relationship does not hold completely due to observations that enter or exit the sample. The number of products added by each firm is reported in the second column of Table 3.1. This variable takes values from 0 to 32 , has a mean value that is near 0.48 , and is not observed during the first period of the sample.

It is also possible that firms that drop products from their production could be those that are more likely to be innovative on average. To investigate this hypothesis, the third column of table 3.1 reports the total number of products dropped by each firm in every year, as defined above. This variable goes from 0 to 30, with a mean value of 0.36 .

A dummy was defined to take value 1 if the number of products added in a single year is greater than zero and 0 in other case. This dummy cannot be observed for the year 1996 because we have no data on the goods produced in 1995 . Around $20 \%$ of the observations reported adding products over a single year period.

Table 3.1 Number of Products Added and Dropped over a Single-year Period

\begin{tabular}{|c|c|c|c|c|c|c|c|c|}
\hline year & stats & $\begin{array}{c}\text { (1) } \\
\text { Number } \\
\text { of } \\
\text { Products }\end{array}$ & $\begin{array}{c}(2) \\
\text { Number } \\
\text { of } \\
\text { Products } \\
\text { Added }\end{array}$ & $\begin{array}{c}(3) \\
\text { Number } \\
\text { of Prod. } \\
\text { Dropped }\end{array}$ & $\begin{array}{c}(4) \\
\text { Added } \\
\text { Prod. } \\
\text { Dummy }\end{array}$ & $\begin{array}{c}(5) \\
\text { Dropped } \\
\text { Prod } \\
\text { Dummy }\end{array}$ & $\begin{array}{c}(6) \\
\text { Share in } \\
\text { Sales } \\
\text { Prod. } \\
\text { Added }\end{array}$ & $\begin{array}{c}(7) \\
\text { Share in } \\
\text { Sales } \\
\text { Prod. } \\
\text { Dropped }\end{array}$ \\
\hline \multirow{5}{*}{$\begin{array}{c}1996 \\
N=1,897\end{array}$} & mean & 2.81 & 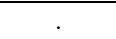 & 0.30 & . & 0.19 & . & 0.05 \\
\hline & $\mathrm{Sd}$ & 2.71 & . & 0.83 & . & 0.39 & . & 0.17 \\
\hline & median & 2 & . & 0 & . & 0 & . & 0 \\
\hline & $\min$ & 1 & . & 0 & . & 0 & . & 0 \\
\hline & $\max$ & 23 & . & 8 & . & 1 & . & 1 \\
\hline \multirow{5}{*}{$\begin{array}{c}1997 \\
N=2,045\end{array}$} & mean & 2.75 & 0.42 & 0.23 & 0.23 & 0.15 & 0.12 & 0.05 \\
\hline & $\mathrm{Sd}$ & 2.60 & 1.04 & 0.72 & 0.42 & 0.35 & 0.30 & 0.18 \\
\hline & median & 2 & 0 & 0 & 0 & 0 & 0 & 0 \\
\hline & $\min$ & 1 & 0 & 0 & 0 & 0 & 0 & 0 \\
\hline & $\max$ & 24 & 13 & 11 & 1 & 1 & 1 & 1 \\
\hline
\end{tabular}

Note: (1) is the total number of products produced in each year, (2) is total number of products added in current year, (3) is total number of products dropped in current year, (4) is a dummy with value one if one or more products were added in current year, (5) is a dummy with value one if one or more products were dropped in current year, (6) is share in current sales of product added in current year $(\mathrm{t}),(7)$ is share in $(\mathrm{t}-1)$ sales of produce dropped during current year $(\mathrm{t})$. $(\mathrm{N})$ is the number of observations in each period. 
Table 3.1 (Continued) Number of Products Added and Dropped over a Single-year

\begin{tabular}{|c|c|c|c|c|c|c|c|c|}
\hline year & stats & $\begin{array}{c}\text { (1) } \\
\text { Number } \\
\text { of } \\
\text { Products }\end{array}$ & $\begin{array}{c}\text { (2) } \\
\text { Number } \\
\text { of } \\
\text { Products } \\
\text { Added }\end{array}$ & $\begin{array}{c}\text { (3) } \\
\text { Number } \\
\text { of Prod. } \\
\text { Dropped }\end{array}$ & $\begin{array}{c}(4) \\
\text { Added } \\
\text { Prod. } \\
\text { Dummy }\end{array}$ & $\begin{array}{c}(5) \\
\text { Dropped } \\
\text { Prod } \\
\text { Dummy }\end{array}$ & $\begin{array}{c}\text { (6) } \\
\text { Share in } \\
\text { Sales } \\
\text { Prod. } \\
\text { Added }\end{array}$ & $\begin{array}{c}(7) \\
\text { Share in } \\
\text { Sales } \\
\text { Prod. } \\
\text { Dropped }\end{array}$ \\
\hline \multirow{5}{*}{$\begin{array}{c}1998 \\
N=2,117\end{array}$} & mean & 2.75 & 0.31 & 0.27 & 0.19 & 0.16 & 0.08 & 0.06 \\
\hline & $\mathrm{Sd}$ & 2.61 & 0.87 & 0.88 & 0.39 & 0.37 & 0.25 & 0.20 \\
\hline & median & 2 & 0 & 0 & 0 & 0 & 0 & 0 \\
\hline & $\min$ & 1 & 0 & 0 & 0 & 0 & 0 & 0 \\
\hline & $\max$ & 25 & 9 & 23 & 1 & 1 & 1 & 1 \\
\hline \multirow{5}{*}{$\begin{array}{c}1999 \\
N=2,077\end{array}$} & mean & 2.73 & 0.25 & 0.32 & 0.14 & 0.17 & 0.05 & 0.09 \\
\hline & $\mathrm{Sd}$ & 2.59 & 0.75 & 0.99 & 0.35 & 0.37 & 0.18 & 0.27 \\
\hline & median & 2 & 0 & 0 & 0 & 0 & 0 & 0 \\
\hline & $\min$ & 1 & 0 & 0 & 0 & 0 & 0 & 0 \\
\hline & $\max$ & 25 & 8 & 11 & 1 & 1 & 1 & 1 \\
\hline \multirow{5}{*}{$\begin{array}{c}2000 \\
\mathrm{~N}=2,059\end{array}$} & mean & 2.85 & 0.44 & 0.50 & 0.21 & 0.19 & 0.11 & 0.09 \\
\hline & $\mathrm{Sd}$ & 2.90 & 1.55 & 1.74 & 0.40 & 0.39 & 0.28 & 0.26 \\
\hline & median & 2 & 0 & 0 & 0 & 0 & 0 & 0 \\
\hline & $\min$ & 1 & 0 & 0 & 0 & 0 & 0 & 0 \\
\hline & $\max$ & 32 & 32 & 30 & 1 & 1 & 1 & 1 \\
\hline \multirow{5}{*}{$\begin{array}{c}2001 \\
\mathrm{~N}=2,071\end{array}$} & mean & 3.33 & 1.04 & 0.41 & 0.32 & 0.15 & 0.16 & 0.08 \\
\hline & $\mathrm{Sd}$ & 3.90 & 2.91 & 1.61 & 0.46 & 0.36 & 0.31 & 0.25 \\
\hline & median & 2 & 0 & 0 & 0 & 0 & 0 & 0 \\
\hline & $\min$ & 1 & 0 & 0 & 0 & 0 & 0 & 0 \\
\hline & $\max$ & 30 & 30 & 27 & 1 & 1 & 1 & 1 \\
\hline \multirow{5}{*}{$\begin{array}{c}2002 \\
\mathrm{~N}=1,915\end{array}$} & mean & 3.53 & 0.46 & 0.50 & 0.15 & 0.17 & 0.04 & 0.09 \\
\hline & $\mathrm{Sd}$ & 4.20 & 1.91 & 1.84 & 0.36 & 0.38 & 0.15 & 0.28 \\
\hline & median & 2 & 0 & 0 & 0 & 0 & 0 & 0 \\
\hline & $\min$ & 1 & 0 & 0 & 0 & 0 & 0 & 0 \\
\hline & $\max$ & 30 & 26 & 23 & 1 & 1 & 1 & 1 \\
\hline \multirow{5}{*}{$\begin{array}{c}2003 \\
N=1,658\end{array}$} & mean & 3.72 & 0.43 & . & 0.15 & . & 0.04 & . \\
\hline & $\mathrm{Sd}$ & 4.51 & 1.79 & . & 0.36 & . & 0.14 & . \\
\hline & median & 2 & 0 & . & 0 & . & 0 & . \\
\hline & $\min$ & 1 & 0 & . & 0 & . & 0 & . \\
\hline & $\max$ & 30 & 28 & . & 1 & . & 1 & . \\
\hline \multirow{6}{*}{ Total } & mean & 3.04 & 0.48 & 0.36 & 0.20 & 0.17 & 0.09 & 0.07 \\
\hline & $\mathrm{Sd}$ & 3.32 & 1.71 & 1.31 & 0.40 & 0.37 & 0.25 & 0.23 \\
\hline & median & 2 & 0 & 0 & 0 & 0 & 0 & 0 \\
\hline & $\min$ & 1 & 0 & 0 & 0 & 0 & 0 & 0 \\
\hline & $\max$ & 32 & 32 & 30 & 1 & 1 & 1 & 1 \\
\hline & $\mathrm{N}$ & 15,839 & 13,942 & 14,173 & 13,942 & 14,181 & 13,942 & 14,173 \\
\hline
\end{tabular}

Note: (1) is the total number of products produced in each year, (2) is total number of products added in current year, (3) is total number of products dropped in current year, (4) is a dummy with value one if one or more products were added in current year, (5) is a dummy with value one if one or more products were dropped in current year, (6) is share in current sales of product added in current year $(\mathrm{t}),(7)$ is share in $(\mathrm{t}-1)$ sales of produce dropped during current year $(t)$. $(N)$ is the number of observations in each period. 
A dummy indicating whether there were any products dropped by each firm during a given year was created. This variable takes value 1 if one or more products were dropped and value 0 in the other case. It is reported in the fifth column of Table 3.1. This dummy has a mean value of 0.17 . The number of products dropped over a one-year period cannot be observed for the year 2003 because we have no information on goods produced in 2004 .

In order to measure the relative importance of sales of innovated products, two variables were defined to measure the share of sales represented by products added and dropped. The sixth column of table 3.1 describes the share of sales that products added in any single year $t$ represented in that same year. On average, $9 \%$ of yearly sales are due to products added in that specific year. The last column of Table 3.1 describes the proportion of sales that products dropped represented in the last year they were produced. On average, approximately $7 \%$ of yearly sales were due to products that were being dropped in that particular year.

Similarly to the recommendation of the OSLO manual that proposes measuring innovation over a three-year period, firms in the Chilean Innovation Survey report their innovation activities over a two-year period. Therefore, Table 3.2 extends the analysis of the innovation measures described in Table 3.1 by referring to product innovations carried out during a two-year period.

For any given year, the number of products added by each firm, reported in the first column of Table 3.2, was computed as the number of products that were produced by a given firm in a given period $(\mathrm{t})$ but that were not produced in the preceding year $(\mathrm{t}-1)$ plus the number of products that were introduced in $(\mathrm{t}-1)$ and that were not present in $(\mathrm{t}-$ 2). Therefore, the number of products added now shows innovations in both the present year and the previous year. This variable cannot be observed during the years 1996 and 1997 because we lack information on products produced in 1995 and 1994. The basic description of number of products added is shown in Figure 3.1. This variable takes values from 0 to 32 and has a mean value that is below 1 .

\section{${\text { Products } \text { Added }_{t}=\text { New Products }}_{t}+$ New Products Pr-1 $_{t}$}

However, as mentioned, it could be that firms that drop products from their product mix are those that are either more innovative or less innovative, on average. The number of products dropped by each firm in every year reported in the second column of table 3.2 corresponds to the number of goods produced in the previous year $(t-1)$ but not produced in the present year $(\mathrm{t})$ plus the number of goods produced in present year $(\mathrm{t})$ but not produced during year $(\mathrm{t}+1)$. Because of the way in which this variable was built, it is not possible to observe it for the first and last periods of the database. The description of the number of products dropped is summarized in more detail in Figure 3.2. This variable goes from 0 to 30 and has a mean value of 0.6.

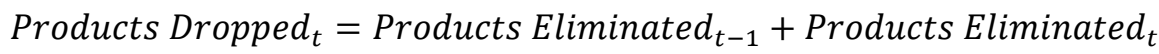


Table 3.2 Number of Products Added and Dropped over a Two-year Period

\begin{tabular}{|c|c|c|c|c|c|c|c|}
\hline year & stats & $\begin{array}{c}\text { (1) } \\
\text { Number } \\
\text { of Prod } \\
\text { Added }\end{array}$ & $\begin{array}{c}(2) \\
\text { Number of } \\
\text { Prod } \\
\text { Dropped }\end{array}$ & $\begin{array}{c}\text { (3) } \\
\text { Added } \\
\text { Prod. } \\
\text { Dummy }\end{array}$ & $\begin{array}{c}(4) \\
\text { Dropped } \\
\text { Prod. } \\
\text { Dummy }\end{array}$ & $\begin{array}{c}(5) \\
\text { Share in } \\
\text { Sales Prod. } \\
\text { Added }\end{array}$ & $\begin{array}{c}(6) \\
\text { Share in } \\
\text { Sales Prod. } \\
\text { Dropped }\end{array}$ \\
\hline \multirow{5}{*}{$\begin{array}{c}1997 \\
N=2,045\end{array}$} & mean & . & 0.53 & . & 0.33 &. & 0.09 \\
\hline & $\mathrm{Sd}$ & . & 1.27 & . & 0.60 & . & 0.27 \\
\hline & median & . & 0 & . & 0 & . & 0 \\
\hline & $\min$ & . & 0 & . & 0 & . & 0 \\
\hline & $\max$ & . & 12 & . & 2 & . & 2 \\
\hline \multirow{5}{*}{$\begin{array}{c}1998 \\
N=2,117\end{array}$} & mean & 0.72 & 0.49 & 0.39 & 0.31 & 0.17 & 0.10 \\
\hline & $\mathrm{Sd}$ & 1.45 & 1.24 & 0.62 & 0.57 & 0.37 & 0.29 \\
\hline & median & 2 & 0 & 0 & 0 & 0 & 0 \\
\hline & $\min$ & 0 & 0 & 0 & 0 & 0 & 0 \\
\hline & $\max$ & 13 & 23 & 2 & 2 & 2 & 2 \\
\hline \multirow{5}{*}{$\begin{array}{c}1999 \\
\mathrm{~N}=2,077\end{array}$} & mean & 0.56 & 0.54 & 0.33 & 0.31 & 0.13 & 0.14 \\
\hline & $\mathrm{Sd}$ & 1.30 & 1.26 & 0.57 & 0.56 & 0.32 & 0.33 \\
\hline & median & 2 & 0 & 0 & 0 & 0 & 0 \\
\hline & $\min$ & 0 & 0 & 0 & 0 & 0 & 0 \\
\hline & $\max$ & 14 & 11 & 2 & 2 & 2 & 2 \\
\hline \multirow{5}{*}{$\begin{array}{c}2000 \\
\mathrm{~N}=2,059\end{array}$} & mean & 0.68 & 0.66 & 0.30 & 0.30 & 0.10 & 0.13 \\
\hline & $\mathrm{Sd}$ & 1.76 & 1.88 & 0.55 & 0.55 & 0.27 & 0.32 \\
\hline & median & 2 & 0 & 0 & 0 & 0 & 0 \\
\hline & $\min$ & 0 & 0 & 0 & 0 & 0 & 0 \\
\hline & $\max$ & 32 & 30 & 2 & 2 & 2 & 2 \\
\hline \multirow{5}{*}{$\begin{array}{c}2001 \\
N=2,071\end{array}$} & mean & 1.46 & 0.76 & 0.47 & 0.31 & 0.21 & 0.13 \\
\hline & $\mathrm{Sd}$ & 3.37 & 2.22 & 0.66 & 0.52 & 0.40 & 0.31 \\
\hline & median & 2 & 0 & 0 & 0 & 0 & 0 \\
\hline & $\min$ & 0 & 0 & 0 & 0 & 0 & 0 \\
\hline & $\max$ & 32 & 30 & 2 & 2 & 2 & 2 \\
\hline \multirow{5}{*}{$\begin{array}{c}2002 \\
N=1,915\end{array}$} & mean & 1.51 & 0.78 & 0.47 & 0.28 & 0.21 & 0.12 \\
\hline & Sd & 3.68 & 2.39 & 0.63 & 0.52 & 0.37 & 0.31 \\
\hline & median & 2 & 0 & 0 & 0 & 0 & 0 \\
\hline & $\min$ & 0 & 0 & 0 & 0 & 0 & 0 \\
\hline & $\max$ & 30 & 28 & 2 & 2 & 2 & 1.93 \\
\hline \multirow{5}{*}{$\begin{array}{c}2003 \\
N=1,658\end{array}$} & mean & 0.91 & . & 0.31 & . & 0.08 &. \\
\hline & $\mathrm{Sd}$ & 2.83 & . & 0.55 & . & 0.22 & . \\
\hline & $\min$ & 0 & . & 0 & . & 0 & . \\
\hline & median & 2 & . & 0 & . & 0 & . \\
\hline & $\max$ & 28 & . & 2 & . & 1.83 & . \\
\hline \multirow[t]{6}{*}{ Total } & mean & 0.97 & 0.63 & 0.38 & 0.31 & 0.15 & 0.12 \\
\hline & $\mathrm{Sd}$ & 2.57 & 1.77 & 0.60 & 0.55 & 0.34 & 0.30 \\
\hline & median & 2 & 0 & 0 & 0 & 0 & 0 \\
\hline & $\min$ & 0 & 0 & 0 & 0 & 0 & 0 \\
\hline & $\max$ & 32 & 30 & 2 & 2 & 2 & 2 \\
\hline & $\mathrm{N}$ & 11,534 & 11,778 & 11,534 & 11,778 & 11,534 & 11,778 \\
\hline
\end{tabular}

Note: (1) is total number of products added in current and previous year, (2) is total number of products dropped in current and previous year, (3) is a dummy with value one if one or more products were added in current and/or previous year, (4) is a dummy with value one if one or more products were dropped in current and/or previous year, (5) is share in current sales of product added in current year $(\mathrm{t})$ plus share in $(\mathrm{t}-1)$ sales of produce added in ( $\mathrm{t}$ $1)$, (6) is share in ( $t-1)$ sales of product dropped in current year $(t)$ plus share in ( $t$ ) sales of product dropped in $(t+1)$. $(\mathrm{N})$ is the number of observations. 
Figure 3.1 Histogram of Number of Products Added

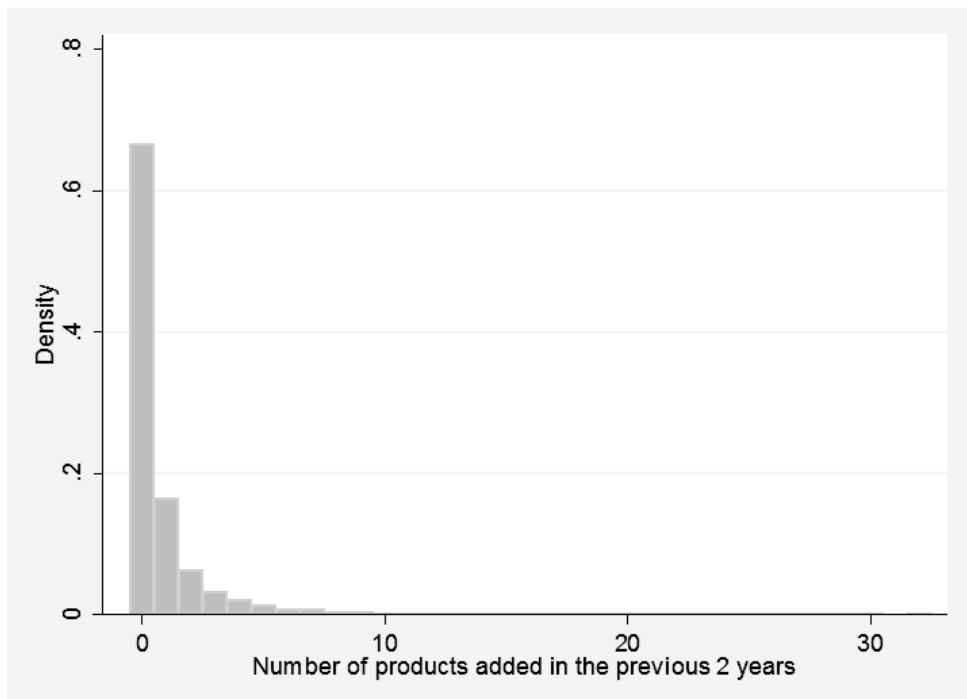

Note: Own calculations using data from Formulario 3 of Chilean Manufacturing Survey ENIA (1996-2003).

Products Added is the number of products in current year $(\mathrm{t})$ production that were absent in previous year (t-1) plus number of products in previous year ( $\mathrm{t}-1)$ but absent in $(\mathrm{t}-2)$.

Figure 3.2 Histogram of Number of Products Dropped

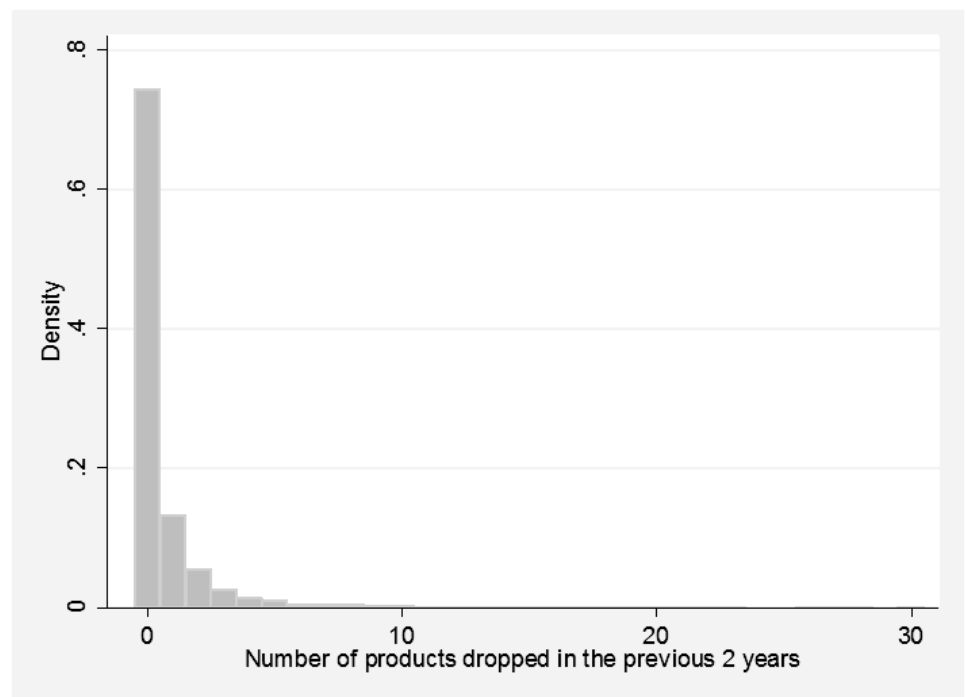

Note: Own calculations using data from Formulario 3 of Chilean Manufacturing Survey ENIA (1996-2003).

Products Dropped is the number of products in previous year $(\mathrm{t}-1)$ but absent in present year $(\mathrm{t})$ plus the number of products in current year $(\mathrm{t})$ but absent in next year $(\mathrm{t}+1)$.

The added product dummy described in the third column of Table 3.2 takes value 1 if the number of products added over a two-year period is greater than zero, while this 
dummy takes value 0 in the opposite case. This variable is not observed during the first two periods of the sample.

The dropped product dummy described on the fourth column of Table 3.2 takes value 1 if the number of products dropped in the present year $\mathrm{t}$ and in the previous year t-1 is greater than zero, while it takes value 0 in the opposite case. This variable cannot be computed for the first and last years of the database.

One of the ways to measure innovation activities that is recommended by the Oslo Manual is to account for the proportion of innovative sales. The share of sales in each firm that corresponds to products added over a two year period was defined as the share of sales in the present year $(\mathrm{t})$ of products produced in $\mathrm{t}$ but not produced in $(\mathrm{t}-1)$ plus the share of sales in ( $t-1)$ of goods produced in $(t-1)$ but not in $(t-2)$. This variable is reported on the fifth column of Table 3.2. On average, the share of sales that corresponded to products added over a two-year period was near 0.15 .

We find that an average of $15 \%$ of the sales corresponds to recently innovated (added) products. The sample contains firms that did not have any new products in their output and firms which only sold new products. More detail about this variable may be found in Figure 3.3. If all products produced last year ( $\mathrm{t}-1)$ were new, and all the products produced in the present year $(\mathrm{t})$ are also new, then the maximum value of this variable is 2.

$$
\text { Added Sales }_{t}=\frac{\text { New Product Sales }}{t}+\frac{\text { New Product Sales }_{t-1}}{\text { Total Sales }_{t}}
$$

Figure 3.3 Histogram of Added Products Share of Sales

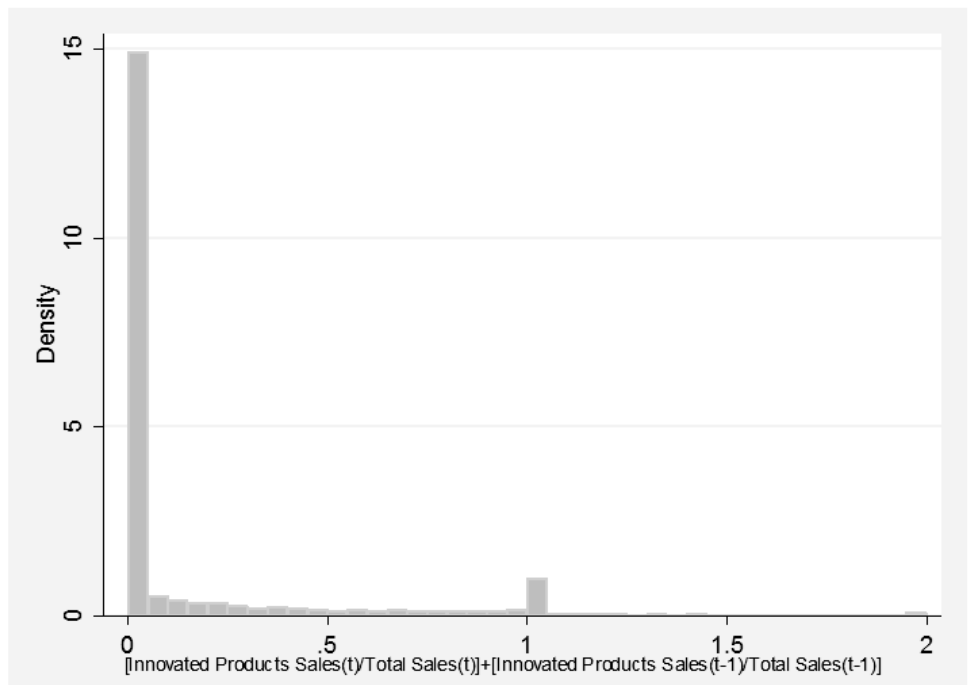

Note: Own calculations using data from Formulario 3 of Chilean Manufacturing Survey ENIA (1996-2003). Products added sales share is the share of sales in ( $\mathrm{t}-1)$ of products produced for the first time in that year plus the share of current sales of products produced for the first time in current year $(t)$. Firms that produced only new products in ( $\mathrm{t}-1)$ and again in $(\mathrm{t})$ have the highest value, equal to 2 . 
To allow for a weighted impact of products dropped on productivity, we calculate the proportion of sales that dropped products represented before they were dropped. The last column of Table 3.2 describes the relative importance of sales of products dropped over a two-year period. The share of sales for each firm that corresponds to products dropped over a two-year period was defined as the share of sales in the present year $(\mathrm{t})$ of products produced in $(\mathrm{t})$ but not produced in $(\mathrm{t}+1)$ plus the share in $(\mathrm{t}-1)$ of products manufactured in ( $\mathrm{t}-1)$ but not in $(\mathrm{t})$. Figure 3.4 shows an additional perspective on this variable. If all firm products were dropped in ( $t-1)$, and all products in present year $(\mathrm{t})$ are dropped again, then this variable can take a maximum value of 2.

$$
\text { Dropped Sales }_{t}=\frac{\text { Dropped Products Sales }}{t}+\frac{\text { Dropped Products Sales }_{t-1}}{\text { Total Sales }_{t}}
$$

Figure 3.4 Histogram of Dropped Products Share of Sales over 2 years.

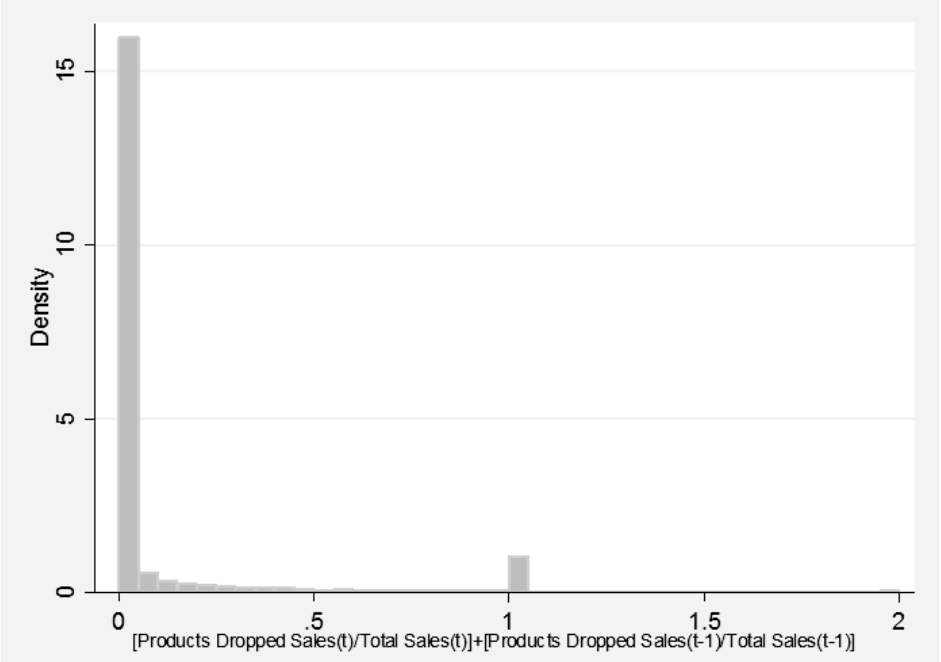

Note: Own calculations using data from Formulario 3 of Chilean Manufacturing Survey ENIA (1996-2003). Products dropped sales share is the share of sales in ( $\mathrm{t}-1)$ of products produced for the last time in that year plus the share of current sales of products produced for the last time in current year ( $\mathrm{t}$ ). Firms that dropped all their products in $(\mathrm{t}-1)$ and again in $(\mathrm{t})$ have the highest value equal to 2 .

\subsubsection{Correlation between the Main Product Innovation Indicators}

We are interested in understanding the relations between the innovation variables that we have developed in this work. One hypothesis is that products added and products dropped may have a positive correlation to the extent that many innovations correspond to the substitution of products. We also expect that the number of products added and dropped are highly correlated to the sales of products added and dropped respectively.

One of the first facts that we see from Table 3.3 is that the number of products at the firm level is positively correlated with all product innovation indicators, especially with those that refer to adding new products to the firms' product mix. The change in the 
number of products is positively and very highly correlated with all variables that reflect the addition of products and it is also correlated positively to the variables that show the number and importance of products dropped. This last finding may be due to the fact that more dynamic firms (those that are expanding their product variety) also need to release themselves from outdated or inefficient production. We also see that the variables that reflect adding products are very highly correlated to each other, while those that refer to products dropped are also highly correlated among themselves. Correlation between adding and dropping products is lower but always positive and strong. This may suggest that a large part of the product innovation activities are related to the replacement of old goods by new ones.

Table 3.3 Correlation Matrix of Product Innovation Variables

\begin{tabular}{|c|c|c|c|c|c|c|c|c|c|}
\hline & & 1 & 2 & 3 & 4 & 5 & 6 & 7 & 8 \\
\hline 1 & Number of Products & 1 & & & & & & & \\
\hline 2 & Change in $\mathrm{N}$ of products & 0.39 & 1 & & & & & & \\
\hline 3 & Number of products added & 0.59 & 0.80 & 1 & & & & & \\
\hline 4 & Number of products dropped & 0.45 & 0.25 & 0.38 & 1 & & & & \\
\hline 5 & Added prod. dummy & 0.43 & 0.41 & 0.61 & 0.26 & 1 & & & \\
\hline 6 & Dropped prod. dummy & 0.36 & 0.12 & 0.26 & 0.64 & 0.33 & 1 & & \\
\hline 7 & Share in sales products added & 0.20 & 0.36 & 0.52 & 0.16 & 0.66 & 0.18 & 1 & \\
\hline 8 & Share in sales products dropped & 0.12 & 0.05 & 0.13 & 0.50 & 0.1 & 0.62 & 0.23 & 1 \\
\hline
\end{tabular}

Note: Product innovation measures computed over a single period. See table 3.1 for variables detail. Data obtained from Chilean Manufacturing Survey years 1996 to 2003. Number of observations is 12,284.

\subsubsection{Correlation between New Price Growth and Innovation Indicators}

For each firm-level price growth and product innovation indicator that we have created and described in Table A4.2 and Table 3.1, we have computed a correlation coefficient with $4^{\text {th }}$ Innovation Survey product and process innovation variables. There were 241 observations from the balanced sample that were also present in the $4^{\text {th }}$ Innovation Survey, which covered the period 2003 and 2004. Because our panel covers 1996 to 2003, these correlations were studied exclusively for the year 2003. Product and process innovation from the 4 th Innovation Survey are variables that take values from 0 (no innovation) to 4 (very high innovation).

We want in the first place to test the hypothesis of our new innovation measures to be similar to the innovation measures from the Chilean Innovation Survey. Some of our innovation measures like the number of products dropped could be negatively related to innovation measures from the Chilean Innovation Survey which could mean that dropping products could be considered by itself as a non-innovative action. On the other hand, if some of our innovation measures relate positively with the Chilean Innovation Survey, we want to know the size of this correlation in order to have a preliminary understanding of how much these variables have in common.

We also test the correlation between our new innovation variables and price growth at the firm-level. Because there has been no availability of firm-level prices before in combination with innovation information, we want to test the hypothesis of price growth 
being directly correlated with innovation. It may be that firms that innovate with new products are also more likely to increase prices faster that other less innovative firms.

The results of the correlation analysis are reported in Table 3.4. As expected, expanding the firm's product variety is the factor most related to product and process innovation. When expressed as a dummy variable, the correlation with self-reported product innovation from the innovation survey is 0.16 , and with process innovation is 0.08 . Number of products added has a correlation of 0.15 with product innovation and 0.07 with process innovation. Number of products added, rescaled from 0 to 4 , has a correlation of 0.16 with product innovation and 0.07 with process innovation from the $4^{\text {th }}$ Innovation Survey.

The correlation between the number of products dropped and product innovation is -0.05 , while the correlation between the products dropped dummy and product innovation is -0.01 .

We find that firm-level inflation is negatively correlated with product and process innovation. Among firms where prices increase faster, there is a lower probability of engaging in process and product innovations. The correlation between the third definition of firm-level price growth and process innovation is -0.09 , while the correlation with product innovation it is -0.11 .

As the table shows that firm-level price growth has a negative correlation with product and process innovation, one may think of several alternative explanations for this finding. One possible implication is that innovative firms are subject to more market competition and therefore their price growth is relatively low compared with noninnovating firms.

Table 3.4 Correlations between Innovation Survey Product and Process Innovation, Product Innovation Indicators and Firm-level price growth

\begin{tabular}{|c|cc|}
\hline & $\begin{array}{c}\text { 4th innovation } \\
\text { survey process } \\
\text { innovation }\end{array}$ & $\begin{array}{c}\text { 4th innovation } \\
\text { survey product } \\
\text { innovation }\end{array}$ \\
\hline Total change in number of products in one year & 0.02 & 0.14 \\
Dummy increased number of products in one year & 0.08 & 0.16 \\
Number of products added in one year & 0.07 & 0.15 \\
Number of products dropped in one year & 0.04 & -0.05 \\
Products added in one year dummy & 0.08 & 0.16 \\
Products dropped in one year dummy & 0.10 & -0.01 \\
Number of products added + products dropped in one year & 0.07 & 0.04 \\
Number of products added in one year (rescaled 1 to 4) & 0.07 & 0.16 \\
Firm price growth 1 & -0.06 & -0.09 \\
Firm price growth 2 & -0.05 & -0.06 \\
Firm price growth 3 & -0.09 & -0.11 \\
\hline
\end{tabular}

Note: Data obtained from the Fourth Chilean Innovation Survey and the Chilean Manufacturing Survey for year 2003. For this matrix, the number of observations present in the manufacturing sample and the $4^{\text {th }}$ Innovation Survey was 241 . 
These results can also be seen in Figure 3.5, which shows positive product innovation correlations and negative correlations between products dropped and product innovation. We can see from this figure that Innovation Survey (IS) Product Innovation is more correlated than (IS) Process Innovation to all the variable defined in this work. In the case of the correlation between our new product innovation indicators and (IS) Product Innovation, these correlations are nearly double the ones with (IS) Process Innovation.

\subsubsection{Basic Descriptive Statistics}

Table 3.5 contains the basic descriptive statistics of the main variables in the model. In the first place, the table reports the statistics of non-deflated, industry-deflated and firmlevel deflated output per employee. For the cases where deflated output was used as dependent variable, the values of intermediates and capital were also deflated with appropriate deflators computed from the Chilean Statistical Office wholesale price data. When non-deflated output was used, the inputs were also expressed in nominal terms. The non-deflated and deflated input levels of capital and intermediates are reported in the same table. Capacity utilization rate is on average $78 \%$ of the 365 days of the year. The firm that declared the lowest capacity utilization was active for the equivalent of one day of the year, while the observations with the highest capacity utilization operated 365 day in a year.

The price growth at the level of firms has been calculated through a careful analysis of the product-firm level database. ${ }^{16}$ In first place, the average yearly price at the productfirm level was calculated by dividing total product sales by the number of units sold. We then took logs of the product-firm level prices. Finally, the first difference of the log of price gave the approximate yearly product-firm level price growth rate. The firm-level price growth rate was calculated after deleting those outliers from the product-firm level data in which the first difference of $\log$ of price was higher than $\log (2)$ or lower than $\log (2)$. We computed a weighted average in order to incorporate information on the relative importance of each product to total firm sales. The overall coverage of productfirm level information was also taken into account by weighting each firm's inflation by the coverage of its product-firm level information and using the average 4-digit industry price growth to represent the share of production that is not detailed at the product-firm level. Table 3.5 shows that the mean value of firm-level yearly inflation rate is approximately $2.9 \%$ and has maximum and minimum values that are near $59 \%$ and $-58 \%$ respectively. Four-digit sector average inflation has a mean value of $2.8 \%$ but has a much smaller dispersion than the firm-level inflation rate. Product-firm level data covers on average $72 \%$ of total firm-level sales before dropping products considered outliers in terms of their price change, and 55\% of total firm-level sales after dropping around 10\% of products considered outliers based on the criteria described above.

\footnotetext{
${ }^{16}$ More detail regarding the computation of firm-level price growth based on product-firm level data can be found in Appendix 4.
} 


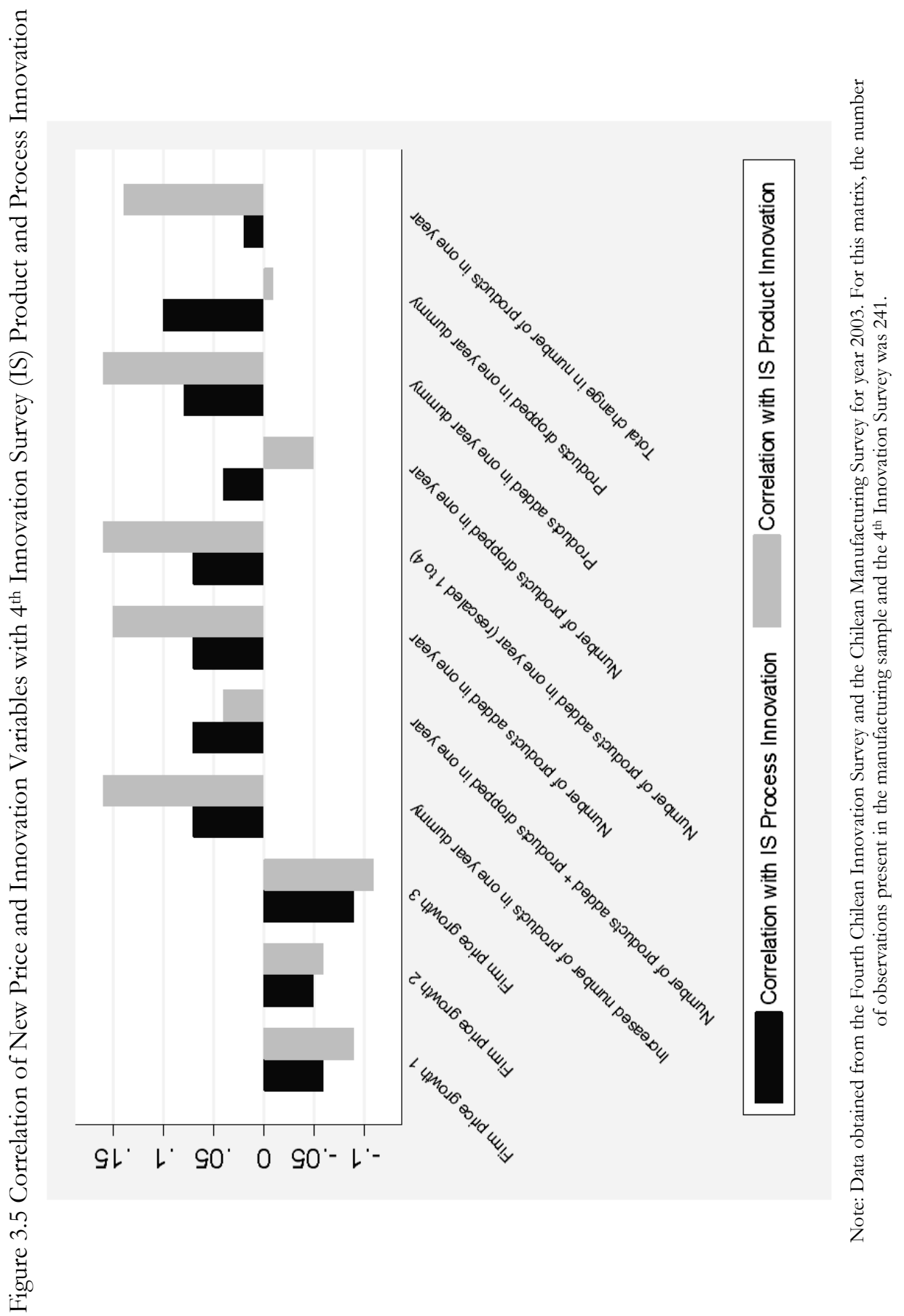



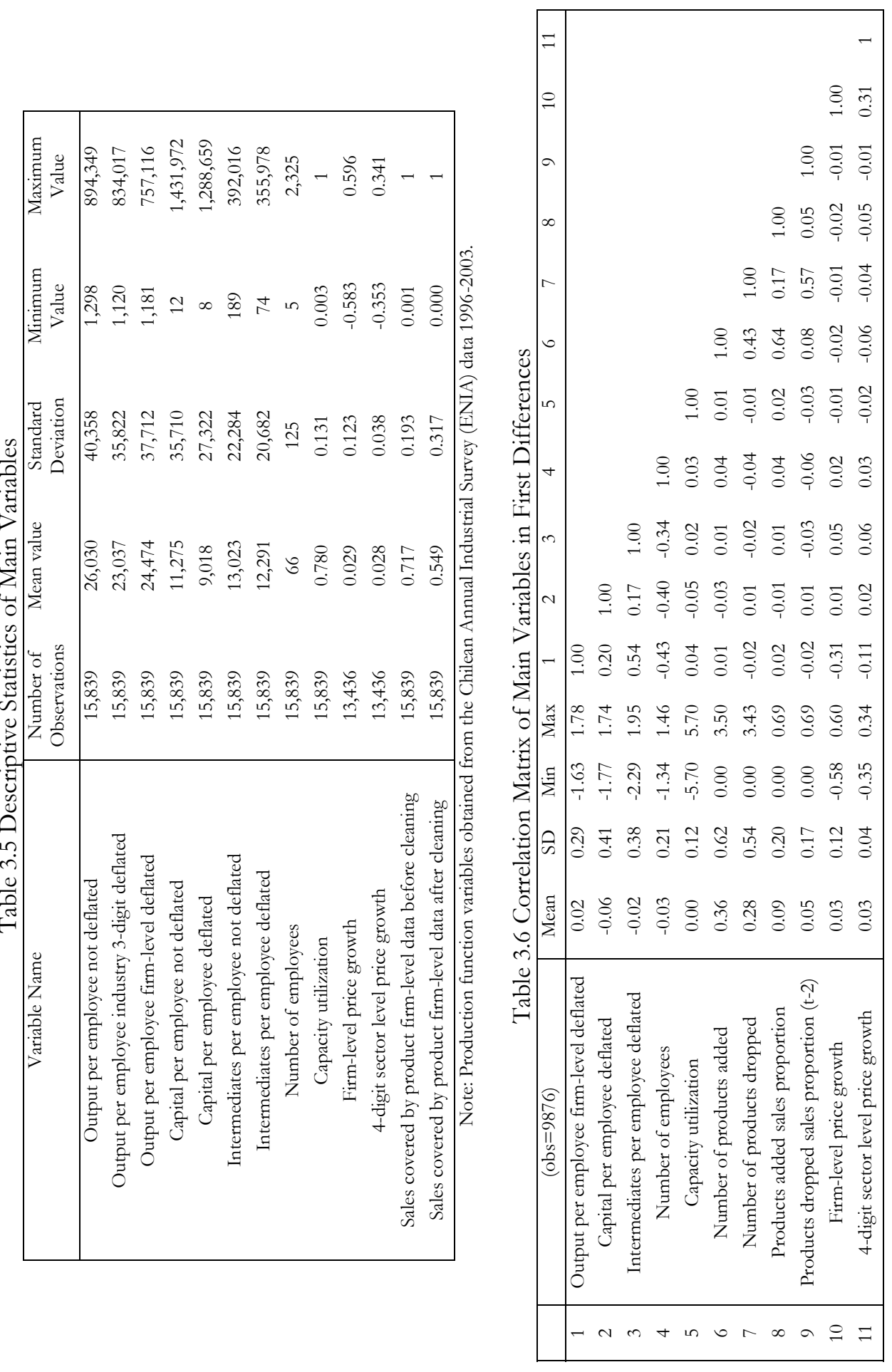
Table 3.6 shows a correlation matrix of the main variables that have been used in this study. The variables include output, productivity, and the newly defined variables that describe firm-level price behavior, products added, products dropped, and the proportion of innovated sales. These variables are expressed in first differences and the main descriptive statistics are also provided. The change in output per employee is positively correlated with changes in capital, intermediate consumption, labor, and capacity utilization. Changes in capacity utilization are positively correlated with total output but negatively correlated with changes in capital per employee. Deflated labor productivity has a negative relationship with prices and products dropped, while also a positive relationship with products added. The proportion of innovated sales is positively correlated with deflated productivity, which may imply a labor productivity advantage for innovative firms. The positive relationship between products added and dropped shows that a part of innovations corresponds to replacement of old products by new ones.

\subsection{Estimation Results}

The main results of this paper are presented in Tables 3.7 to 3.17. Results show estimated input and scale elasticities that are feasible and in accordance with recent literature. Non-reported geographical, sector, and year dummies have been included in all the regressions.

\subsubsection{OLS Preliminary Estimates}

The left panel of Table 3.7 contains the most simple productivity function specification of this paper. These panel-data estimations using variables in levels were made by the Ordinary Least Squares method. Using variables in levels implies that the cross-sectional and time-series dimensions of the data are treated in the same way. All parameters are highly significant, which already gives a positive indication for this basic production function specification. The first column (1) uses non-deflated output per employee and non-deflated inputs. This is the simplest case, in which the production function has been simplified to a revenue function that is compared with different equations that use various deflating procedures. The specification of the second column (2) uses 4-digit industry-level deflated output per employee, while capital and intermediates are also deflated using appropriate price indexes for different kinds of capital and intermediates. Column (3) uses firm-level deflated output, while capital and intermediates are also deflated in the same way as in column (2). Columns (4) and (5) use non-deflated variables but consider as controls the industry-level prices and the firm-level prices, respectively.

The capital per employee parameter is close to 0.12 , while number of employees fluctuates around 0.09 , showing that larger firms are on average more productive. The parameter of intermediate consumption lies around 0.63. Capacity utilization also has a positive and significant parameter, which shows that the omission of this variable would cause a bias on the estimated input elasticities. The parameters remain fairly stable 
throughout the 5 columns. This may indicate that price dispersion is not large enough to cause a significant bias in the non-deflated or industry deflated estimates. Adding industry and firm-level price growth as regressors in columns (4) and (5) results in positive and very significant parameters. This means that price growth does have a significant influence in the accounting of average per worker productivity, even though its omission does not cause a significant bias on the factor elasticity parameters.

The right side panel of Table 3.7 contains the preliminary estimates in first differences using OLS. These estimations use the (log) "first differences" of the variables in the model. This way the estimations rely on the time-series dimension of the data. First differences control for individual heterogeneity simply by removing the firm effects from the equation. The number of observations is smaller in this case because one year of data is lost when taking first differences of the variables. The number of employees appears with a negative sign in these estimates that take the rates of growth of the variables. It is important to make a distinction between the interpretations of the results of the equations in levels from those of the equations in first differences. We find that labor input's rate of growth is negatively correlated with labor productivity, which does not mean that the same variables in levels should necessarily present the same sign. In the case of the estimates on first differences, one possible interpretation of the negative labor input elasticity is the existence of decreasing returns to scale. Capital per employee, number of employees, and intermediate consumption remain fairly stable across columns. This shows that using non-deflated labor productivity, deflating it by an industry price index, or deflating it by an individual firm price index makes no big difference in the estimation of the production function parameters. The estimated coefficient of capacity utilization is even higher than that of capital in the equations on first differences. The role that this variable plays in the adjustment of capital stock is very important. The services provided by capital, which we represent by the book value of capital, are better understood if we adjust by changes in capacity utilization rate.

Table 3.8 contains the results of the same experiment that is shown in Table 3.7, but assumes constant returns to scale by imposing the labor parameter to be equal to zero. When imposing constant returns to scale, the capital per employee parameter results in a significantly higher parameter. The increase in the capital elasticity parameter is particularly important for the case of the estimates in first differences, which may imply that assuming constant returns to scale is a very restrictive condition for this case.

The evidence points out the existence of firms operating with decreasing returns to scale, which is in accordance with standard microeconomic theory. Results show that, across the regressions in levels, from the left panel, and also across the estimates in first differences, from the right panel, intermediates per employee and capacity utilization parameters in the model in Table 3.8 appear to remain very stable. This result further confirms that using non-deflated or deflating with firm-level or industry-level price growth does not make a big difference to the simple revenue function estimation. The evidence we found in this regard supports what was found previously by Mairesse and Jaumandreu (2005), which used self-reported price growth in order to account for firmlevel inflation. 


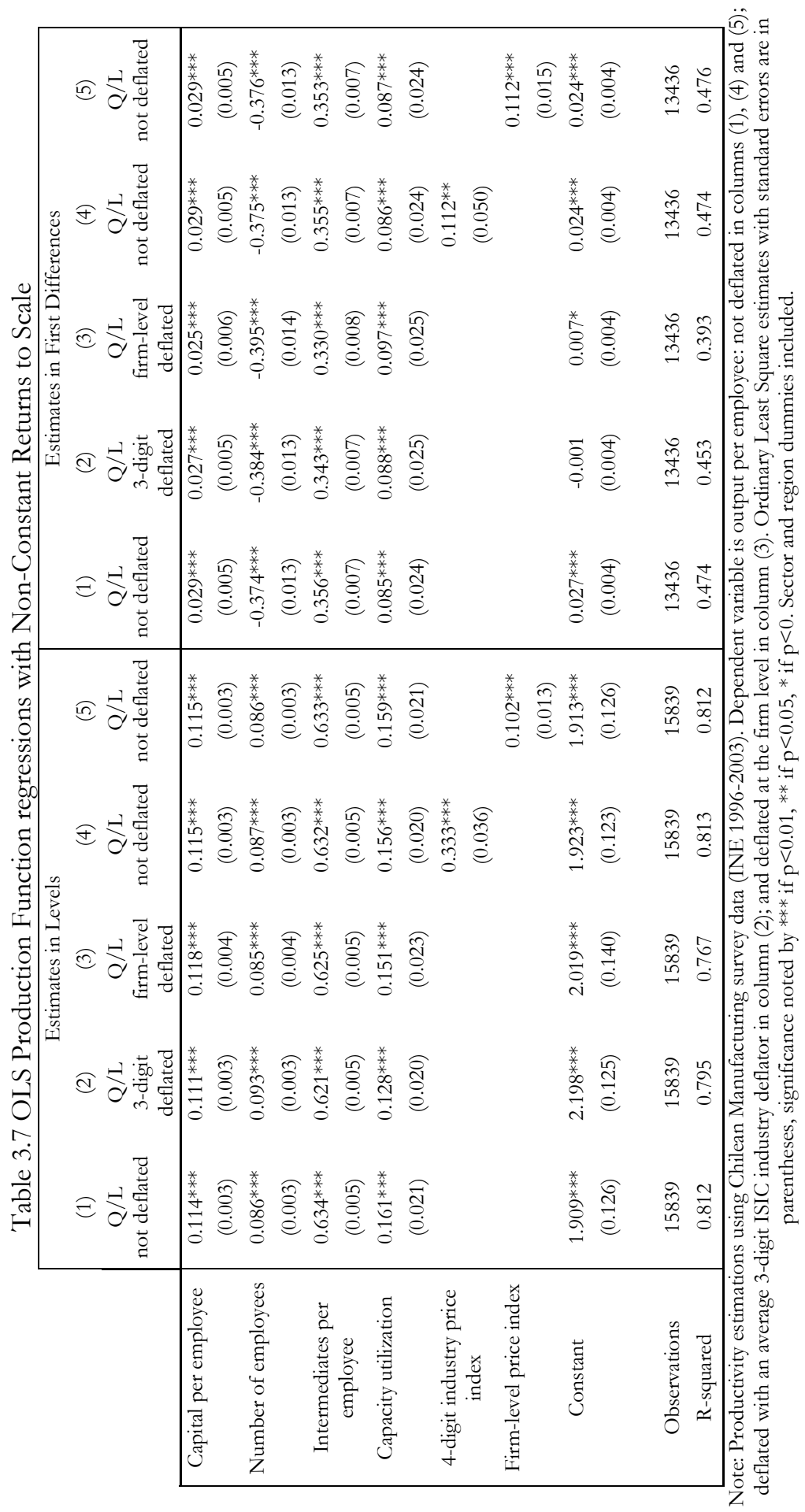




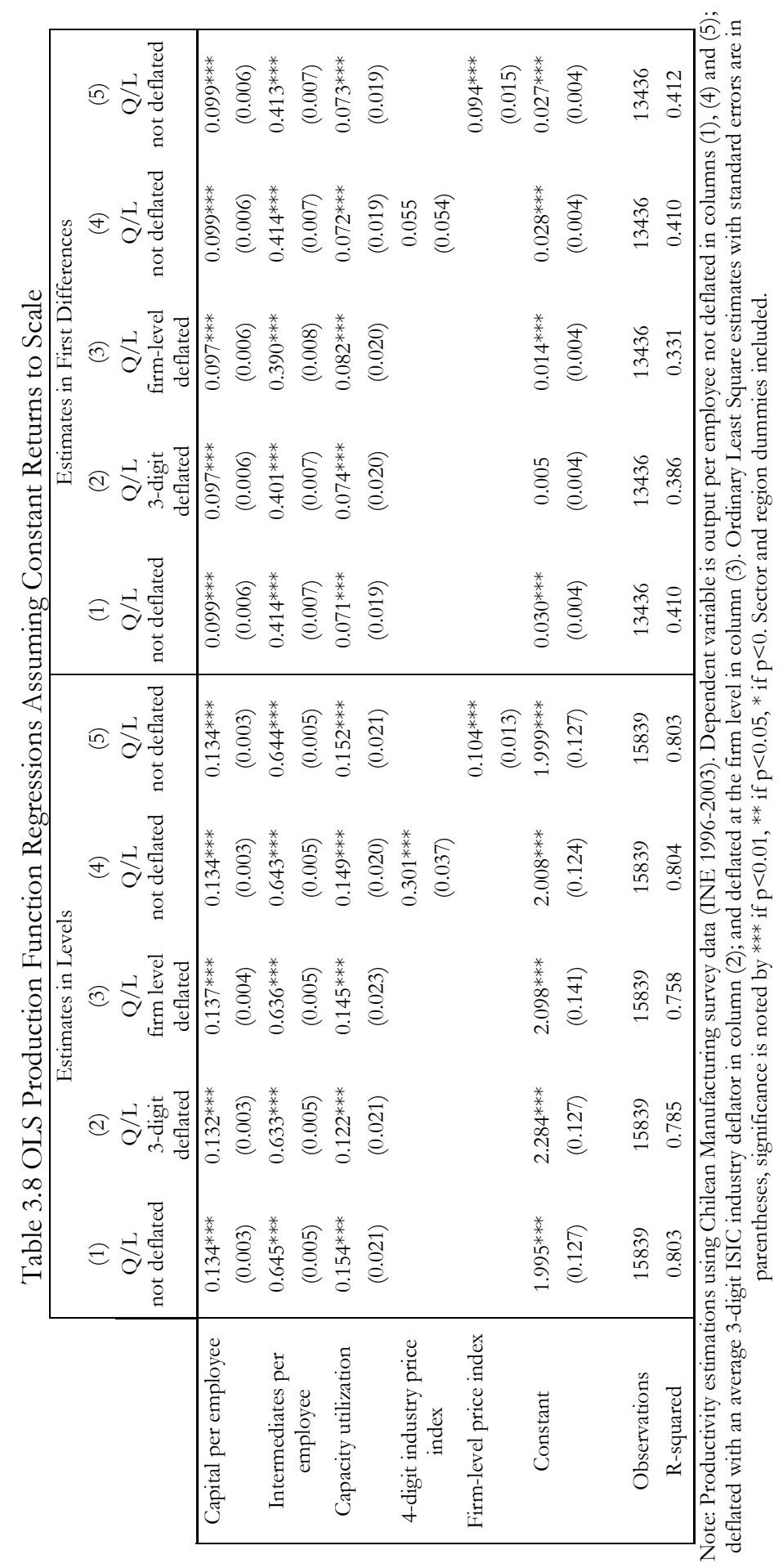




\subsubsection{Instrumental Variable Estimates}

Because OLS estimation is not able to take into account the omission of managerial inputs and other factors that are likely related both to the decision of input level and output obtained, the parameters of the Production Function estimation are probably biased with the bias having the same positive sign that the effect of managerial inputs over output. We approach this endogeneity problem using Instrumental Variables.

Tables 3.9 and 3.10 contain the estimates of the labor productivity model using Instrumental Variables. The variables that were instrumented are capital per employee, intermediates per employee, and number of employees. The instruments used throughout these sets of regressions were capital cost, number of hours worked in the firm during the year, and wages. Correlations between instruments and instrumented variables range from 0.14 to 0.69 , while correlations of the instruments with the dependent variable are significantly lower.

Table 3.9, which is the IV version of Table 3.7, shows some interesting results. Most of the parameters remain significant and with the expected signs, even though some of their magnitudes change. The value of the intermediates elasticity parameter is significantly lower on the IV estimates. Nevertheless, the parameter of capital per employee ratio is larger in the IV regressions but only significantly different on the first differences estimates. We can also notice an important reduction of the R-squared measure in the IV estimates with respect to OLS, especially for the case of the regressions in first differences. The lower panel of Table 3.9 shows that the scale parameter that is represented by the estimated elasticity of number of employees to labor productivity is insignificant. This raises again the question of whether there are constant returns to scale.

When constant returns to scale are assumed, we force that the number of employees does not affect the productivity per employee. We drop the variable that contains the number of employees and re-estimate the equations using Instrumental Variables. The left panel of Table 3.10 shows that the model is consistent, at least in the sense that parameters maintain their signs and significance levels, even though some of their magnitudes are affected. Capitals per employee and capacity utilization appear in these equations with significantly higher values than those found in the previous tables.

The right panel of Table 3.10 shows the results of the IV estimates in first differences when imposing constant returns to scale. Comparing the input elasticities parameters to those in the lower panel of Table 3.9 shows that the constant returns to scale assumption makes no significant difference to the input parameters in the case of the estimates in first differences.

Throughout these Instrumental Variables regressions results, the Kleibergen-Paap LM statistic rejected that the equation was under-identified. Nevertheless, the Sargan test rejects the validity of the instruments, and the weak identification using Cragg-Donald Wald F statistic does not reject that the instruments are weak. Therefore, and because we were not able to find better instruments, we prefer to focus on the OLS estimates in what follows. 


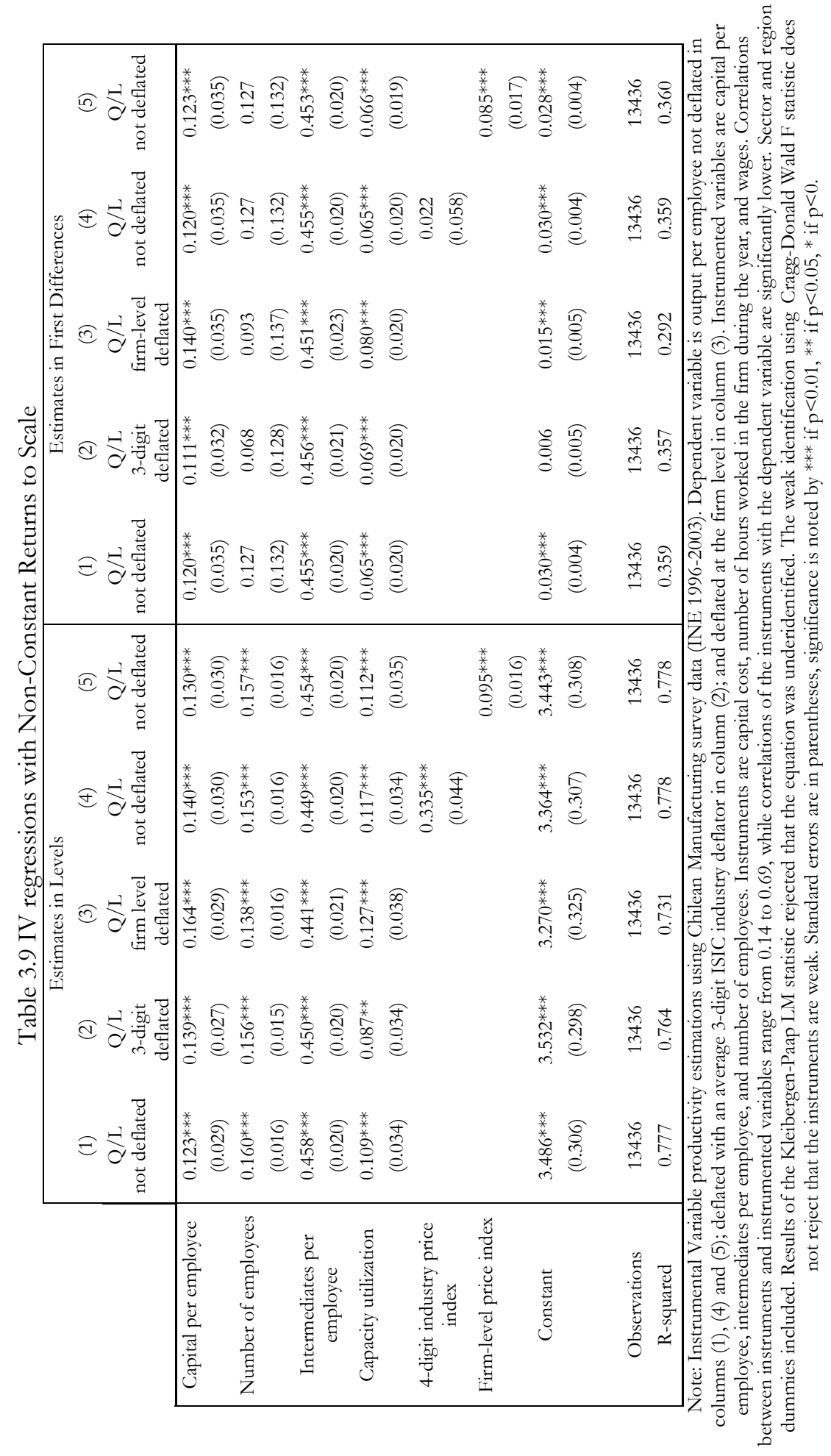




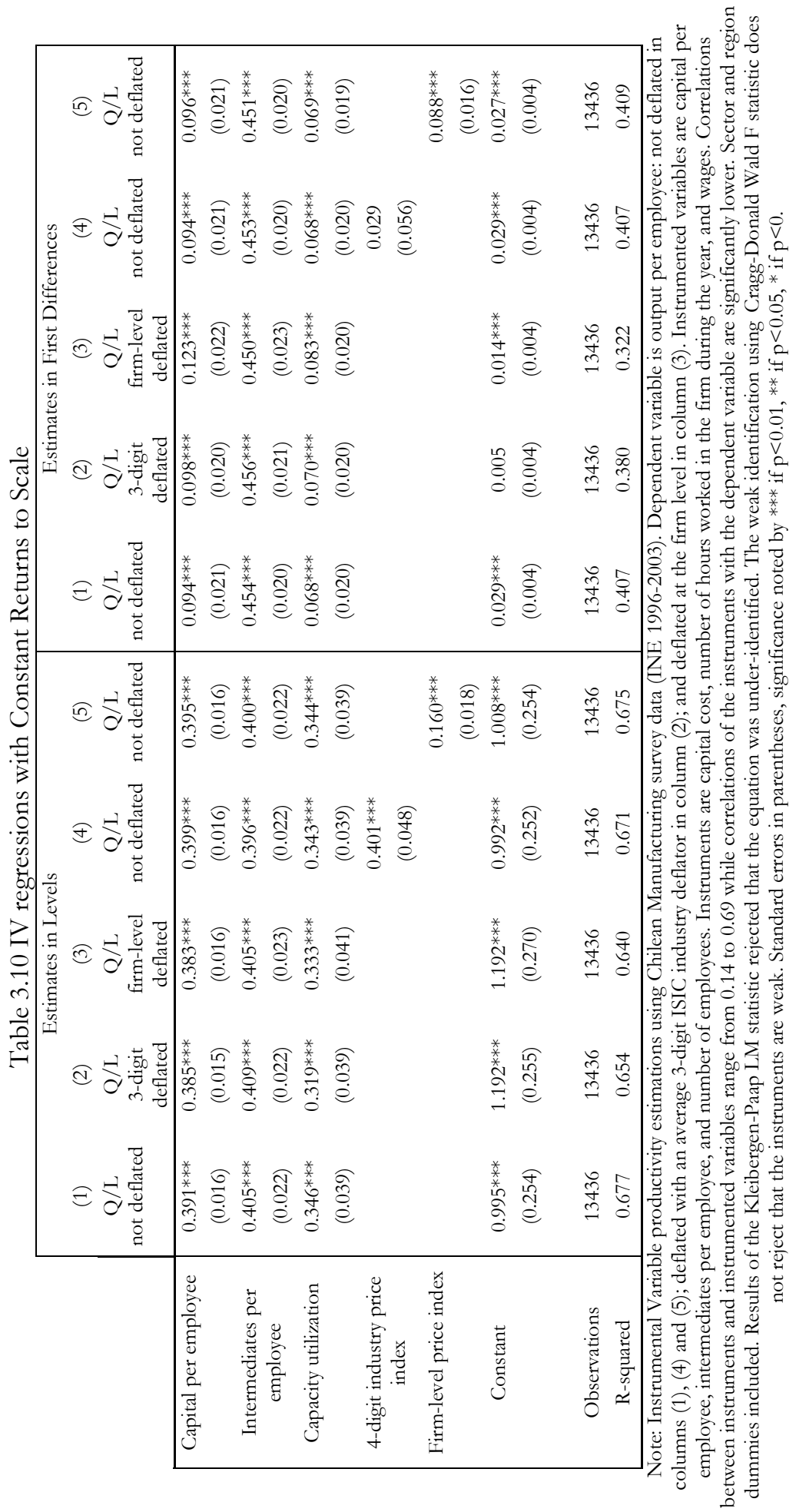




\subsubsection{Products Added or Dropped and the Proportion of Innovative Sales}

Table 3.11 shows the OLS results of including the total numbers of products added and dropped in the present and the previous year. In the left panel (estimates in levels) we find that the input parameters are robust to the inclusion of innovation indicators. In fact, the signs, magnitude, and significance of the parameters, as well as the R-squared measures, do not differ much from those in table 3.7. The number of products added appears with a significant and positive parameter, which confirms the expectations of the model. On the other side, the number of products dropped appears to have a negative coefficient, which is also in accordance with the results we expected to find.

When manufacturers expand the varieties of products that they produce, it is likely that output per employee will increase, not only because the firm's demand for innovated products may be larger, but also because new varieties of products offer new combinations of ways in which inputs can be organized and allocated for achieving higher productivity.

The right panel of table 3.11 (estimates in first differences) shows results that also support the findings of the input elasticity parameter estimates from Table 3.7. The parameters of capital per employee, capacity utilization, intermediates per employee, and number of employees remain robust to the inclusion of product innovation indicators. Furthermore, there is evidence to support a positive impact on average per worker productivity of adding products and a negative effect on average per worker productivity of dropping products.

Many of the products added and dropped correspond to a replacement of new products by old ones. Because products added and products dropped are positively correlated variables with opposite signs, it could be the case that estimating the model excluding one of the two variables will result in a much lower and even insignificant effect of the included innovation variable. This hypothesis is evaluated in Table 3.12, where the number of products dropped is excluded, and in Table 3.13, where the number of products added is excluded. The results in the left panel of Table 3.12 show that the number of products added in a two-year period seems to lose significance in the absence of the number of products dropped in the case of the equations in levels.

Because we have found in previous estimations that constant returns to scale may result a too restrictive assumption for the parameters, tables 3.11 to 3.17 are focused on the production function model without imposing constant returns to scale. The estimation of the model imposing constant returns to scale can be found on Appendix 6 . 


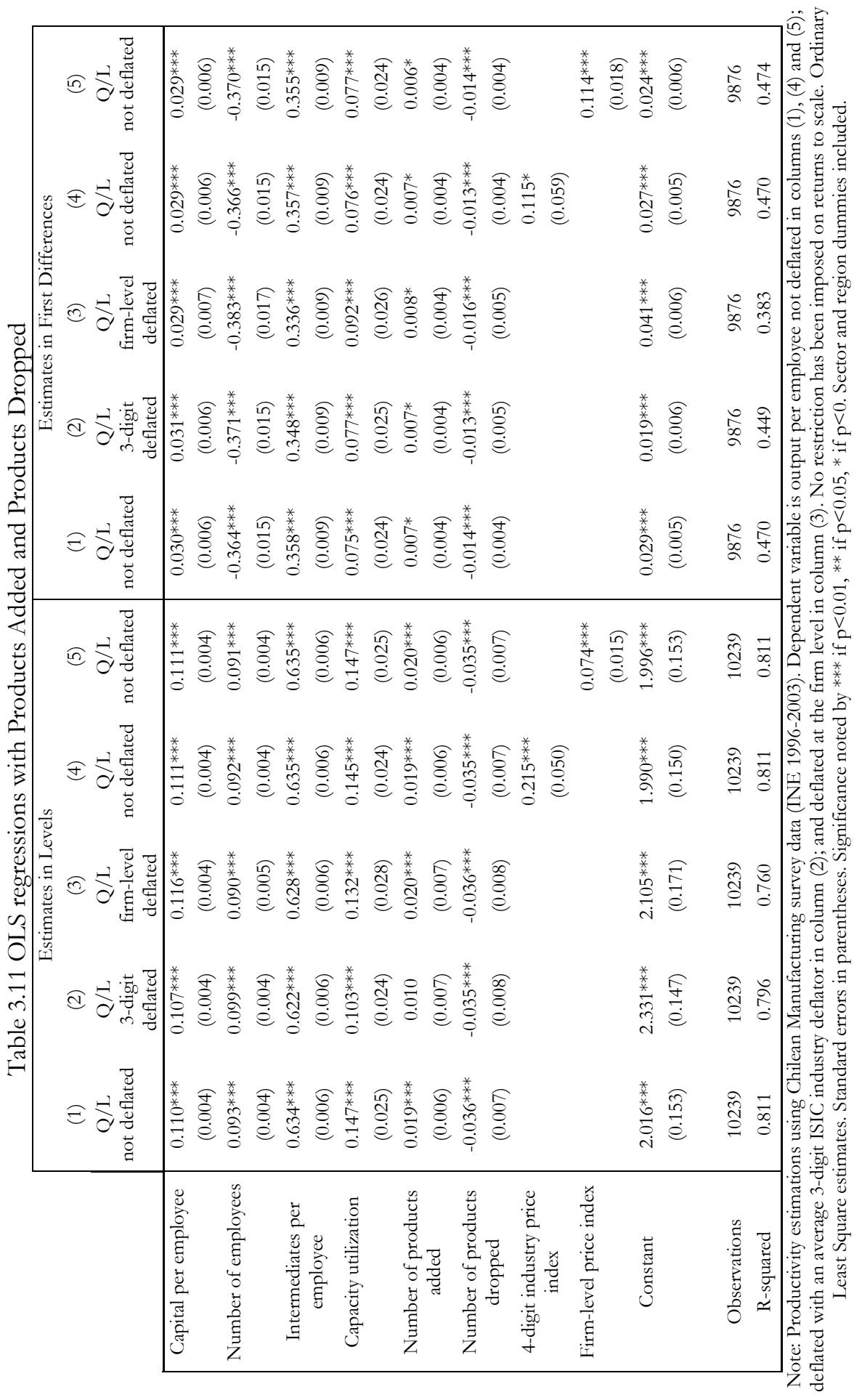


The other input parameters nevertheless remain robust with respect to the evidence found on the estimates in levels from Table 3.7. The right panel of Table 3.12 presents the estimates in first differences, where all the elasticity parameters do not change significantly with respect to the OLS first differences estimates that don't consider product innovation indicators. The results show that, in this case, the effect of the number of products added remains present, even though the number of products dropped is omitted.

Table 3.13 evaluates the effects of the number of products dropped only by excluding the number of products added from the equations. It may be seen that the parameters of the basic model presented in Table 3.7 remain robust to the inclusion of this single product innovation indicator. Results show that reducing the varieties of products by dropping products from the inventories has a negative effect on labor productivity, independently of whether products were added or not in the same period at the firm level. The magnitude of this negative effect is smaller than in the case of Table 3.11. This result suggests that, even though products added and products dropped are positively correlated and influence the dependent variable in opposed directions, the effect of number of products dropped remains robust to the omission of the number of products added, at least it terms of the sign and the significance.

Table 3.14 evaluates a different innovation measure that reflects the proportion of sales that correspond to innovated (added) products and the proportion of sales of dropped products. We are interested in comparing these results with those obtained in table 3.11. On the estimates in levels, as on the estimates in first differences, we find that this is also a good measure of innovation, and the effects are still present after controlling for added and dropped products' relative importance in total sales. Even though the positive effect of products added and the negative effect of products dropped are still significant, we find that the magnitudes of the effects are smaller when controlling for their relative importance in total sales. Because products added and products dropped are positively correlated, it could be the case that excluding one of the two variables when estimating the model will result in a much lower and even insignificant effect of the included innovation variable. We evaluated this possibility in Table 3.15, where the number of products dropped is excluded, and in Table 3.16, where the number of products added is excluded. We found that the results are robust to the exclusion of each one of the innovation variables. 


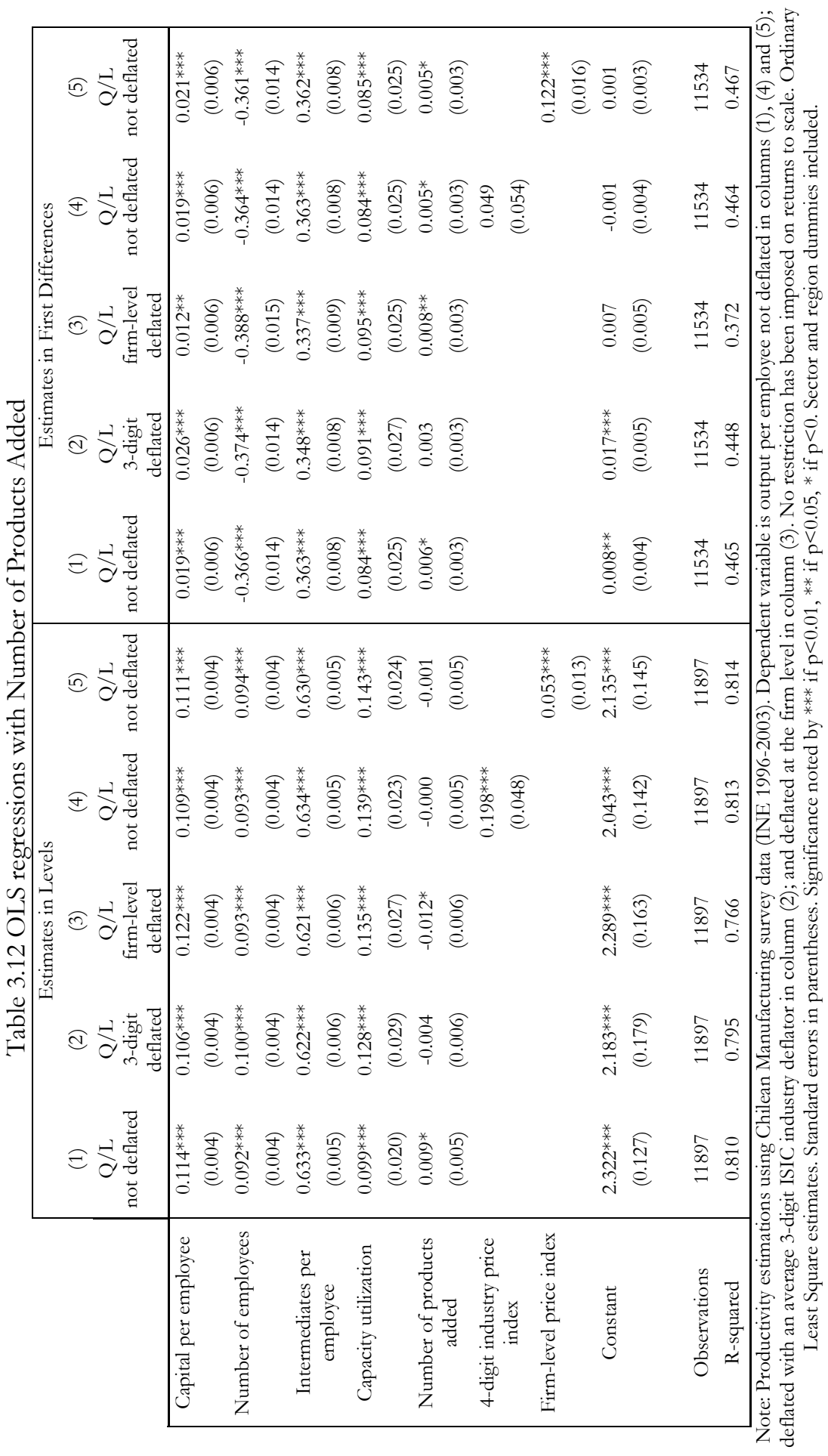




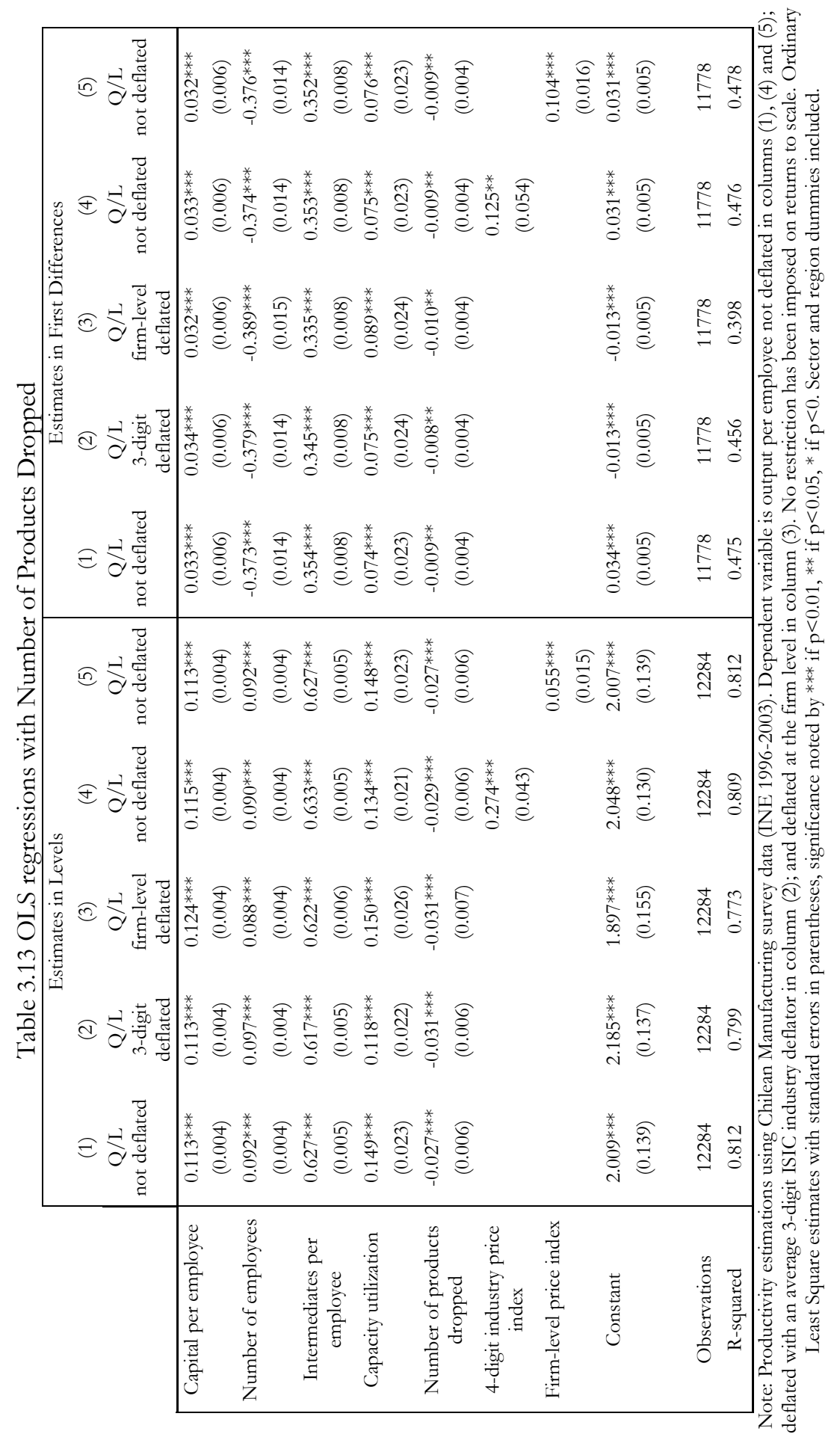




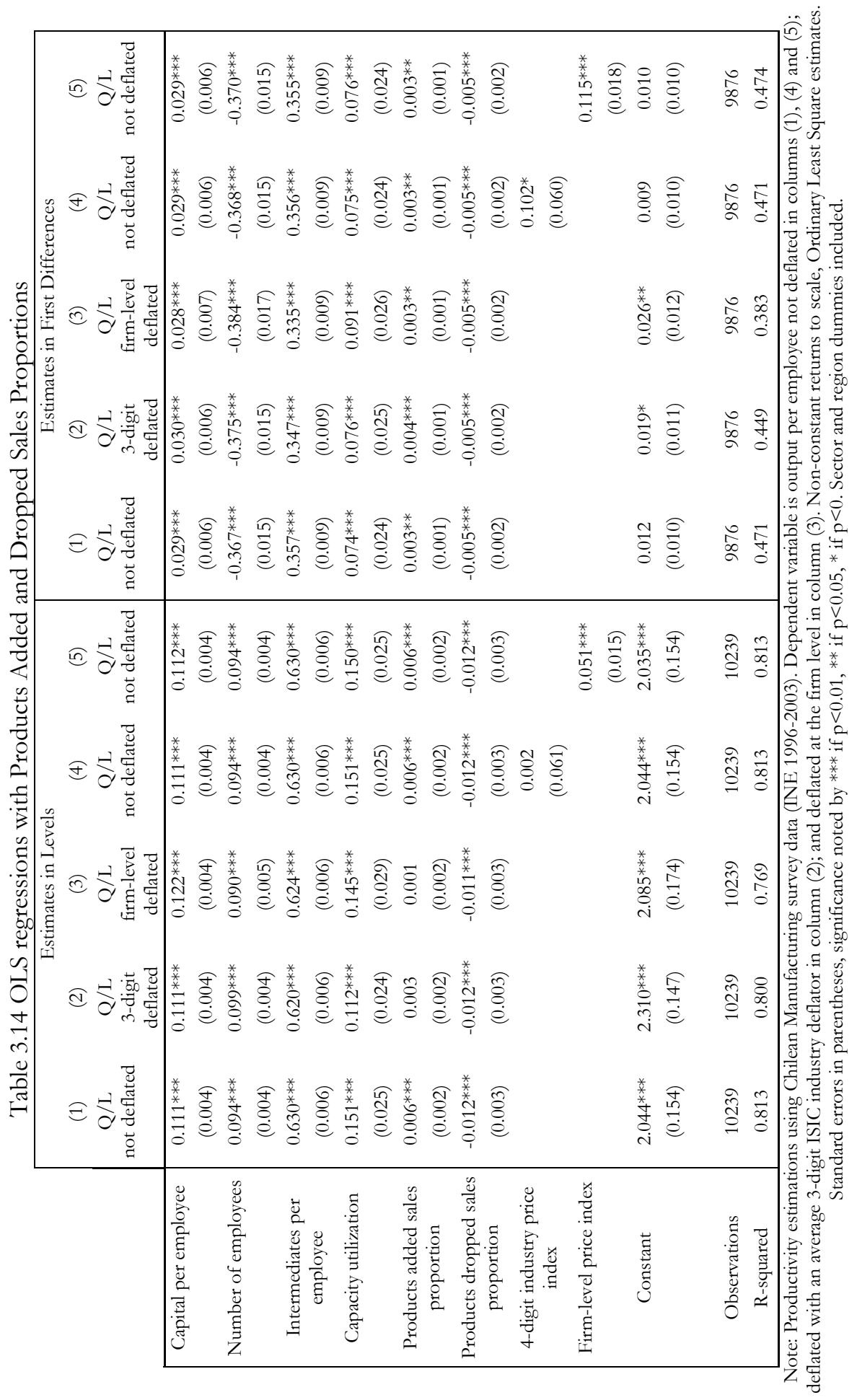




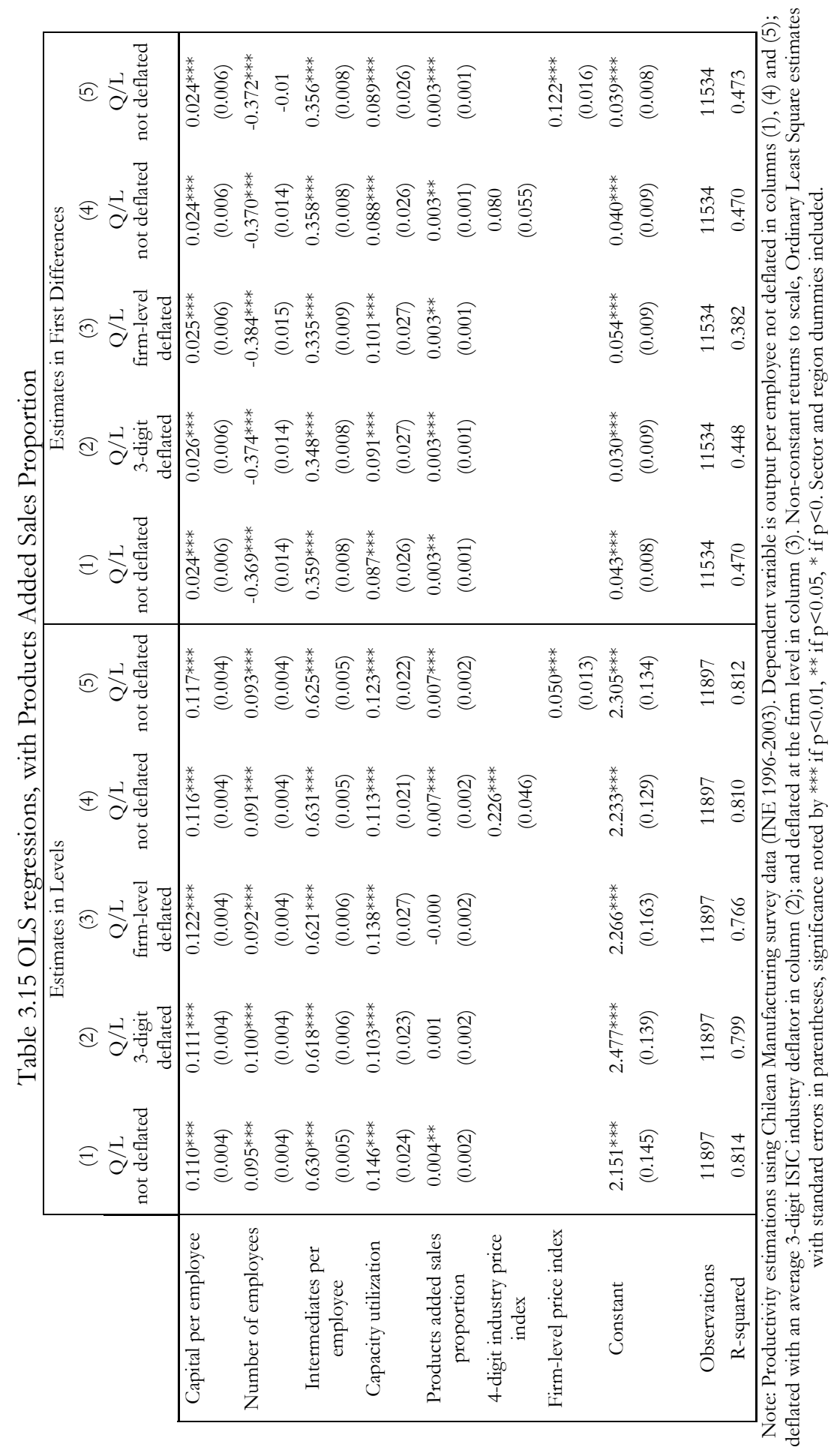




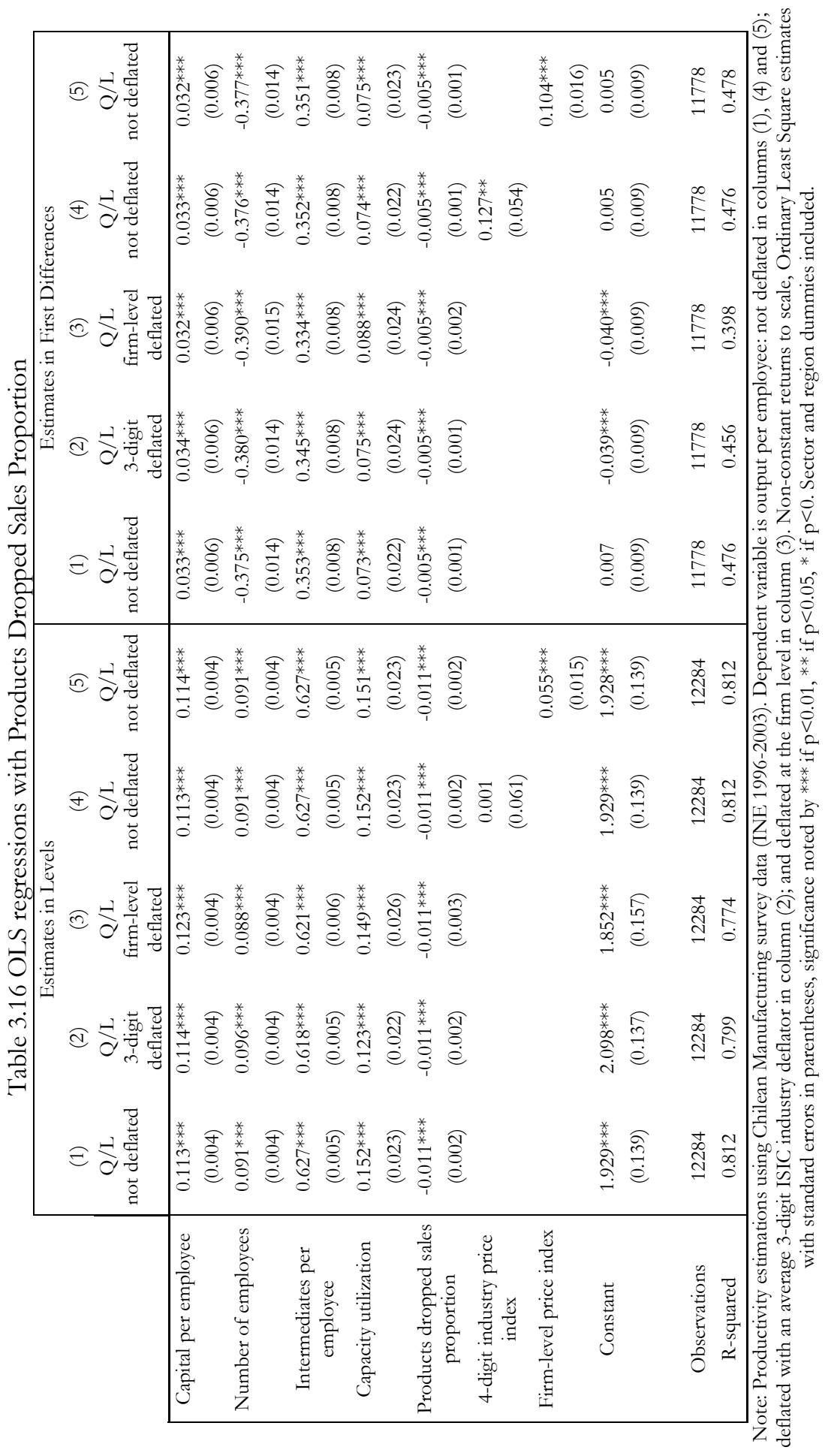


Based on the results shown so far, some questions may arise with respect to the relationships among different product innovation behaviors. We are interested in knowing the impact of products added on labor productivity, both in the presence and in the absence of products dropped. We specified four dummies that describe the four different possible combinations of innovative behaviors. In the first place, the "only added products" dummy takes value 1 when the number of products added in the past 2 periods is greater than 0 only if there were no products dropped in the same period, and it takes value 0 in any other case. The "only dropped products" dummy takes value 1 of there were one or more products dropped over the previous 2 years but there were no products added in the same period and takes value 0 in any other case. The "added and dropped products" dummy takes value 1 if products were added and products were dropped and takes value 0 in any other case. The "no added or dropped products" dummy takes value 1 only if no products were added and no products were dropped over a two-year period.

Table 3.17 shows the result in our main model of including these dummies except "added and dropped products", because it is linearly dependent on the other dummies and the constant. The parameter significance levels are very high in most of the cases. In the left panel we find the results of the model expressed in levels. In all regressions, the coefficients "only added products" and "only dropped products" are positive which means that their productivity value is higher than in the case of "added and dropped products". The value of the "no products added or dropped" dummy coefficient is in most cases also higher than the constant coefficient that stands for "added and dropped products". The parameter "only dropped products" has a higher value than "only added products," which means that, among the firms that dropped products, the ones that also added products are driving the negative parameter of "products dropped" in Table 3.7. This explanation is supported by the fact that in the level equations from Table 3.13 the value of "added and dropped products dummy" is the lowest of the four intercepts in the equation. From this equation we also conclude that the value of doing nothing (the value of the "no added or dropped products dummy") is higher than the value of replacing products (the value of the constant that stands for "added and dropped products").

The right panel of Table 3.17 gives additional information on the effects of products replacement on productivity. The estimates in first differences show that, even though the replacement of goods has a negative impact on the present level of productivity, it has a positive impact on the rate of growth of productivity. The value of "added and dropped products" has a relatively high value that is about two times as large as the value of the "no added or dropped products" parameter. We find that the highest value is associated with the "only added products" behavior. The option of "no products added or dropped" has a lower value but in some cases is higher than the "only dropped products" value. 


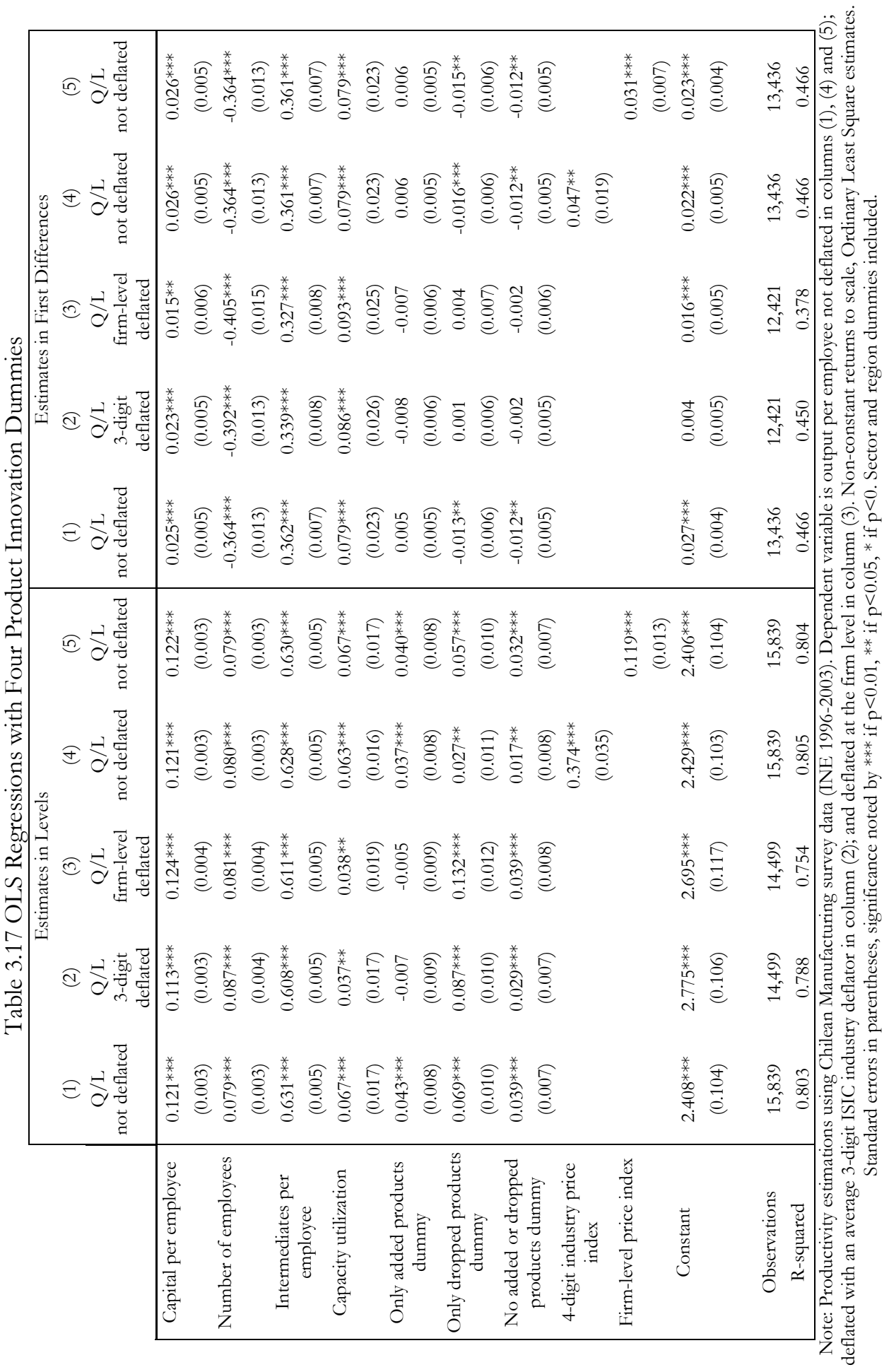




\subsection{Concluding Remarks}

This work studied the relationships among inputs, prices, product innovation, and productivity at the firm level using Chilean data for the period 1996-2003. The main contribution of this work is that, besides using firm-level industrial data, it takes advantage of an additional survey form that collects product-firm level information. We compared the estimation of the revenue function (using a nominal output measure) and the production function (using a real output measure). The outcomes were also compared to the usual case in which output is deflated by an industry level deflator.

Results show that estimating the production or revenue function does not yield significantly different results when a variety of deflators are used to express output in constant prices. This may indicate that intra-industry price dispersion is enough correlated with output as to cause a significant bias on the non-deflated or industry deflated estimates. Therefore, using non-deflated or deflating with firm-level or industrylevel price growth does not make a big difference to the input elasticities in the function estimation. The evidence we found in this regard supports what was found previously by Mairesse and Jaumandreu (2005), which used self-reported price growth in order to account for firm-level inflation.

In this paper, we found firm-level evidence to support the idea that product diversification has a positive effect on manufacturing productivity. It seems that variations in the range of products manufactured by firms have an impact on the level and the rate of growth of average output per employee. In particular, the incorporation of new products is clearly associated with a higher and increasing level of productivity among Chilean manufacturing firms.

The results of this study show that the behavior of only adding products is positively and strongly related to increases in productivity in the case of the estimates in levels and also in the rates of growth. The findings also show that dropping products has an immediate negative effect on labor productivity. This suggests that the reduction in output associated with products dropped is not contemporaneously accompanied by a reduction in labor, probably due to labor input rigidities.

The positive effect of adding products is not independent of whether some products are taken out of production at the same time. On average, firms that replace products face a contemporaneous reduction in labor productivity but a clear increase in the rate of growth of labor productivity. Additionally, we find that the behavior of only dropping products also has a positive effect on labor productivity in levels and almost no effect in first differences. The combinations of innovative activities such as adding and dropping products may result in positive productivity gains in terms of rate of growth, while doing no product-mix changes results in lower productivity gains.

This chapter adds to the literature at least in two ways. First, it incorporates some new measures of product innovation into the traditional productivity estimates. We have found that the addition of new products by a firm is significantly associated with a positive increase in average worker productivity and that there is a complex relationship 
between the behaviors of adding and dropping products. Second, the main methodological contribution of this work is proposing a measure for firm-level price change. Using this measure, nominal output can be expressed in real terms in order to estimate the production function.

Results of this chapter imply that promoting product innovation has an additional positive effect that was previously not properly accounted for. Expanding product variety at the firm level may spur productivity by mechanisms that are not fully explained in previous literature and must be further studied. It is possible that firm-level product diversification generates access to new knowledge that, once used inside a firm, may be shared among all employees, thus expanding productivity. Products dropped allow resources to be freed for more efficient uses. However, if the dropped products are not replaced, the effect on the rate of growth of productivity is negative. Further studies should also refer to models in which firm-level output price information is incorporated into a system that considers demand for output and inputs as determinants of the production process, in the style of the work that was done in Mairesse and Jaumandreu (2006). 


\section{References}

Ackerberg, D., L. Benkard, S. Berry, and A. Pakes (2006). "Econometric Tools for Analyzing Market Outcomes". Handbook of Econometrics Vol 6, 4171-4276

Abbott, T.A. (1989). "Price Dispersion in U.S. Manufacturing". Center for Economic Studies, U.S. Bureau of Census. Discussion Paper 89-7.

Abbott, T.A. (1991). "Producer Price dispersion and the Analysis of Production". Journal of Productivity Analysis 3,179-195.

Agosin, M., (1999). “Trade and Growth in Chile”. Cepal Review 68 August 1999.

Agosin, M. and Bravo-Ortega, C. (2009). "The Emergence of New Successful Export Activities in Latin America: The Case of Chile". IADB Research Network Working Paper \#R-552

Alvarez, R., Bravo-Ortega, C. and Navarro, L. (2012). "Product Mix Changes and performance in Chilean Plants" Mimeo.

Benavente J.M. (2006). "The Role of Research and Innovation in Promoting Productivity in Chile". Economics of Innovation and New Technology 15 (4-5) : 301-315. Junio.

Benavente J.M., De Gregorio, J., Nuñez, M. (2006). "Rates of Return for Industrial R\&D in Chile". Departmento de Economia Universidad de Chile, Serie Documentos de Trabajo N 220.

Benavente J.M. , S. Dobblelaere and J. Mairesse (2009). "Interaction between Product Market and Labor Market Power : Evidence from France, Belgium and Chile". Applied Economic Letters 16 (6) : 573-577. Abril.

Benavente, J. M. and Lauterbach, R. (2008). "Technological innovation and employment: complements or substitutes?" The European Journal of Development Research, 20:2, $318-329$

Blundell, R. and Bond, S. (2000). "GMM Estimation with Persistent Panel Data: An Application to Production Functions”. Econometric Reviews 19, 321-340.

Crepon, B., Desplatz, R. and Mairesse, J. (1999). "Estimating Price-Cost Margins, Scale Economies and Workers' Bargaining Power at the Firm Level” CREST WP no G9917. 
Crepon, B., Duguet, E. and Mairesse, J. (1998). "Research, Innovation, and Productivity: An Econometric Analysis at the Firm Level.". Economics of Innovation and New Technology, 7(2), 115-158.

Dobbelaere, S. and Mairesse, J. (2009). "Panel Data Estimates of the Production Function and Product and labor Market Imperfections". Tinbergen Institute Discussion Paper TI 2009-001/3

Foster, L., Haltiwagner, J., and Syverson, C. (2008). "Reallocation, Firm Turnover, and Efficiency: Selection on Productivity or Profitability?” American Economic Review, 98:1.

Griliches, Z. (1957). "Specification Bias in the Estimation of Production Functions". Journal of Farm Economics, Vol. 39, No. 1, pp 8-20.

Griliches Z. and J. Mairesse, (1984). "Productivity and Research - Development at the Firm Level". in Research and Development, Patents and Productivity, Z. Griliches ed., The University Press of Chicago, 271-297.

Griliches Z. and J. Mairesse, (1998). "Production Functions: The Search for Identification", in Econometrics and Economic Theory in the 20th Century : The Ragnar Frish Centennial Symposium, S.Ström ed., Cambridge University Press, 169-203.

Hall, R.E., (1988). "The Relationship between Price and Marginal Cost in US Industry" Journal of Political Economy, 96, 921-947.

Hall, B., Lotti, F., and Mairesse, J. (2008). "Employment, Innovation, and Productivity: Evidence from Italian Microdata". Industrial and Corporate Change, Volume 17, Number 4, pp. 813-839.

Hall, Bronwyn, Mairesse, J. and Mohnen P., (2010). "Measuring the Returns to R\&D”. Chapter prepared for the Handbook of the Economics of Innovation, B. H. Hall and N.

Rosenberg (eds.), UNU-MERIT Working Paper 2010-006

Harrison, R., Jaumandreu, J., Mairesse, J., and Peters, B., (2008). "Does Innovation Stimulate Employment? A Firm-Level Analysis Using Comparable Micro-Data from Four European Countries” NBER Working Paper No. 14216

INE (2009a). "Microdatos Industriales Revisados, Informe Metodologico (1998-2005)". INE Studies and Documents, www.ine.cl

INE (2009b). "Manual Metodológico del Índice de Precios al Consumidor (IPC) Nacional Base Anual 2009=100", Instituto Nacional de Estadísticas, Subdirección de Operaciones Departamento de Estadísticas de Precios. 
INE (2009c). "Microdatos Industriales y Normas Sobre Secreto Estadistico, Asoectos Metodologicos ENIA 2001-2005”. INE Studies and Documents, www.ine.cl

Jaumandreu J and J. Mairesse, (2006). "Using Price and Demand Information to Identify Production Functions”, MPRA Paper 1247, University Library of Munich, Germany.

Klette J. and Z. Griliches, (1996). "The inconsistency of common scale estimators when output prices are unobserved and endogenous". Journal of Applied Econometrics, 11.

Levinsohn, J. and Petrin, A. (2003). "Production Functions Using Inputs to Control for Unobservables", The Review of Economic Studies, Vol 70, No. 2, pp 317-341.

Mairesse, J. and Jaumandreu, J (2005). "Panel-data Estimates of the Production Function and the Revenue Function: What Difference Does It Make?”. Scand. J. of Economics 107(4), 1-22.

Mairesse, J. and Mohnen, P. (1994). "R\&D and Productivity Growth: What Have we Learned from Econometric Studies?”, Eunetic Conference on Evolutionary Economics of Technological Change: Assessment of Results and New Frontiers, 817- 888, Strasbourg, October 6-8, 1994.

Marschak, J. and Andrews, W. (1944). "Random simultaneous equations and the theory of production", Econometrica, 12, 143-205.

Navarro, L. (2009). "Plant Level Evidence on Product Mix Changes in Chilean Manufacturing”. Department of Economics, ILADES-Georgetown University. Presented at MEIDE Conference May of 2009.

Fernandes, A. M., Paunov, C. (2010). "Does Trade Stimulate Innovation? Evidence From Firm-Product Data”. OECD Development Centre Working Paper No. 286.

Fernandes, A. M., Paunov, C. (2008). "Foreign Direct Investment in Services and Manufacturing Productivity Growth: Evidence for Chile”. Policy Research Working Paper No. 4730. The World Bank, Development Research Group.

Olley, S. and Pakes, A.(1996). "The Dynamics of Productivity in the Telecommunications Equipment Industry” Econometrica 64 1263-1295

Organization for Economic Co-operation and Development (1992, 1996, 2005). "Oslo Manual", Paris, 1st, 2nd, 3rd edition. 


\title{
Chapter 4 MARKUP AND RENT SHARING IN MANUFACTURING: NEW EVIDENCE FROM CHILEAN FIRMS
}

\begin{abstract}
This work jointly estimates Price-Cost Markups and Union Bargaining Power using input elasticities and shares of input cost over sales. A novelty of this chapter is that it uses real output and productivity growth which are calculated using firm-level price corrected output growth, using new product-firm level data from the Chilean manufacturing industry between 1996 and 2003. The industry is divided and compared across seven manufacturing sectors. The Paper, Printing, and Publishing industry was found to have the lowest markups, measured by the estimations in levels, followed by the Textile industry. The Food and Beverages industry appears to have the highest average markup of price over marginal cost and also the highest extent of rent sharing. The Textile industry was found to be the sector where workers get the smallest share of rents. One finding of the present paper that is new and differs from all previous evidence is that in some industries workers do not receive a share of turnover that surpasses their own contribution to output, in some cases workers receive a share that is lower than their average marginal productivity. In the sample we analyzed, production activity was subject to a strong contraction in 1998 and 1999, when output growth was -2\% and $8 \%$. Nevertheless, firm rents are distributed between capital owners and employees, resulting in different labor market outcomes across sectors of the manufacturing industry. We found that deflating output at the firm level or at the industry level does not change the estimated parameters significantly, even though some differences may be found in the estimated standard deviations.
\end{abstract}




\subsection{Introduction}

One of the key concerns of empirical economists is the effects of market power on social welfare and the variations in resource allocation that result from deviations from perfect competition. In the manufacturing industry, imperfect competition implies that firms can raise prices above marginal costs and reduce the level of output below the socially optimal level. Many approaches in the economic literature empirically analyze and describe monopoly and monopsony power. Typically, this kind of analysis requires estimating demand and supply elasticities as a starting point for assessing the competitiveness of a market.

This paper follows the model developed by Crepon, Desplatz, and Mairesse (1999, 2002, 2007), which is an extension of the approach by Hall (1988). Earlier work by Solow (1957) developed a model that estimated total factor productivity growth as a measure of technical change. The model by Crepon et al. (1999) has the advantage of explicitly considering imperfect competition in the labor market. As shown in that paper, ignoring the existence of labor market imperfection causes a biased estimation of markups due to the omission of the share of rents that are captured by the workers in a manufacturing firm. When the condition that labor is priced competitively is relaxed, the Solow residual can be decomposed into three parts: a markup of price over marginal cost, a parameter that represents the bargaining power of workers, and the rate of technical change.

This work used a rich dataset from the Chilean manufacturing industry. This dataset allows us to clearly distinguish the changes in prices from the changes in quantities at the firm level. The absence of information on prices in previous work did not allow observation of changes of output in real terms. Instead, real sales value was estimated by deflating nominal sales with industry-level average price growth, forcing an assumption of no price or markup variations among firms within the same sector. This paper relaxes that assumption by introducing firm-level information on prices.

One of the main objectives of this study is to evaluate whether estimating the model using real output instead of industry level deflated output will make significant differences in the estimated parameters. Additionally, it separates the Chilean manufacturing industry into seven sectors that we characterize individually using the model. We then draw some preliminary conclusions on market power distribution across the manufacturing industry in Chile.

The analysis was at first focused on the whole manufacturing industry level. The model was then re-estimated using a disaggregation of the Chilean manufacturing industry into seven economic sectors: Foods-Beverages, Textiles-Leather, WoodFurniture, Paper-Publishing, Chemicals-Petroleum-Plastic, Non-Metallic Minerals, Metallurgic-Machinery. We divided firms into sectors that use similar technologies and inputs to obtain parameters that reflect the average overall level of competition in a specific industry. Nevertheless, it is not possible from our results to measure the market power of a specific firm or product market. Therefore, this study is intended as a general analysis of Chilean manufacturing rather than an empirical measure of market competition from an antitrust point of view. 
The results show that deflating output at the firm level does not lead to a change in the estimated parameters, in contrast to what we find by deflating output at the two, three, or four-digit level. In fact, the differences in the parameters estimated with different deflations are never significant. Nevertheless, the standard deviations of the estimated parameters are higher in the firm-level deflated model in comparison with the industry-level deflated equations. This result is consistent with a downward bias of the estimated standard deviations when deflating output using the same industry-level deflator for a large group of firms.

In regard to the markup of price over cost, this paper found a parameter that is always high and significant, which implies that imperfect competition predominates in the Chilean manufacturing industry. Some of the lowest markups of price over cost were found in the Paper, Printing, and Publishing sector, followed by the Textile industry. The highest estimated markups were seen in the Food and Beverages sector and the Wood, Wood Products, and Furniture industries.

The results also suggest that workers in general receive a small share of firm rents. In fact, the only sector that shows some degree of rent sharing that remains stable across regressions is the Food, Beverages, and Tobacco industry. The sectors where employees are relatively disadvantaged with respect to rent sharing are Textiles and Metallurgic industries.

The rest of this document is structured as follows. Section 2 contains a literature review that mentions previous work on which this study was based; these studies are related to mark-up, rent sharing, and production function estimation. Section 3 discusses some theoretical considerations of the model and refers to the main contributions that were made to the econometric model prior to this empirical application. Section 4 describes the data and discusses its sources and values. The estimation strategy is discussed in section 5. Section 6 presents the main estimation results and comments on some of their implications. Section 7 concludes and summarizes the main findings.

\subsection{Previous Literature}

\subsubsection{The Empirical Study of Market Power}

The role of market power when estimating production functions in the manufacturing industry requires the analysis of various consequences of monopoly and monopsony in market outcomes.

The paper by Bresnahan (1989) studied industries with market power and reviewed previous work on the same topic. He analyzed previously published econometric studies of market power. He focused on work that referred to single markets and also groups of related markets. He also mentioned that the increase in the number of such studies and substantial advances in the methods for carrying them out constituted a dramatic shift in the focus of empirical work in the industrial organization field.

Baker and Bresnahan (2006) present a more recent survey of econometric studies on market power and their relevance for antitrust legal cases. The paper by Just and Chern 
(1980) is an example of an empirical work that ended up as legal evidence in an antitrust case in the United States.

One approach that empirical economists have developed to detect imperfect competition is measuring some of the key variables that are affected by market power. Because price and quantity are simultaneously determined for each specific market, the presence of an external shock that affects either of them may be used to evaluate what happens to the other as a response. Evaluating the changes of price and quantities when an external shock affecting demand or supply is introduced can prove the existence of market power in some cases ${ }^{17}$. However, this kind of model has the limitation of ignoring the possibility that inputs were not priced competitively.

\subsubsection{Market Power and Rent Distribution}

Jovanovic (1979) presented a long-run equilibrium theory of turnover and explained some of the market outcomes that had been observed by empirical investigators. A worker's productivity in a particular job becomes known as the worker's experience in a particular job increases. Turnover is generated by the existence of differences in a worker's productivity across different jobs. This positive profit is caused by the variation in the quality of the worker-employer match.

McDonald and Solow (1981) searched for a convincing theoretical explanation of the behavior of wage rates during fluctuations in output and employment. They found that previous literature confirms the prevailing view that real-wage movements are more or less independent of the business cycle. They proposed and studied two main questions. The first asked why nominal wages should be sticky. The second focused on real wages and asked why fluctuations in the demand for labor should so often lead to large changes in employment and small changes in the real wage.

Evidence that the share of rents captured by workers is related to the power of firms in the labor market was also found by the model of Christofides and Oswald (1992). They proposed that microeconomic forces that influence real wages were not fully understood. Their paper studied pay determination using data on approximately 600 labor contracts. They found that real wages were higher when past profitability in the employer's industry had been also high. They also found that wages are negatively related to the level of unemployment in the employer's region.

Abowd, Kramarz, and Margolis (1994) studied a longitudinal sample of over one million French workers and over 500,000 employing firms. Wages were decomposed into components related to observable characteristics, including worker and firm heterogeneity. They found that firms that pay higher wages, controlling for personeffects, are more productive and more profitable.

Another work that studied market power and wages is Nickell, Vainiomaki, and Wadhwani (1994). They analyzed time-series on nearly 800 British manufacturing firms to address various questions concerning the role of market power in wage determination.

${ }^{17}$ See, for example, the work by Just and Chern (1980) 
Among their results, they found that product market power has a positive impact on wages; this impact is enhanced in large firms but is not influenced by union status.

Blanchflower, Oswald, and Sanfey (1996) suggested a new test for rent-sharing in the U.S. labor market. Using an unbalanced panel from the manufacturing sector, they showed that a rise in a sector's profitability leads, after some years, to an increase in the long-run level of wages in that sector. The paper controlled for workers' characteristics, industry fixed effects, and unionism.

Buguin (1996) developed a production function model with efficient bargaining between oligopolistic firms and unions to distinguish between product market power and union power in capturing economic rents. The model was formalized using the generalized Nash bargaining solution, and was empirically tested on four Belgian manufacturing sectors. Buguin showed that product market power is significantly eroded by wage rents, but firms retain most of their power during negotiations.

Hildreth and Oswald (1997) discussed whether the competitive model provides an adequate representation of the labor market. Using longitudinal firm data, their article suggested that the labor market is not competitive. As predicted by rent-sharing models of the labor market, changes in profitability are related to long-run changes in wages. They concluded that these are not temporary wage effects and are not driven by the unionized workplaces in the data.

\subsubsection{Mark-up and Rent sharing in the Manufacturing Industry}

This paper focuses on the measurement of market power and the distribution of rents in the entire manufacturing industry and does not focus on a specific monopolistic firm. It follows a research line that originated after the work by Solow (1957), who proposed estimating total factor productivity growth as a measure of technical change. Based on this model, Hall (1988) developed an empirical measure of how much market outcomes deviate from perfect competition. His model documented the disparity between price and marginal cost, where marginal cost was estimated from annual variations in cost. He found that some U.S. industries have marginal cost well below price. He also argued that cyclical variations in labor input were small compared with variations in output. In booms, firms produce substantially more output and sell it for a price that exceeds the costs of the added inputs.

Following the bargaining model of Robert Hall, the work by Crepon, Desplatz, and Mairesse $(1999,2002,2007)$ developed the model on which this paper is based. They presented a model for estimating price cost margins, scale economies, and workers' bargaining power from a panel of firm-level data. They extended Hall's framework, based on the estimation of the Solow residual. They allowed for the possibility that wages were bargained off the labor demand curve, according to an efficient bargaining model. One interesting aspect of their methodology is that it does not require measuring the opportunity cost of labor for the estimation of the union bargaining power because they use the value of labor marginal productivity as a benchmark for salary. They found substantial imperfections in both the product and labor markets in French manufacturing and they showed that the lack of explicit consideration of labor market imperfection 
results in a significant underestimation of markups, due to the omission of the part of product rents captured by workers.

After the model by Crepon et al. (1999, 2002, 2007), many papers have followed with a variety of empirical applications. The work by Dobbelaere (2004) analyzed imperfections in both the product market and the labor market for firms in the Belgian manufacturing industry over the period 1988-1995. She further investigated the heterogeneity in price-cost mark-up and workers' bargaining power parameters among 18 sectors within the manufacturing industry. Using a sample of more than 7000 firms, she also confirmed that ignoring the imperfection in the labor market leads to an underestimation of the price-cost margin.

Benavente and Contreras (2006) followed the same model by Crepon et al. (2002). Using that model, they jointly estimated markup and rent sharing in the Chilean manufacturing industry for the period from 1993 to 1999. Using GMM, they found that workers take around $21 \%$ of the rent. The remaining rent stays in hands of the capital owners. They also showed that not considering imperfections on the input market causes biased estimations of the markup. They used industry-level deflated sales in their work.

Dobbelaere and Mairesse (2009) provided evidence of rent sharing from different dimensions in the same data. They use real current production deflated by the two-digit producer price index of the French industrial classification. Taking advantage of a rich matched employer-employee dataset for France over the period 1984-2001, they compared industry differences in rent-sharing parameters derived from three different approaches: the accounting approach, the standard labor economics approach, and the productivity approach. They classified industries into six categories according to their level of competition in the product market (perfect competition and imperfect competition) and the rent sharing between firms and workers (right to manage bargaining, efficient bargaining, and monopsony). A paper by Benavente, Dobbelaere, and Mairesse (2009) compared three applications of the model by Crepon et al. (2002), using Chilean, Belgian, and French manufacturing industry data.

All these papers that followed and added to the model developed by Crepon et al (1999) have failed to consider that the share of turnover captured by workers in not necessarily higher than average marginal productivity of labor. In fact the evidence presented in the present chapter will show that in some cases the payment to the labor force at the firm level can be on average lower that the level of the marginal productivity of labor.

Arai (2003) studied the relationship between wages and firms' ability to pay. He used Swedish data on workers and firms' balance-sheet reports for his empirical analysis. His results indicate that experienced and highly educated workers are sorted into profitable firms. Wages are positively correlated with profits and the capital-labor ratio. $\mathrm{He}$ controlled for worker quality, degree of effort, supervision, job characteristics, local unemployment, firms' employment history, and employer size.

Postel-Vinay and Robin (2002) developed and estimated an equilibrium search model to evaluate the distribution of wages and the relation between market imperfections and wages. They found that the share of the cross-sectional wage variance that is explained by 
person effects varies across skill groups. According to their estimations, the contribution of market imperfections to wage dispersion is typically around $50 \%$.

Estevao and Tevlin (2003) estimated the effects of rents per worker on wages and found parameters that were significantly positive. Using the U.S. input-output tables to isolate demand shocks, they identified the effects of the industry financial situation on wages. Their instrumental variables estimates revealed substantial rent sharing, much larger than it would be consistent with a purely competitive labor market.

There is a varied literature that relates the final product market outcomes with the input markets to evaluate the presence of market power. The paper by Neven, Roller, and Zhang (2006) allowed for endogenous costs in the estimation of price-cost margins. They estimated price-cost margins when firms bargain over wages. They proposed that pricecost margins are determined by wages and vice versa. They used data from eight European airlines from 1976-1994, and showed that the treatment of endogenous costs has important implications for the measurement of price-cost margins and the assessment of market power. They found that observed prices in Europe were virtually identical to monopoly prices, even though observed margins are consistent with Nash behavior.

\subsubsection{Managerial Efforts, Innovation, and Market Power}

There is also abundant literature that relates market power with firm performance. Schamalensee (1989) provided a vast literature review that was concerned with interindustry studies of the relationships among various measures of market structure, conduct, and performance. Schmidt (1997) showed in his paper that increasing the level of market competition has two opposing effects on managerial incentives. On one side, it increases risk, which has a positive effect on managerial effort. On the other side, it reduces profits, which may make it less attractive to exert high managerial effort. $\mathrm{He}$ finds that the total effect of market competition on managerial effort is ambiguous. Nickell (1996) proposed some arguments to claim that competition improves firm performance, not only in terms of innovation but especially in terms of productivity growth. Dixit and Stiglitz (1977) showed that monopoly power does not necessarily turn resources away from a sector because it may also allow paying fixed costs, enabling entry to the market. They investigated whether market equilibrium yields the social optimum level of welfare in terms of quantities and varieties of commodities.

Van Reenen (1996) examined the impact of technological innovation on wages using a panel of British firms. A head-count measure of major innovations between 1945 and 1983 was combined with share price and accounting information. Innovating firms were found to have higher average wages, but rival innovation tends to depress own wages. $\mathrm{He}$ claimed this result to be consistent with a model where wages are partly determined by a sharing in the rents generated by innovation. 


\subsection{Markup and Rent Sharing Econometric Model}

The model has its origin in the derivations of Solow (1957) in which total factor productivity could be measured based on the difference between output growth and input growth rates. This work was followed by Hall (1988), who measured market power of firms by documenting the differences between price and marginal cost. The paper by Klette (1994) allowed for imperfect competition in the product market; although it assumed that firms were price takers in the input market, it was able to obtain an estimate of the scale elasticity parameter and the markup of price over cost. The later model by Crepon, Desplatz, and Mairesse (1999) proposed an estimation of the production function equation assuming that markups, scale economies, and the workers' bargaining power were constant over time and therefore could be estimated jointly with the input and scale elasticities. This last addition to the model defines the labor share as a function of a parameter that measures the workers' bargaining power.

However, in the work by Klette and Griliches (1996), evidence has been found that using non-deflated sales as a measure of real output creates a downwards bias in the scale estimate. Crepon, Duguet, and Mairesse (1999) also proposed a methodology that considers output prices that are unobserved and endogenous. They designed a modification to the equation that takes this bias into account by adding a variable reflecting the output growth at the industry level. In this paper, we avoid the problems that arise from not observing the output price changes using a firm-level price growth estimate obtained from product-firm level information.

This paper follows the model by Crepon, Desplatz, and Mairesse (1999) and does not use the extensions to account for the unobserved output prices problem. We further relax the idea of a reservation wage represented by the marginal productivity of labor as a fixed benchmark to calculate workers share of profits. Instead, we use the value of labor marginal productivity as a reference point for estimating workers bargaining power without assuming that the reservation wage is not lower than the benchmark.

\subsubsection{Markup of Prices over Marginal Costs}

We start from a traditional production function of firm $i$ in period $t$, expressing the idea that output quantity is produced from capital, labor, and materials satisfying the equation:

$$
Q_{i t}=A_{i t} F\left(K_{i t}, L_{i t}, M_{i t}\right)
$$

where $A_{i t}$ is an index of technical change defined as "Total Factor Productivity." The logarithmic differentiation of the production function is defined as:

$$
\Delta q_{i t}=\Delta a_{i t}+\varepsilon_{i t}^{K} \Delta k_{i t}+\varepsilon_{i t}^{L} \Delta l_{i t}+\varepsilon_{i t}^{M} \Delta m_{i t}
$$


where we know that the variables expressed as log-derivatives can be replaced by the rates of growth and the resulting elasticities will be the averages over adjacent years.

We can first assume that there is imperfect competition in the product market and that firms are price takers in the input markets. We consider labor and materials as variable costs and capital as a quasi-fixed factor. Because firms maximize short-run benefits, labor and materials move to their short-run equilibrium in every period. Under these conditions we can define that marginal cost $C_{i t}^{Q}$ is equal to marginal revenue $R_{i t}^{Q}$. Another way to express this relationship is to define the firm markup $\mu_{i t}$ as the ratio of output price $P_{i t}$ to marginal cost:

$$
\mu_{i t}=\frac{P_{i t}}{R_{i t}^{Q}}=\frac{P_{i t}}{C_{i t}^{Q}}
$$

Short run profit maximization implies the two following first order conditions:

$$
\begin{aligned}
\varepsilon_{i t}^{L} & =\mu_{i t} S_{i t}^{L} \\
\varepsilon_{i t}^{M} & =\mu_{i t} S_{i t}^{M}
\end{aligned}
$$

Where $\varepsilon_{i t}^{L}$ and $\varepsilon_{i t}^{M}$ are the elasticities of output with respect to the variable inputs labor and materials, we know that $\mu_{i t}$ is defined as the markup of price over cost and $S_{i t}^{L}$ and $S_{i t}^{M}$ are the shares of labor and material costs in total firm revenue. These relationships mean that the elasticity of output with respect to a variable input is equal to the ratio of that specific input cost to output.

Without necessarily imposing constant returns to scale, we can propose that the elasticity of scale is $\lambda_{i t}=\varepsilon_{i t}^{L}+\varepsilon_{i t}^{M}+\varepsilon_{i t}^{K}$. We can also express the capital elasticity in terms of the scale parameter, the markup of price over cost, and the shares of each variable input over sales.

$$
\varepsilon_{i t}^{K}=\lambda_{i t}-\mu_{i t} S_{i t}^{L}-\mu_{i t} S_{i t}^{M}
$$

This equation provides a convenient way to estimate capital elasticity with respect to output without having to calculate the user cost of capital or the share of capital costs in revenues. Instead, for the estimation of capital elasticity, we can calculate an average scale elasticity $\lambda$ that in some cases may be assumed to yield constant returns $(\lambda=1)$.

When we find profits that are not equal to zero, we may be interested in determining if the source of profit is related to the existence of increasing returns to scale (the case of a natural monopoly) or the presence of imperfect competition. We can obtain the profit ratio if we divide the markup by the elasticity of scale such that: $P_{i t} /\left(C_{i t} / Q_{i t}\right)=$ $\mu_{i t} / \lambda_{i t}$

Inserting materials, labor, and capital elasticities into the logarithmic differentiation of the production function and rearranging the terms gives: 


$$
\Delta q_{i t}=\mu_{i t}\left\{S_{i t}^{L}\left(\Delta l_{i t}-\Delta k_{i t}\right)+S_{i t}^{M}\left(\Delta m_{i t}-\Delta k_{i t}\right)\right\}+\lambda_{i t} \Delta k_{i t}+\Delta a_{i t}
$$

We can rewrite the equation as the Solow residual ${ }^{18}$ decomposed into a markup of price over cost, a scale factor, and a measure of productivity growth.

$$
S R_{i t}=\left(\mu_{i t}-1\right)\left\{S_{i t}^{L}\left(\Delta l_{i t}-\Delta k_{i t}\right)+S_{i t}^{M}\left(\Delta m_{i t}-\Delta k_{i t}\right)\right\}+\left(\lambda_{i t}-1\right) \Delta k_{i t}+\Delta a_{i t}
$$

If we assume that the scale parameter and the markup coefficient are constant and represent average parameters, and if we introduce the notation $\Delta x_{i t}^{\mu}=S_{i t}^{L}\left(\Delta l_{i t}\right.$ $\left.\Delta k_{i t}\right)+S_{i t}^{M}\left(\Delta m_{i t}-\Delta k_{i t}\right)$, we can estimate the following model:

$$
S R_{i t}=\left(\mu_{i t}-1\right) \Delta x_{i t}^{\mu}+\left(\lambda_{i t}-1\right) \Delta k_{i t}+\Delta u_{i t}
$$

where $\Delta u_{i t}$ is a disturbance term that includes Total Factor Productivity growth and all other errors and shocks.

\subsubsection{Labor Force Market Power}

The model so far has assumed that perfect competition applies to the labor market. When labor is in equilibrium, wage equals marginal revenue of labor and therefore firms act as price takers in the labor market. We will now relax the assumption that labor is priced competitively and follow the efficient bargaining model of McDonald and Solow (1981). This model proposed that wage is bargained between firms and their employees. In order to obtain the desired parameter, a given level of wage is assumed as a benchmark for the market power factor estimation. The level of salary that equals the marginal revenue of labor was chosen as this benchmark. In the context of the efficient bargaining model, workers maximize $L_{i t}\left(w_{i t}-\bar{w}_{i t}\right)$, where $\bar{w}_{i t}$ is the marginal productivity wage. Firms maximize their short-run profit given by $R_{i t}-w_{i t} L_{i t}-j_{i t} M_{i t}$. The Nash solution to the bargaining model results in the weighted maximization of workers' collective objective and the firm short-run profit such that:

$$
\max _{w_{i t}, L_{i t}, M_{i t}}\left[L_{i t}\left(w_{i t}-\bar{w}_{i t}\right)\right]^{\theta_{i t}}\left[R_{i t}-w_{i t} L_{i t}-j_{i t} M_{i t}\right]^{1-\theta_{i t}}
$$

The first order condition of this maximization gives the following expression for wage:

$$
w_{i t}=R_{i t}^{L}+\theta_{i t} \frac{R_{i t}-R_{i t}^{L} L_{i t}-j_{i t} M_{i t}}{L}=\theta_{i t} \frac{R_{i t}-j_{i t} M_{i t}}{L}+\left(1-\theta_{i t}\right) R_{i t}^{L}
$$

\footnotetext{
${ }^{18}$ The conventional Solow residual or Total Factor Productivity is defined by: $S R_{i t}=\Delta q_{i t}-S_{i t}^{L} \Delta l_{i t}-S_{i t}^{M} \Delta m_{i t}-\left(1-S_{i t}^{L}-S_{i t}^{M}\right) \Delta k_{i t}$
} 
where $w_{i t}$ is workers' wage, $R_{i t}$ is total firm revenue, $R_{i t}^{L}$ is marginal revenue of labor, $j_{i t}$ is the cost of materials, and $\mathrm{L}$ and $\mathrm{M}$ represent the amounts of labor and materials used by firms. This equation shows that workers are paid the value of their marginal productivity plus a share of firm's profits after inputs have been paid. In the original model, the marginal productivity wage is a reservation wage, but we can relax that assumption if desired and allow a parameter range of $-1<\theta_{i t}<1$.

If $\theta_{i t}=0$, workers are being paid on average the value of their marginal productivities. If $\theta_{i t}>0$, workers receive a share of firm rents on top of the payment of their marginal productivities. If $\theta_{i t}$ is negative, it means that the reservation wage is lower than the value of marginal revenue of labor. In this last case, the parameter gives a minimum measure of the distance between marginal productivity wage and the reservation wage, expressed in terms of the value of total markup of price over marginal cost. The actual unobserved reservation wage could be even lower than that, but we are not able to measure it within this model. We can rewrite the previous equation in terms of the markup of price over cost $\mu_{i t}$, labor and materials shares $S_{i t}^{L}$ and $S_{i t}^{M}$ and labor elasticity $\varepsilon_{i t}^{L}$ :

$$
S_{i t}^{L}=\theta_{i t}\left(1-S_{i t}^{M}\right)+\left(1-\theta_{i t}\right) \frac{1}{\mu_{i t}} \varepsilon_{i t}^{L}
$$

The estimated markup in this setting now includes the part of the rent that is captured by the workforce. Inserting the previous equation into the Solow residual with the notation $\Delta x_{i t}^{\theta}=\left(S_{i t}^{L}+S_{i t}^{M}-1\right)\left(\Delta l_{i t}-\Delta k_{i t}\right)$ we can write:

$$
S R_{i t}=\left(\mu_{i t}-1\right) \Delta x_{i t}^{\mu}+\left(\lambda_{i t}-1\right) \Delta k_{i t}+\mu_{i t} \frac{\theta}{1-\theta} \Delta \mathrm{x}_{i t}^{\theta}+\Delta u_{i t}
$$

It can be now defined that the Solow residual is decomposed into a markup of price over $\operatorname{cost}\left(\mu_{i t}-1\right)$, a scale factor $\left(\lambda_{i t}-1\right)$, a rent sharing factor $\frac{\theta}{1-\theta}=\lambda$ that represents the proportion of the rent that is being captured by workers, and a measure of productivity growth that contains all other shocks, $\Delta u_{i t}$.

Finally, the paper of Dobbelaere and Mairesse (2010) showed that a joint market imperfection parameter $(\psi)$ could be defined by taking into account both labor market and materials market imperfections, given that we have access to data on at least two variable input factors.

$$
\psi=\frac{\left(\varepsilon_{M}^{Q}\right)_{i t}}{\left(\alpha_{M}\right)_{i t}}-\frac{\left(\varepsilon_{L}^{Q}\right)_{i t}}{\left(\alpha_{L}\right)_{i t}}=\mu_{i t} \frac{\theta_{i t}}{1-\theta_{i t}}\left[\frac{1-\left(\alpha_{L}\right)_{i t}-\left(\alpha_{M}\right)_{i t}}{\left(\alpha_{L}\right)_{i t}}\right]
$$

This expression shows that the joint market imperfection parameter $(\psi)$ is a measure of the firm's market power in the materials market relative to its market power in the labor market. If $\psi<0$, then firms exercise more power in the labor market than in the 
materials market. If $\psi=0$, both input markets are equally competitive. If $\psi>0$, then workers bargain efficiently and get a share of rents higher than the share material providers get relative to their own marginal productivities.

\subsection{Chilean Manufacturing Industry Data}

The data used for this research has been collected by Instituto Nacional de Estadisticas (INE). This paper uses data from the main Encuesta Nacional Industrial Annual (ENIA) survey (Form 1) and the product-firm level annex from ENIA (Form 3). Firms are first described in terms of the level of output, which can be deflated by each individual firm's price growth. When the product-firm level ENIA annex is merged with firm-level ENIA information, the result is a very rich industrial dataset that provides high quality information on price growth within firms' products.

The database used for this paper has been cleaned to make sure no significant outliers are found within the most important variables of the model. In terms of the input shares in output, no individual input share (capital, materials, and labor) was allowed to be equal to or greater than 1 . The share of capital in output was restricted to a minimum of 0.05 and a maximum of 0.6. The growth of capital per employee expressed as the first difference of the $\log$ values was restricted to a maximum value of $0.69=\ln (2)$. The same limit was applied to the rate of growth of materials/output, output per employee, and number of employees.

Table 4.1 Number of Observations by Industrial Sector

\begin{tabular}{|c|c|c|c|c|}
\hline $\begin{array}{l}\text { Industry } \\
\text { Number }\end{array}$ & $\begin{array}{l}\text { Number } \\
\text { of firms }\end{array}$ & $\begin{array}{l}\text { Number of } \\
\text { observations }\end{array}$ & $\begin{array}{l}\text { ISIC REV2 } \\
\text { Code }\end{array}$ & Industry Sector Definition \\
\hline 1 & 702 & 4496 & 31 & $\begin{array}{l}\text { Manufacture of food, beverages } \\
\text { and tobacco }\end{array}$ \\
\hline 2 & 362 & 2277 & 32 & Textile, wearing apparel and leather \\
\hline 3 & 214 & 1303 & 33 & $\begin{array}{l}\text { Manufacture of wood and wood } \\
\text { products, including furniture }\end{array}$ \\
\hline 4 & 142 & 674 & 34 & $\begin{array}{c}\text { Manufacture of paper and paper products, } \\
\text { printing and publishing }\end{array}$ \\
\hline 5 & 243 & 1565 & 35 & $\begin{array}{l}\text { Manufacture of chemicals and chemical, } \\
\text { petroleum, coal, rubber and plastic products }\end{array}$ \\
\hline 6 & 113 & 661 & 36 and 39 & $\begin{array}{l}\text { Manufacture of non-metallic mineral } \\
\text { products and other manufacturing industries }\end{array}$ \\
\hline 7 & 406 & 2384 & 37 and 38 & $\begin{array}{l}\text { Basic metal and manufacture of fabricated metal } \\
\text { products, machinery and equipment }\end{array}$ \\
\hline
\end{tabular}

Table 4.1 contains the basic information on the number of firms and the number of observations that represent those firms on different industrial sectors. The sample consists of 2,182 firms over an 8-year period from 1996 to 2003. The unbalanced panel of 13,360 observations contains only firms for which data is available on 3 or more 
consecutive years. Productive units for which data was available with gaps in time have been dropped from the sample.

The largest industry in terms of number of firms is the manufacture of Food, Beverages, and Tobacco, followed by the Metallic industries and Textiles. Table 4.2 contains the description of the panel. Almost $80 \%$ of the sample is made of firms for which information was provided in 6 or more consecutive periods.

Table 4.2 Unbalanced Panel Summary
\begin{tabular}{|c|c|c|}
\hline $\begin{array}{c}\text { Number of } \\
\text { surveys }\end{array}$ & $\begin{array}{c}\text { Number } \\
\text { of firms }\end{array}$ & $\begin{array}{c}\text { Number of } \\
\text { observations }\end{array}$ \\
\hline 3 & 267 & 801 \\
4 & 286 & 1144 \\
5 & 216 & 1080 \\
6 & 272 & 1632 \\
7 & 425 & 2975 \\
8 & 716 & 5728 \\
Total & 2182 & 13360 \\
\hline
\end{tabular}

Table 4.3 All Manufacturing Industries Descriptive Statistics

\begin{tabular}{|c|c|c|c|c|c|c|}
\hline Variables & Mean & Std. Dev. & $\mathrm{p} 25$ & $\mathrm{p} 50$ & $\mathrm{p} 75$ & $\mathrm{~N}$ \\
\hline Annual output firm-level deflated q(f) & $2,280,097$ & $9,332,376$ & 182,207 & 386,628 & $1,232,649$ & 13,360 \\
\hline Annual output industry 2 digit deflated q(i2) & $2,215,851$ & $8,907,208$ & 180,970 & 380,733 & $1,183,781$ & 13,360 \\
\hline Annual output industry 3digit deflated q(i3) & $2,216,640$ & $8,851,341$ & 181,882 & 381,192 & $1,192,537$ & 13,360 \\
\hline Annual output industry 4digit deflated q(i4) & $2,233,351$ & $9,110,452$ & 181,436 & 381,321 & $1,201,454$ & 13,360 \\
\hline Number of employees & 64 & 120 & 17 & 27 & 57 & 13,360 \\
\hline Annual intermediates expenditures deflated & $1,165,534$ & $4,397,433$ & 83,578 & 188,406 & 610,611 & 13,360 \\
\hline Capital deflated & $1,187,575$ & $5,350,734$ & 42,135 & 128,815 & 450,389 & 13,360 \\
\hline Labor share in nominal output $\alpha_{-}\{\mathrm{N}\}$ & 0.175 & 0.091 & 0.109 & 0.163 & 0.223 & 13,360 \\
\hline Materials share in nominal output $\alpha_{-}\{\mathrm{M}\}$ & 0.494 & 0.167 & 0.372 & 0.485 & 0.609 & 13,360 \\
\hline Capital share in nominal output $1-\alpha_{-}\{N\}-\alpha_{-}\{M\}$ & 0.331 & 0.152 & 0.229 & 0.334 & 0.436 & 13,360 \\
\hline Output growth rate firm-level deflated $\Delta \mathrm{q}(\mathrm{f})$ & -0.004 & 0.223 & -0.125 & -0.002 & 0.124 & 11,178 \\
\hline Output growth rate industry 2 digit deflated $\Delta \mathrm{q}(\mathrm{i} 2)$ & -0.007 & 0.207 & -0.116 & -0.005 & 0.107 & 11,178 \\
\hline Output growth rate industry 3 digit deflated $\Delta \mathrm{q}(\mathrm{i} 3)$ & -0.007 & 0.207 & -0.116 & -0.004 & 0.108 & 11,178 \\
\hline Output growth rate industry 4 digit deflated $\Delta \mathrm{q}$ (i4) & -0.007 & 0.208 & -0.118 & -0.004 & 0.110 & 11,178 \\
\hline Labor growth rate $\Delta \mathrm{n}$ & -0.018 & 0.163 & -0.095 & 0.000 & 0.061 & 11,178 \\
\hline Materials growth rate $\Delta \mathrm{m}$ & -0.020 & 0.289 & -0.188 & -0.016 & 0.150 & 11,178 \\
\hline Capital growth rate $\Delta \mathrm{k}$ & 0.045 & 0.106 & 0.000 & 0.005 & 0.054 & 11,178 \\
\hline$S R=\Delta q-\alpha_{n} \Delta n-\alpha_{m} \Delta m-\left(1-\alpha_{n}-\alpha_{m}\right) \Delta k$ & -0.006 & 0.179 & -0.113 & -0.006 & 0.099 & 11,178 \\
\hline SR without 1998 and 1999 & 0.009 & 0.174 & -0.094 & 0.010 & 0.117 & 7,769 \\
\hline
\end{tabular}

Note: Descriptive statistics from Chilean manufacturing industry data (ENIA). Includes ISIC Rev.2 sectors 31 to 39. Unbalanced panel with 2,182 firms from 1996 to 2003.

Table 4.3 contains the descriptive statistics of the entire sample. Annual output is provided with four different deflation options for comparison. In the first place, output is deflated at the firm level with the price growth that was calculated as the weighted 
average price growth of each product within firms. Then the ISIC REV2 code is used to take the average price growth of a specific industry at three different aggregation levels. The average manufacturing firm in Chile has 64 employees, while the value of intermediates and capital are highly dispersed. The share of labor and intermediates in nominal output are 0.17 and 0.49 respectively, on average. The resulting capital share on nominal output is 0.33 .

On average, operational profits before taxes represented a $64 \%$ of the value of capital. An interesting feature of this data is that deflated output growth had on average a very low negative value independently of the deflation used. This effect is due to a financial crisis that hit the Chilean manufacturing sector in 1998 and 1999, resulting in average manufacturing output changes of $-2 \%$ and $-8 \%$ respectively. Labor and materials also present negative growth, while the average annual growth of capital is less than $5 \%$. The resulting Solow residuals estimated from this dataset are negative. The estimated Solow residual takes a value of 1\% when we exclude crisis years 1998 and 1999 from the sample.

Tables 4.4 to 4.10 summarize the descriptive statistics of the sample that has been divided into 7 economic sectors. Table 4.4 summarizes the Food, Beverages, and Tobacco industries than contain one-third of the observations. In terms of sales size, this industry has firms that are slightly above the manufacturing average. In terms of number of employees, however, these firms are smaller than the manufacturing average. When deflated at the firm level, this industry has a positive though very low output rate of growth. After counting the change on inputs, the resulting Solow residual is a negative and very small number.

Table 4.4 Manufacture of Food, Beverages and Tobacco Industries

\begin{tabular}{|c|c|c|c|c|c|c|}
\hline Variables & Mean & Std. Dev. & $\mathrm{p} 25$ & $\mathrm{p} 50$ & p75 & $\mathrm{N}$ \\
\hline Annual output firm-level deflated q(f) & $2,596,299$ & $11,600,000$ & 160,011 & 291,622 & $1,040,039$ & 4,496 \\
\hline Annual output industry 2digit deflated q(i2) & $2,516,999$ & $10,900,000$ & 158,978 & 282,267 & $1,011,915$ & 4,496 \\
\hline Annual output industry 3digit deflated q(i3) & $2,507,173$ & $10,800,000$ & 159,082 & 282,095 & $1,013,110$ & 4,496 \\
\hline Annual output industry 4digit deflated q(i4) & $2,539,740$ & $11,200,000$ & 158,964 & 282,093 & $1,045,619$ & 4,496 \\
\hline Number of employees & 61 & 125 & 16 & 24 & 44 & 4,496 \\
\hline Annual intermediates expenditures deflated & $1,441,546$ & $5,810,951$ & 77,478 & 140,743 & 595,860 & 4,496 \\
\hline Capital deflated & $1,063,503$ & $4,601,241$ & 26,055 & 66,938 & 305,725 & 4,496 \\
\hline Labor share in nominal output $\alpha \_\{N\}$ & 0.148 & 0.069 & 0.097 & 0.146 & 0.191 & 4,496 \\
\hline Materials share in nominal output $\alpha \_\{\mathrm{M}\}$ & 0.518 & 0.157 & 0.403 & 0.504 & 0.620 & 4,496 \\
\hline Capital share in nominal output $1-\alpha_{-}\{N\}-\alpha_{-}\{M\}$ & 0.335 & 0.147 & 0.233 & 0.333 & 0.437 & 4,496 \\
\hline Output growth rate firm-level deflated $\Delta \mathrm{q}(\mathrm{f})$ & 0.002 & 0.199 & -0.101 & -0.001 & 0.107 & 3,794 \\
\hline Output growth rate industry 2 digit deflated $\Delta \mathrm{q}(\mathrm{i} 2)$ & -0.003 & 0.182 & -0.091 & -0.008 & 0.085 & 3,794 \\
\hline Output growth rate industry 3 digit deflated $\Delta \mathrm{q}(\mathrm{i} 3)$ & -0.003 & 0.182 & -0.090 & -0.008 & 0.085 & 3,794 \\
\hline Output growth rate industry 4 digit deflated $\Delta \mathrm{q}(\mathrm{i} 4)$ & -0.003 & 0.183 & -0.091 & -0.006 & 0.088 & 3,794 \\
\hline Labor growth rate $\Delta \mathrm{n}$ & -0.008 & 0.162 & -0.080 & 0.000 & 0.062 & 3,794 \\
\hline Materials growth rate $\Delta \mathrm{m}$ & -0.015 & 0.248 & -0.155 & -0.013 & 0.121 & 3,794 \\
\hline Capital growth rate $\Delta \mathrm{k}$ & 0.050 & 0.112 & 0.000 & 0.005 & 0.062 & 3,794 \\
\hline$S R=\Delta q-\alpha_{n} \Delta n-\alpha_{m} \Delta m-\left(1-\alpha_{n}-\alpha_{m}\right) \Delta k$ & -0.007 & 0.169 & -0.107 & -0.007 & 0.088 & 3,794 \\
\hline
\end{tabular}

Note: Descriptive statistics from Chilean manufacturing industry data (ENIA). Includes ISIC Rev.2 sector 31. Unbalanced panel with 702 firms from 1996 to 2003. 
Table 4.5 refers to the Textile, Wearing Apparel and Leather industries and contains $17 \%$ of the observations in the sample. These firms are $50 \%$ smaller than the industry average, though their average number of employees is almost on the same level. They use much less intermediates and capital, which is consistent with a labor intensive industry. Output and input growth are also small and negative, which is also consistent with an almost zero negative Solow residual.

Table 4.5 Textile, Wearing Apparel and Leather Industries Descriptive Statistics

\begin{tabular}{|c|cccccc|}
\hline Variables & Mean & Std. Dev. & $\mathrm{p} 25$ & $\mathrm{p} 50$ & $\mathrm{p} 75$ & $\mathrm{~N}$ \\
\hline Annual output firm-level deflated $\mathrm{q}(\mathrm{f})$ & $1,027,991$ & $1,854,562$ & 167,579 & 365,436 & $1,014,490$ & 2,277 \\
Annual output industry 2digit deflated $\mathrm{q}(\mathrm{i} 2)$ & $1,006,427$ & $1,820,954$ & 159,757 & 365,129 & 979,435 & 2,277 \\
Annual output industry 3digit deflated $\mathrm{q}(\mathrm{i} 3)$ & $1,011,281$ & $1,834,778$ & 159,845 & 363,900 & 980,904 & 2,277 \\
Annual output industry 4digit deflated $\mathrm{q}(\mathrm{i} 4)$ & $1,014,490$ & $1,841,536$ & 161,321 & 364,686 & 973,145 & 2,277 \\
Number of employees & 58 & 96 & 16 & 28 & 59 & 2,277 \\
Annual intermediates expenditures deflated & 523,593 & 998,002 & 80,142 & 189,832 & 477,577 & 2,277 \\
Capital deflated & 540,055 & $1,559,972$ & 41,833 & 121,661 & 377,538 & 2,277 \\
Labor share in nominal output $\alpha \_\{\mathrm{N}\}$ & 0.183 & 0.097 & 0.111 & 0.170 & 0.232 & 2,277 \\
Materials share in nominal output $\alpha \_\{\mathrm{M}\}$ & 0.502 & 0.179 & 0.365 & 0.491 & 0.630 & 2,277 \\
Capital share in nominal output $1-\alpha \_\{\mathrm{N}\}-\alpha \_\{\mathrm{M}\}$ & 0.315 & 0.165 & 0.207 & 0.322 & 0.426 & 2,277 \\
Output growth rate firm-level deflated $\Delta \mathrm{q}(\mathrm{f})$ & -0.038 & 0.215 & -0.160 & -0.035 & 0.090 & 1,915 \\
Output growth rate industry 2 digit deflated $\Delta \mathrm{q}(\mathrm{i} 2)$ & -0.040 & 0.198 & -0.155 & -0.039 & 0.082 & 1,915 \\
Output growth rate industry 3 digit deflated $\Delta \mathrm{q}(\mathrm{i} 3)$ & -0.040 & 0.199 & -0.154 & -0.039 & 0.085 & 1,915 \\
Output growth rate industry 4digit deflated $\Delta \mathrm{q}(\mathrm{i} 4)$ & -0.040 & 0.200 & -0.156 & -0.037 & 0.085 & 1,915 \\
Labor growth rate $\Delta \mathrm{n}$ & -0.037 & 0.160 & -0.113 & -0.009 & 0.043 & 1,915 \\
Materials growth rate $\Delta \mathrm{m}$ & -0.057 & 0.295 & -0.235 & -0.056 & 0.133 & 1,915 \\
Capital growth rate $\Delta \mathrm{k}$ & 0.032 & 0.092 & 0.000 & 0.001 & 0.031 & 1,915 \\
$\alpha_{n} \Delta n-\alpha m \Delta m-\left(1-\alpha_{n}-\alpha_{m}\right) \Delta k$ & -0.012 & 0.185 & -0.126 & -0.011 & 0.105 & 1,915 \\
\hline
\end{tabular}

Note: Descriptive statistics from Chilean manufacturing industry data (ENIA). Includes ISIC Rev.2 sector 32. Unbalanced panel with 362 firms from 1996 to 2003.

Table 4.6 refers to the industry of Wood, Wood Products, and Furniture, containing nearly $10 \%$ of the firms in the sample. In terms of output and inputs, this industry looks very close to the manufacturing average. It has a higher number of employees but the labor share on output is as low as the whole manufacturing average, which tells us that the salaries might be on average lower on this industry. Output growth is very small but positive. Labor and materials growth are negative and small, while capital growth is near $5 \%$, resulting in an average Solow residual that is close to zero.

Table 4.7 refers to the Paper, Printing, and Publishing industries, with nearly 5\% of the observations contained in the full manufacturing sample. These firms have more than double the average sales level of the whole Chilean manufacturing sector. They have average capital around 400\% higher than the full sample. With 99 employees on average, that receive $19 \%$ of the turnover, the share that stockholders get before taxes and other non-operational costs is $37 \%$ of the sales, equivalent to $39 \%$ of the capital stock. 
Table 4.6 Manufacture of Wood and Wood Products and Furniture Industries Descriptive Statistics

\begin{tabular}{|c|c|c|c|c|c|c|}
\hline Variables & Mean & Std. Dev. & $\mathrm{p} 25$ & p50 & $\mathrm{p} 75$ & $\mathrm{~N}$ \\
\hline Annual output firm-level deflated $q(\mathrm{f})$ & $2,235,349$ & $5,876,237$ & 185,008 & 464,049 & $1,207,481$ & 1,303 \\
\hline Annual output industry 2 digit deflated q(i2) & $2,150,444$ & $5,545,596$ & 181,459 & 437,035 & $1,182,625$ & 1,303 \\
\hline Annual output industry 3 digit deflated q(i3) & $2,155,472$ & $5,557,415$ & 182,852 & 436,379 & $1,194,247$ & 1,303 \\
\hline Annual output industry 4digit deflated q(i4) & $2,157,212$ & $5,578,309$ & 182,965 & 439,555 & $1,199,375$ & 1,303 \\
\hline Number of employees & 78 & 148 & 19 & 31 & 72 & 1,303 \\
\hline Annual intermediates expenditures deflated & $1,198,979$ & $2,953,129$ & 97,365 & 246,148 & 641,214 & 1,303 \\
\hline Capital deflated & $1,178,922$ & $3,822,631$ & 57,310 & 146,969 & 568,151 & 1,303 \\
\hline Labor share in nominal output $\alpha \_\{N\}$ & 0.173 & 0.103 & 0.100 & 0.150 & 0.222 & 1,303 \\
\hline Materials share in nominal output $\alpha_{-}\{\mathrm{M}\}$ & 0.533 & 0.159 & 0.424 & 0.530 & 0.634 & 1,303 \\
\hline Capital share in nominal output $1-\alpha_{-}\{N\}-\alpha_{-}\{\mathrm{M}\}$ & 0.293 & 0.149 & 0.196 & 0.301 & 0.396 & 1,303 \\
\hline Output growth rate firm-level deflated $\Delta \mathrm{q}(\mathrm{f})$ & 0.009 & 0.263 & -0.154 & 0.005 & 0.175 & 1,089 \\
\hline Output growth rate industry 2 digit deflated $\Delta \mathrm{q}(\mathrm{i} 2)$ & 0.007 & 0.252 & -0.142 & 0.016 & 0.164 & 1,089 \\
\hline Output growth rate industry 3 digit deflated $\Delta \mathrm{q}(\mathrm{i} 3)$ & 0.007 & 0.251 & -0.141 & 0.013 & 0.162 & 1,089 \\
\hline Output growth rate industry 4 digit deflated $\Delta \mathrm{q}(\mathrm{i} 4)$ & 0.007 & 0.251 & -0.143 & 0.014 & 0.162 & 1,089 \\
\hline Labor growth rate $\Delta \mathrm{n}$ & -0.011 & 0.177 & -0.095 & 0.000 & 0.071 & 1,089 \\
\hline Materials growth rate $\Delta \mathrm{m}$ & -0.010 & 0.322 & -0.212 & -0.015 & 0.194 & 1,089 \\
\hline Capital growth rate $\Delta \mathrm{k}$ & 0.052 & 0.122 & 0.000 & 0.008 & 0.063 & 1,089 \\
\hline$S R=\Delta q-\alpha_{n} \Delta n-\alpha_{m} \Delta m-\left(1-\alpha_{n}-\alpha_{m}\right) \Delta k$ & 0.001 & 0.193 & -0.114 & 0.004 & 0.124 & 1,089 \\
\hline
\end{tabular}

Note: Descriptive statistics from Chilean manufacturing industry data (ENIA). Includes ISIC Rev.2 sector 33.

Unbalanced panel with 214 firms from 1996 to 2003.

Table 4.7 Manufacture of Paper and Paper Products, Printing and Publishing Industries

\begin{tabular}{|c|c|c|c|c|c|c|}
\hline Variables & Mean & Std. Dev. & p25 & p50 & $\mathrm{p} 75$ & $\mathrm{~N}$ \\
\hline Annual output firm-level deflated $q(\mathrm{f})$ & $4,915,490$ & $13,500,000$ & 205,159 & 505,433 & $1,863,086$ & 674 \\
\hline Annual output industry 2digit deflated q(i2) & $4,897,805$ & $13,500,000$ & 213,600 & 523,481 & $1,648,339$ & 674 \\
\hline Annual output industry 3 digit deflated q(i3) & $4,906,301$ & $13,500,000$ & 207,038 & 511,711 & $1,648,339$ & 674 \\
\hline Annual output industry 4digit deflated q(i4) & $4,805,165$ & $13,200,000$ & 207,038 & 522,799 & $1,703,197$ & 674 \\
\hline Number of employees & 99 & 222 & 18 & 28 & 75 & 674 \\
\hline Annual intermediates expenditures deflated & $2,051,693$ & $5,136,688$ & 87,601 & 246,432 & 672,970 & 674 \\
\hline Capital deflated & $4,656,178$ & $16,200,000$ & 74,994 & 198,375 & 918,347 & 674 \\
\hline Labor share in nominal output $\alpha \_\{N\}$ & 0.189 & 0.088 & 0.122 & 0.189 & 0.247 & 674 \\
\hline Materials share in nominal output $\alpha_{-}\{\mathrm{M}\}$ & 0.443 & 0.171 & 0.317 & 0.419 & 0.573 & 674 \\
\hline Capital share in nominal output $1-\alpha_{-}\{N\}-\alpha_{-}\{M\}$ & 0.368 & 0.142 & 0.270 & 0.375 & 0.473 & 674 \\
\hline Output growth rate firm-level deflated $\Delta \mathrm{q}(\mathrm{f})$ & 0.007 & 0.188 & -0.097 & 0.008 & 0.109 & 532 \\
\hline Output growth rate industry 2 digit deflated $\Delta \mathrm{q}(\mathrm{i} 2)$ & 0.009 & 0.172 & -0.081 & 0.018 & 0.099 & 532 \\
\hline Output growth rate industry 3 digit deflated $\Delta \mathrm{q}(\mathrm{i} 3)$ & 0.009 & 0.173 & -0.084 & 0.018 & 0.101 & 532 \\
\hline Output growth rate industry 4digit deflated $\Delta \mathrm{q}(\mathrm{i} 4)$ & 0.010 & 0.175 & -0.092 & 0.014 & 0.104 & 532 \\
\hline Labor growth rate $\Delta \mathrm{n}$ & -0.010 & 0.143 & -0.082 & 0.000 & 0.061 & 532 \\
\hline Materials growth rate $\Delta \mathrm{m}$ & -0.006 & 0.257 & -0.140 & -0.016 & 0.139 & 532 \\
\hline Capital growth rate $\Delta \mathrm{k}$ & 0.040 & 0.105 & 0.000 & 0.005 & 0.042 & 532 \\
\hline$S R=\Delta q-\alpha_{n} \Delta n-\alpha_{m} \Delta m-\left(1-\alpha_{n}-\alpha_{m}\right) \Delta k$ & -0.003 & 0.158 & -0.100 & -0.001 & 0.086 & 532 \\
\hline
\end{tabular}

Note: Descriptive statistics from Chilean manufacturing industry data (ENIA). Includes ISIC Rev.2 sector 34. Unbalanced panel with 142 firms from 1996 to 2003. 
Table 4.8 summarizes the industry of Chemicals, Chemical Petroleum, Coal, Rubber, and Plastic Products that represent nearly an $11 \%$ of the whole Chilean manufacturing industry sample. This industry is characterized by sales almost $50 \%$ higher than the manufacturing average. Capital about 20\% higher than the manufacturing average. Capital share on output is 0.35 , which means that every year a typical firm of this sector makes a profit of $80 \%$ of the value of its capital before taking taxes and non-operational costs into account.

Table 4.8 Chemicals and Chemical Petroleum, Coal, Rubber and Plastic Products Industries

\begin{tabular}{|c|c|c|c|c|c|c|}
\hline Variables & Mean & Std. Dev. & p25 & $\mathrm{p} 50$ & $\mathrm{p} 75$ & $\mathrm{~N}$ \\
\hline Annual output firm-level deflated q(f) & $3,350,088$ & $13,900,000$ & 326,348 & 790,836 & $2,400,388$ & 1,565 \\
\hline Annual output industry 2 digit deflated q(i2) & $3,247,834$ & $13,200,000$ & 313,119 & 755,368 & $2,311,471$ & 1,565 \\
\hline Annual output industry 3 digit deflated q(i3) & $3,261,238$ & $13,200,000$ & 317,209 & 762,393 & $2,340,436$ & 1,565 \\
\hline Annual output industry 4digit deflated q(i4) & $3,299,322$ & $13,600,000$ & 317,209 & 768,735 & $2,364,748$ & 1,565 \\
\hline Number of employees & 73 & 118 & 20 & 37 & 78 & 1,565 \\
\hline Annual intermediates expenditures deflated & $1,592,936$ & $5,650,202$ & 156,511 & 369,209 & $1,211,746$ & 1,565 \\
\hline Capital deflated & $1,454,183$ & $4,259,939$ & 106,410 & 309,068 & $1,035,342$ & 1,565 \\
\hline Labor share in nominal output $\alpha \_\{N\}$ & 0.163 & 0.079 & 0.105 & 0.152 & 0.207 & 1,565 \\
\hline Materials share in nominal output $\alpha_{-}\{\mathrm{M}\}$ & 0.492 & 0.160 & 0.371 & 0.486 & 0.610 & 1,565 \\
\hline Capital share in nominal output $1-\alpha_{-}\{N\}-\alpha_{-}\{M\}$ & 0.346 & 0.141 & 0.249 & 0.344 & 0.445 & 1,565 \\
\hline Output growth rate firm-level deflated $\Delta \mathrm{q}(\mathrm{f})$ & 0.034 & 0.204 & -0.082 & 0.043 & 0.159 & 1,322 \\
\hline Output growth rate industry 2 digit deflated $\Delta \mathrm{q}(\mathrm{i} 2)$ & 0.026 & 0.184 & -0.081 & 0.037 & 0.132 & 1,322 \\
\hline Output growth rate industry 3 digit deflated $\Delta \mathrm{q}(\mathrm{i} 3)$ & 0.029 & 0.184 & -0.077 & 0.041 & 0.136 & 1,322 \\
\hline Output growth rate industry 4 digit deflated $\Delta \mathrm{q}(\mathrm{i} 4)$ & 0.029 & 0.186 & -0.074 & 0.033 & 0.135 & 1,322 \\
\hline Labor growth rate $\Delta \mathrm{n}$ & 0.002 & 0.153 & -0.069 & 0.000 & 0.073 & 1,322 \\
\hline Materials growth rate $\Delta \mathrm{m}$ & 0.019 & 0.283 & -0.140 & 0.022 & 0.181 & 1,322 \\
\hline Capital growth rate $\Delta \mathrm{k}$ & 0.056 & 0.107 & 0.000 & 0.019 & 0.073 & 1,322 \\
\hline$S R=\Delta q-\alpha_{n} \Delta n-\alpha_{m} \Delta m-\left(1-\alpha_{n}-\alpha_{m}\right) \Delta k$ & 0.003 & 0.171 & -0.095 & 0.001 & 0.106 & 1,322 \\
\hline
\end{tabular}

Note: Descriptive statistics from Chilean manufacturing industry data (ENIA). Includes ISIC Rev.2 sector 35. Unbalanced panel with 243 firms from 1996 to 2003.

Table 4.9 describes Non-Metallic Mineral Products, and other Manufacturing Industries, with around 5\% of the whole industrial sector. Sales on this miscellaneous group of firms are nearly 30\% higher than the value of capital. These firms are on average among the smallest in the industry in terms of number of employees and sales. The small but negative growth of output is driven, as in the rest of the sample, by the fact that there were negative output growth rates in the manufacturing industry of $2 \%$ and $8 \%$ respectively in the years 1998 and 1999, counteracting the nearly $2 \%$ average output growth that was observed during the other 5 years in the period 1997-2003.

The last sector grouped in Table 4.10 describes the behavior of Basic Metal, Fabricated Metal Products, Machinery, and Equipment Industries. This industry contains 18\% of the Chilean manufacturing observations. Sales are lower than the average manufacturing, though capital is also about a half of the value of sales. The capital share on sales may be 
explained by saying that operational rents are $61 \%$ of the capital value before taxes and non-operational costs.

Table 4.9 Non-metallic Mineral Products and Other Manufacturing Industries

\begin{tabular}{|c|c|c|c|c|c|c|}
\hline Variables & Mean & Std. Dev. & $\mathrm{p} 25$ & $\mathrm{p} 50$ & p75 & $\mathrm{N}$ \\
\hline Annual output firm-level deflated $\mathrm{q}(\mathrm{f})$ & $1,187,795$ & $3,302,603$ & 159,521 & 343,381 & 891,492 & 661 \\
\hline Annual output industry 2 digit deflated q(i2) & $1,132,887$ & $2,953,491$ & 165,264 & 333,961 & 949,726 & 661 \\
\hline Annual output industry 3 digit deflated q(i3) & $1,130,732$ & $2,954,814$ & 163,732 & 334,587 & 950,854 & 661 \\
\hline Annual output industry 4digit deflated q(i4) & $1,116,587$ & $2,891,075$ & 167,346 & 335,706 & 904,354 & 661 \\
\hline Number of employees & 48 & 70 & 18 & 26 & 48 & 661 \\
\hline Annual intermediates expenditures deflated & 498,943 & $1,249,135$ & 67,863 & 132,371 & 355,556 & 661 \\
\hline Capital deflated & 914,080 & $5,511,002$ & 67,134 & 168,167 & 308,555 & 661 \\
\hline Labor share in nominal output $\alpha \_\{N\}$ & 0.213 & 0.105 & 0.138 & 0.198 & 0.285 & 661 \\
\hline Materials share in nominal output $\alpha_{-}\{\mathrm{M}\}$ & 0.427 & 0.154 & 0.323 & 0.413 & 0.521 & 661 \\
\hline Capital share in nominal output $1-\alpha_{-}\{N\}-\alpha_{-}\{\mathrm{M}\}$ & 0.360 & 0.153 & 0.265 & 0.362 & 0.465 & 661 \\
\hline Output growth rate firm-level deflated $\Delta \mathrm{q}(\mathrm{f})$ & -0.024 & 0.246 & -0.159 & -0.018 & 0.113 & 548 \\
\hline Output growth rate industry 2 digit deflated $\Delta \mathrm{q}(\mathrm{i} 2)$ & -0.019 & 0.227 & -0.147 & -0.020 & 0.123 & 548 \\
\hline Output growth rate industry 3 digit deflated $\Delta \mathrm{q}(\mathrm{i} 3)$ & -0.020 & 0.228 & -0.147 & -0.019 & 0.116 & 548 \\
\hline Output growth rate industry 4 digit deflated $\Delta \mathrm{q}(\mathrm{i} 4)$ & -0.023 & 0.227 & -0.148 & -0.019 & 0.115 & 548 \\
\hline Labor growth rate $\Delta \mathrm{n}$ & -0.042 & 0.169 & -0.134 & -0.043 & 0.045 & 548 \\
\hline Materials growth rate $\Delta \mathrm{m}$ & -0.026 & 0.319 & -0.235 & -0.009 & 0.182 & 548 \\
\hline Capital growth rate $\Delta \mathrm{k}$ & 0.038 & 0.102 & 0.000 & 0.001 & 0.051 & 548 \\
\hline$S R=\Delta q-\alpha_{n} \Delta n-\alpha_{m} \Delta m-\left(1-\alpha_{n}-\alpha_{m}\right) \Delta k$ & -0.017 & 0.189 & -0.134 & -0.016 & 0.096 & 548 \\
\hline
\end{tabular}

Note: Descriptive statistics from Chilean manufacturing industry data (ENIA). Includes ISIC Rev.2 sectors 36 and 39. Unbalanced panel with 113 firms from 1996 to 2003.

Table 4.10 Basic Metal, Fabricated Metal Products, Machinery and Equipment Industries

\begin{tabular}{|c|c|c|c|c|c|c|}
\hline Variables & Mean & Std. Dev. & $\mathrm{p} 25$ & p50 & $\mathrm{p} 75$ & $\mathrm{~N}$ \\
\hline Annual output firm-level deflated $q(\mathrm{f})$ & $1,759,513$ & $5,073,395$ & 204,706 & 414,624 & $1,180,126$ & 2,384 \\
\hline Annual output industry 2 digit deflated q(i2) & $1,703,383$ & $5,073,676$ & 200,907 & 405,226 & $1,166,440$ & 2,384 \\
\hline Annual output industry 3 digit deflated q(i3) & $1,708,349$ & $5,110,803$ & 203,972 & 409,011 & $1,167,482$ & 2,384 \\
\hline Annual output industry 4digit deflated q(i4) & $1,744,071$ & $5,331,043$ & 204,204 & 412,520 & $1,158,252$ & 2,384 \\
\hline Number of employees & 56 & 74 & 17 & 30 & 58 & 2,384 \\
\hline Annual intermediates expenditures deflated & 893,568 & $3,013,356$ & 80,800 & 185,732 & 557,963 & 2,384 \\
\hline Capital deflated & 964,925 & $3,379,585$ & 54,927 & 155,841 & 462,810 & 2,384 \\
\hline Labor share in nominal output $\alpha \_\{N\}$ & 0.211 & 0.101 & 0.136 & 0.199 & 0.271 & 2,384 \\
\hline Materials share in nominal output $\alpha_{-}\{\mathrm{M}\}$ & 0.456 & 0.171 & 0.330 & 0.439 & 0.571 & 2,384 \\
\hline Capital share in nominal output $1-\alpha \_\{N\}-\alpha_{-}\{\mathrm{M}\}$ & 0.332 & 0.152 & 0.230 & 0.339 & 0.438 & 2,384 \\
\hline Output growth rate firm-level deflated $\Delta \mathrm{q}(\mathrm{f})$ & -0.013 & 0.256 & -0.157 & -0.005 & 0.144 & 1,978 \\
\hline Output growth rate industry 2 digit deflated $\Delta \mathrm{q}(\mathrm{i} 2)$ & -0.014 & 0.241 & -0.152 & -0.008 & 0.132 & 1,978 \\
\hline Output growth rate industry 3 digit deflated $\Delta \mathrm{q}(\mathrm{i} 3)$ & -0.013 & 0.241 & -0.152 & -0.007 & 0.134 & 1,978 \\
\hline Output growth rate industry 4 digit deflated $\Delta q(i 4)$ & -0.014 & 0.245 & -0.158 & -0.007 & 0.133 & 1,978 \\
\hline Labor growth rate $\Delta \mathrm{n}$ & -0.031 & 0.168 & -0.115 & -0.019 & 0.058 & 1,978 \\
\hline Materials growth rate $\Delta \mathrm{m}$ & -0.028 & 0.335 & -0.233 & -0.024 & 0.183 & 1,978 \\
\hline Capital growth rate $\Delta \mathrm{k}$ & 0.040 & 0.095 & 0.000 & 0.006 & 0.048 & 1,978 \\
\hline$S R=\Delta q-\alpha_{n} \Delta n-\alpha_{m} \Delta m-\left(1-\alpha_{n}-\alpha_{m}\right) \Delta k$ & -0.007 & 0.191 & -0.124 & -0.004 & 0.107 & 1,978 \\
\hline
\end{tabular}

Note: Descriptive statistics from Chilean manufacturing industry data (ENIA). Includes ISIC Rev.2 sectors 37 and 38. Unbalanced panel with 406 firms from 1996 to 2003. 
In summary, there were a variety of market outcomes across manufacturing sectors in Chile from 1996 to 2003. In general, profits before non-operational costs were high and represented something between 20 and $40 \%$ of total turnover. This result is found even though a foreign financial crisis decreased aggregated demand, causing an $8 \%$ decrease of industrial activity in 1998. Yearly capital revenues in the manufacturing industry over an 8 -year period have ranged from $39 \%$ to $82 \%$ yearly before taxes and non-operational costs across the seven sectors considered for this study. Total factor productivity growth as measured by the Solow (1957) residual was $1 \%$ as a yearly average when not considering crisis years 1998 and 1999.

\subsection{Estimation Strategy}

This section proposes a strategy to measure the rents captured by capitalists and workers in the Chilean manufacturing industry. Our results may be compared to the output obtained by Crepon, Desplatz, and Mairesse $(1999,2002,2005)$ and the empirical papers that followed. One of the main objectives of this application is to test the presence of heterogeneity among the estimated values of the parameters when output has been deflated at the firm level or at the industry level using either two, three, or four digits of ISIC code disaggregation, in order to estimate the sector averages of output price growth. This study has therefore used a firm-level price growth that was computed using product-firm level data for every firm in our sample. Secondly, we have taken the average price growth at the three different disaggregation levels and have calculated real output and real output growth four times using each particular firm-level or industry-level deflator.

The output of the empirical application is presented in a way that allows identifying not only the main parameters of the model but also the factor elasticities of the standard production function. We present the results obtained from Chilean data over the period 1996-2003 with and without imposing constant returns to scale. The model was initially estimated at the manufacturing level and was re-estimated seven times, separating firms into the main manufacturing economic sectors present in the sample. In the first place, the model was estimated using OLS with the log values of the variables in levels. Secondly, the estimates in First Differences were obtained by OLS. In these regressions, we take into account endogeneity problems that arise when measuring rents or profits. We therefore estimated the model using a First-Differenced GMM estimator first developed by Arellano and Bond (1991). The second and third lags of the variables in levels were used as instruments of the variables in first differences. In this differenced GMM model, some variables have time series persistence. When using the FirstDifferenced GMM estimator on a finite sample, the parameters may be affected by large biases. We have therefore used a system GMM estimator as our last estimation method. The augmented version of the GMM model was first proposed by Arellano and Bover (1995) and fully developed by Blundell and Bond (1998, 2000). The system GMM specification includes the level moments as additional instruments and uses a two-step 
standard-error correction. We estimate the model using the xtabond 2 command in Stata version 10 and follow the procedures outlined in Roodman (2006).

In this work, we compared levels and first differences estimates. An equation in levels uses the $\log$ actual values of the variables in the model. In first differences, the annual growth rate of each variable is used instead of the logarithms. Estimating equations in levels and first differences should not differ much if there is contemporaneous adjustment of all variables in the model to any given exogenous impact related to the equation. If we do not assume a smooth and fast adjustment of output to its optimal level for any given change in inputs, we would expect that the estimates in levels would yield approximately the short term relationship of the variables, while the first differences estimates would offer a two-year average of the elasticity values.

In the data used for this study, we find an important exogenous shock that negatively affected the value of output and inputs in the years 1998 and 1999. This shock is connected to a foreign market financial crisis that affected interest rates and raw materials prices and consequently affected production in the manufacturing industry. One consequence of estimating on first differences is that the elasticities become more sensitive to the values of input and output over the years in which aggregated demand decreased. When GMM methods are employed, the second and third lags are used as instruments and therefore the effect is mostly compensated by focusing on an even more restricted sample (1999-2003).

Using the Delta Method, we report the output elasticities with respect to labor $\left(\varepsilon_{N}^{Q}\right)$, materials $\left(\varepsilon_{M}^{Q}\right)$, and capital $\left(\varepsilon_{K}^{Q}\right)$. The scale parameter $(\lambda)$ is the summation of these three elasticities. We then report the estimated markup of the reduced model without workers' bargaining power ( $\mu$ only) and we adjust the markup parameter by the scale elasticity parameter $(\mu$ only $/ \lambda)$. The four main parameters of the model are displayed next in each table, The joint market imperfection parameter $(\psi)$ reflects the average market power exercised by firms in the labor market relative to the market power they exercise in the materials market. This parameter is equal to zero when both input markets are equally competitive, positive when workers can bargain more than material suppliers can, and negative when firms exercise more monopsony power over workers that they do over materials. The markup of price over cost $(\mu)$ indicates imperfect competition in the final product market when it has a value larger than one. The workers bargaining power $(\theta)$ results from comparing the share of rents captured by workers with their marginal contribution to output. The extent of rent sharing $(\gamma)$ is a statistical measure of the share of the firm rents that are actually being shared with the workers.

\subsection{Estimation Results}

\subsubsection{Manufacturing Level Results}

Table 4.11 presents the first results of the estimation using the entire manufacturing sample. Constant returns to scale were imposed in this table. The first result that clearly appears from these preliminary estimates is that the different deflations of output made 
almost no significant difference in the estimated parameter values. The estimated parameter standard deviations were marginally larger when output was deflated at the firm level.

In the first panel, the model was estimated by OLS in levels without explicitly considering simultaneity. The results show immediately that there is a large markup. This finding is independent of whether labor market imperfections are taken into account. When the bargaining power of workers is not included in the estimation, the markup parameter is biased downwards, which is the result found by Crepon, Desplatz, and Mairesse (1999). There appears to be some rent sharing between capital owners and workers; the joint market imperfection parameter is positive on the OLS levels regressions, implying that some workers get a larger share of rents than do material providers. We will later see that the positive rent sharing parameter is caused by the imposition of constant returns, which creates a downward bias on the labor elasticity parameter.

Secondly, the model was estimated in first differences in order to eliminate unobserved firm-specific effects. We gave up the first year of our panel in order to estimate with this method and the results seem to be sensitive to that change. The first year of our 8-year panel was 1996, a period in which the Chilean economy was expanding vigorously. Estimating in first differences gives more importance to the periods in the middle of the panel, including 1998 and 1999, when output growth was negative due to a financial crisis that hit from foreign markets.

The results show that, in first differences, and when returns to scale were forced to be constant, the markups were less than one. It could be the case that the endogeneity of quasi-fixed inputs is causing a bias on the estimated parameters in the absence of instrumental variables estimation.

The estimation method used in the third panel of Table 4.11 accounts for endogeneity problems. The instruments used correspond to the regression variables in levels with 2 and 3 lags. We find severely biased parameters showing firms that operate with theoretically unfeasible marginal productivities. This large bias, which we found on the estimations using GMM in differences, has also been documented in the work by Blundell and Bond (2000) and has to do with autocorrelation of the instruments. We found that the Sargan test rejected the null hypothesis that proposes joint validity of the instruments used. There also seems to be autocorrelation of second order from the AR(2) test. These findings lead us to our last estimation method, which uses lagged first differences of the series as additional instruments for the level equations.

The fourth panel displays a dynamic GMM specification which allows for an autoregressive component in the productivity shock. The instruments used correspond to the variables in levels and first differences with 2 and 3 lags. This definition of instruments leaves out of the second stage estimation the observations from the first four years of the sample and therefore has the advantage of focusing the estimation on the period right after the financial crisis that hit the manufacturing industry in 1998-1999 


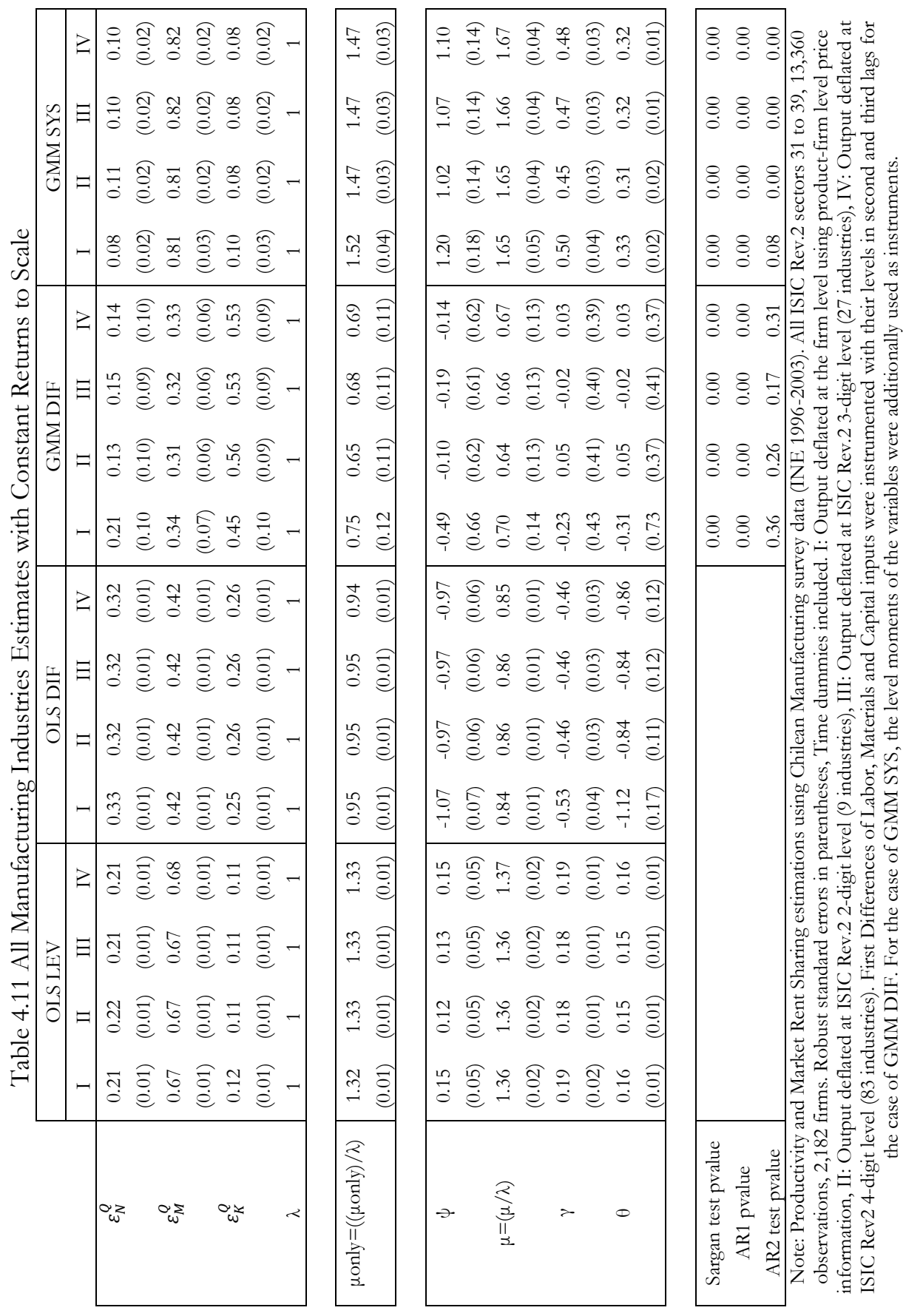


When using GMM methods the use of lagged variables as instruments implies that the sample in the main estimations is reduced to the period 1999-2003. We have found that estimating over this restricted sample with OLS does not alter the results significantly.

The results are very much in accordance with economic theory and consistent with the results from Blundell and Bond (2000) and the papers that followed. We find a larger material elasticity in comparison to the OLS results. The imposition of constant returns to scale forces the labor elasticities to take a very small value and hence to show workers as having relatively higher levels of market power. Markup of price over cost is higher when allowing workers' bargaining power into the model. In this case, the Sargan test also rejects the joint validity of the set of instruments, but there seems to be no problem of $\mathrm{AR}(1)$ or $\mathrm{AR}(2)$ autocorrelation. We will further find that Sargan rejection is most likely due to the heterogeneity of the full manufacturing sample, because this problem disappears when estimating the model on more homogeneous industry level samples.

Table 4.12 shows the results for the whole manufacturing industry allowing the scale economies to be different than 1. If we are interested in a model that produces an output consistent with our basic assumptions, we expect returns to scale to be equal or close to 1. Very few differences are found on the estimated parameters across columns and within panels, which means that deflating at the firm or industry level does not make a significant difference in the results, even when constant returns are not imposed.

In the first estimation panel by OLS in levels, allowing non-constant returns had almost no effect on capital and material elasticities but had a positive impact on labor elasticity that was allowed to be larger in comparison to the case when constant returns were imposed. Adding the three elasticities leads to a highly significant scale economy equal to 1.07. The share that workers obtain from rents in these estimates is not significantly different from zero. The joint market imperfection parameter value suggests that, taking the intermediates market as a neutral reference, firms are exercising monopsony power over the labor market, on average.

The second panel of table 4.12 displays the OLS estimates of the variables in first differences. The marginal productivity parameters are lower now than when scale economies were assumed in the previous table. The OLS first differences estimates suggest an overall average markup of price over cost equal to 1.04. We also find from the negative bargaining power parameter that workers are on average being paid less than their marginal productivity. According to joint market imperfection parameters found on these regressions, firms are paying less to workers than to material supplies relative to their respective marginal productivities.

The third panel from Table 4.12 shows the GMM in differences results. We find that this set of regressions expresses the model in an exaggerated way, proposing a scale economy higher than 2 with very large market power indicators. This result may be explained by the autocorrelation problems mentioned by Blundell and Bond (2000). Because very heterogeneous firms were grouped for estimation in this table, the joint validity of the instruments was again rejected by the Sargan test. There appears to be some $\operatorname{AR}(2)$ autocorrelation but no evidence of $\operatorname{AR}(1)$. 


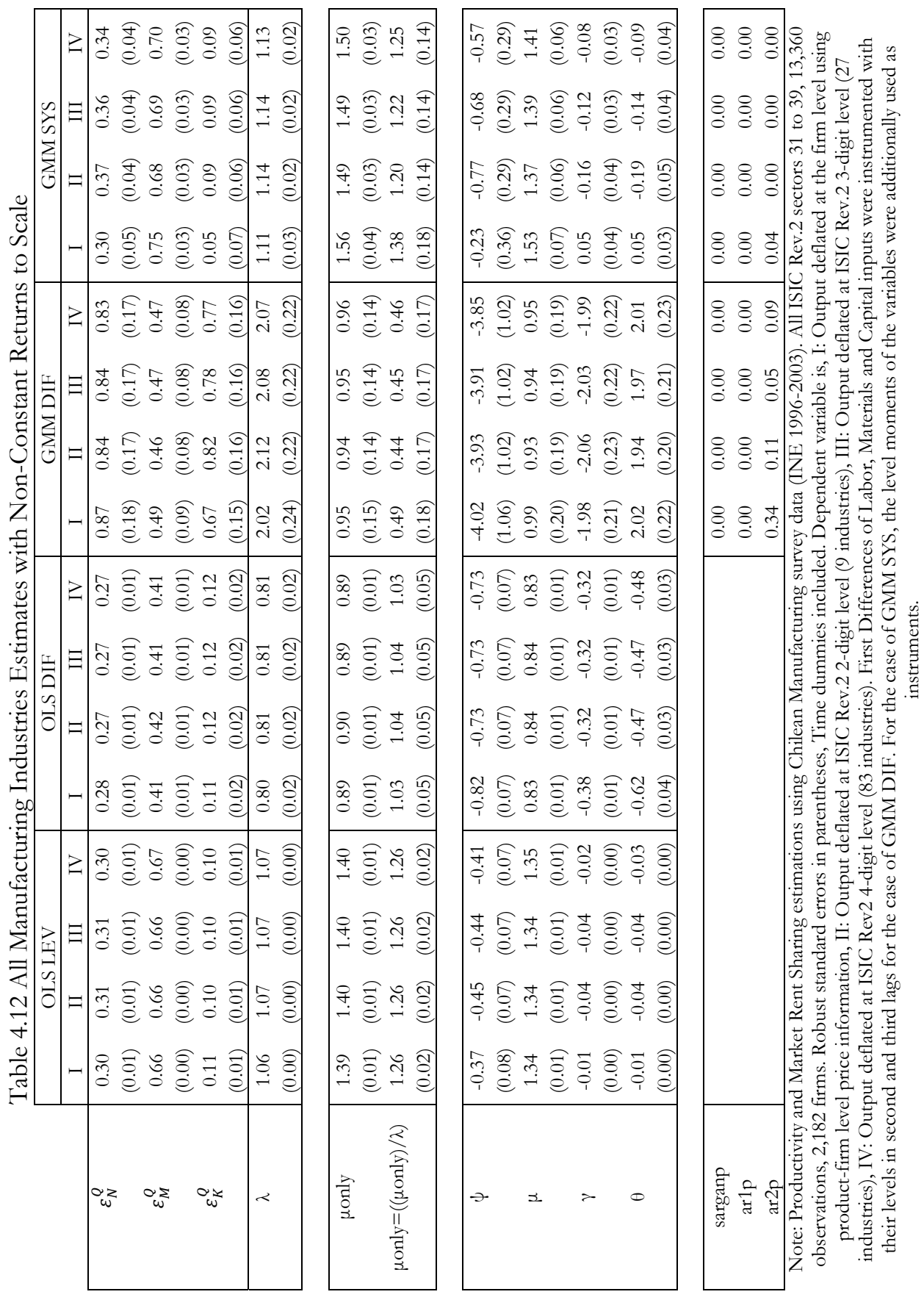


The last panel is therefore a preferred estimation method because it uses GMM as a system that considers the first differences and level moments as instruments in a dynamic specification. We find a large markup and negative bargaining power of workers. If the main assumptions of our model are true for the average firm in our sample, then these parameters indicate that workers are being paid less than their marginal productivities. The joint market imperfection parameter is not significantly different from zero, which means that firms are not exercising more power in the labor market than in the materials market. The joint validity of instruments and autocorrelations $\operatorname{AR}(1)$ and $\operatorname{AR}(2)$ was rejected by the tests in the lower part of the table.

It has been argued in the previous work by Bergoeing et al (2011) that some variable may have skewed distributions and this may alter the results. Bergoeing et al (2011) decided to run regressions on medians rather than means because of this. For the case of this chapter we have preferred to run regressions on means because we are interested in comparing these results to other experiences that used this model.

In summary, from Tables 4.11 and 4.12, we find that markups of price over marginal cost are high, which is consistent with the existence of imperfect competition. Workers may have positive bargaining power only when constant returns to scale are imposed. Imposing constant returns to scale results in a downward biased elasticity of labor with respect to output. Therefore, when constant returns are imposed, we find an overestimation of workers' ability to capture a share of the firm's rent. As it can be seen from the tables, OLS in levels and OLS in first differences may result in scale economy parameters that are biased because of endogeneity. GMM in differences is not a good solution because it presents autocorrelation problems in the instruments. Therefore, for the industry level regressions, the OLS levels estimates are reported as the simplest preliminary estimation method accompanied by the results of system GMM that is the preferred estimation method.

\subsubsection{Industry Level Analysis}

Tables 4.13 to 4.19 summarize the results of estimating the model after separating the manufacturing industry into seven economic sectors according to the ISIC Rev.2 classification. Results are reported with and without imposing constant returns to scale. Small differences are found in the parameters when output has been deflated at the firm or industry level. These differences are almost never significant in any industry.

Table 4.13 refers to the Manufacture of Food, Beverages, and Tobacco industries. Results show a markup parameter that varies among estimations but is significantly higher than 1, with values between 1.26 and 1.42. This shows that imperfect competition occurs in this industry. Not taking workers bargaining into account made very little difference in the estimated markup parameter. Workers' bargaining power is positive and significant in most of the cases, which suggests there may be a share of the rents being captured by workers. 


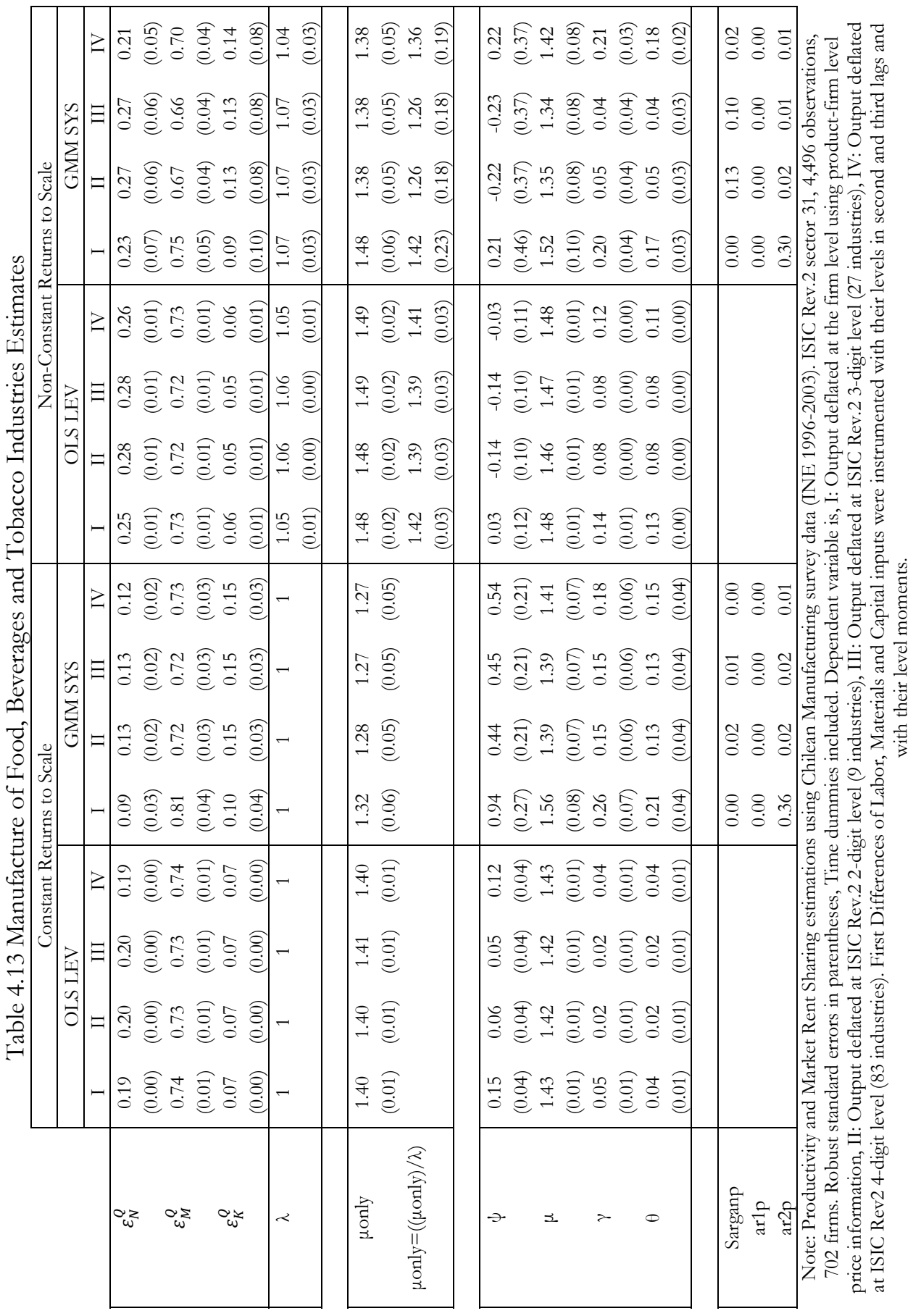


The joint market imperfection parameter is positive when constant returns are imposed and equal to zero when non-constant returns are allowed. This result shows that workers do not necessarily have greater bargaining power than material suppliers, but, when constant returns are imposed, the resulting downward biased labor elasticities produce relatively higher workers' bargaining power.

Some different results were found with data from the Textile, Wearing Apparel, and Leather industry estimates. Table 4.14 displays the results of estimating the model for this industry and again finds markup values that are consistent with imperfect competition. The markup measures are significantly smaller once workers' bargaining power has been taken into account. We find a negative value for workers bargaining power. The numbers suggest that workers may be getting wages lower than their marginal productivity, which means they do not receive a share of the rent but instead give a share of their own marginal productivity value to firm owners. In the context of the Textile, Wearing Apparel, and Leather industry, many hypotheses could explain this deviation from the market equilibrium defined by the theoretical model. If we accept the fact that textiles are highly tradable goods, then in the equilibrium marginal productivity of labor across countries that are open to trade should be equal. It could be the case that the presence of cheap textile imports coming from other countries forces a lower payment to the labor force on this industry in comparison with other manufacturing industries. This explanation is plausible in the context of international trade theory. According to most mainstream models, the marginal productivities of inputs will be pushed to the values of the marginal productivities seen in the international markets, given that the economy is open to trade and trading costs are low.

Table 4.15 refers to the Wood, Wood Products, and Furniture industry results. The markup parameter is much greater than 1 , which indicates the presence of imperfect competition in this manufacturing sector. In this industry, workers capture some part of the rent, even though this result is not always significant and the model that was estimated without allowing for workers' bargaining power did not yield a significantly different markup parameter. The joint market imperfection parameter indicates a higher degree of monopsony power of the average firm with respect to intermediates in comparison with its market power in the case of labor market. This last effect, which could suggest some extent of rent sharing toward workers, disappears after relaxing the assumption of constant returns to scale. 


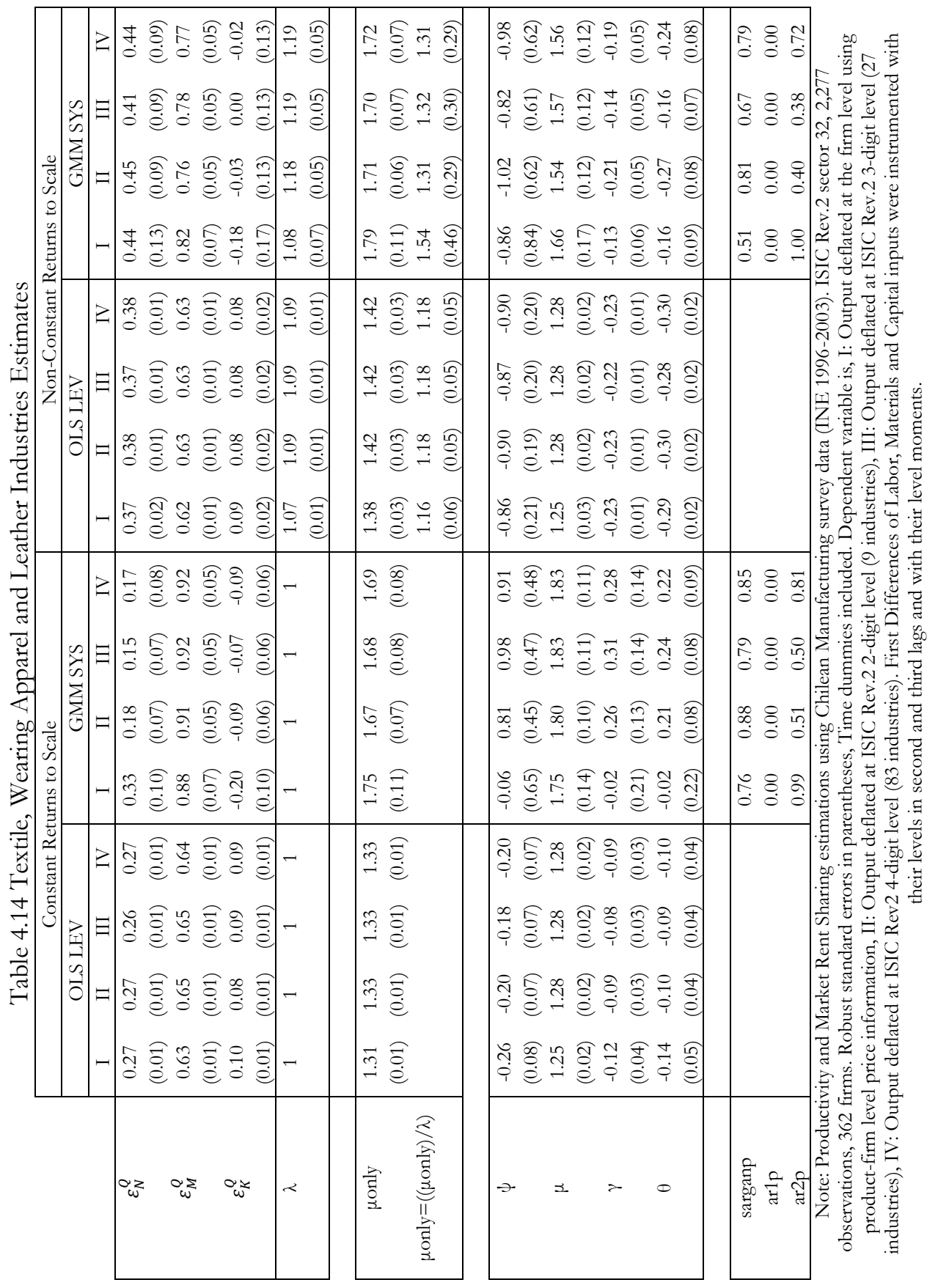




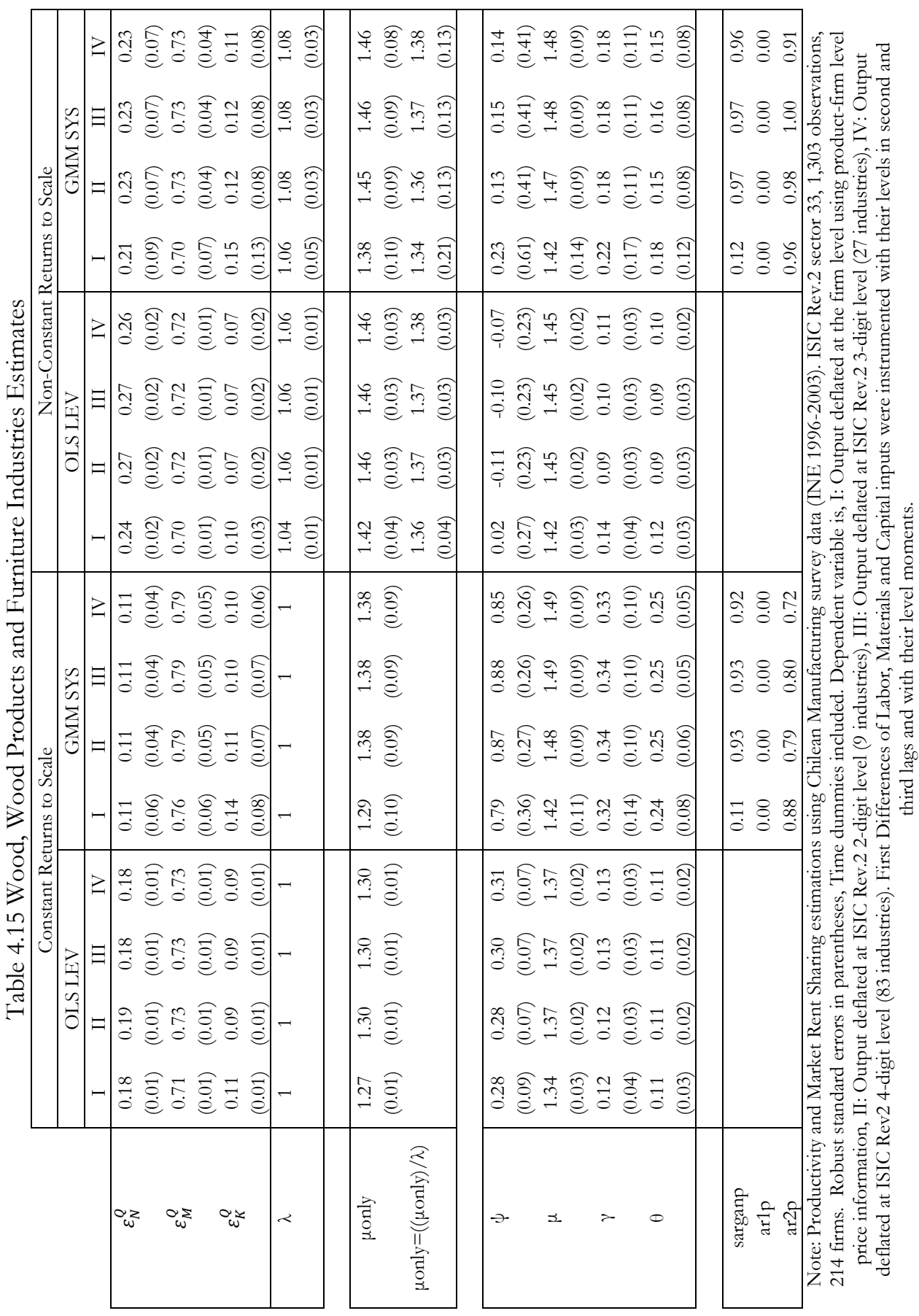


The results of estimating the model on the industry of Paper, Paper Products, Printing, and Publishing are summarized in Table 4.16. Markups show significant evidence of imperfect final product markets. Returns to scale are higher than 1 when the constant returns assumption is relaxed. Workers appear to receive some share of the rent when imposing constant returns to scale but this result again disappears when relaxing this assumption. In fact, when non-constant returns are allowed, the parameter for the bargaining power of workers is lower than zero, which means that workers are not bargaining at all and that their actual reservation wage is lower than the value of their own average marginal productivity. It is not clear whether firms enjoy a higher degree of monopsony power in the labor market than they do in the intermediates market because the joint market imperfection parameter is not very significant across columns in Table 4.16.

Table 4.17 shows the results of estimating the model with data from Manufacture of Chemicals, Chemical Petroleum, Coal, Rubber, and Plastic Products sector. It is clear that workers get on average a rent share equal to 0 or a value very little above 0 . This translates into a rent sharing measure that is similarly small. The markup parameter is always significantly large, which implies prices above marginal cost. The joint market imperfection parameter does not hold a value significantly different from zero across estimations, which implies that firms on average do not exercise more power in the labor market than they do on the intermediate market.

The results of the model estimated for the Non-Metallic Mineral Products and Other Manufacturing Industry are displayed in Table 4.18. We find this industry fits the model very well on average because the scale economy parameter is not significantly larger or smaller than one. Markups are high and always significantly above 1, which implies that average firms set prices above marginal cost. The particularity of this market is that workers' bargaining power is also positive, ending up with a significantly positive rent sharing parameter almost every time. The joint market imperfection parameter was found to be significantly positive in some regressions when constant returns were imposed. However, in the third and fourth panel, when constant returns to scale were not imposed, results showed that this parameter is not significantly different from zero.

The last industry evaluated with this model was Basic Metal, Metal Products, Machinery, and Equipment. These results are displayed in Table 4.19. We find a markup parameter that is significantly above 1 , which implies that imperfect competition exists on average in the final product market in this industry. 


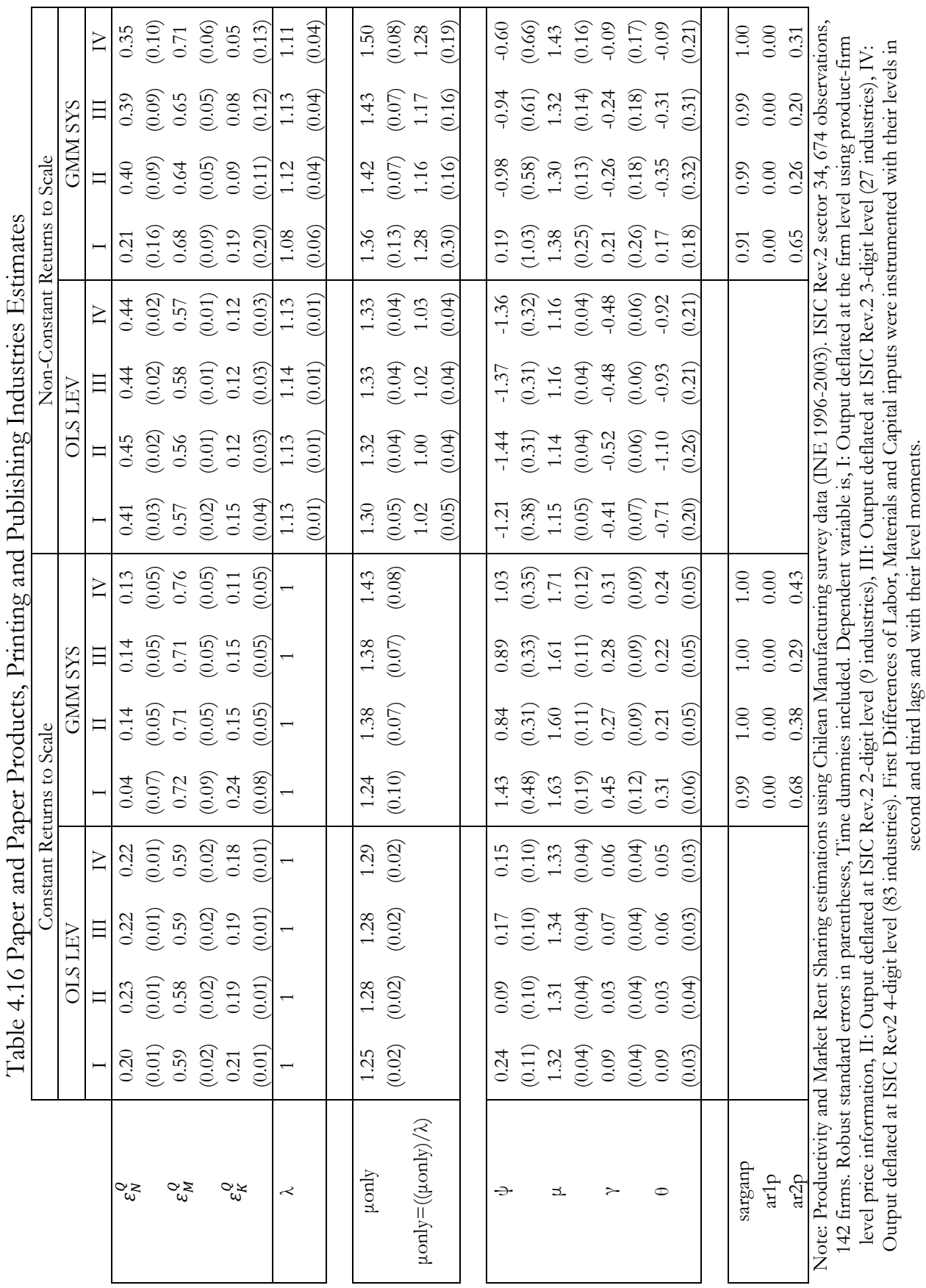




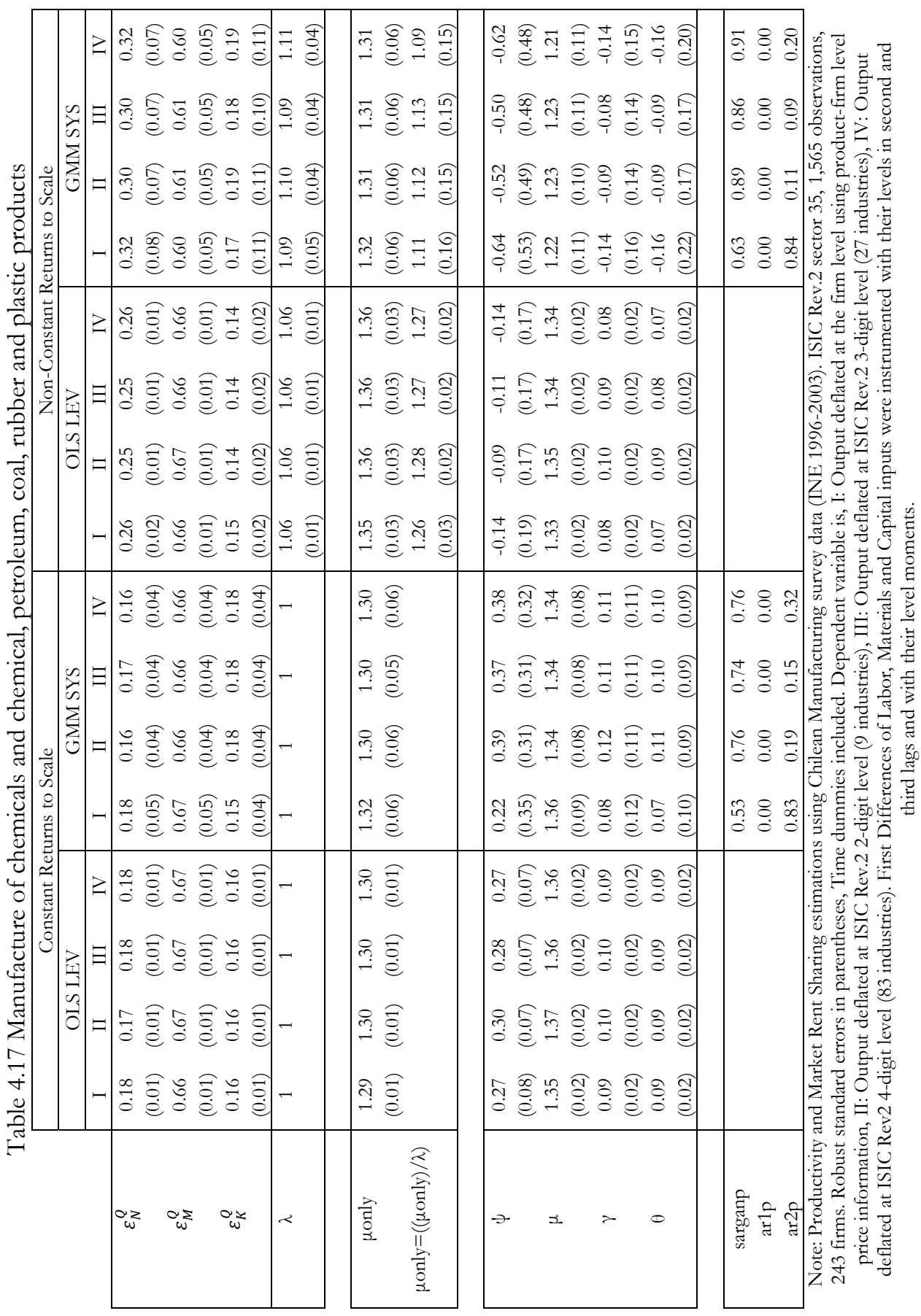




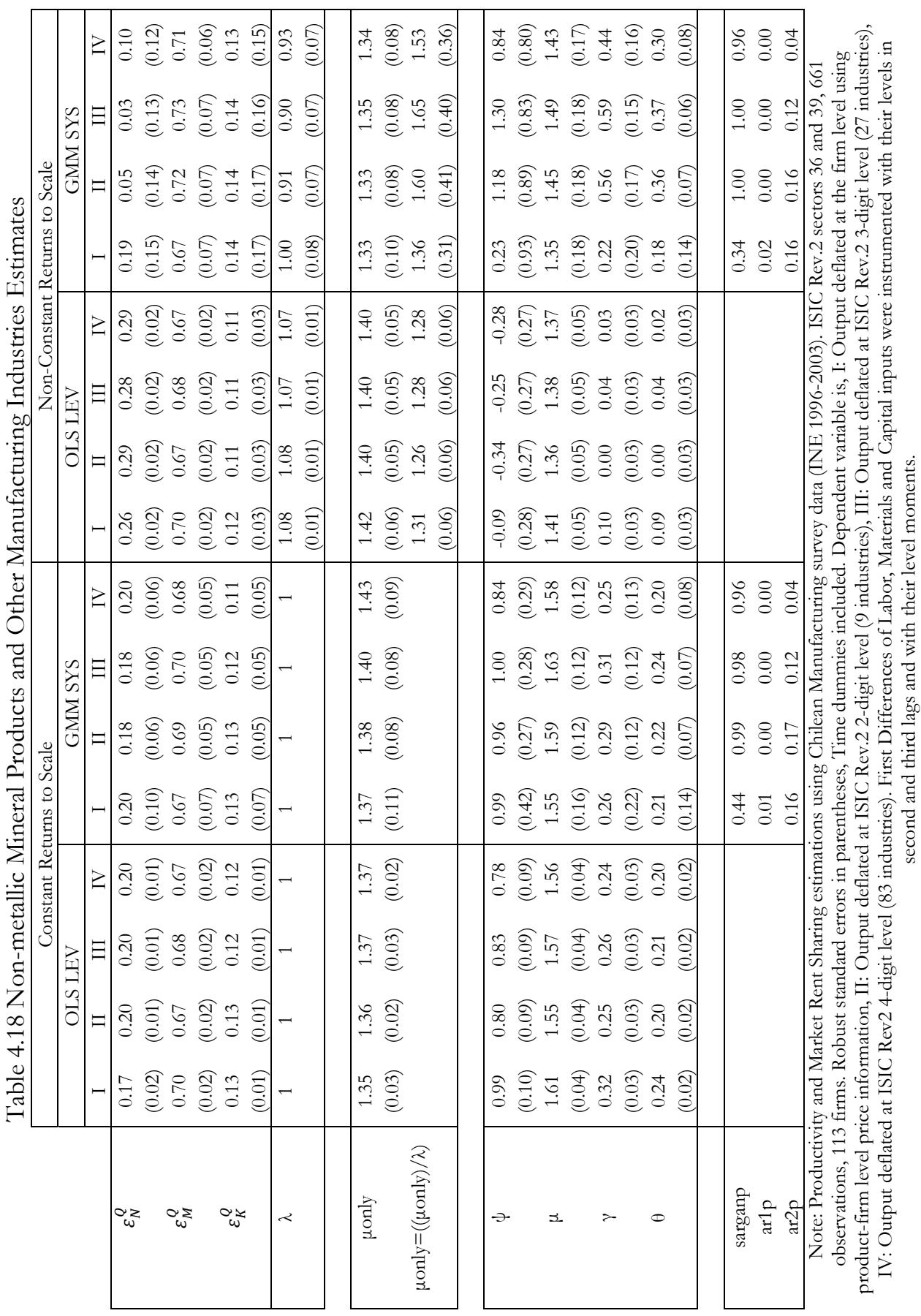




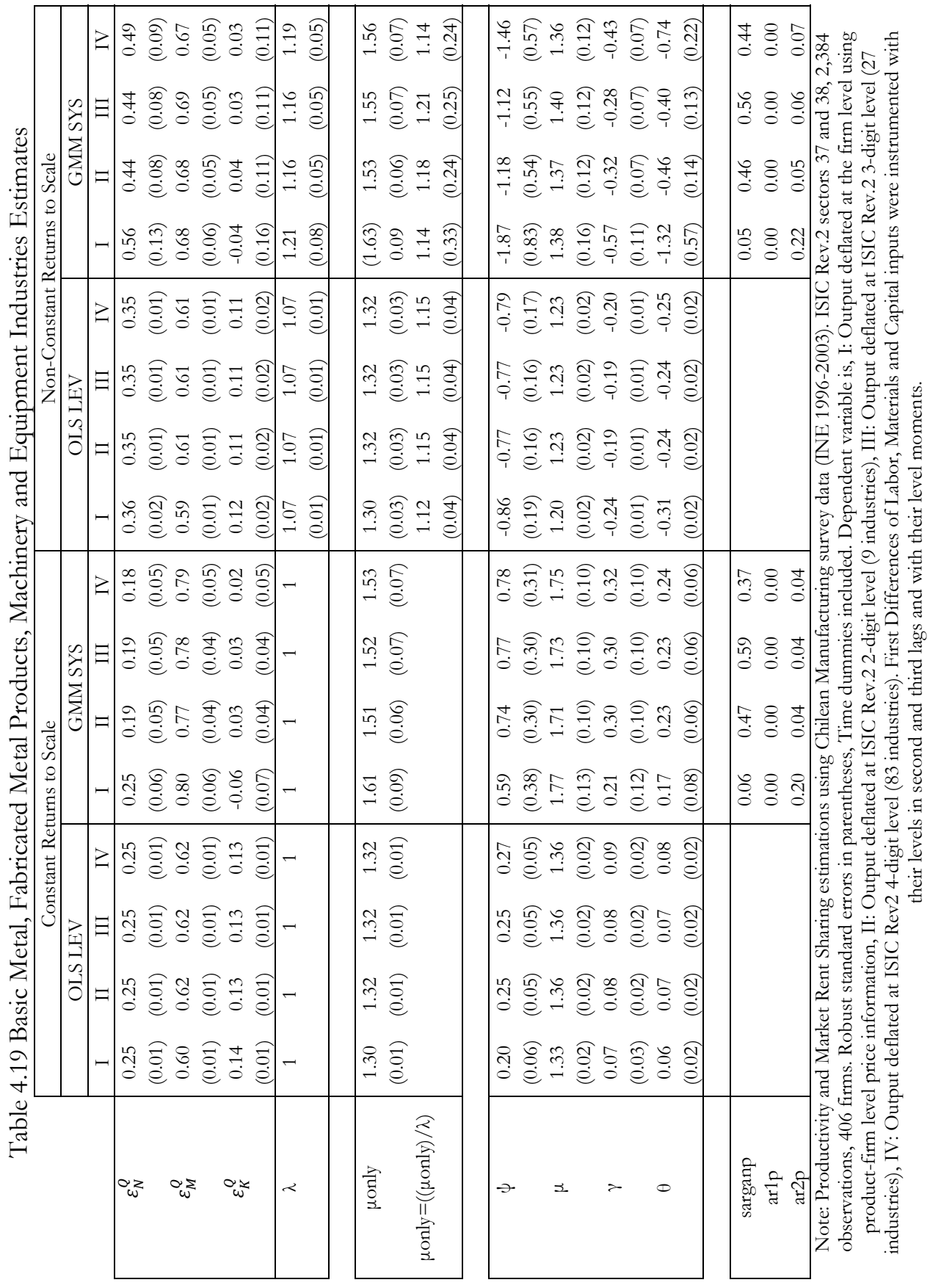


Table 4.19 also shows that not accounting for workers' market power always results in biased estimates of the price-cost markup. Returns to scale are significantly higher than 1 when constant returns are not forced. When constant returns were imposed, workers were found to have some degree of market power. However, when this assumption is relaxed, the parameter becomes negative and significant as a result of higher estimated labor productivity. The joint market imperfection parameter does not hold a significant sign across estimations. In the case of constant returns, it appears that the average firms exercise more market power on intermediate markets than they do on the labor market. This result reverses under non-constant returns, but with relatively high standard errors.

When instrumental variables were used in the second and fourth panel of each table (Tables 4.13 to 4.19), the p-value of the Sargan test, $\operatorname{AR}(1)$ test and $\operatorname{AR}(2)$ test were reported. We found that, at the industry level, the validity of instruments is only partially rejected in the food and beverages sector. In other industries, the joint instrument validity test is passed for almost every column. Autocorrelations $\operatorname{AR}(1)$ and $\operatorname{AR}(2)$ were not always rejected by the tests done at the industry-level samples, even though at the manufacturing level these tests are found to be very significant. For this reason, using system GMM is the most adequate method to estimate this model for the present Chilean dataset, taking endogeneity into account.

Table 4.20 summarizes the findings from the OLS Estimates in Levels. It was found that imperfect competition prevails in the final product markets for all seven manufacturing sectors evaluated on this study. The extent of rent sharing varies among sectors. In most Chilean manufacturing industries, workers appear to have little or no bargaining power. According to the non-constant returns results, among the industries in which workers may have a higher degree of bargaining power are the Food and Beverages sector, the Wood, Wood Products, and Furniture sector, and the Chemicals and Plastic sector. Among the manufacturing sectors with the lowest share of rents captured by workers, we found the Textile, Wearing Apparel, and Leather industry and the Metallurgic sector.

Table 4.21 summarizes the results from the GMM system estimates. Imperfect competition always applies, regardless of sector and returns to scale assumptions. The two sectors where workers have some degree of market power according to the nonconstant returns estimates were Textiles and Metallurgic industries. The sectors where workers do share some part of the rents are the Manufacture of Food and Beverages sector and the Non-Metallic Mineral Products, and Other Manufacturing Industries.

According to these results, imperfect competition applies in each and every market in the Chilean manufacturing industry. In most cases, workers do not capture a significant share of profits. In extreme cases, employees are getting paid on average less than their marginal productivity. Finally, these results describe the extent to which different output deflation methods can produce heterogeneity in the estimated parameters. It was found that deflation at the firm or industry level does not produce significantly different elasticities but does make some small difference in the estimated standard deviations. 


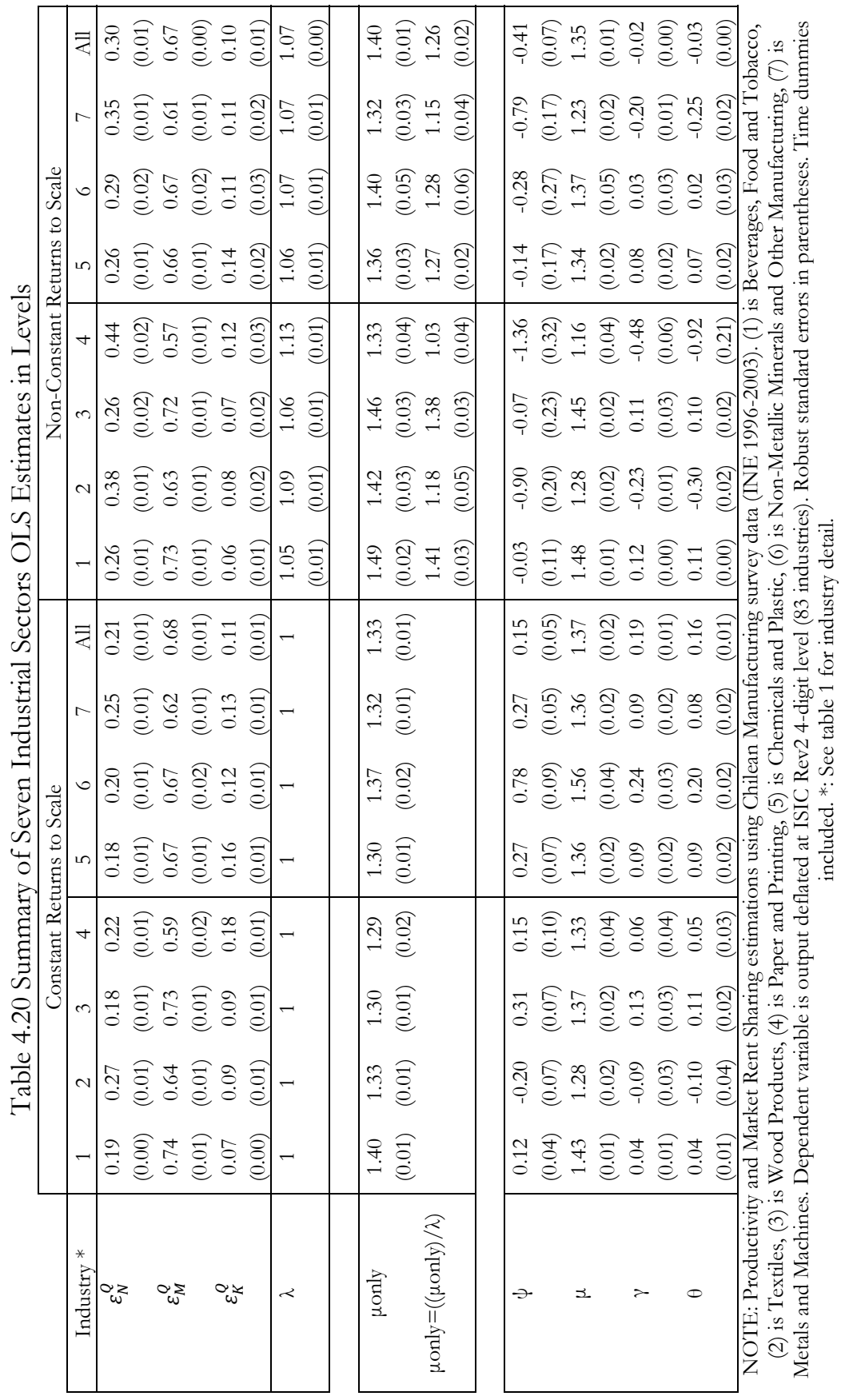




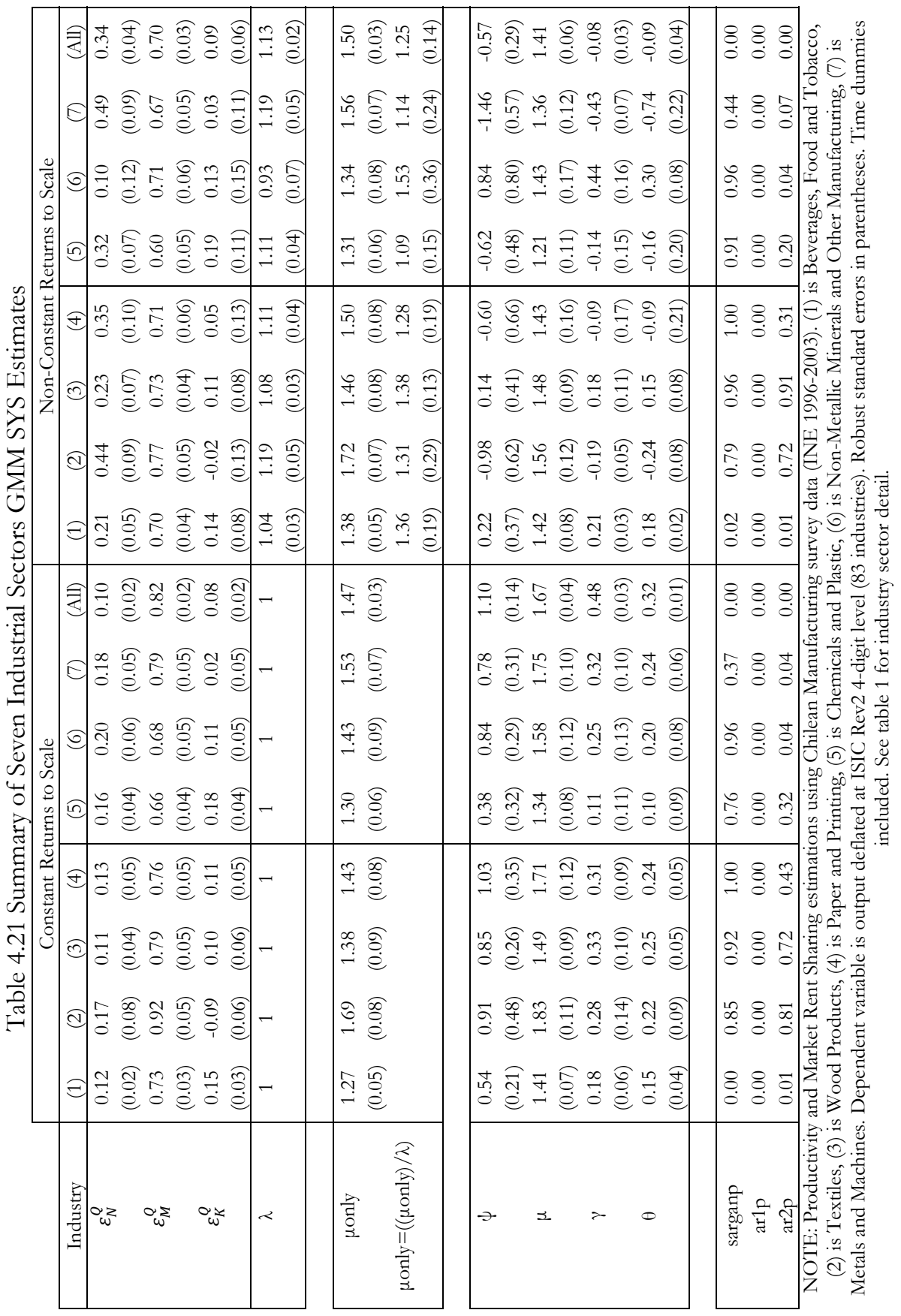




\subsection{Concluding Remarks}

This work has estimated an empirical model to measure price cost markups and workers' bargaining power in terms of input elasticities and input shares on sales. It relied on the theoretical model presented by Crepon, Desplatz, and Mairesse (1999) and work that followed, with which our results can be compared. The model is based on the idea of a production function that can be expressed in terms of the rates of growth of inputs and output. The estimation of the Solow residual allows obtaining parameters that measure markup and workers' bargaining power.

This work was focused on the Chilean Manufacturing Industry between 1996 and 2003. The industry was divided into seven sectors to allow comparing the results across industries. The data used for this study came from the Chilean National Statistical Office (INE) that includes information on quantities and prices of products within firms. One advantage of this dataset is that it allows obtaining real firm output growth deflated at the firm level.

At the manufacturing level, this work found evidence that, on average, imperfect competition predominates in the final good markets. Workers have little bargaining power over rents when constant returns to scale are imposed. When returns to scale are allowed to be different than 1, the small bargaining power of workers disappears completely in most cases. It was found that this discrepancy is due to an underestimation of labor elasticity when constant returns were imposed.

At the industry level, results showed that imperfect competition applies across all the Chilean manufacturing sectors that were evaluated in this study. From the estimations in levels, the industry of Paper, Printing, and Publishing appears to have the lowest markup of price over cost, followed by the Textiles industry. Food and Beverages has been found to have the largest markup, even though returns to scale are nearly constant. Relatively high markups are also found in the Manufactures of Wood, Wood Products, and Furniture industries and in the production of Non-Metallic Minerals and Other Manufacturing.

In general, results show that workers have little bargaining power over rents generated in Chilean industry. The sector in which employees appeared to have a relatively higher degree of market power was Manufacture of Food, Beverages, and Tobacco. Other sectors where workers enjoy some degree of rent sharing are Manufactures of Wood, Wood Products, and Furniture and Non-Metallic Minerals and Other Manufacturing. These sectors were also found to be those that are able to yield higher profits on average. On the other hand, those sectors where markup profits were found to be lower are also the ones where the share obtained by workers is smaller.

The model and estimation methods used in this paper allow us to draw conclusions about the average firm's behavior. We are also capable of distinguishing some differences among the average firms across different manufacturing sectors. Nevertheless, these results cannot be generalized to specific firms in our sample and therefore this study is not relevant from an antitrust perspective. 
Further research should investigate whether or not the differences in product and labour market imperfections among sectors could be due to export orientation and/or labour unions effects. Additionally, because some of the variables in the model have skewed distribution further research should evaluate the effect of running regressions over medians instead of means. 


\section{References}

Abowd, J.M., F. Kramarz and D. Margolis, (1999). High wage workers and high wage firms, Econometrica, 67(2), 251-33.

Arai, M., (2003). "Wages, profits, and capital intensity: Evidence from matched worker firm data," Journal of Labor Economics, 21(3), 593-618.

Arellano, M. and S. Bond, (1991). "Some tests of specification for panel data: Monte Carlo evidence and an application to employment equations," Review of Economic Studies, 58(2), 277-297.

Arrantz-Aperte, L. and Heshmati, A., (2003). "Determinants of Profit Sharing in the Finnish Sector," Working Papers 492, Hanken School of Economics.

Blanchłower, D.G., A.J. Oswald and P. Sanfey, (1996). "Wages, profits and rent sharing," Quarterly Journal of Economics, 111(444), 227-252.

Baker, J. B. and Bresnahan T. (2006). "Economic Evidence in Antitrust: Defining Markets and Measuring Market Power." Stanford Law and Economics Olin Working Paper No. 328.

Benavente, J. M., Dobbelaere, S. and Mairesse, J. (2009). "Interaction between product market and labour market power: evidence from France, Belgium and Chile," Applied Economics Letters, 16: 6, 573-577.

Bergoeing, R., Loayza, N., and Piguillem, F. (2011). "The Aggregate and Complementary Impact of Micro Distortions". Departamento de Economia, Universidad de Chile, STD 338, Santiago, Abril 2011.

Blanchflower, D. G., Oswald, A. J. and Sanfey, P. (1996). "Wages, profits and rentsharing." The Quarterly Journal of Economics, 111, 227-50.

Bresnahan, T. (1989). Empirical studies of industries with market power, in Handbook of Industrial Organization, Vol. 2 (Eds) R. Schmalensee and R. Willig, North Holland, Amsterdam.

Bughin, J. (1996). Trade unions and firms' product market power, The Journal of Industrial Economics, XLIV, 289-307.

Contreras, J. S. and Benavente, J. M. (2006). Margen de utilidad y distribucion de las rentas: la industria manufacturera chilena durante los noventas, Serie Documentos de Trabajo 219, Departamento de economia, Universidad de Chile. 
Crepon, B., Desplatz, R. and Mairesse, J. (1999) Estimating price-cost margins, scale economies and workers' bargaining power at the firm level, CREST Working Paper G9917, Centre de Recherche en Economie et Statistique.

Crépon, B., R. Desplatz and J. Mairesse, (2005). Price-cost margins and rent sharing: Evidence from a panel of French manufacturing firms, Annales d'e Economie et de Statistique, Special issue in memory of Zvi Griliches, 79/80, 585-611.

Crepon, B., Desplatz, R. and Mairesse, J. (2002). Price-cost margins and rent sharing: evidence from a panel of French manufacturing firms, Centre de Recherche en Economie et Statistique, revised version.

Crepon, B., Duguet, E. and Mairesse, J. (1998). "Research, Innovation, and Productivity: An Econometric Analysis at the Firm Level.". Economics of Innovation and New Technology, 7(2), 115-158.

Christofides, L.N and A.J. Oswald, (1992). "Real wage determination and rent sharing in collective bargaining agreements”, Quarterly Journal of Economics, 107(3), 985-1002

Dixit, A., and Stiglitz, J. (1977). "Monopolistic Competition and Optimum Product Diversity," American Economic Review, LXVII, 297-308.

Dobbelaere, S. (2004). Estimation of price-cost margins and union bargaining power for Belgian manufacturing, International Journal of Industrial Organization, 22, 1381-98.

Dobbelaere, S. and Mairesse, J. (2004). Micro evidence on rent sharing from different perspectives, NBER working paper 16220.

Dobbelaere, S. and Mairesse, J. (2009). "Panel Data Estimates of the Production Function and Product and Labor Market Imperfections”. TI 2009-001/3 Tinbergen Institute Discussion Paper. Forthcoming on Journal of Applied Econometrics.

Estevao, M. and Tevlin, S. (2003). Do Firms Share their Success with Workers? The Response of Wages to Product Market Conditions. Economica (2003) 70, 597-617

Hall, R. E. (1988). The relationship between price and marginal cost in US industry, Journal of Political Economy, 96, 921-47.

Hildreth, A. and Oswald, A. (1997). Rent sharing and wages: evidence from company and establishment panels, Journal of Labour Economics, 15, 318-37. 
Jovanovic, B., (1979). Job matching and the theory of turnover, Journal of Political Economy, 87(5), 972-99

Just, R. E. and Chern, W. S. (1980). Tomatoes, Technology, and Oligopsony, The Bell Journal of Economics, Vol. 11, No. 2., pp. 584-602.

Klette, T.J. (1994). "Estimating Price- Cost Margins and Scale Economies from a Panel of Microdata," Discussion Papers 130, Research Department of Statistics Norway.

Klette, T.J. and Griliches, Z. (1996) The inconsistency of common scale estimators when output prices are unobserved and endogenous, Journal of Applied Econometrics, 11, 343-61.

Martins, P.S. (2009). Rent sharing before and after the wage bill, Applied Economics, 42(17), 2133-2151.

Mairesse, J. and Jaumandreu, J. (2005). Panel-data estimates of the production function and the revenue function: What difference does it make?, Scandinavian Journal of Economics, 107, 651-72.

McDonald, I. M. and Solow, R. M. (1981). Wage bargaining and employment, American EconomicReview, 71, 896-908.

Neven, D.J., Roller, L. and Zhang, Z. (2006). Endogenous costs and price-costs margins: an application to the European airline industry, Journal of Industrial Economics, 54, 351-68.

Nickell, S. (1996). "Competition and Corporate Performance," Journal of Political Economy, CIV , 724-746.

Nickell, S.J., J. Vainiomaki and S. Wadhwani, (1994) Wages and product market power, Economica, 61(244), 457-47

Postel-Vinay, F. and J.M. Robin, (2002). Equilibrium wage dispersion with worker and employer heterogeneity, Econometrica, 70(6), 2295-2350.

Roodman, D., (2005). "xtabond2: Stata Module to Extend xtabond Dynamic Panel Data Estimator.” Center for Global Development, Washington.

Schmalensee, R. (1989). "Inter-industry studies of structure and performance." in Handbook of Industrial Organization, Vol. 2 (Eds) R. Schmalensee and R. Willig, North Holland, Amsterdam. 
Schmidt, K. (1997). "Managerial Incentives and Product Market Competition" Review of Economic Studies, LXIV, 191-213.

Solow, R., (1957). "Technical Change and the Aggregate Production Function." Review of Economics and Statistics, 39 312-320.

Van Reenen, J., (1996). The creation and capture of rents: Wages and innovation in a panel of U.K. companies, Quarterly Journal of Economics, 111(1), 195-226.

Woolridge, J. (2002). Econometric Analysis of Cross sections and Panel Data, Cambridge, MA: MIT Press 



\section{FINAL CONCLUSION}

This thesis analyzed the Chilean manufacturing industry, focusing on the role of innovation, labor productivity, and information flows in spurring economic growth in the industry. It went from a macroeconomic analysis of economic growth and development, describing exports and industry composition, to a meso-economic evaluation of the industry sectors and a micro-econometric analysis of manufacturing data at the firm level.

In aggregate terms, Chile has achieved economic success during the past decades. This success included high economic growth rates and improving development standards. Chile enjoys a relatively stable democracy, with an open economy, good macroeconomic policies, reasonable institutional quality, and a financial sector that facilitates transactions. Chile has among its advantages a natural resource industry that has fostered growth in other sectors. Even though copper extraction has provided growing income in recent years, it is important for the economy to diversify production to include other exports that can be produced through the accumulation of knowledge, instead of reliance on a natural resource that is exhaustible and subject to price fluctuations. One of the challenges for the future is to develop an economy that grows sustainably. Innovations, public education, export market diversity, inequality of income, and mining exports revenue allocation are some of the most important concerns to which economists and politicians should pay attention in the near future.

Exogenous fluctuations in the price of copper have a huge impact on Chilean exchange rates, creating distortions in other markets and threatening the stability of other exporting industries. Stimulating industrial investment, facilitating the import of capital goods, improving the educational system, and promoting R\&D are some of the state's most important roles for promoting diversified economic growth in the next decades. The National Innovation System established in Chile in 2006 implies greater growth opportunities but it is not alone going to generate the growth potential that Chile needs for the future. Becoming internationally competitive in diversified manufactured goods and services requires innovation and the development of other capacities that were not needed for the export of primary commodities like copper.

A section of this work has empirically measured R\&D cooperation determinants among Chilean innovating firms during the years 2003-2004. The data used for this study came from the Fourth Chilean Innovation Survey (2005) and had the feature of distinguishing among different kinds of $\mathrm{R} \& \mathrm{D}$ partners with which firms can cooperate. 
The empirical model related the probability of R\&D cooperation to information flows and innovation restrictions among firms that have innovated.

The findings showed that incoming spillovers determine a significantly greater probability of R\&D cooperation among innovative firms. This is seen in all regressions, independently of which kind of partner is being considered. Incoming spillovers or information flows affect cooperation with universities and with consulting agents to a larger extent than cooperation with competitors, suppliers, and customers. These results imply that one way to promote innovation is to improve access to information flows that are public but do not always find their way to the minds of those that can use them to achieve an innovation. Promoting information spillovers could happen through the collection and sharing of data that is relevant to markets, such as prices and product characteristics. Information flows are also stronger if the know-how of many of the industries in the market are easily accessible to everyone who wants to learn. If education promotes information flows, and information flows spur R\&D cooperation and innovation, than a better and deeper educational system is the path toward economic success.

This empirical analysis also found that the use of legal protection to protect firms' knowledge has a positive effect on cooperation. This shows that, in order to promote $\mathrm{R} \& \mathrm{D}$ cooperation agreements, the state should protect the legal rights of those products and designs that are patented or protected by legitimate secrecy agreements. The authority should also offer a serious commitment to consign patent rights to organizations or individuals that create innovations that are new to the market.

This work has also studied the relation between inputs, prices, product innovation, and productivity at the firm level using Chilean data for the period 1996-2003. Besides using firm-level industrial data, this study had the advantage of an additional survey form that collected information at the level of products inside firms. We compared the estimation of the revenue function (using a nominal output measure) and the production function (using a real output measure). The outcomes were also compared to the usual case in which output is deflated by an industry level deflator.

Results showed that estimating the production or revenue function does not yield significantly different results when a variety of deflators are used to express output in constant prices. This may indicate that price dispersion is not large enough to cause a significant bias on the non-deflated or industry deflated estimates.

This study found evidence that product diversification has a positive effect on manufacturing productivity. It seems that variations in the range of products manufactured by firms have an impact on the level and the rate of growth of average output per employee. In particular, the incorporation of new products is clearly associated with a higher and increasing level of productivity among Chilean manufacturing firms. The findings also show that dropping products has an immediate negative effect on labor productivity. This suggests that the reduction in output associated with products dropped is not contemporaneously accompanied by a reduction in labor, probably due to labor input rigidities. 
This work adds to the literature by incorporating some new measures of product innovation into the traditional productivity estimates. Additionally, this study proposed a measure for firm-level yearly price change. Using this measure, nominal output can be expressed in real terms to separate the growth of physical output from the growth of product prices.

The last part of this research has estimated an empirical model to measure price cost markups and workers' bargaining power, expressed in terms of input elasticities and input shares on sales. The empirical model used is based on the idea of a production function that can be expressed in terms of the rates of growth of inputs and output. The estimation of the Solow residual allows obtaining parameters that measure markup and workers' bargaining power.

The industry was divided into seven sectors to allow comparing the results across industries. At the manufacturing level, this work found evidence that, on average, imperfect competition observed through high price-cost markups predominates in the final good markets. At the industry level, results also showed that imperfect competition applies across all the Chilean manufacturing sectors that were evaluated in this study. From the estimations in levels, the industry of Paper, Printing, and Publishing appears to have the lowest markup of price over cost, followed by the Textiles industry. Food and Beverages has been found to have the largest markup, even though returns to scale are nearly constant. Results also showed that workers have little bargaining power over rents generated in Chilean industry. The sector in which employees appeared to have a relatively higher degree of market power was Manufacture of Food, Beverages, and Tobacco. Other sectors where workers enjoy some degree of rent sharing are Manufactures of Wood, Wood Products, and Furniture and Non-Metallic Minerals and Other Manufacturing. These sectors were also found to be those that, on average, are able to yield higher markups. On the other hand, those sectors where markups were found to be lower are also the ones where the share obtained by workers is smaller. 



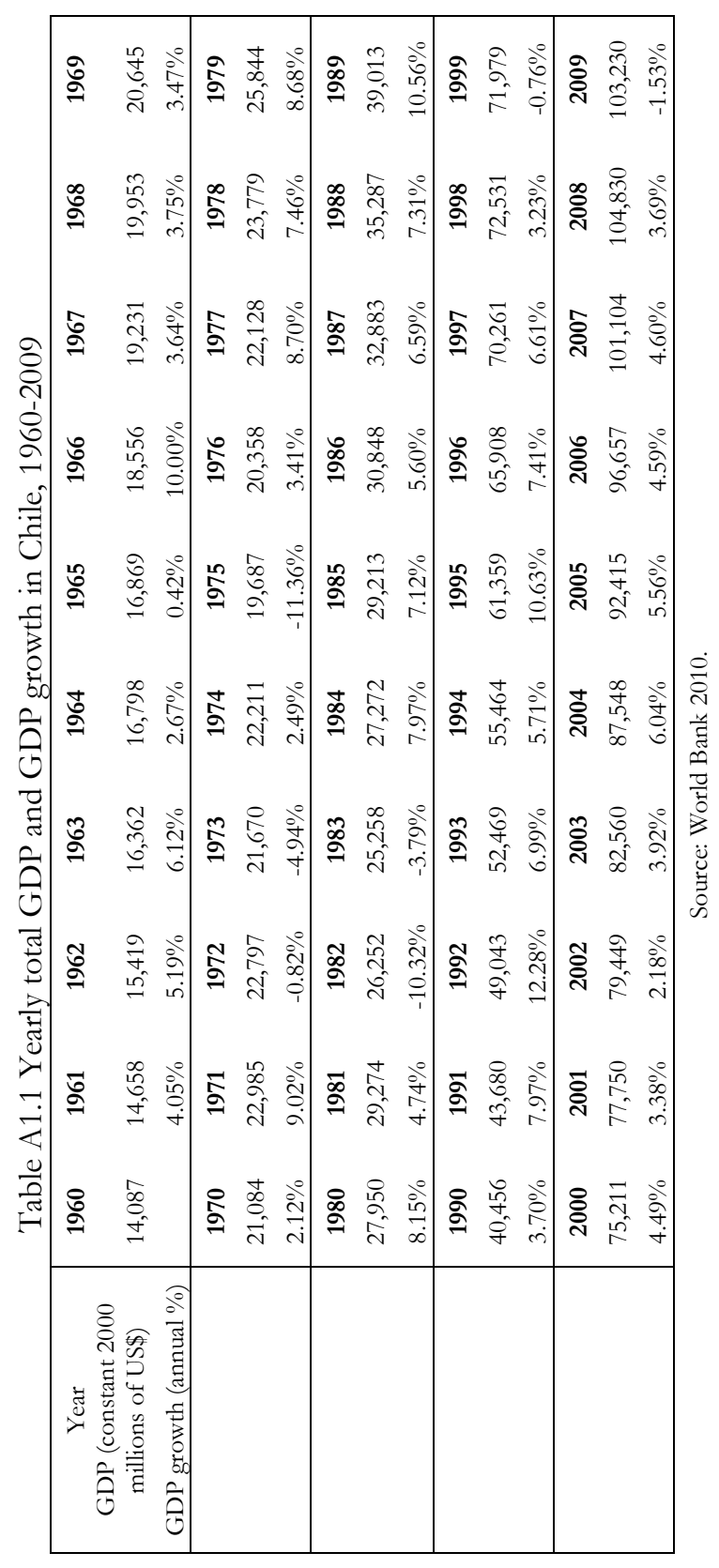


Table A1.2 Average Per capita Income and GINI Index in Chile, 1980-2009

\begin{tabular}{|c|c|c|}
\hline Year & $\begin{array}{l}\text { GDP per capita, PPP } \\
\text { (constant } 2005 \text { US\$) }\end{array}$ & GINI index \\
\hline 1980 & 5,366 & \\
\hline 1981 & 5,536 & \\
\hline 1982 & 4,887 & \\
\hline 1983 & 4,627 & \\
\hline 1984 & 4,914 & \\
\hline 1985 & 5,178 & \\
\hline 1986 & 5,377 & \\
\hline 1987 & 5,636 & 56.43 \\
\hline 1988 & 5,947 & \\
\hline 1989 & 6,462 & \\
\hline 1990 & 6,583 & 55.52 \\
\hline 1991 & 6,980 & \\
\hline 1992 & 7,695 & \\
\hline 1993 & 8,084 & \\
\hline 1994 & 8,398 & 55.19 \\
\hline 1995 & 9,140 & \\
\hline 1996 & 9,669 & 55.06 \\
\hline 1997 & 10,162 & \\
\hline 1998 & 10,352 & 55.74 \\
\hline 1999 & 10,144 & \\
\hline 2000 & 10,470 & 55.36 \\
\hline 2001 & 10,697 & \\
\hline 2002 & 10,807 & \\
\hline 2003 & 11,107 & 54.92 \\
\hline 2004 & 11,653 & \\
\hline 2005 & 12,172 & \\
\hline 2006 & 12,599 & 52 \\
\hline 2007 & 13,045 & \\
\hline 2008 & 13,390 & \\
\hline 2009 & 13,057 & \\
\hline
\end{tabular}

Source: World Bank (2010) and Central Bank of Chile (2010). 
Table A1.3 Interest Rate, Inflation Rate and Unemployment rate in Chile, 1980-2009

\begin{tabular}{|c|c|c|c|}
\hline Year & $\begin{array}{c}\text { Deposit interest } \\
\text { Rate }(\%)\end{array}$ & $\begin{array}{c}\text { Inflation } \\
\text { (annual \%) }\end{array}$ & $\begin{array}{c}\text { Unemployment, total } \\
\text { (\% of labor force) }\end{array}$ \\
\hline 1980 & 37.72 & 35.14 & 10.41 \\
1981 & 40.90 & 19.69 & 11.31 \\
1982 & 48.68 & 9.94 & 19.60 \\
1983 & 28.01 & 27.27 & 14.65 \\
1984 & 27.63 & 19.86 & 13.89 \\
1985 & 32.10 & 29.46 & 12.17 \\
1986 & 19.04 & 20.61 & 8.73 \\
1987 & 25.28 & 19.89 & 7.90 \\
1988 & 15.16 & 14.68 & 6.26 \\
1989 & 27.79 & 17.03 & 5.32 \\
\hline 1990 & 40.35 & 26.03 & 5.66 \\
1991 & 22.35 & 21.78 & 5.27 \\
1992 & 18.29 & 15.43 & 4.41 \\
1993 & 18.24 & 12.73 & 4.49 \\
1994 & 15.12 & 11.44 & 5.87 \\
1995 & 13.73 & 8.24 & 4.71 \\
1996 & 13.48 & 7.36 & 6.33 \\
1997 & 12.02 & 6.14 & 6.12 \\
1998 & 14.92 & 5.11 & 6.34 \\
1999 & 8.56 & 3.34 & 9.81 \\
\hline 2000 & 9.20 & 3.84 & 9.16 \\
2001 & 6.19 & 3.57 & 9.13 \\
2002 & 3.80 & 2.49 & 8.94 \\
2003 & 2.73 & 2.81 & 8.50 \\
2004 & 1.94 & 1.05 & 8.81 \\
2005 & 3.93 & 3.05 & 8.00 \\
2006 & 5.11 & 3.39 & 7.69 \\
2007 & 5.61 & 4.41 & 7.14 \\
2008 & 7.49 & 8.70 & 7.80 \\
2009 & 2.05 & 1.50 & 9.69 \\
\hline $504 c e$ & $B 9$ & \\
\hline
\end{tabular}

Source: World Bank (2010) and Central Bank of Chile (2010). 
Table A1.4 Chilean Consolidated Public Debt, 1990-2008

\begin{tabular}{|c|c|c|}
\hline Year & Current US\$ Millions & $\%$ of GDP \\
\hline 1990 & 9,611 & 30.46 \\
1991 & 8,698 & 23.88 \\
1992 & 8,251 & 18.56 \\
1993 & 7,824 & 16.4 \\
1994 & 7,390 & 13.4 \\
1995 & 5,755 & 8.07 \\
1996 & 4,729 & 6.24 \\
1997 & 4,380 & 5.29 \\
1998 & 3,796 & 4.78 \\
1999 & 3,935 & 5.39 \\
\hline 2000 & 4,832 & 6.38 \\
2001 & 4,209 & 6.14 \\
2002 & 3,568 & 5.3 \\
2003 & 6,140 & 8.3 \\
2004 & 5,814 & 6.08 \\
2005 & 3,250 & 2.75 \\
2006 & $-8,899$ & -6.08 \\
2007 & $-23,284$ & -14.21 \\
2008 & $-40,630$ & -23.77 \\
\hline
\end{tabular}

Source: Author's calculations using data from Central Bank of Chile (2010). 
Table A1.5 Labor Market Development Indicators in Chile, 1980-2009

\begin{tabular}{|c|c|c|c|c|}
\hline Year & $\begin{array}{c}\text { Urban } \\
\text { population }(\% \text { of } \\
\text { total })\end{array}$ & $\begin{array}{c}\text { Labor force, } \\
\text { female }(\% \text { of total } \\
\text { labor force) }\end{array}$ & $\begin{array}{c}\text { School enrollment, } \\
\text { secondary ( } \% \\
\text { gross) }\end{array}$ & $\begin{array}{l}\text { Ratio of female } \\
\text { to male tertiary } \\
\text { enrollment }(\%)\end{array}$ \\
\hline 1980 & 81.20 & 29.29 & 62.52 & 77.04 \\
\hline 1981 & 81.48 & 28.85 & 63.37 & \\
\hline 1982 & 81.76 & 29.79 & 63.88 & \\
\hline 1983 & 82.04 & 30.68 & 68.84 & 74.56 \\
\hline 1984 & 82.32 & 30.76 & 71.93 & 75.88 \\
\hline 1985 & 82.60 & 29.38 & 75.57 & 77.83 \\
\hline 1986 & 82.74 & 29.44 & 77.73 & 79.73 \\
\hline 1987 & 82.88 & 29.81 & & 81.43 \\
\hline 1988 & 83.02 & 30.16 & 82.51 & \\
\hline 1989 & 83.16 & 30.25 & 81.10 & \\
\hline 1990 & 83.30 & 30.49 & 78.19 & \\
\hline 1991 & 83.52 & 30.35 & 97.27 & \\
\hline 1992 & 83.74 & 31.54 & 97.42 & \\
\hline 1993 & 83.96 & 32.34 & 77.38 & 85.21 \\
\hline 1994 & 84.18 & 32.33 & & 86.25 \\
\hline 1995 & 84.40 & 31.89 & & 86.02 \\
\hline 1996 & 84.70 & 32.31 & & 85.30 \\
\hline 1997 & 85.00 & 32.92 & & 87.40 \\
\hline 1998 & 85.30 & 33.38 & 78.06 & 87.62 \\
\hline 1999 & 85.60 & 33.55 & 79.50 & 91.43 \\
\hline 2000 & 85.90 & 33.40 & 82.70 & 91.70 \\
\hline 2001 & 86.24 & 33.27 & & \\
\hline 2002 & 86.58 & 33.60 & 85.57 & 93.14 \\
\hline 2003 & 86.92 & 34.34 & 87.80 & 94.42 \\
\hline 2004 & 87.26 & 35.57 & 89.15 & 95.05 \\
\hline 2005 & 87.60 & 35.42 & 90.79 & 95.69 \\
\hline 2006 & 87.88 & 35.76 & 91.18 & 99.67 \\
\hline 2007 & 88.16 & 36.84 & 90.60 & 100.76 \\
\hline 2008 & 88.44 & 37.52 & 90.39 & 102.83 \\
\hline 2009 & 88.72 & 37.18 & & \\
\hline
\end{tabular}

Source: World Bank 2010. 
Table A1.6 Development Indicators in Chile, 1980-2009

\begin{tabular}{|c|c|c|c|c|}
\hline Year & $\begin{array}{c}\text { Life expectancy } \\
\text { at birth, total } \\
\text { (years) }\end{array}$ & $\begin{array}{c}\text { Fertility rate, } \\
\text { total (births } \\
\text { per woman) }\end{array}$ & $\begin{array}{c}\text { Mobile } \\
\text { phones (per } \\
100 \text { people) }\end{array}$ & $\begin{array}{c}\text { Internet users } \\
\text { (per } 100 \\
\text { people) }\end{array}$ \\
\hline 1980 & 69.06 & 2.68 & & \\
\hline 1981 & 69.73 & 2.66 & & \\
\hline 1982 & 70.35 & 2.65 & & \\
\hline 1983 & 70.90 & 2.65 & & \\
\hline 1984 & 71.39 & 2.66 & & \\
\hline 1985 & 71.83 & 2.66 & & \\
\hline 1986 & 72.21 & 2.66 & & \\
\hline 1987 & 72.56 & 2.65 & 0.00 & \\
\hline 1988 & 72.90 & 2.65 & 0.00 & \\
\hline 1989 & 73.23 & 2.64 & 0.04 & \\
\hline 1990 & 73.55 & 2.62 & 0.11 & 0.00 \\
\hline 1991 & 73.87 & 2.60 & 0.27 & 0.00 \\
\hline 1992 & 74.16 & 2.56 & 0.47 & 0.04 \\
\hline 1993 & 74.45 & 2.51 & 0.61 & 0.07 \\
\hline 1994 & 74.72 & 2.45 & 0.82 & 0.14 \\
\hline 1995 & 75.00 & 2.39 & 1.37 & 0.35 \\
\hline 1996 & 75.31 & 2.32 & 2.18 & 0.68 \\
\hline 1997 & 75.64 & 2.25 & 2.76 & 1.06 \\
\hline 1998 & 76.01 & 2.19 & 6.41 & 1.66 \\
\hline 1999 & 76.40 & 2.13 & 14.84 & 4.10 \\
\hline 2000 & 76.80 & 2.08 & 22.06 & 16.60 \\
\hline 2001 & 77.19 & 2.05 & 32.69 & 18.74 \\
\hline 2002 & 77.54 & 2.02 & 39.57 & 19.06 \\
\hline 2003 & 77.83 & 1.99 & 45.56 & 25.47 \\
\hline 2004 & 78.07 & 1.97 & 57.43 & 28.18 \\
\hline 2005 & 78.25 & 1.96 & 64.85 & 31.18 \\
\hline 2006 & 78.39 & 1.95 & 75.61 & 34.50 \\
\hline 2007 & 78.50 & 1.94 & 83.88 & 31.03 \\
\hline 2008 & 78.61 & 1.93 & 88.05 & 32.47 \\
\hline 2009 & 78.73 & 1.93 & 96.94 & 33.98 \\
\hline
\end{tabular}

Source: World Bank 2010. 
Table A1.7 Education Expenditure in Chile, 1990-2008 (\% of current GDP)

\begin{tabular}{|c|c|c|c|}
\hline Year & $\begin{array}{c}\text { Public } \\
\text { Education } \\
\text { Expenditure } \\
\text { of GDP) }\end{array}$ & $\begin{array}{c}\text { Private } \\
\text { Education } \\
\text { Expenditure } \\
\text { of GDP) }\end{array}$ & $\begin{array}{c}\text { Total Education } \\
\text { Expenditure } \% \\
\text { of GDP) }\end{array}$ \\
\hline 1990 & 1.5 & 2.4 & 3.9 \\
1991 & 1.6 & 2.4 & 4 \\
1992 & 1.7 & 2.5 & 4.2 \\
1993 & 1.9 & 2.7 & 4.6 \\
1994 & 2 & 2.8 & 4.8 \\
1995 & 2 & 2.7 & 4.7 \\
1996 & 2.2 & 3 & 5.2 \\
1997 & 2.2 & 3.2 & 5.4 \\
1998 & 2.6 & 3.5 & 6.1 \\
1999 & 2.9 & 3.8 & 6.7 \\
\hline 2000 & 2.9 & 3.9 & 6.8 \\
2001 & 2.9 & 4.1 & 7 \\
2002 & 3 & 4.1 & 7.1 \\
2003 & 3.1 & 4.1 & 7.2 \\
2004 & 3 & 3.9 & 6.9 \\
2005 & 2.9 & 3.7 & 6.6 \\
2006 & 2.7 & 3.3 & 6.9 \\
2007 & 2.5 & 3.6 & \\
2008 & 2.7 & 4.2 & 6 \\
\hline
\end{tabular}

Source: MINEDUC (2010) 
Table A1.8 Manufacture Exports, Copper Exports and GDP in Chile, 1980-2009

\begin{tabular}{|c|c|c|c|}
\hline Year & $\begin{array}{l}\text { Manufacture exports } \\
\text { (current millions US\$) }\end{array}$ & $\begin{array}{c}\text { Copper Exports } \\
\text { (current millions US\$) }\end{array}$ & $\begin{array}{l}\text { GDP (current } \\
\text { millions US\$) }\end{array}$ \\
\hline 1980 & 4,278 & 21,525 & 275,723 \\
\hline 1981 & 2,958 & 17,126 & 326,449 \\
\hline 1982 & 2,697 & 16,698 & 243,394 \\
\hline 1983 & 2,578 & 18,504 & 197,704 \\
\hline 1984 & 2,684 & 15,703 & 192,327 \\
\hline 1985 & 2,612 & 17,600 & 164,860 \\
\hline 1986 & 3,623 & 17,501 & 177,225 \\
\hline 1987 & 4,670 & 22,267 & 209,021 \\
\hline 1988 & 6,444 & 34,774 & 246,409 \\
\hline 1989 & 8,371 & 39,447 & 283,850 \\
\hline 1990 & 9,420 & 38,496 & 315,589 \\
\hline 1991 & 11,954 & 36,031 & 364,242 \\
\hline 1992 & 13,615 & 39,103 & 444,679 \\
\hline 1993 & 15,215 & 32,657 & 476,940 \\
\hline 1994 & 19,565 & 44,854 & 551,542 \\
\hline 1995 & 21,606 & 63,921 & 713,492 \\
\hline 1996 & 24,389 & 58,385 & 757,690 \\
\hline 1997 & 27,862 & 68,510 & 828,090 \\
\hline 1998 & 28,182 & 53,237 & 793,736 \\
\hline 1999 & 28,858 & 61,638 & 729,953 \\
\hline 2000 & 31,197 & 72,863 & 752,105 \\
\hline 2001 & 32,902 & 65,259 & 685,683 \\
\hline 2002 & 30,980 & 62,793 & 672,654 \\
\hline 2003 & 33,342 & 75,530 & 739,896 \\
\hline 2004 & 41,761 & 145,300 & 956,527 \\
\hline 2005 & 53,196 & 177,626 & $1,182,496$ \\
\hline 2006 & 63,338 & 333,506 & $1,467,726$ \\
\hline 2007 & 69,114 & 379,132 & $1,643,152$ \\
\hline 2008 & 84,469 & 365,502 & $1,708,503$ \\
\hline 2009 & 60,282 & 262,711 & $1,636,691$ \\
\hline
\end{tabular}

Source: World Bank (2010) and COCHILCO (2009) 


\section{Appendix 2 R\&D Cooperation Determinants Model Variable Definitions}

Cooperation: Variable that takes the value 0 if the firm does not declare that it has cooperated on innovative activities with any other agent (suppliers, clients, competitors, consultants, universities, research institutes) and takes the value 1 if the firm has declared that it cooperates with at least one of them.

Cooperation with competitors: Variable that takes the value 1 when the firm has declared that it cooperates with its competitors in innovating and takes the value 0 otherwise.

Cooperation with Consultants: Variable that takes the value 1 when the firm has declared that it cooperates with private consultants or R\&D laboratories in innovating, and takes the value 0 otherwise.

Cooperation with Suppliers or Customers: Variable that takes the value 1 when the firm has declared that it cooperates with its suppliers or customers in innovating, and takes the value 0 otherwise.

Cooperation with Universities: Variable that takes the value 1 when the firm has declared that it cooperates with universities or public research institutes in innovating, and takes the value 0 otherwise.

Incoming Spillovers: Variable that takes the value 0 if innovation ideas are not originated by professional conferences, exhibitions, meetings, and journals, and takes values between 1 (low) and 4 (high) when these sources are declared to be sources for innovating ideas. Rescaled between 1 (high) and 0 (not relevant).

Basic nature of R\&D: Variable that takes the value 0 if innovation ideas are not originated by institutional sources and takes values between 1 (low) and 4 (high) when institutional sources are declared to be sources for innovating ideas. Rescaled between 1 (high) and 0 (not relevant).

Lack of Information: Variable that takes the value 0 if lack of information is not an obstacle for the innovative process, as declared by the firm, and takes values between 1 (low importance) and 4 (high importance) when the lack of information is an obstacle for innovating. Rescaled between 0 (not relevant) and 1 (high). 
Legal Protection: Variable that takes the value 0 if the firm has no patents or know-how agreements and takes the value 1 otherwise.

Cost-Risk: Sum of the scores of importance of the following declared obstacles to innovating (values between 0 (not relevant) and 4 (very important obstacle)): Difficulty in finding sources of finance; High cost of innovating; High risk perceived; Payback period too long. Rescaled between 0 (not relevant) and 1 (high).

Industry Level Imitation: Mean of Imitation for each industry. The industry has been defined with a 2-digit classification.

Industry Level of Incoming Spillovers: Mean of Incoming Spillovers for each industry. The industry has been defined with a 2-digit classification.

Industry Level of Legal Protection: Mean of Legal Protection for each industry. The industry has been defined with a 2-digit classification.

Industry Level of Cooperation: Mean of Cooperation for each industry. The industry has been defined with a 2-digit classification.

Industry Level of Cooperation with Competitors: Mean of Cooperation with Competitors for each industry. The industry has been defined with a 2-digit classification.

Industry Level of Cooperation with Consultants: Mean of Cooperation with Consultants for each industry. The industry has been defined with a 2-digit classification.

Industry Level of Cooperation with Suppliers or Customers: Mean of Cooperation with Suppliers or Customers for each industry. The industry has been defined with a 2digit classification.

Industry Level of Cooperation with Universities: Mean of Cooperation with Universities for each industry. The industry has been defined with a 2-digit classification.

R\&D Intensity: Ratio between intramural R\&D expenditures and turnover.

Size: Log of number of employees of the firm.

Size squared: square of log of number of employees. 


\section{Appendix 3 Chilean Survey Data on Manufacturing and Innovation}

\section{A3.1 Introduction to the Data}

This appendix describes a database and the variables that will be used as the basis of production function regressions. The databases that have been reproduced, combined, and edited for the purposes of this research have their origin in the Chilean Manufacturing Industry and are focused on an 8-year period from 1996 to 2003. The firm-level Chilean Industrial survey "Encuesta Nacional Industrial Anual (ENIA)" collects detailed yearly data on firms' basic characteristics, employment, wages, inputs, energy consumption and energy production, external services, depreciation, interest, taxes, capital goods, investment, sales, other income, inventories, and monetary correction based on the consumer price index. An additional survey questionnaire form (Formulario 3) has been applied to a subsample of the ENIA firms. This survey provides yearly information on product quantities and prices for each production line within firms, offering a very detailed description of products and also providing information on inventories and exports. When necessary, and in order to answer particular questions about firms' knowledge creation, this research will also make use of the Chilean Innovation Survey databases, which have been collected during the same period by the Chilean Statistical Office (INE) every three years on behalf of the Chilean Ministry of Economics.

All survey data used and described in this section was collected by the Chilean National Statistical Office. A Chilean public statistical institution was firstly established by law in 1843. At the present time, "Instituto Nacional de Estadisticas" (INE) is a technical agency that produces, analyzes, and publishes the official and public Chilean statistics. INE provides economic, social, demographic, environmental, and census data and cooperates with the OECD statistical unit in order to maintain internationally comparable databases These databases allow public, private, and research agents to make informed and responsible decisions, allowing the development of an open and democratic society. The institution employs more than 1500 people and has gained the credibility among its users based on the laws and norms that govern its behavior.

In what follows, we first describe the original files used to create a main database, and we discuss how the information was merged. Secondly, we describe the creation of the main database, the most important variables that were defined, and the basic cleaning of the data. Finally, we present a set of preliminary non-deflated panel data production function estimates. 


\section{A3.2 Panel Data from Different Surveys}

Firm-level Industrial Survey data was obtained from Chilean firms for each year of the period 1996-2003. A difficulty arises in combining all the available survey data across years since the statistical office has used three identification variables at different stages of the data collection. This created different databases that were not merged easily, despite the fact that they contain information on the same group of firms. The ID variables "Padron" and "Nui" identify establishments as productive units; that is to say they disregard the fact that some manufacturing firms may be sold or simply change owners over time. The third ID variable "Rol" considers the manufacturing firm as a tributary unit. Whenever a firm changed its tributary identification R.U.T. because of an acquisition or a tributary condition change, a new "Rol" identification value was assigned to that establishment.

In the Chilean industrial survey ENIA, there was a change on the definition of the identification variable that took place in 2001. The establishment identifier used previously, "Padron," was replaced by "Nui" (Unique identification number). This way, instead of providing a match with both ID variables, two different files containing ENIA survey data were made available for the year 2001. The main divergence among these files is the identification variable that they use. One of the files uses as an ID the variable "Padron," which was used for the last time in 2001. The second file identifies the observations with a new ID variable named "Nui," which has been used from 2001 onward. Another difference between these files is the number of observations that they contain. The divergence in the number of observations is due to the existence in both files of different numbers of firms that did not answer or incompletely answered the survey in 2001. Incomplete observations will be deleted in further stages of the data analysis, but may be useful at this stage as we match the two ID variables together.

In order to create a panel that could merge the observations before and after 2001, it was necessary to merge the two 2001 ENIA databases according to other variables in a way that they would not produce duplicates. The combination of four variables produced no repeated observations in either 2001 version of the database. Therefore, the matching of the observations from these two databases has allowed connecting each observation identified with Padron to the same observation identified with Nui. The variables that were used to connect the two identification variables are:

- Legal Organization (with 9 different categories)

- Total Male Workers

- Total Income

- Value Added

Because there are no duplicate firms in any of the 2001 versions of the ENIA in terms of these four variables, we can merge the firms from the two databases one by one. As a result, we were able to obtain the correspondence of Padron and Nui for 3,895 firms that were present in both 2001 databases

Product-firm level data was collected for a large subsample of the Chilean Industrial Survey (ENIA) during the period 1996-2003. We have used two files containing product level data from 1996 to 1999 and from 1999 to 2003, respectively. The data is raw in the 
sense that it contains a number of missing values and incomplete entries. Consequently, some observations will have to be deleted with a careful cleaning before performing any estimation procedures.

The two product-firm level databases have codified observations with different firmlevel identification variables. In the first database (1996-1999), the firm ID was defined as "Rol," while in the second (1999-2003) it was defined as "Nui." Therefore we took the observations of the year 1999 from both databases and merged them together using a similar algorithm as the one described above, which was used for merging the two ENIA ID variables. For this procedure, observations were merged according to the other eight variables on each file. The variables included in two of these (1999) databases are:

- Product Code

- Product Name

- Initial Stock

- Units Sold

- Value Sold

- Sales Tax

- Final Stock

- Exported Share

In this exercise using both databases, 14 observations turned out to be duplicated according to the eight listed variables. These were deleted from the sample because it was impossible to merge those observations for the two sample periods. There were 22 firms that were identified with a single "Rol" in 1999 but were separated into 2 different "Nui," most likely for having their production divided into two physical establishments. These firms were dropped from the sample to avoid further discrepancies and duplicated ID values. As a result, we were able to obtain the merge for 3,349 firms that were present in both databases.

Table A3.1 provides information on the number of observations that were made available by the statistical office for each survey in each year. The last column represents the number of establishments that were surveyed in each year and for which we could identify the three IDs (Nui, Padron and Rol).

Additionally, two files containing useful merging information were obtained from the Chilean Statistical Office. In the first place, a file contained 5,480 observations with "Padron" and "Rol". A second file provided the match between "Rol" and "Nui" for 1,020 observations for which we also have the 2003-2004 innovation survey.

There is a subset with 4,055 establishments for which the correlative Pardon-RolNui was built from the information above. From this group, a total of 3,890 establishments had information at the firm level and at the product level for at least one single year. Our unbalanced panel is then made by these 3,890 firms, while those firms that do not have both ENIA and product-quantity data were dropped and will not be used for this study. A preliminary unclean balanced panel of firms that contains firm-level and product-level information has 1733 observations in all eight years from 1996 to 2003.

In the Chilean Industrial Survey, establishments are separated into economic sectors disaggregated at the four-digit level ISIC rev2 and ISIC rev3. Whenever an observation 
has more than one value for one sector variable in different versions (years) of the survey, the mode of this variable at the level of establishment will replace the sector of multi-sectorial firms whenever the objective of a certain calculation implies locating the firm into one specific economic sector. This constraint may be removed in further stages of this study to allow for the existence of multi-sector firms where such an assumption may seem a more appropriate idea.

Table A3.1 Number of Observations in Firm-level and Product-firm level Data

\begin{tabular}{|c|c|c|c|c|c|}
\hline & \multicolumn{2}{|c|}{ ENIA Form 1 } & \multicolumn{2}{c|}{ ENIA Form 3 } & Resulting matching \\
\hline Year $\backslash$ ID & Padron & Nui & Nui & Rol & Nui-Padron-Rol \\
\hline 1996 & 5,466 & & & 5,208 & 3,528 \\
1997 & 5,243 & & & 5,115 & 3,603 \\
1998 & 4,820 & & & 4,740 & 3,631 \\
1999 & 4,004 & & 4,555 & 4,037 & 3,431 \\
2000 & 4,549 & & 4,403 & & 3,482 \\
2001 & 4,651 & 5,042 & 4,495 & & 3,597 \\
2002 & & 5,375 & 4,808 & & 3,394 \\
2003 & & 5,353 & 4,796 & & 3,117 \\
\hline
\end{tabular}

Note: Firm-level ENIA Form 1 data identified observations with the variable "padron" from 1996 to 2001 and with the variable "nui" from 2001 to 2003. Product-firm level data collected with ENIA Form 3 was identified with "rol" from 1996 to 1999 and with "nui” from 1999 to 2003. The last column indicates the number of observations for which both firm-level and product-firm level information was observed

The 1,020 manufacturing establishments surveyed in the 2003-2004 Fourth Innovation Survey can be merged with the respective Industrial Survey and Product Survey for the case of most firms that also answered these questionnaires. Additionally, the 560 establishments that answered the 2000-2001 Third Innovation Survey can be matched to the respective Industrial Survey and Product Survey whenever those firms additionally answered one or both of those separate surveys.

\section{A3.3 Creation of a Firm-Level Panel Database}

A set of firm-level variables was created to incorporate relevant parts of the information provided at the product-firm level. Each year of the product-firm level data was merged with the ENIA survey at the firm level and product-firm level variables were dropped. All years were afterwards appended together to create a panel. All variables linearly dependent which contained no observations were deleted. All variables containing only 0 values were also deleted. In some years, the variable names from the ENIA survey were incorrectly defined in the original files. The variable names were corrected in such a way that they all can be matched with the variable definition file that was provided separately by the statistical office. A main database was created and all the variables were labeled and ordered according to the ENIA Methodological Report (2005). 


\section{A3.4 Measurement of Book Value of Capital}

Our definition of book value of capital is the reported book value of capital in year $\mathrm{t}$ 1 plus the value of net investment in period t. Deflated book value of capital is expressed in terms of the first year prices. A detailed disaggregation at the 2-digit industry level may be found in tables A3.2 and A3.3. Table A3.2 shows book value of capital net growth and finds that, across industries and years, the average capital growth was $9.8 \%$ for the whole Chilean manufacturing industry. We see in Table A3.3 that investment varied and presented the highest values in industries 32,33 and 37.

Table A3.2 Average Industry-level Yearly Growth of Capital Book Value

\begin{tabular}{|c|c|c|c|c|c|c|c|c|c|c|}
\hline & 31 & 32 & 33 & 34 & 35 & 36 & 37 & 38 & 39 & Average \\
\hline 1997 & $15.2 \%$ & $3.9 \%$ & $10.0 \%$ & $17.2 \%$ & $8.6 \%$ & $21.2 \%$ & $27.7 \%$ & $16.9 \%$ & $19.1 \%$ & $15.5 \%$ \\
1998 & $11.1 \%$ & $13.9 \%$ & $7.1 \%$ & $7.4 \%$ & $13.9 \%$ & $6.4 \%$ & $15.4 \%$ & $17 . \%$ & $13.5 \%$ & $11.8 \%$ \\
1999 & $11.4 \%$ & $7.9 \%$ & $13.4 \%$ & $27.2 \%$ & $18.1 \%$ & $1.2 \%$ & $-8.3 \%$ & $5.2 \%$ & $5.1 \%$ & $9.0 \%$ \\
2000 & $14.1 \%$ & $10.2 \%$ & $23.4 \%$ & $12.9 \%$ & $13.6 \%$ & $22.0 \%$ & $11.9 \%$ & $11 . \%$ & $22.7 \%$ & $15.8 \%$ \\
2001 & $8.8 \%$ & $-5.3 \%$ & $-1.8 \%$ & $2.6 \%$ & $-10.4 \%$ & $9.0 \%$ & $2.7 \%$ & $-0.7 \%$ & $20.4 \%$ & $2.8 \%$ \\
2002 & $5.5 \%$ & $11.1 \%$ & $13.8 \%$ & $1.7 \%$ & $18.1 \%$ & $6.3 \%$ & $10.6 \%$ & $9.7 \%$ & $-1.4 \%$ & $8.4 \%$ \\
2003 & $5.4 \%$ & $8.4 \%$ & $1.7 \%$ & $11.8 \%$ & $5.7 \%$ & $-2.3 \%$ & $1.3 \%$ & $-1.8 \%$ & $8.0 \%$ & $5.4 \%$ \\
Average & $10.2 \%$ & $7.2 \%$ & $11.1 \%$ & $11.5 \%$ & $9.7 \%$ & $9.1 \%$ & $8.8 \%$ & $8.3 \%$ & $12.5 \%$ & $9.8 \%$ \\
\hline
\end{tabular}

Note: (31) Manufacture of Food, Beverages and Tobacco, (32) Textile, Wearing Apparel and Leather Industries, (33)

Manufacture of Wood and Wood Products, Including Furniture, (34) Manufacture of Paper and Paper Products, Printing and Publishing, (35) Manufacture of Chemicals and Chemical, Petroleum, Coal, Rubber and Plastic Products, (36) Manufacture of Non-Metallic Mineral Products, except Products of Petroleum and Coal, (37) Basic Metal Industries, (38) Manufacture of Fabricated Metal Products, Machinery and Equipment, (39) Other Manufacturing Industries.

Table A3.3 Average Industry-level Yearly Capital Investment

\begin{tabular}{|c|c|c|c|c|c|c|c|c|c|c|}
\hline & 31 & 32 & 33 & 34 & 35 & 36 & 37 & 38 & 39 & Average \\
\hline 1997 & $11.7 \%$ & 139.6 & $19.8 \%$ & $11.7 \%$ & $16.7 \%$ & $19.3 \%$ & $21.8 \%$ & $10.6 \%$ & $9.3 \%$ & $28.9 \%$ \\
1998 & $9.6 \%$ & $8.7 \%$ & $19.2 \%$ & $9.7 \%$ & $16.9 \%$ & $8.9 \%$ & $88.4 \%$ & $12.5 \%$ & $54.0 \%$ & $25.3 \%$ \\
1999 & $9.0 \%$ & $5.0 \%$ & $44.4 \%$ & $16.3 \%$ & $11.8 \%$ & $4.4 \%$ & $1.5 \%$ & $6.7 \%$ & $3.0 \%$ & $11.3 \%$ \\
2000 & $9.8 \%$ & $7.8 \%$ & $15.6 \%$ & $5.0 \%$ & $10.7 \%$ & $2.9 \%$ & $4.6 \%$ & $4.7 \%$ & $7.9 \%$ & $7.7 \%$ \\
2001 & $14.8 \%$ & $5.3 \%$ & $9.4 \%$ & $8.9 \%$ & $10.6 \%$ & $12.1 \%$ & $8.1 \%$ & $11.4 \%$ & $3.4 \%$ & $9.3 \%$ \\
2002 & $10.7 \%$ & $9.7 \%$ & $13.8 \%$ & $3.7 \%$ & $11.7 \%$ & $10.2 \%$ & $2.8 \%$ & $13.9 \%$ & $12.1 \%$ & $9.8 \%$ \\
2003 & $9.1 \%$ & $6.2 \%$ & $15.7 \%$ & $9.5 \%$ & $-6.8 \%$ & $10.5 \%$ & $12.5 \%$ & $6.2 \%$ & $-6.5 \%$ & $6.3 \%$ \\
Average & $10.7 \%$ & $26.0 \%$ & $19.7 \%$ & $9.2 \%$ & $10.2 \%$ & $9.8 \%$ & $20.0 \%$ & $9.4 \%$ & $11.9 \%$ & $14.1 \%$ \\
\hline
\end{tabular}

Note: (31) Manufacture of Food, Beverages and Tobacco, (32) Textile, Wearing Apparel and Leather Industries, (33) Manufacture of Wood and Wood Products, Including Furniture, (34) Manufacture of Paper and Paper Products, Printing and Publishing, (35) Manufacture of Chemicals and Chemical, Petroleum, Coal, Rubber and Plastic Products, (36) Manufacture of Non-Metallic Mineral Products, except Products of Petroleum and Coal, (37) Basic Metal Industries, (38) Manufacture of Fabricated Metal Products, Machinery and Equipment, (39) Other Manufacturing Industries.

\section{A3.5 Generating Production Function Variables}

A set of variables in levels was first defined summarizing the information of output and input in levels. Capacity utilization is defined as the total number of days worked in a given year. Advertising represents the firm's yearly expenditures on publicity and advertising through all available channels. Investment is defined as the summation of the 
firm's expenses in land, buildings, machinery, and vehicles. Cost variables were also defined and grouped into employment costs and intermediates costs. All these variables were computed with the data provided by the ENIA survey (Form 1). A group of variables defined the share of costs to output considering investment, employment, and intermediates costs. A group of variables defined per-employee ratios of output, inputs, investment, and capital. The logs of these variables were generated and the first differences of the logs were defined to represent growth rates.

\section{A3.6 Basic Data Cleaning}

Only firms with five or more employees were kept in the sample; therefore 72 observations were deleted. 789 observations with zero value of capital were dropped. 144 observations were dropped for being outliers in terms of per employee ratios of capital, output, and intermediates. 275 observations were dropped for being outliers in terms of the ratios of labor to output, intermediates to output, and cost to output. Additionally 1237 observations were dropped for having outlier rates of growth in key variables such as output per employee, capital per employee, number of employees, and intermediate consumption. Finally, 24 observations were dropped for having reported a value of output at the firm level that was incompatible with the summation of the values reported at the product-firm level. In summary, 25,522 observations were reduced by $10 \%$ by deleting 2,541 undesirable values. The sample was then made using 22,981 observations in an unbalanced panel.

\section{A3.7 Summary of Main Variables and Production Variables Definitions}

Table A3.4 contains the basic descriptive statistics of the main variables of our database. Up to this stage, research variables are expressed in nominal terms. Output increased steadily during the period except in 1998 and 1999 when an external economic crisis affected the Chilean manufacturing industry. On average in 2003, the annual production of Chilean manufacturing firms was 5,845 million pesos, equivalent to approximately U.S. $\$ 10$ million. From 1996 to 2003, Chilean manufacturing industry firms increased their output on average by $45 \%$.

Capital increased on average over 35\% and did not decrease in 1998 and 1999 when output was slightly reduced by the economic crisis. On average in 2003, Chilean manufacturing firms had a capital of 2,934 million pesos, equivalent to approximately U.S. $\$ 5$ million.

The use of intermediate goods increased with output in all years except in 1998 and 1999 when output also decreased. The average use of intermediates during the 1996 to 2003 period was around 1,676 million pesos or around U.S. \$2.6 million per manufacturing firm.

Employment in the sample varied from a minimum 5 to a maximum of 3,409 employees over the period 1996 to 2003 for our group of Chilean manufacturing industry firms. The average number of employees fell in 1998 and 1999 but recovered to a level just above the starting point toward the end of our research period in 2003. 
Employment cost increased in every year of the period, except in 1999, when employment was drastically reduced. During the 1996 to 2003 period, the average Chilean manufacturing firm had an employment cost of 357 million pesos or U.S. $\$ 600,000$. After experiencing a drop in 1999, investment grew quickly from 2000 to 2003, with overall growth during the whole period 1996 to 2003 of $200 \%$.

Table A3.4 Descriptive Statistics of Basic Production Variables

\begin{tabular}{|c|c|c|c|c|c|c|c|c|}
\hline Year & stats & $Y$ & $K$ & $M$ & $L$ & $W$ & $I$ & $C U$ \\
\hline \multirow{4}{*}{$\begin{array}{c}1996 \\
(\mathrm{~N}=3,005)\end{array}$} & mean & $3,189,570$ & $1,920,987$ & $1,402,067$ & 80 & 300,415 & 179,251 & 285 \\
\hline & $\mathrm{Sd}$ & $13,700,000$ & $12,000,000$ & $5,319,424$ & 159 & $1,021,622$ & $1,152,835$ & 49 \\
\hline & Min & 18,980 & 221 & 2,485 & 10 & 5,367 & $-11,300,000$ & 108 \\
\hline & Max & $310,000,000$ & $422,000,000$ & $133,000,000$ & 3,365 & $27,600,000$ & $30,500,000$ & 365 \\
\hline \multirow{4}{*}{$\begin{array}{c}1997 \\
(\mathrm{~N}=3,013)\end{array}$} & mean & $3,357,295$ & $1,908,599$ & $1,444,890$ & 80 & 327,762 & 174,511 & 284 \\
\hline & $\mathrm{Sd}$ & $14,500,000$ & $12,800,000$ & $5,817,214$ & 163 & $1,126,637$ & $1,037,903$ & 48 \\
\hline & Min & 19,611 & 176 & 3,303 & 10 & 6,508 & $-3,294,801$ & 101 \\
\hline & Max & $299,000,000$ & $530,000,000$ & $151,000,000$ & 3,409 & $32,300,000$ & $24,200,000$ & 365 \\
\hline \multirow{4}{*}{$\begin{array}{c}1998 \\
(\mathrm{~N}=3,009)\end{array}$} & mean & $3,095,934$ & $1,950,763$ & $1,426,847$ & 76 & 330,774 & 187,231 & 284 \\
\hline & $\mathrm{Sd}$ & $11,800,000$ & $14,400,000$ & $5,484,636$ & 154 & $1,139,656$ & $1,604,108$ & 48 \\
\hline & Min & 20,684 & 491 & 3,975 & 10 & 5,600 & $-2,512,924$ & 1 \\
\hline & Max & $238,000,000$ & $545,000,000$ & $137,000,000$ & 3,274 & $32,900,000$ & $64,600,000$ & 365 \\
\hline \multirow{4}{*}{$\begin{array}{c}1999 \\
(\mathrm{~N}=2,633)\end{array}$} & mean & $2,952,459$ & $2,008,740$ & $1,271,006$ & 68 & 305,153 & 134,974 & 287 \\
\hline & $\mathrm{Sd}$ & $20,800,000$ & $26,100,000$ & $5,676,174$ & 147 & $1,336,742$ & $1,956,719$ & 49 \\
\hline & Min & 19,911 & 415 & 4,708 & 6 & 4,382 & $-1,506,842$ & 1 \\
\hline & Max & $923,000,000$ & $1,280,000,00$ & $152,000,000$ & 2,952 & $39,900,000$ & $95,400,000$ & 365 \\
\hline \multirow{4}{*}{$\begin{array}{c}2000 \\
(\mathrm{~N}=2,837)\end{array}$} & Mean & $3,506,637$ & $2,280,034$ & $1,520,149$ & 69 & 329,819 & 185,389 & 286 \\
\hline & $\mathrm{Sd}$ & $21,700,000$ & $28,200,000$ & $6,440,834$ & 142 & $1,344,722$ & $2,317,737$ & 47 \\
\hline & Min & 10,260 & 182 & 1,567 & 5 & 2,592 & $-10,600,000$ & 1 \\
\hline & Max & $956,000,000$ & $1,440,000,00$ & $163,000,000$ & 2,828 & $39,000,000$ & $73,000,000$ & 365 \\
\hline \multirow{4}{*}{$\begin{array}{c}2001 \\
(\mathrm{~N}=2,993)\end{array}$} & Mean & $4,374,042$ & $2,596,638$ & $1,818,061$ & 70 & 357,040 & 352,155 & 284 \\
\hline & $\mathrm{Sd}$ & $24,600,000$ & $34,100,000$ & $9,125,874$ & 147 & $1,393,242$ & $7,551,847$ & 48 \\
\hline & Min & 10,670 & 190 & 2,348 & 5 & 3,676 & $-7,768,427$ & 110 \\
\hline & Max & $905,000,000$ & $1,690,000,00$ & $347,000,000$ & 2,918 & $39,100,000$ & $400,000,000$ & 365 \\
\hline \multirow{4}{*}{$\begin{array}{c}2002 \\
(\mathrm{~N}=2,878)\end{array}$} & Mean & $5,406,342$ & $3,063,228$ & $2,169,489$ & 78 & 426,407 & 304,172 & 285 \\
\hline & $\mathrm{Sd}$ & $25,300,000$ & $36,200,000$ & $7,982,346$ & 168 & $1,494,770$ & $5,347,354$ & 47 \\
\hline & Min & 12,717 & 195 & 2,893 & 5 & 3,584 & $-5,691,304$ & 86 \\
\hline & Max & $859,000,000$ & $1,840,000,00$ & $176,000,000$ & 2,787 & $49,200,000$ & $277,000,000$ & 365 \\
\hline \multirow{4}{*}{$\begin{array}{c}2003 \\
(\mathrm{~N}=2,613)\end{array}$} & Mean & $5,845,103$ & $2,934,553$ & $2,417,128$ & 82 & 491,256 & 548,614 & 284 \\
\hline & $\mathrm{Sd}$ & $30,300,000$ & $32,800,000$ & $9,170,683$ & 181 & $1,933,955$ & $15,600,000$ & 47 \\
\hline & Min & 13,475 & 128 & 2,209 & 5 & 5,083 & $-7,462,902$ & 50 \\
\hline & Max & $1,170,000,000$ & $1,560,000,00$ & $196,000,000$ & 2,666 & $67,900,000$ & $789,000,000$ & 365 \\
\hline \multirow{4}{*}{$\begin{array}{c}\text { Total } \\
(\mathrm{N}=22,981)\end{array}$} & Mean & $3,945,095$ & $2,323,928$ & $1,676,188$ & 75 & 357,001 & 255,520 & 285 \\
\hline & $\mathrm{Sd}$ & $21,000,000$ & $26,100,000$ & $7,028,787$ & 158 & $1,364,514$ & $6,352,681$ & 48 \\
\hline & Min & 10,260 & 128 & 1,567 & 5 & 2,592 & $-11,300,000$ & 1 \\
\hline & Max & $1,170,000,000$ & $1,840,000,00$ & $347,000,000$ & 3,409 & $67,900,000$ & $789,000,000$ & 365 \\
\hline
\end{tabular}

Note: Firm-level data from Chilean Annual Industrial Survey (ENIA). (Y) is total output, (K) is book value of capital including machines, vehicles and buildings, $(\mathrm{M})$ is total cost of materials including raw materials, water, electricity and fuels, (L) is the number of employees, (W) is total wages paid. (I) is net investment and (CU) is capacity utilization measured by the number of days worked yearly.

Our measure of capacity utilization is the number of days worked during the year. The average number of days worked during the year is 284 and presents little variation in 
time. Nevertheless, this value is higher in 1999 and 2000. This may be due to the financial crisis that affected other average values among the variables of the ENIA survey.

Table A3.5 Descriptive Statistics of Basic Production Variables Expressed in Ratios

\begin{tabular}{|c|c|c|c|c|c|c|c|c|}
\hline Year & Stats & $\frac{W}{Q}$ & $\frac{M}{Q}$ & $\frac{C}{Q}$ & $\frac{I}{Q}$ & $\frac{Q}{L}$ & $\frac{K}{L}$ & $\frac{M}{L}$ \\
\hline \multirow{4}{*}{$\begin{array}{c}1996 \\
(\mathrm{~N}=3,005)\end{array}$} & Mean & 0.16 & 0.49 & 0.65 & 0.03 & 24,642 & 11,154 & 12,290 \\
\hline & $\mathrm{Sd}$ & 0.09 & 0.19 & 0.19 & 0.15 & 43,026 & 35,047 & 21,501 \\
\hline & Min & 0.01 & 0.02 & 0.06 & -5.40 & 1,036 & 12.28 & 139.82 \\
\hline & Max & 0.79 & 1.17 & 1.36 & 3.16 & 742,724 & 770,254 & 348,590 \\
\hline \multirow{4}{*}{$\begin{array}{c}1997 \\
(\mathrm{~N}=3,013)\end{array}$} & Mean & 0.17 & 0.48 & 0.65 & 0.04 & 24,898 & 11,318 & 12,005 \\
\hline & $\mathrm{Sd}$ & 0.09 & 0.19 & 0.19 & 0.24 & 41,300 & 36,858 & 20,023 \\
\hline & Min & 0.01 & 0.02 & 0.05 & -0.54 & 1,267 & 16.00 & 235.93 \\
\hline & Max & 0.81 & 1.17 & 1.46 & 12.07 & 819,777 & $1,108,536$ & 272,506 \\
\hline \multirow{4}{*}{$\begin{array}{c}1998 \\
(\mathrm{~N}=3,009)\end{array}$} & Mean & 0.18 & 0.47 & 0.65 & 0.04 & 25,302 & 12,058 & 12,574 \\
\hline & $\mathrm{Sd}$ & 0.10 & 0.19 & 0.18 & 0.39 & 40,209 & 44,619 & 22,439 \\
\hline & Min & 0.01 & 0.02 & 0.06 & -1.17 & 1,379 & 34.59 & 188.53 \\
\hline & Max & 0.71 & 1.15 & 1.42 & 19.64 & 762,092 & $1,431,972$ & 332,497 \\
\hline \multirow{4}{*}{$\begin{array}{c}1999 \\
(\mathrm{~N}=2,633)\end{array}$} & Mean & 0.19 & 0.48 & 0.66 & 0.02 & 24,602 & 12,055 & 12,255 \\
\hline & $\mathrm{Sd}$ & 0.10 & 0.19 & 0.19 & 0.12 & 39,227 & 28,782 & 22,344 \\
\hline & Min & 0.01 & 0.02 & 0.06 & -1.01 & 1,471 & 21.84 & 181.08 \\
\hline & Max & 0.80 & 1.13 & 1.48 & 3.66 & 719,402 & 610,508 & 353,018 \\
\hline \multirow{4}{*}{$\begin{array}{c}2000 \\
(\mathrm{~N}=2,837)\end{array}$} & Mean & 0.19 & 0.48 & 0.67 & 0.02 & 27,835 & 14,250 & 13,728 \\
\hline & $\mathrm{Sd}$ & 0.11 & 0.19 & 0.20 & 0.11 & 42,751 & 41,786 & 23,289 \\
\hline & Min & 0.01 & 0.02 & 0.05 & -1.69 & 1,610 & 10.24 & 156.70 \\
\hline & Max & 0.85 & 1.13 & 1.47 & 2.71 & 608,736 & $1,124,483$ & 366,950 \\
\hline \multirow{4}{*}{$\begin{array}{c}2001 \\
(\mathrm{~N}=2,993)\end{array}$} & Mean & 0.18 & 0.48 & 0.66 & 0.03 & 32,973 & 15,263 & 15,816 \\
\hline & $\mathrm{Sd}$ & 0.11 & 0.19 & 0.20 & 0.25 & 58,830 & 55,887 & 27,901 \\
\hline & Min & 0.01 & 0.02 & 0.05 & -2.20 & 1,779 & 11.88 & 328.22 \\
\hline & Max & 0.84 & 1.19 & 1.43 & 10.02 & 940,779 & $1,328,199$ & 383,283 \\
\hline \multirow{4}{*}{$\begin{array}{c}2002 \\
(\mathrm{~N}=2,878)\end{array}$} & Mean & 0.17 & 0.48 & 0.65 & 0.02 & 38,412 & 17,545 & 18,009 \\
\hline & $\mathrm{Sd}$ & 0.11 & 0.19 & 0.20 & 0.09 & 68,164 & 59,886 & 31,511 \\
\hline & Min & 0.01 & 0.02 & 0.04 & -1.49 & 1,413 & 9.85 & 359.87 \\
\hline & Max & 0.88 & 1.13 & 1.48 & 2.12 & 894,349 & $1,046,101$ & 400,267 \\
\hline \multirow{4}{*}{$\begin{array}{c}2003 \\
(\mathrm{~N}=2,613)\end{array}$} & Mean & 0.17 & 0.48 & 0.64 & 0.02 & 40,450 & 16,259 & 19,562 \\
\hline & $\mathrm{Sd}$ & 0.10 & 0.19 & 0.20 & 0.23 & 66,738 & 55,135 & 34,282 \\
\hline & Min & 0.01 & 0.02 & 0.05 & -3.32 & 2,243 & 10.67 & 277.00 \\
\hline & Max & 0.90 & 1.16 & 1.49 & 9.42 & 920,789 & $1,256,201$ & 398,835 \\
\hline \multirow{4}{*}{$\begin{array}{c}\text { Total } \\
(\mathrm{N}=22,981)\end{array}$} & Mean & 0.17 & 0.48 & 0.65 & 0.03 & 29,759 & 13,695 & 14,466 \\
\hline & $\mathrm{Sd}$ & 0.10 & 0.19 & 0.19 & 0.22 & 51,516 & 46,000 & 25,875 \\
\hline & Min & 0.01 & 0.02 & 0.04 & -5.40 & 1,036 & 9.85 & 139.82 \\
\hline & Max & 0.90 & 1.19 & 1.49 & 19.64 & 940,779 & $1,431,972$ & 400,267 \\
\hline
\end{tabular}

Note: Firm-level data from Chilean Annual Industrial Survey (ENIA). (W/Q) is total wages divided by total output, $(\mathrm{M} / \mathrm{Q})$ is the materials' share in total output, (C/Q) is the proportion of variable cost in total output, (I/Q) is the ratio of net investment to output, $(\mathrm{Q} / \mathrm{L})$ is total output divided by the number of employees, $(\mathrm{K} / \mathrm{L})$ is the average amount of capital per employee and $(\mathrm{M} / \mathrm{L})$ is the average quantity of intermediates per employee. 
The amount reported to have been spent on advertisement increases more than 100\% from 1996 to 2003. It decreased in 1998 and 1999 but it experienced a fast growth afterwards. This information could also suggest an increase over time of the penetration of information and communication technologies in the Chilean society.

A group of variables defined the share of costs to output considering investment, employment, and intermediates costs. Additionally, a group of variables defined ratios per employee of output, intermediates and capital. Table A3.5 summarizes the results of the ratio variables.

The ratio of labor cost to output was around 0.17 and remained very stable during the period 1996 to 2003. The lowest value of this variable on average was 0.16 in 1996 and the highest was 0.19 in 2000 . The ratio of intermediates to output was also very stable at around 0.48 on average for the case of the Chilean manufacturing firms included in our sample. The highest average ratio of intermediates to output was in 1996 (0.49) while the lowest was in 1998 (0.47). The ratio of total variable cost (labor and intermediates) to output was on average 0.65 . This variable reached its highest level of 0.67 in 2000 and its lowest level of 0.64in 2003.

Investment represented $3 \%$ of output for the firms in our sample during the period covered by this study. Output per employee increased quickly from 2000 to 2003. The average value of this variable was 30 million pesos per employee during the period 1996 to 2003. Capital and intermediates per employee also increased rapidly during the period 2000 to 2003 , which may be the explanation for the per-employee productivity growth observed in the same period.

\section{A3.8 Preliminary Panel Data Production Function Regression}

With panel data on individual firm's inputs and output, cross-sectional and timeseries estimates can be obtained. In the first place, Total Effects may be obtained by OLS without grouping observations into individual firms or time periods. Random Effects estimates can be computed by taking into account that the error term is made by a random effect specific to the individual and a time varying effect assuming that the overall error term is exogenous. Between Effects regression is based only on the interindividual differences of the variables and is performed on the average cross-section values. The Fixed Effects regression considers only the intra-individual changes of the variables, using each observation in terms of the intra-firm deviation from the mean.

Under the assumption that the changes in output caused by changes of input levels are stable across firms and constant in time, we should see no differences among the four different balanced and unbalanced panel estimates shown in Table A3.6. Nevertheless, we observe differences in the estimated parameters, especially among Between Effects and Fixed Effects estimates. This result leads us to conclude that changes in input levels have a determinate impact on output when they occur along a time span within specific firms, while these effects are different when calculated across firms and at a specific moment in time. The balanced and unbalanced sample results are similar throughout the table. We find variations across estimates but we conclude that restricting the sample to the balanced panel does not change these basic results in a meaningful way. 


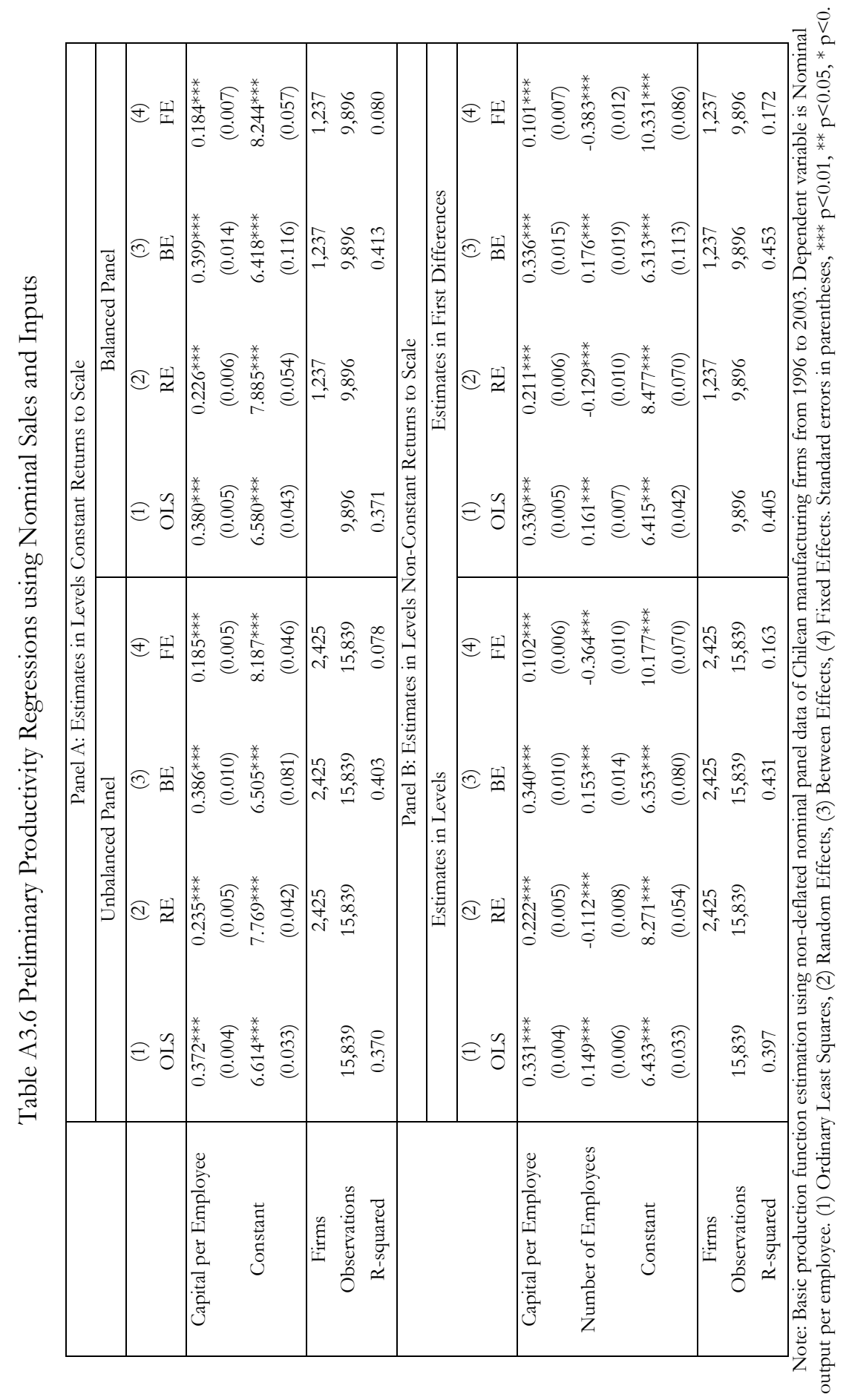




\section{Appendix 4 Firm-Level Price Growth}

\section{A4.1 Constructing Firm-level Price Growth Rates}

Different deflators were defined for each of the variables of the ENIA survey that were originally expressed in nominal terms. One of the most innovative elements of this work is the definition of a firm-level output deflator. Industrial data normally provides output expressed in nominal terms; this constitutes a restraint when the researcher uses panel data and is interested in separating growth of physical output from growth of output prices. Using the information provided by Form 3 of the ENIA survey, we are able to observe quantities and prices for each product inside firms. This data will be the starting point for the definition of a firm-level output deflator variable.

Other output deflators can be defined at four, three, and two-digit ISIC Rev.2 industry classification code by taking the industry average price growth. Using information from wholesale price index calculations obtained from INE, it was also possible to create a three-digit industry level deflator for output.

When estimating firm-level price growth, as well as when considering the change of firms' product-mix, we require a sample that contains no gaps. Therefore observations with leaps will be discarded from the unbalanced panel at this stage. Additionally, the rest of this section considers only firms observed at least on three consecutive years during the period 1996-2003.

From the products-quantities data, we have obtained information at the productfirm level. That is to say, the statistical unit of measure is one product inside one firm. Cleaning of the product-firm level data is necessary before statistical computations can be done. The data cleaning process will depend on what we are aiming to calculate with the data. In the case of the product-firm level information, this study is first of all interested in computing a price inflation index at the level of firms. This firm-level variable will be merged with the industrial survey ENIA in order to deflate sales and estimate production functions that incorporate information on price changes.

We have calculated the average yearly price at the product-firm level by dividing total product sales by the number of units sold. We then have taken logs of the product-firm level prices. Finally, the first difference of the log of price gave us the approximate yearly product-firm level price growth rate.

The firm-level price growth rate variable will be merged with the industrial survey ENIA in order to deflate sales and estimate production functions that incorporate information on price changes at the firm level. Several considerations make it difficult to choose the way in which we should represent firm-level inflation rates using product-firm level information.

In the first place, we must consider that there are an important number of outliers at the product-firm level that will most likely produce biased means and standard errors in our estimated firm-level inflation rates. We are interested in the average behavior of 
manufacturing industry firms as well as in specific sector average productivity and price elasticity. If there is a small group of products that experience huge price variations that are not likely to be explained by the information at hand, then we would prefer not to consider these observations for the computation of firm-level price growth.

Table A4.1 Descriptive Statistics of Product-level data Coverage over Total Sales

\begin{tabular}{|c|c|c|c|}
\hline Year & Stats & Coverage before cleaning & Coverage after cleaning \\
\hline \multirow{4}{*}{$\begin{array}{c}1996 \\
(\mathrm{~N}=1,897)\end{array}$} & Mean & $69.9 \%$ & $69.9 \%$ \\
\hline & $\mathrm{Sd}$ & $20.7 \%$ & $20.7 \%$ \\
\hline & Min & $0.2 \%$ & $0.2 \%$ \\
\hline & Max & $100.0 \%$ & $100.0 \%$ \\
\hline \multirow{4}{*}{$\begin{array}{c}1997 \\
(\mathrm{~N}=2,045)\end{array}$} & Mean & $70.9 \%$ & $51.7 \%$ \\
\hline & $\mathrm{Sd}$ & $19.9 \%$ & $32.7 \%$ \\
\hline & Min & $0.1 \%$ & $0.0 \%$ \\
\hline & Max & $100.0 \%$ & $100.0 \%$ \\
\hline \multirow{4}{*}{$\begin{array}{c}1998 \\
(\mathrm{~N}=2,117)\end{array}$} & Mean & $70.6 \%$ & $54.8 \%$ \\
\hline & $\mathrm{Sd}$ & $19.7 \%$ & $31.4 \%$ \\
\hline & Min & $1.6 \%$ & $0.0 \%$ \\
\hline & Max & $99.9 \%$ & $98.8 \%$ \\
\hline \multirow{4}{*}{$\begin{array}{c}1999 \\
(\mathrm{~N}=2,077)\end{array}$} & Mean & $70.9 \%$ & $57.9 \%$ \\
\hline & $\mathrm{Sd}$ & $19.8 \%$ & $30.2 \%$ \\
\hline & Min & $0.9 \%$ & $0.0 \%$ \\
\hline & Max & $100.0 \%$ & $99.7 \%$ \\
\hline \multirow{4}{*}{$\begin{array}{c}2000 \\
(\mathrm{~N}=2,059)\end{array}$} & Mean & $72.2 \%$ & $52.1 \%$ \\
\hline & $\mathrm{Sd}$ & $18.9 \%$ & $33.1 \%$ \\
\hline & Min & $0.4 \%$ & $0.0 \%$ \\
\hline & Max & $100.0 \%$ & $100.0 \%$ \\
\hline \multirow{4}{*}{$\begin{array}{c}2001 \\
(\mathrm{~N}=2,071)\end{array}$} & Mean & $73.0 \%$ & $38.1 \%$ \\
\hline & $\mathrm{Sd}$ & $18.0 \%$ & $34.4 \%$ \\
\hline & Min & $0.5 \%$ & $0.0 \%$ \\
\hline & Max & $100.0 \%$ & $100.0 \%$ \\
\hline \multirow{4}{*}{$\begin{array}{c}2002 \\
(\mathrm{~N}=1,915)\end{array}$} & Mean & $72.9 \%$ & $56.8 \%$ \\
\hline & $\mathrm{Sd}$ & $18.6 \%$ & $30.4 \%$ \\
\hline & Min & $0.4 \%$ & $0.0 \%$ \\
\hline & Max & $100.0 \%$ & $100.0 \%$ \\
\hline \multirow{4}{*}{$\begin{array}{c}2003 \\
(\mathrm{~N}=1,658)\end{array}$} & Mean & $73.3 \%$ & $60.3 \%$ \\
\hline & $\mathrm{Sd}$ & $17.9 \%$ & $28.4 \%$ \\
\hline & Min & $0.5 \%$ & $0.0 \%$ \\
\hline & Max & $100.0 \%$ & $100.0 \%$ \\
\hline \multirow{4}{*}{$\begin{array}{c}\text { Total } \\
(\mathrm{N}=15,839)\end{array}$} & Mean & $71.7 \%$ & $54.9 \%$ \\
\hline & $\mathrm{Sd}$ & $19.3 \%$ & $31.7 \%$ \\
\hline & Min & $0.1 \%$ & $0.0 \%$ \\
\hline & Max & $100.0 \%$ & $100.0 \%$ \\
\hline
\end{tabular}

Note: Coverage is the percentage of total firm sales reported at the firm level in ENIA form 1 that has also been reported at the product-firm level in ENIA form 3.

Secondly, different products inside firms have different relative importance to sales. Therefore, when taking the firm-level average, we should consider weighting each 
product with its relative importance to total sales. Taking weighted averages would help us avoid the possibility of relatively unimportant products determining the estimated inflation at the firm level.

Thirdly, we must take into account that the production reported at the product level does not cover all the sales of firms. According to the information provided in Table A4.1, product-firm level data covers on average $72 \%$ of total sales at the firm level before cleaning the product-firm level observations, and $55 \%$ of total sales after cleaning.

The data cleaning was done by the removal of observations that had inflation rates that were too high or too low to be representative in the manufacturing industry. Taking coverage into account should result in weighting each firm's inflation by the coverage of its product-firm level information and allowing average industry inflation to represent the inflation of the products that are not represented in the information provided.

Different methods were used to calculate the average yearly price growth rate at the firm level. First, I have computed the simple average of the inflation rate of all products from each firm within each year. This is to say, I have not corrected for the presence of outliers or for the coverage and or for products' relative importance to sales. This estimated price growth is not reported due to some implausible values that resulted from the presence of outliers.

The first column of Table A4.2 (inf1) shows a firm-level price growth rate computed as a simple average only after deleting from the product-firm data those outliers in which the first difference of $\log$ of price was higher than $\log (2)$ or lower than $-\log (2)$. Around $12.4 \%$ of all the product-firm level observations were deleted. The statistics computed show much smaller standard errors and a mean that is very close to the median value, while the maximum and minimum values are now restricted by the definition above.

The second column of Table A4.2 (inf2) shows the main statistics of firm-level price growth rate that was calculated using the firm-level weighted average of product-firm level inflation. This result was also obtained after deleting outliers with the same criteria described above. Results do not differ much from the second column but we believe this estimated inflation is much more accurate at the firm level because it weights products according to their relative importance to the firm's sales.

The third column of Table A4.2 corresponds to the estimation of the firm-level yearly price growth rate (Firm price growth 3) that takes into account all three of the considerations previously mentioned. This firm-level price change rate was calculated after deleting outliers using the same criteria as the previous two firm-level price growth estimations, correcting by weight and coverage.

Firm price growth 3 was computed using a weighted average in order to incorporate information about the relative importance of each product to total firm sales. The overall coverage of product-firm level information was also taken into account, weighting each firm's inflation by the coverage of its product-firm level information and using the average industry four-digit ISIC Rev.2 output price inflation to represent the share of production that is not detailed at the product-firm level. 
Table A4.2 Descriptive Statistics of Firm-level Price Growth Rates

\begin{tabular}{|c|c|c|c|c|}
\hline Year & Stats & Firm price growth 1 & Firm price growth 2 & Firm price growth 3 \\
\hline \multirow{4}{*}{$\begin{array}{c}1997 \\
(\mathrm{~N}=2,045)\end{array}$} & mean & $1.9 \%$ & $1.9 \%$ & $2.1 \%$ \\
\hline & $\mathrm{Sd}$ & $19.7 \%$ & $20.5 \%$ & $13.2 \%$ \\
\hline & Min & $-68.0 \%$ & $-68.0 \%$ & $-57.4 \%$ \\
\hline & Max & $69.1 \%$ & $69.1 \%$ & $58.4 \%$ \\
\hline \multirow{4}{*}{$\begin{array}{c}1998 \\
(\mathrm{~N}=2,117)\end{array}$} & mean & $3.5 \%$ & $4.0 \%$ & $4.0 \%$ \\
\hline & $\mathrm{Sd}$ & $18.0 \%$ & $18.7 \%$ & $12.0 \%$ \\
\hline & Min & $-68.1 \%$ & $-68.6 \%$ & $-57.6 \%$ \\
\hline & $\operatorname{Max}$ & $67.9 \%$ & $69.0 \%$ & $57.3 \%$ \\
\hline \multirow{4}{*}{$\begin{array}{c}1999 \\
(\mathrm{~N}=2,077)\end{array}$} & mean & $3.0 \%$ & $3.3 \%$ & $3.1 \%$ \\
\hline & $\mathrm{Sd}$ & $17.1 \%$ & $18.0 \%$ & $11.8 \%$ \\
\hline & Min & $-67.6 \%$ & $-67.6 \%$ & $-51.0 \%$ \\
\hline & $\operatorname{Max}$ & $69.1 \%$ & $69.1 \%$ & $58.9 \%$ \\
\hline \multirow{4}{*}{$\begin{array}{c}2000 \\
(\mathrm{~N}=2,059)\end{array}$} & mean & $3.1 \%$ & $3.1 \%$ & $3.1 \%$ \\
\hline & $\mathrm{Sd}$ & $17.0 \%$ & $17.8 \%$ & $11.7 \%$ \\
\hline & Min & $-69.1 \%$ & $-69.1 \%$ & $-57.1 \%$ \\
\hline & $\operatorname{Max}$ & $68.2 \%$ & $68.2 \%$ & $59.6 \%$ \\
\hline \multirow{4}{*}{$\begin{array}{c}2001 \\
(\mathrm{~N}=2,071)\end{array}$} & mean & $1.9 \%$ & $1.9 \%$ & $1.9 \%$ \\
\hline & $\mathrm{Sd}$ & $19.3 \%$ & $19.8 \%$ & $12.3 \%$ \\
\hline & Min & $-68.2 \%$ & $-68.2 \%$ & $-56.9 \%$ \\
\hline & $\operatorname{Max}$ & $69.2 \%$ & $69.2 \%$ & $56.1 \%$ \\
\hline \multirow{4}{*}{$\begin{array}{c}2002 \\
(\mathrm{~N}=1,915)\end{array}$} & mean & $2.5 \%$ & $3.1 \%$ & $3.0 \%$ \\
\hline & $\mathrm{Sd}$ & $18.1 \%$ & $18.8 \%$ & $12.2 \%$ \\
\hline & Min & $-69.3 \%$ & $-69.3 \%$ & $-54.9 \%$ \\
\hline & $\operatorname{Max}$ & $69.2 \%$ & $69.2 \%$ & \\
\hline \multirow{4}{*}{$\begin{array}{c}2003 \\
(\mathrm{~N}=1,658)\end{array}$} & mean & $2.8 \%$ & $3.1 \%$ & $3.0 \%$ \\
\hline & $\mathrm{Sd}$ & $17.0 \%$ & $17.6 \%$ & $11.5 \%$ \\
\hline & Min & $-68.2 \%$ & $-68.2 \%$ & $-58.3 \%$ \\
\hline & $\operatorname{Max}$ & $67.6 \%$ & $66.8 \%$ & $56.8 \%$ \\
\hline \multirow{4}{*}{$\begin{array}{c}\text { Total } \\
(\mathrm{N}=13,942)\end{array}$} & mean & $2.7 \%$ & $2.9 \%$ & $2.9 \%$ \\
\hline & $\mathrm{Sd}$ & $18.1 \%$ & $18.8 \%$ & $12.1 \%$ \\
\hline & Min & $-69.3 \%$ & $-69.3 \%$ & $-58.3 \%$ \\
\hline & $\operatorname{Max}$ & $69.2 \%$ & $69.2 \%$ & $59.6 \%$ \\
\hline
\end{tabular}

Note: Firm price growth 1 is the simple average of the price growth rate of all products from each firm after deleting product observations in which the first difference of $\log$ of price was higher than $\log (2)$ or lower than $\log (2)$. Firm price growth 2 is the firm-level weighted average of product price growth after deleting outliers. Firm price growth 3 is the firm-level weighted average of price growth after deleting outliers and correcting by overall coverage of product-firm level information.

Results show that statistics based on this last computation appear to be the ones with lowest standard errors, having mean and median values similar to the ones in the previous two columns and in accordance with what we expected for the Chilean manufacturing industry in the period 1996-2003.

\section{A4.2 Computation of the Industry-level Price Index}

One of the objectives of this study is to compare the firm-level output price growth indexes presented above with industry-level average price growths, which have been 
widely used in previous production function estimation studies. Industry-level inflation rates were computed as the averages of firm-level inflation. We used ISIC Industry Classification at the level of 4, 3 and 2-digits. We have used industry averages of the third firm-level price growth presented in Table A4.2 to calculate industry-level output price growth rates at different levels of disaggregation. We used Industry Classification ISIC Rev.2 industry classification at four, three, and two-digit level of disaggregation. Additionally, we have calculated an ISIC Rev.2 three-digit output price-growth index using wholesale price growth information provided by the Chilean Statistical Office.

Table A4.3 Industry-level (ISIC Rev. 2) Price Growth Rates at 2, 3 and 4-digit level

\begin{tabular}{|c|c|c|c|c|c|}
\hline Year & Stats & $\begin{array}{l}\text { ISIC 2-digit } \\
\text { (9 sectors) }\end{array}$ & $\begin{array}{l}\text { ISIC 3-digit } \\
\text { (27 sectors) }\end{array}$ & $\begin{array}{l}\text { ISIC 4-digit } \\
\text { (85 sectors) }\end{array}$ & $\begin{array}{l}\text { ISIC 3-digit } \\
\text { (INE 2009a) }\end{array}$ \\
\hline $\begin{array}{c}1997 \\
(\mathrm{~N}=2,045)\end{array}$ & $\begin{array}{c}\text { Mean } \\
\text { Sd } \\
\text { Min } \\
\text { Max }\end{array}$ & $\begin{array}{l}1.8 \% \\
1.2 \% \\
-2.9 \% \\
4.2 \%\end{array}$ & $\begin{array}{l}1.7 \% \\
1.8 \% \\
-5.4 \% \\
8.2 \%\end{array}$ & $\begin{array}{l}1.8 \% \\
3.5 \% \\
-9.6 \% \\
29.5 \%\end{array}$ & $\begin{array}{l}2.3 \% \\
3.7 \% \\
-5.9 \% \\
13.3 \%\end{array}$ \\
\hline $\begin{array}{c}1998 \\
(\mathrm{~N}=2,117)\end{array}$ & $\begin{array}{l}\text { mean } \\
\text { sd } \\
\min \\
\max \end{array}$ & $\begin{array}{c}3.9 \% \\
1.7 \% \\
-4.1 \% \\
5.5 \%\end{array}$ & $\begin{array}{c}3.9 \% \\
2.1 \% \\
-8.0 \% \\
14.5 \%\end{array}$ & $\begin{array}{c}4.0 \% \\
3.0 \% \\
-35.3 \% \\
19.0 \%\end{array}$ & $\begin{array}{l}3.7 \% \\
3.6 \% \\
-20.2 \% \\
9.6 \%\end{array}$ \\
\hline $\begin{array}{c}1999 \\
(\mathrm{~N}=2,077)\end{array}$ & $\begin{array}{l}\text { mean } \\
\text { sd } \\
\min \\
\max \end{array}$ & $\begin{array}{l}3.1 \% \\
1.3 \% \\
-2.1 \% \\
4.7 \%\end{array}$ & $\begin{array}{c}3.1 \% \\
1.8 \% \\
-4.1 \% \\
8.0 \%\end{array}$ & $\begin{array}{c}3.1 \% \\
3.1 \% \\
-14.3 \% \\
19.5 \%\end{array}$ & $\begin{array}{c}1.0 \% \\
4.1 \% \\
-5.3 \% \\
22.7 \%\end{array}$ \\
\hline $\begin{array}{c}2000 \\
(\mathrm{~N}=2,059)\end{array}$ & $\begin{array}{l}\text { mean } \\
\text { sd } \\
\min \\
\max \end{array}$ & $\begin{array}{l}3.2 \% \\
1.7 \% \\
1.2 \% \\
7.4 \%\end{array}$ & $\begin{array}{c}3.1 \% \\
2.2 \% \\
-0.1 \% \\
15.8 \%\end{array}$ & $\begin{array}{c}3.1 \% \\
3.8 \% \\
-18.4 \% \\
26.0 \%\end{array}$ & $\begin{array}{l}4.7 \% \\
7.2 \% \\
-0.4 \% \\
48.3 \%\end{array}$ \\
\hline $\begin{array}{c}2001 \\
(\mathrm{~N}=2,071)\end{array}$ & $\begin{array}{c}\text { Mean } \\
\text { Sd } \\
\text { Min } \\
\text { Max }\end{array}$ & $\begin{array}{l}2.0 \% \\
2.2 \% \\
-0.5 \% \\
7.4 \%\end{array}$ & $\begin{array}{l}2.0 \% \\
3.6 \% \\
-6.0 \% \\
11.5 \%\end{array}$ & $\begin{array}{l}1.9 \% \\
5.7 \% \\
-22.7 \% \\
19.9 \%\end{array}$ & $\begin{array}{l}5.8 \% \\
7.8 \% \\
-28.2 \% \\
31.7 \%\end{array}$ \\
\hline $\begin{array}{c}2002 \\
(\mathrm{~N}=1,915)\end{array}$ & $\begin{array}{c}\text { Mean } \\
\text { Sd } \\
\text { Min } \\
\text { Max }\end{array}$ & $\begin{array}{c}3.0 \% \\
1.9 \% \\
-4.4 \% \\
5.7 \%\end{array}$ & $\begin{array}{l}2.9 \% \\
2.3 \% \\
-4.4 \% \\
12.8 \%\end{array}$ & $\begin{array}{c}2.9 \% \\
3.7 \% \\
-25.7 \% \\
34.1 \%\end{array}$ & $\begin{array}{c}4.6 \% \\
2.6 \% \\
-0.6 \% \\
10.8 \%\end{array}$ \\
\hline $\begin{array}{c}2003 \\
(\mathrm{~N}=1,658)\end{array}$ & $\begin{array}{c}\text { Mean } \\
\text { Sd } \\
\text { Min } \\
\text { Max }\end{array}$ & $\begin{array}{c}3.0 \% \\
1.9 \% \\
-3.8 \% \\
8.9 \%\end{array}$ & $\begin{array}{c}3.0 \% \\
2.5 \% \\
-9.0 \% \\
13.0 \%\end{array}$ & $\begin{array}{c}3.0 \% \\
3.4 \% \\
-9.0 \% \\
29.7 \%\end{array}$ & $\begin{array}{c}5.1 \% \\
2.9 \% \\
-0.7 \% \\
12.1 \%\end{array}$ \\
\hline $\begin{array}{c}\text { Total } \\
(\mathrm{N}=13,942)\end{array}$ & $\begin{array}{c}\text { Mean } \\
\text { Sd } \\
\text { Min } \\
\text { Max }\end{array}$ & $\begin{array}{c}2.9 \% \\
1.9 \% \\
-4.4 \% \\
8.9 \%\end{array}$ & $\begin{array}{c}2.8 \% \\
2.5 \% \\
-9.0 \% \\
15.8 \%\end{array}$ & $\begin{array}{c}2.8 \% \\
3.9 \% \\
-35.3 \% \\
34.1 \%\end{array}$ & $\begin{array}{c}3.8 \% \\
5.3 \% \\
-28.2 \% \\
48.3 \%\end{array}$ \\
\hline
\end{tabular}

Note: Average price growth of each industrial sector classified at 2, 3 or 4-digits of disaggregation according to ISIC Rev.2 Classification. 
Table A4.3 shows the main descriptive statistics of industry-level price growth rates. Results show that the main difference between these inflation rates is the standard errors, which decrease when more aggregated industries are considered. Average manufacturing industry inflation rates are near 3\% per year. The first column of Table A4.3 contains the average price growth across firms at the two-digit level of disaggregation, which divides manufacturing into 9 sectors. The mean of this industry-level price growth rate is $2.9 \%$, while its standard deviation is $1.9 \%$.

The second column of Table A4.3 was computed by aggregating firms at the threedigit level, which creates 27 groups of firm according to their economic industry sector, finding a yearly average price growth near $2.8 \%$ and a standard deviation of $2.5 \%$. The third column of Table A4.3 contains the description of industry-level price growth aggregated at the four-digit level, which divides manufacturing into 85 sectors. It results in a similar mean value and a standard deviation of $3.5 \%$. A direct conclusion from this table is that standard variations are increasing at the higher level of disaggregation.

Finally, the fourth column of Table A4.3 shows the industry-level average price growth at three digits of disaggregation, computed with the wholesale price index data provided by the Chilean Statistical Office ${ }^{19}$. This index has a higher mean value, close to $3.8 \%$, and a standard deviation of $5.3 \%$, which is also higher than in the case of average price growth computed from firm-level information.

\section{A4.3 Correlation between Firm and Industry-level Price Changes}

Table A4.4 shows the correlation matrix of all different firm-level and industry-level price growth rates calculated in tables A4.2 and A4.3. The three main firm-level price growth definitions are relatively free of noisy outlier observations and therefore have a much higher correlation to the other price growth estimates. The correlation between firm-level price growth 2 and firm-level price growth 3 is $94 \%$, while the correlation of the latter to firm-level price growth 4 is $89 \%$.

Table A4.4 Correlation of Firm-level Price Growth Rates and Industry-level Inflation Rates

\begin{tabular}{|l|c|ccccccc|}
\hline & & 1 & 2 & 3 & 4 & 5 & 6 & 7 \\
\hline 1 & Firm price growth 1 & 1.00 & & & & & & \\
2 & Firm price growth 2 & 0.94 & 1.00 & & & & & \\
3 & Firm price growth 3 & 0.84 & 0.89 & 1.00 & & & & \\
4 & ISIC 2-digit industry inflation & 0.11 & 0.11 & 0.16 & 1.00 & & & \\
5 & ISIC 3-digit industry inflation & 0.14 & 0.14 & 0.21 & 0.76 & 1.00 & & \\
6 & ISIC 4-digit industry inflation & 0.22 & 0.23 & 0.32 & 0.49 & 0.66 & 1.00 & \\
7 & ISIC 3-digit computed by INE(2009a) & 0.05 & 0.05 & 0.07 & 0.24 & 0.36 & 0.22 & 1.00 \\
\hline
\end{tabular}

Industry-level price growth rates are highly correlated to each other. The highest correlation, $76 \%$, is between the two-digit and the three-digit industry level inflation.

19 This Price Index was obtained from manufacturing wholesale price data provided by Instituto Nacional de Estadisticas (INE). 
Three-digit industry-level inflation estimated from firm-level averages is also highly correlated with three-digit industry inflation from wholesale price data provided by the statistical office. The correlation of these two last variables is $36 \%$.

\section{A4.4 Deflated Output and Input Variables at Firm and Industry-level}

In this section, we present the basic results obtained from deflating output using the four firm-level options and the four industry-level options defined in the previous section. Additionally, we define variable deflators for each of the main inputs and present the results of deflating these variables.

Even though there is no need to focus on the observations of the balanced panel only, it is not possible to use firm-level deflators for observations that have missing values in one or more periods between years that contain observed values. This section contains only observations with no holes between years that is to say, only observations that appear in the unbalanced panel in consecutive years are allowed to remain in the sample. Additionally, this section considers only firms observed in at least three consecutive years during the period 1996-2003.

\section{A4.5 Using Industry-level and Firm-level Output Deflators}

There are several differences that may be observed among the varied ways to deflate output. Table A4.5 shows how using a different deflation may lead to different average values of output levels among manufacturing firms. The first firm-level deflated column uses a price growth estimate that was obtained after cleaning the product-firm level sample from outliers. It offers an estimated average output that decreases in 1999 as a result of a general economic contraction but increases as expected in all other periods. We can also see that no firm appears with a negative output value due to an excessive deflation.

The second column was obtained by deflating output with a price index that was estimated as the weighted average of products' price growth. The third uses an additional correction for the coverage of reported products on total firm sales. Firm price growth 3 is used to deflate the third column of Table A4.5; this is preferred because it takes more information into account.

As Table A4.6 shows, industry-level deflated output appears fairly stable at all three different levels of disaggregation with which price growth was computed. We find that standard deviations tend to be larger using the most disaggregated index. The last column of Table A4.6 contains output deflated at the three-digit industry level using information about wholesale price growth from the Statistical Office, similar to what was used by Benavente et al (2006). We find that the standard deviations are slightly smaller in this case compared to the previous three columns in which average firm-level price growth was used to obtain industry level deflated output. A comparison of the results of estimating average price growth from industry level information and firm level information is found in figure A4.1. There are significant differences between the two estimations which suggest that large intra industry price variation exists. 
Table A4.5 Comparison between Three Options of Firm-level Deflated Output

\begin{tabular}{|c|c|c|c|c|}
\hline Year & Stats & $\begin{array}{c}\text { Firm-level deflated } \\
\text { Output (inf1) }\end{array}$ & $\begin{array}{c}\text { Firm-level deflated } \\
\text { Output (inf2) }\end{array}$ & $\begin{array}{c}\text { Firm-level deflated } \\
\text { Output (inf3) }\end{array}$ \\
\hline \multirow{4}{*}{$\begin{array}{c}1996 \\
\mathrm{~N}=(1,897)\end{array}$} & Mean & $2,177,138$ & $2,177,138$ & $2,177,138$ \\
\hline & $\mathrm{Sd}$ & $7,966,814$ & $7,966,814$ & $7,966,814$ \\
\hline & Min & 29,966 & 29,966 & 29,966 \\
\hline & Max & $169,000,000$ & $169,000,000$ & $169,000,000$ \\
\hline \multirow{4}{*}{$\begin{array}{c}1997 \\
\mathrm{~N}=(2,045)\end{array}$} & Mean & $2,283,282$ & $2,280,269$ & $2,215,559$ \\
\hline & $\mathrm{Sd}$ & $8,603,238$ & $8,531,980$ & $8,228,526$ \\
\hline & Min & 15,953 & 17,131 & 21,658 \\
\hline & Max & $201,000,000$ & $201,000,000$ & $175,000,000$ \\
\hline \multirow{4}{*}{$\begin{array}{c}1998 \\
\mathrm{~N}=(2,117)\end{array}$} & Mean & $2,373,194$ & $2,367,732$ & $2,243,479$ \\
\hline & $\mathrm{Sd}$ & $9,843,151$ & $9,759,177$ & $8,901,117$ \\
\hline & Min & 13,785 & 14,570 & 17,711 \\
\hline & Max & $232,000,000$ & $232,000,000$ & $212,000,000$ \\
\hline \multirow{4}{*}{$\begin{array}{c}1999 \\
\mathrm{~N}=(2,077)\end{array}$} & Mean & $2,909,695$ & $2,892,655$ & $2,558,041$ \\
\hline & $\mathrm{Sd}$ & $27,500,000$ & $27,100,000$ & $19,700,000$ \\
\hline & Min & 21,014 & 17,941 & 22,461 \\
\hline & Max & $1,170,000,000$ & $1,160,000,000$ & $808,000,000$ \\
\hline \multirow{4}{*}{$\begin{array}{c}2000 \\
\mathrm{~N}=(2,059)\end{array}$} & Mean & $3,131,308$ & $3,163,571$ & $2,769,146$ \\
\hline & $\mathrm{Sd}$ & $25,100,000$ & $25,400,000$ & $18,800,000$ \\
\hline & Min & 14,782 & 11,703 & 14,362 \\
\hline & Max & $1,030,000,000$ & $1,050,000,000$ & $733,000,000$ \\
\hline \multirow{4}{*}{$\begin{array}{c}2001 \\
\mathrm{~N}=(2,071)\end{array}$} & Mean & $3,408,720$ & $3,452,218$ & $3,040,539$ \\
\hline & $\mathrm{Sd}$ & $21,600,000$ & $21,900,000$ & $16,900,000$ \\
\hline & Min & 10,583 & 10,328 & 10,802 \\
\hline & Max & $809,000,000$ & $822,000,000$ & $588,000,000$ \\
\hline \multirow{4}{*}{$\begin{array}{c}2002 \\
N=(1,915)\end{array}$} & Mean & $3,708,043$ & $3,707,998$ & $3,229,091$ \\
\hline & $\mathrm{Sd}$ & $20,700,000$ & $20,600,000$ & $16,000,000$ \\
\hline & Min & 10,276 & 10,626 & 10,675 \\
\hline & Max & $701,000,000$ & $696,000,000$ & $498,000,000$ \\
\hline \multirow{4}{*}{$\begin{array}{c}2003 \\
N=(1,658)\end{array}$} & Mean & $4,096,627$ & $4,104,448$ & $3,538,429$ \\
\hline & $\mathrm{Sd}$ & $25,700,000$ & $25,500,000$ & $19,400,000$ \\
\hline & Min & 8,036 & 8,352 & 8,768 \\
\hline & Max & $898,000,000$ & $891,000,000$ & $638,000,000$ \\
\hline \multirow{4}{*}{$\begin{array}{c}\text { Total } \\
\mathrm{N}=(15,839)\end{array}$} & Mean & $2,984,201$ & $2,991,543$ & $2,700,448$ \\
\hline & $\mathrm{Sd}$ & $19,800,000$ & $19,800,000$ & $15,200,000$ \\
\hline & Min & 8,036 & 8,352 & 8,768 \\
\hline & Max & $1,170,000,000$ & $1,160,000,000$ & $808,000,000$ \\
\hline
\end{tabular}

Note: (inf1) is deflated using the simple average of the price growth rate of all products from each firm after deleting product observations in which the first difference of $\log$ of price was higher than $\log (2)$ or lower than $-\log (2)$. (inf2) is deflated using firm-level weighted average of product price growth after deleting outliers. (inf3) is deflated using firm-level weighted average of price growth after deleting outliers and correcting by overall coverage of productfirm level information. 
Table A4.6 Comparison between 2, 3 and 4-digit Industry-level Deflated Output

\begin{tabular}{|c|c|c|c|c|c|}
\hline Year & Stats & $\begin{array}{l}\text { Industry-level } \\
\text { Output (ISIC } \\
\text { Rev2. 2-digit) }\end{array}$ & $\begin{array}{l}\text { Industry-level } \\
\text { Output (ISIC } \\
\text { Rev2. 3-digit) }\end{array}$ & $\begin{array}{l}\text { Industry-level } \\
\text { Output (ISIC } \\
\text { Rev2. 4-digit) }\end{array}$ & $\begin{array}{l}\text { Industry-level } \\
\text { ISIC 3-digit } \\
\text { (INE 2009a) }\end{array}$ \\
\hline \multirow{4}{*}{$\begin{array}{c}1996 \\
(\mathrm{~N}=1,897)\end{array}$} & Mean & $2,177,138$ & $2,177,138$ & $2,177,138$ & $2,177,138$ \\
\hline & $\mathrm{Sd}$ & $7,966,814$ & $7,966,814$ & $7,966,814$ & $7,966,814$ \\
\hline & Min & 29,966 & 29,966 & 29,966 & 29,966 \\
\hline & Max & $169,000,000$ & $169,000,000$ & $169,000,000$ & $169,000,000$ \\
\hline \multirow{4}{*}{$\begin{array}{c}1997 \\
(\mathrm{~N}=2,045)\end{array}$} & Mean & $2,222,442$ & $2,212,828$ & $2,256,408$ & $2,184,587$ \\
\hline & $\mathrm{Sd}$ & $8,326,979$ & $8,200,774$ & $8,435,652$ & $7,950,899$ \\
\hline & Min & 22,080 & 21,658 & 22,060 & 20,256 \\
\hline & Max & $176,000,000$ & $175,000,000$ & $180,000,000$ & $168,000,000$ \\
\hline \multirow{4}{*}{$\begin{array}{c}1998 \\
(\mathrm{~N}=2,117)\end{array}$} & Mean & $2,181,387$ & $2,169,778$ & $2,177,961$ & $2,144,593$ \\
\hline & $\mathrm{Sd}$ & $8,424,611$ & $8,292,712$ & $8,469,244$ & $7,920,596$ \\
\hline & Min & 20,059 & 19,587 & 19,587 & 17,984 \\
\hline & Max & $191,000,000$ & $190,000,000$ & $192,000,000$ & $174,000,000$ \\
\hline \multirow{4}{*}{$\begin{array}{c}1999 \\
(N=2077)\end{array}$} & Mean & $2,539,444$ & $2,540,056$ & $2,623,346$ & $2,591,366$ \\
\hline & $\mathrm{Sd}$ & $22,600,000$ & $23,000,000$ & $25,300,000$ & $25,100,000$ \\
\hline & Min & 18,515 & 18,268 & 17,776 & 17,491 \\
\hline & Max & $961,000,000$ & $983,000,000$ & $1,090,000,000$ & $1,090,000,000$ \\
\hline \multirow{4}{*}{$\begin{array}{c}2000 \\
(\mathrm{~N}=2,059)\end{array}$} & Mean & $2,754,160$ & $2,753,232$ & $2,844,053$ & $2,680,596$ \\
\hline & $\mathrm{Sd}$ & $22,800,000$ & $23,100,000$ & $25,800,000$ & $22,000,000$ \\
\hline & Min & 9,174 & 9,129 & 8,988 & 8,688 \\
\hline & Max & $951,000,000$ & $968,000,000$ & $1,090,000,000$ & $924,000,000$ \\
\hline \multirow{4}{*}{$\begin{array}{c}2001 \\
(\mathrm{~N}=2,071)\end{array}$} & Mean & $3,090,803$ & $3,097,134$ & $3,118,456$ & $2,944,305$ \\
\hline & $\mathrm{Sd}$ & $22,100,000$ & $22,300,000$ & $22,800,000$ & $21,200,000$ \\
\hline & Min & 9,303 & 9,325 & 9,815 & 8,985 \\
\hline & Max & $888,000,000$ & $895,000,000$ & $917,000,000$ & $855,000,000$ \\
\hline \multirow{4}{*}{$\begin{array}{c}2002 \\
(\mathrm{~N}=1,915)\end{array}$} & Mean & $3,283,500$ & $3,274,635$ & $3,302,143$ & $3,094,997$ \\
\hline & $\mathrm{Sd}$ & $21,400,000$ & $21,200,000$ & $21,500,000$ & $20,000,000$ \\
\hline & Min & 10,874 & 10,947 & 10,993 & 12,615 \\
\hline & Max & $806,000,000$ & $795,000,000$ & $806,000,000$ & $757,000,000$ \\
\hline \multirow{4}{*}{$\begin{array}{c}2003 \\
(\mathrm{~N}=1,658)\end{array}$} & Mean & $3,582,324$ & $3,573,871$ & $3,624,387$ & $3,328,611$ \\
\hline & $\mathrm{Sd}$ & $27,000,000$ & $26,700,000$ & $27,700,000$ & $25,300,000$ \\
\hline & Min & 11,557 & 11,435 & 11,556 & 13,934 \\
\hline & Max & $1,010,000,000$ & $997,000,000$ & $1,030,000,000$ & $955,000,000$ \\
\hline \multirow{4}{*}{$\begin{array}{c}\text { Total } \\
(\mathrm{N}=15,839)\end{array}$} & Mean & $2,706,396$ & $2,702,434$ & $2,743,284$ & $2,625,332$ \\
\hline & $\mathrm{Sd}$ & $18,900,000$ & $18,900,000$ & $20,000,000$ & $18,500,000$ \\
\hline & Min & 9,174 & 9,129 & 8,988 & 8,688 \\
\hline & Max & $1,010,000,000$ & $997,000,000$ & $1,090,000,000$ & $1,090,000,000$ \\
\hline
\end{tabular}

Note: Output deflated with the average price growth rates computed at the sector level with 2, 3 or 4-digit disaggregation of the ISIC Rev.2 Classification.

Figure A4.1 shows a comparison between average price growth obtained in two different ways. The dark bars show average all manufacturing inflation rates using the industry-level price growth estimated in this work from the simple averages of firm-level price variations within each sector at the 3-digit ISIC rev.2 disaggregation level. This measure corresponds to the second column of Table A4.6. In this case the firm-level 
price growth was obtained from the weighted average of product-firm level price growths, nevertheless at the manufacturing level simple all firms had the same weight when taking the simple average price growth. The second measure of price growth shown by the light bars of the graph was obtained using the wholesale price index provided by INE. This information contains the product-level price growth weighted averages at the 3-digit ISIC Rev.2 disaggregation level. If we could assume that there is very little or no price dispersion among firms in the same 3-digit sectors then the two measures would yield a very similar result.

Figure A4.1 proves that there is significant price dispersion among firms within the 3-digit disaggregation level. For this reason and as it was explained by Klette and Griliches (1996) the results of estimating the production function using sector-level price growth could be biased. Therefore this work compares different output deflations and their relevance when estimating the production function.

Figure A4.1 Firm-level Price Growth and INE ISIC Rev.2 3-digit Price Growth

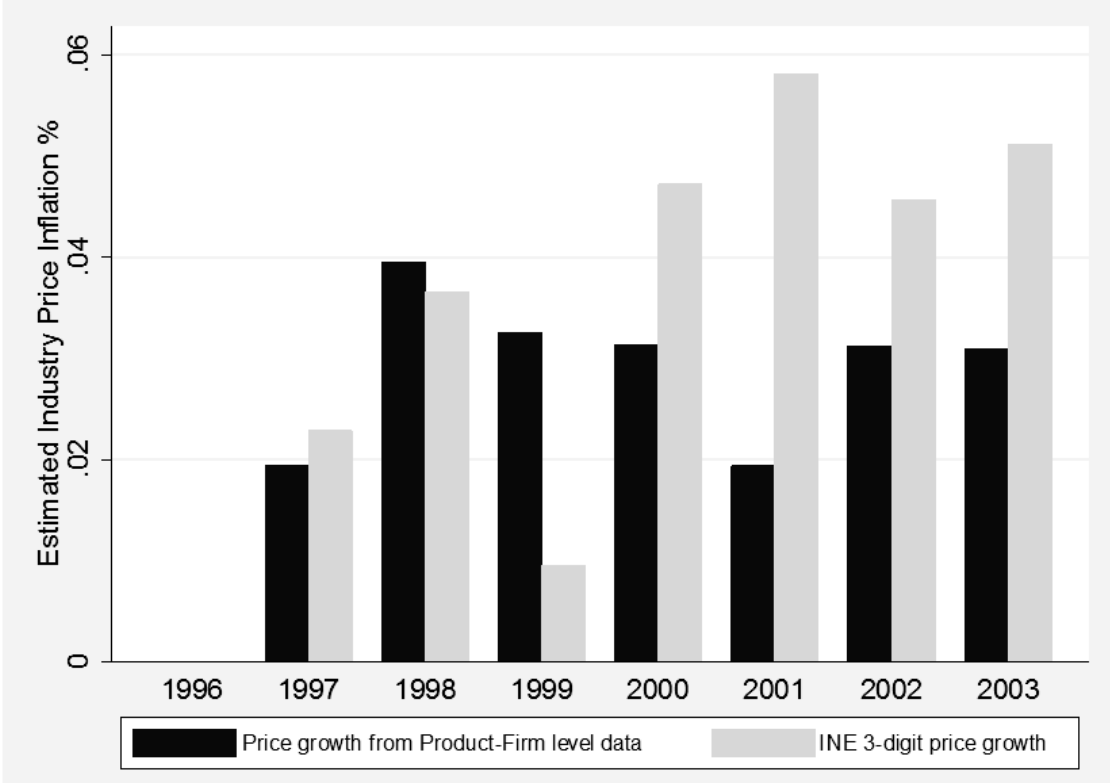

Note: Chilean manufacturing firm-level price growth, estimated as the weighted average of the price growth rate of all products from each firm after deleting product observations in which the first difference of log of price was higher than $\log (2)$ or lower than $-\log (2)$ and correcting by overall coverage of product-firm level information. INE 3-digit inflation is the wholesale price index estimated from INE (2009a) database.

\section{A4.6 Input Deflators}

Different deflators were defined to be used for each of the variables of the ENIA survey that were originally expressed in nominal terms. Using information about wholesale price growths obtained from INE, it was also possible to create different deflators for materials, fuels, land, buildings, machinery, and vehicles. From the average deflators of materials, water, electricity, and fuels, we obtained a variable that was used to 
deflate intermediate goods. Additionally, we used firm-level information on quantities and payments for energy services to determine the firm-level price growth of water and electricity. In this way, we also defined deflators for these variables.

Table A4.7 shows the average deflation variable for each of the inputs from 1997 to 2003. In order to bring values to the 1996 level, prices deflators increase over time, because these variables show accumulated inflation from 1996 to 2003.

A distinction is made between raw and elaborated materials, which show an accumulated inflation of $24 \%$ and $31 \%$ respectively in 2003. Of all inputs, fuels show the highest price growth level. From 1996 to 2003, the price of fuel inputs increased more than $100 \%$. The price of land did not increase as much as the price of buildings during the same period. Land has an accumulated price increase of $15 \%$ while buildings have an accumulated price increase of $45 \%$ up to 2003 . Machines and vehicles also have separate deflators. While machines are analyzed using a deflating variable that accumulates to $41 \%$ in 2003, the value of vehicles is deflated with a variable accumulating to $69 \%$ in 2003 . The general consumer price index serves as a reference for deflation during the period. It accumulated to $27 \%$ from 1996 to 2003 . This variable may be used to deflate inputs that are not considered in any of the other specific input categories, such as the value of publicity and advertising. Deflation of basic energy services, water, and electricity has been also separated into two variables. Industrial water shows a decrease of its average price from 1996 to 2003, accumulating a 9\% price decrease over the period, while the average price paid for industrial electricity decreased $14 \%$ over the same period.

Table A4.7 Estimated Price Growth for Individual Inputs

\begin{tabular}{|c|ccccccccc|}
\hline Year & $\begin{array}{c}\text { Raw } \\
\text { Materials }\end{array}$ & $\begin{array}{c}\text { Elaborated } \\
\text { Materials }\end{array}$ & Fuels & Buildings & Machines & Vehicles & $\begin{array}{c}\text { Price cons } \\
\text { index }\end{array}$ & Water & Electricity \\
\hline 1997 & $-10.5 \%$ & -2.2 & 1.6 & $-0.7 \%$ & $2.8 \%$ & $1.3 \%$ & $5.6 \%$ & $5 \%$ & $8.9 \%$ \\
1998 & $0.2 \%$ & 5.4 & 14.2 & $3.1 \%$ & $7 \%$ & $10.7 \%$ & $4.5 \%$ & $3.8 \%$ & $-0.2 \%$ \\
1999 & $3.8 \%$ & 2.1 & 18.2 & $0.9 \%$ & $5.7 \%$ & $13.1 \%$ & $2.4 \%$ & $5.1 \%$ & $16.3 \%$ \\
2000 & $10.6 \%$ & 5 & 51.7 & $10.7 \%$ & $2.4 \%$ & $7.6 \%$ & $4.4 \%$ & $9.3 \%$ & $1.9 \%$ \\
2001 & $7.3 \%$ & 10.4 & 6.9 & $11.4 \%$ & $9.3 \%$ & $10.6 \%$ & $2.6 \%$ & $0.6 \%$ & $3.5 \%$ \\
2002 & $5.1 \%$ & 6 & 1 & $10.2 \%$ & $6 \%$ & $5.7 \%$ & $2.8 \%$ & $3.6 \%$ & $3.7 \%$ \\
2003 & $6.9 \%$ & 1.5 & 19 & $2.8 \%$ & $2 \%$ & $5.9 \%$ & $1.1 \%$ & $17 \%$ & $-1.4 \%$ \\
\hline
\end{tabular}

Note: Annual estimated price growth of Chilean Manufacturing inputs 1996-2003. Firm-level total sales and quantity data used for estimation of Water and Electricity average price growth. INE wholesale price data used for all other prices. (Raw Materials) is the average estimated price growth of copper, iron, flour, cellulose, rubber and cotton, (Elaborated Materials) is the average of fabric, dyes, processed wood and iron bars. (Fuels) is the average of coal, gas, diesel and propane. (Buildings) is the average of glass, bricks, ceramics, cement, plaster, iron bars and concrete mixers. (Machines) is the average of heavy machinery and farm equipments, centrifuges and refrigerating machines, personal computers, and communication equipment. (Vehicles) is the average price growth of cars, buses, and trucks. Price consumer index includes a basket of all main commodities and is estimated by INE (2009b).

Table A4.8 describes the levels of inputs in real terms obtained by deflating the nominal variables using input-specific deflators described in Table A4.7. Intermediates represent the sum of raw materials, elaborated materials, fuels, energy use, and water consumption, all of which were deflated separately. Capital is determined by deflated land, buildings, machines and vehicles. For electricity and water, it was possible to 
calculate firm-level price growth from the available data. For the rest of intermediates and capital variables, the Wholesale Price Index (IPM) was used. Gross Investment is deflated in the same way as the book value of Capital, by deflating land, buildings, machines, and vehicles investments separately. Publicity and Employment Cost are deflated using the Price Consumer Index.

Table A4.8 Descriptive Statistics of Deflated Input Variables

\begin{tabular}{|c|c|c|c|c|c|c|}
\hline year & stats & $M$ & $K$ & $I$ & $W$ & $P u b$ \\
\hline \multirow{4}{*}{$\begin{array}{c}1996 \\
(\mathrm{~N}=1,897)\end{array}$} & mean & $1,015,223$ & $1,115,450$ & 127,454 & 233,899 & 39,171 \\
\hline & sd & $3,451,556$ & $5,169,301$ & 984,992 & 820,230 & 509,130 \\
\hline & $\min$ & 8,552 & 500 & $-11,300,000$ & 5,367 & 0 \\
\hline & $\max$ & $86,100,000$ & $114,000,000$ & $30,500,000$ & $25,400,000$ & $16,300,000$ \\
\hline \multirow{4}{*}{$\begin{array}{c}1997 \\
(\mathrm{~N}=2,045)\end{array}$} & mean & $1,117,919$ & $1,113,680$ & 90,422 & 234,914 & 42,862 \\
\hline & sd & $3,790,977$ & $4,928,681$ & 599,307 & 799,986 & 590,475 \\
\hline & $\min$ & 6,584 & 827 & $-3,092,349$ & 6,108 & 0 \\
\hline & $\max$ & $87,600,000$ & $105,000,000$ & $16,100,000$ & $23,400,000$ & $23,900,000$ \\
\hline \multirow{4}{*}{$\begin{array}{c}1998 \\
(\mathrm{~N}=2,117)\end{array}$} & mean & $1,128,852$ & $1,122,506$ & 106,857 & 235,156 & 36,864 \\
\hline & sd & $3,754,263$ & $7,094,857$ & 699,641 & 808,857 & 486,918 \\
\hline & $\min$ & 4,359 & 853 & $-276,946$ & 6,800 & 0 \\
\hline & $\max$ & $77,800,000$ & $264,000,000$ & $20,500,000$ & $24,100,000$ & $19,900,000$ \\
\hline \multirow{4}{*}{$\begin{array}{c}1999 \\
(\mathrm{~N}=2,077)\end{array}$} & mean & $1,173,210$ & $1,555,408$ & 108,620 & 239,122 & 41,057 \\
\hline & sd & $5,287,106$ & $23,800,000$ & $1,845,725$ & $1,062,114$ & 642,050 \\
\hline & $\min$ & 5,950 & 347 & $-1,304,190$ & 3,793 & 0 \\
\hline & $\max$ & $170,000,000$ & $1,070,000,000$ & $82,600,000$ & $34,500,000$ & $27,400,000$ \\
\hline \multirow{4}{*}{$\begin{array}{c}2000 \\
(\mathrm{~N}=2,059)\end{array}$} & mean & $1,238,521$ & $1,675,600$ & 120,824 & 231,790 & 44,580 \\
\hline & sd & $5,394,611$ & $26,000,000$ & $1,463,093$ & 972,859 & 700,110 \\
\hline & $\min$ & 3,547 & 147 & $-1,079,298$ & 2,106 & 0 \\
\hline & $\max$ & $132,000,000$ & $1,160,000,000$ & $59,300,000$ & $31,700,000$ & $29,900,000$ \\
\hline \multirow{4}{*}{$\begin{array}{c}2001 \\
(\mathrm{~N}=2,071)\end{array}$} & mean & $1,357,345$ & $1,620,910$ & 292,745 & 230,575 & 50,748 \\
\hline & sd & $8,336,227$ & $26,400,000$ & $6,961,731$ & 923,259 & 604,297 \\
\hline & $\min$ & 2,081 & 133 & $-2,866,206$ & 2,851 & 0 \\
\hline & $\max$ & $308,000,000$ & $1,180,000,000$ & $310,000,000$ & $26,900,000$ & $21,900,000$ \\
\hline \multirow{4}{*}{$\begin{array}{c}2002 \\
(\mathrm{~N}=1,915)\end{array}$} & mean & $1,226,015$ & $1,587,699$ & 185,143 & 247,349 & 55,177 \\
\hline & sd & $4,797,535$ & $26,500,000$ & $4,714,204$ & $1,097,194$ & 601,620 \\
\hline & $\min$ & 2,843 & 121 & $-4,206,765$ & 3,307 & 1 \\
\hline & $\max$ & $89,300,000$ & $1,140,000,000$ & $205,000,000$ & $36,400,000$ & $19,400,000$ \\
\hline \multirow{4}{*}{$\begin{array}{c}2003 \\
(\mathrm{~N}=1,658)\end{array}$} & mean & $1,331,336$ & $1,367,542$ & 437,353 & 272,992 & 64,894 \\
\hline & sd & $6,018,332$ & $21,900,000$ & $14,100,000$ & $1,393,966$ & 647,787 \\
\hline & $\min$ & 1,913 & 331 & $-3,599,795$ & 3,897 & 1 \\
\hline & $\max$ & $145,000,000$ & $878,000,000$ & $573,000,000$ & $49,300,000$ & $20,800,000$ \\
\hline \multirow{4}{*}{$\begin{array}{c}\text { Total } \\
(\mathrm{N}=15,839)\end{array}$} & mean & $1,196,724$ & $1,396,250$ & 177,615 & 239,893 & 46,431 \\
\hline & sd & $5,317,337$ & $20,000,000$ & $5,541,863$ & 990,822 & 600,725 \\
\hline & $\min$ & 1,913 & 121 & $-11,300,000$ & 2,106 & 1 \\
\hline & $\max$ & $308,000,000$ & $1,180,000,000$ & $573,000,000$ & $49,300,000$ & $29,900,000$ \\
\hline
\end{tabular}

Note: Chilean manufacturing input data deflated with ad hoc price growth for each component. (M) is deflated materials including raw materials, water, electricity, and fuels. $(\mathrm{K})$ is capital including machines, vehicles, and buildings. (I) is net investment including machines, vehicles, and buildings. (W) and (Pub) are total wage and publicity, respectively, both deflated by Price Consumer Index IPC data estimated monthly by Instituto Nacional de Estadisticas 


\section{Appendix 5 Computation of Product Innovation Variables}

This section discusses the creation of a set of variables that are meant to represent product innovation at the firm level in the Chilean Manufacturing Industry. The availability of product-firm level data offers the opportunity of following products inside firms in order to account for products added, products dropped, and yearly total number of varieties produced.

There are two main ways in which a firm can innovate. First, innovations may be adopted to ease production of goods by changing the processes that produce these goods. A very simple example is when a machine is introduced to perform an action that was previously done by an employee.

Secondly, innovations may change the products that are being produced. Product innovations are alterations to the characteristics of the output and may include adding a new product, dropping an existing product, or significantly modifying a product. Product innovations may be either new to a firm or new to the entire market.

According to the guidelines of the OSLO manual, national innovations surveys collect firm-level data that defines these two concepts as process innovations and product innovations. This work makes reference to these definitions as we pursue a better understanding of the relationship between technological change, market power, and efficiency of production.

One of the objectives of this section is to obtain a measure of product innovation based on the manufacturing industry information provided for eight years at the productfirm level. Because we observe a panel of products within firms, we have information that shows whenever a product was added or dropped from a particular firm's product mix. From the data at hand, we can think of several ways in which a product innovation variable may be approximated. In this section, we describe the basic statistical characteristics of this information.

Table A5.1 provides an innovative method for measuring product innovation based on the panel of product data. It reports descriptive statistics of some basic product innovation indicators at the firm level for the balanced panel of manufacturing firms included in the database.

In the first place, we have counted the number of products that each firm produces in each year. Table A5.1 shows in its first column the descriptive statistics of the number of products reported to have been produced by Chilean manufacturing firms from 1996 to 2003. In the balanced panel, the number of products at the firm level varies from 1 to 23 with an average that appears to be very close to 2.8 . The median value of the number of products is 2 . 
Table A5.1 Descriptive Statistics of Product Innovation Indicators

\begin{tabular}{|c|c|c|c|c|c|c|}
\hline year & stats & $\begin{array}{l}\text { Number of } \\
\text { Products }\end{array}$ & $\begin{array}{l}\text { Change in } \\
\mathrm{N} \text { of } \\
\text { Products }\end{array}$ & $\begin{array}{c}\text { Increased N } \\
\text { of prod. } \\
\text { dummy }\end{array}$ & $\begin{array}{c}\text { Product. } \\
\text { innovation } \\
\text { Rescaled } 1 \text { to } 4\end{array}$ & $\begin{array}{c}\text { Number of } \\
\text { products added } \\
\text { or dropped }\end{array}$ \\
\hline $\begin{array}{c}1996 \\
(\mathrm{~N}=1,897)\end{array}$ & $\begin{array}{c}\text { mean } \\
\text { Sd } \\
\min \\
\max \end{array}$ & $\begin{array}{c}2.806537 \\
2.706649 \\
1 \\
23\end{array}$ & . & . & . & . \\
\hline $\begin{array}{c}1997 \\
(\mathrm{~N}=2,045)\end{array}$ & $\begin{array}{l}\text { mean } \\
\text { Sd } \\
\min \\
\max \end{array}$ & $\begin{array}{c}2.748655 \\
2.599376 \\
1 \\
24\end{array}$ & $\begin{array}{c}-0.02313 \\
0.949814 \\
-8 \\
6\end{array}$ & $\begin{array}{c}0.224939 \\
0.417644 \\
0 \\
1\end{array}$ & $\begin{array}{c}0.382885 \\
0.842604 \\
0 \\
4\end{array}$ & $\begin{array}{c}0.6489 \\
1.474491 \\
0 \\
16\end{array}$ \\
\hline $\begin{array}{c}1998 \\
(\mathrm{~N}=2,117)\end{array}$ & $\begin{array}{l}\text { mean } \\
\text { Sd } \\
\min \\
\max \end{array}$ & $\begin{array}{c}2.75248 \\
2.614875 \\
1 \\
25\end{array}$ & $\begin{array}{c}0.030259 \\
0.761027 \\
-7 \\
7\end{array}$ & $\begin{array}{c}0.188002 \\
0.390806 \\
0 \\
1\end{array}$ & $\begin{array}{c}0.287671 \\
0.704364 \\
0 \\
4\end{array}$ & $\begin{array}{c}0.58479 \\
1.416889 \\
0 \\
24\end{array}$ \\
\hline $\begin{array}{c}1999 \\
(\mathrm{~N}=2,077)\end{array}$ & $\begin{array}{c}\text { mean } \\
\text { Sd } \\
\min \\
\max \end{array}$ & $\begin{array}{c}2.734714 \\
2.588401 \\
1 \\
25\end{array}$ & $\begin{array}{c}0.012077 \\
0.80618 \\
-7 \\
7\end{array}$ & $\begin{array}{c}0.142995 \\
0.350152 \\
0 \\
1\end{array}$ & $\begin{array}{c}0.229177 \\
0.651407 \\
0 \\
4\end{array}$ & $\begin{array}{c}0.562591 \\
1.341775 \\
0 \\
13\end{array}$ \\
\hline $\begin{array}{c}2000 \\
(\mathrm{~N}=2,059)\end{array}$ & $\begin{array}{c}\text { mean } \\
\text { Sd } \\
\min \\
\max \end{array}$ & $\begin{array}{c}2.854784 \\
2.906511 \\
1 \\
32\end{array}$ & $\begin{array}{c}0.094693 \\
0.985255 \\
-8 \\
12\end{array}$ & $\begin{array}{c}0.205925 \\
0.404474 \\
0 \\
1\end{array}$ & $\begin{array}{c}0.342399 \\
0.810406 \\
0 \\
4\end{array}$ & $\begin{array}{c}0.949004 \\
2.857623 \\
0 \\
62\end{array}$ \\
\hline $\begin{array}{c}2001 \\
(\mathrm{~N}=2,071)\end{array}$ & $\begin{array}{c}\text { mean } \\
\text { Sd } \\
\min \\
\max \end{array}$ & $\begin{array}{c}3.327861 \\
3.901838 \\
1 \\
30\end{array}$ & $\begin{array}{c}0.514063 \\
3.142575 \\
-30 \\
27\end{array}$ & $\begin{array}{c}0.315307 \\
0.46475 \\
0 \\
1\end{array}$ & $\begin{array}{c}0.64027 \\
1.150719 \\
0 \\
4\end{array}$ & $\begin{array}{c}1.454853 \\
3.871082 \\
0 \\
47\end{array}$ \\
\hline $\begin{array}{c}2002 \\
(\mathrm{~N}=1,915)\end{array}$ & $\begin{array}{c}\text { mean } \\
\mathrm{Sd} \\
\min \\
\max \end{array}$ & $\begin{array}{c}3.528982 \\
4.203493 \\
1 \\
30 \\
\end{array}$ & $\begin{array}{c}0.178068 \\
2.368625 \\
-27 \\
26 \\
\end{array}$ & $\begin{array}{c}0.153003 \\
0.360084 \\
0 \\
1 \\
\end{array}$ & $\begin{array}{c}0.300261 \\
0.838703 \\
0 \\
4 \\
\end{array}$ & $\begin{array}{c}0.961358 \\
2.993474 \\
0 \\
44\end{array}$ \\
\hline $\begin{array}{c}2003 \\
(\mathrm{~N}=1,658)\end{array}$ & $\begin{array}{c}\text { mean } \\
\text { Sd } \\
\min \\
\max \end{array}$ & $\begin{array}{c}3.724367 \\
4.514513 \\
1 \\
30\end{array}$ & $\begin{array}{c}0.191797 \\
2.144593 \\
-18 \\
28\end{array}$ & $\begin{array}{c}0.147768 \\
0.354977 \\
0 \\
1\end{array}$ & $\begin{array}{c}0.282268 \\
0.810276 \\
0 \\
4\end{array}$ & $\begin{array}{l}. \\
. \\
.\end{array}$ \\
\hline $\begin{array}{c}\text { Total } \\
(\mathrm{N}=15,839)\end{array}$ & $\begin{array}{c}\text { mean } \\
\text { Sd } \\
\min \\
\max \end{array}$ & $\begin{array}{c}3.04028 \\
3.321117 \\
1 \\
32\end{array}$ & $\begin{array}{c}0.139253 \\
1.805802 \\
-30 \\
28\end{array}$ & $\begin{array}{c}0.19868 \\
0.399021 \\
0 \\
1\end{array}$ & $\begin{array}{c}0.354469 \\
0.85269 \\
0 \\
4\end{array}$ & $\begin{array}{c}0.858342 \\
2.53038 \\
0 \\
62\end{array}$ \\
\hline
\end{tabular}

Note: Number of products is the average total number of products reported each year on ENIA Form 3 at the product-firm level data (average number of products within firms). The change in number of products is the number of products manufactured in present year $(\mathrm{t})$ minus the same number in the previous year $(\mathrm{t}-1)$. The dummy

for increased number of products takes value one if the change in the number of products is greater than zero.

Product innovation rescaled takes value 0 if no product was added, 1 if 1 product was added, 2 if 2 products were added, 3 if 3 or 4 products were added, and 4 if 5 or more products added. Number of products added and dropped is the number of products produced in current year $(\mathrm{t})$ but not present in $(\mathrm{t}-1)$ plus the number of products produced in (t) but not produced in $(t+1)$.

A basic approximation of product innovation is the net change in the number of products manufactured by a firm from one year to the next. This variable was created by subtracting at the firm level the number of products reported in year t-1 from the 
number of products produced in year $t$. The yearly descriptive statistics of this variable are reported in the second column of table 8 . The median value of the number of product net changes is 0 , which shows that most firms do not change the number of products from one year to the next. The change in the number of products in any given year ranges from -17 to 15 with a mean value of 0.16 .

A dummy variable was then defined to take value 1 if the net change of the total number of goods manufactured during a one-year period is greater than zero and 0 otherwise. This variable is reported in the third column of table A5.1. It may be seen that $12 \%$ of the observations show a positive change in the number of goods produced.

Because product innovation is reported in the Chilean Innovation Survey on a scale from 0 (no innovation) to 4 (very high innovation level), a product innovation variable was created to be rescaled from 0 to 4 in order to fit in the same categories. Product innovation was rescaled using the number of products added, defined as the number of products that were produced by a firm in any given period $t$ but not produced in the previous year $\mathrm{t}-1$. Based on this number, rescaled product innovation is reported in the fourth column of table 8 and takes value 0 for firms that did not add any product in a given year. If the number of products added was 1 , the variable takes value 1 . If the number of products added is two, the variable is coded 2 . Rescaled product innovation takes value 3 if 3 or 4 products were added and it takes value 4 if 5 or more products were added in a given year. The mean value of this variable is 0.28 and the median value is 0 . Because the number of products produced in 1995 is unknown, the net change in the number of products, the dummy for increased number of products, and product innovation rescaled from 0 to 4 are not observed in 1996.

If adding and dropping products from the firm's product mix are both changes that represent product innovations, then a possible measure of a firm's innovative behavior is the summation of these two variables. We define the number of products dropped in year $t$ as the number of products produced in year $t$ but not in year $t+1$, and the number of products added in year $\mathrm{t}$ as the number of products reported in year $\mathrm{t}$ but not in $\mathrm{t}-1$. The total number of products added and dropped is shown in the last column of table A5.1. Because of the way in which this variable was constructed, it cannot be observed for the first period or the last period of the database. 


\section{Appendix 6 Innovation and Productivity with Constant Returns}

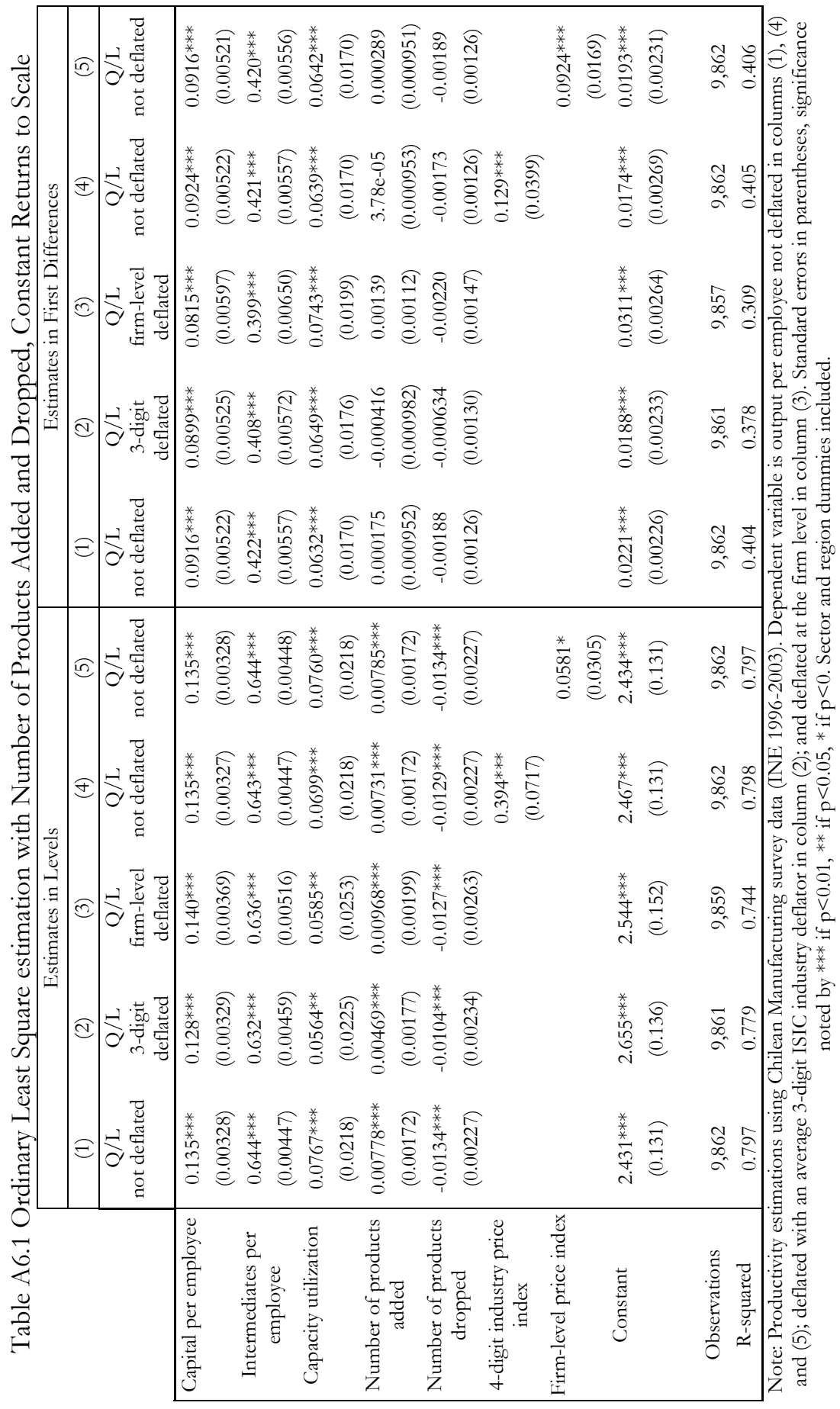




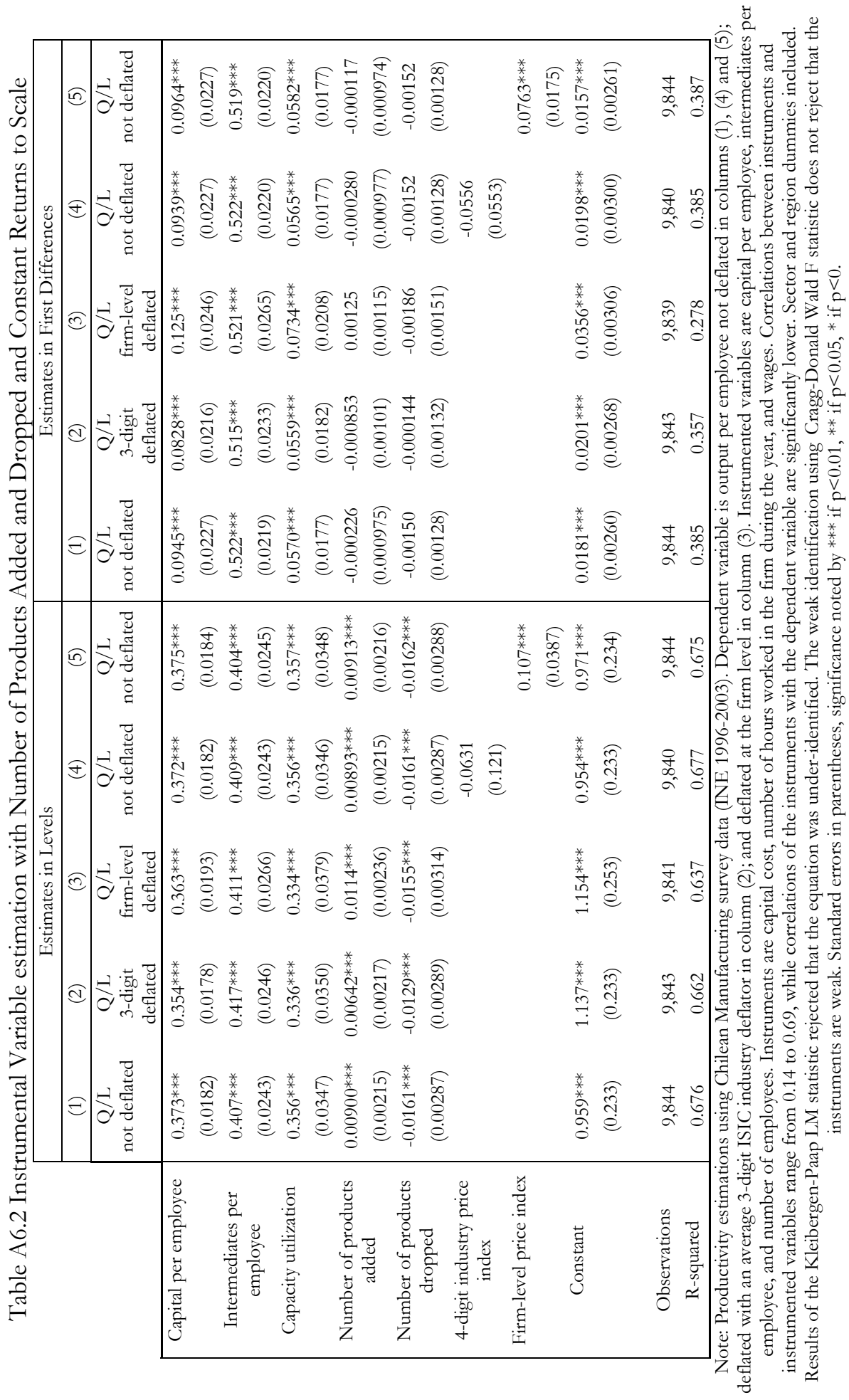




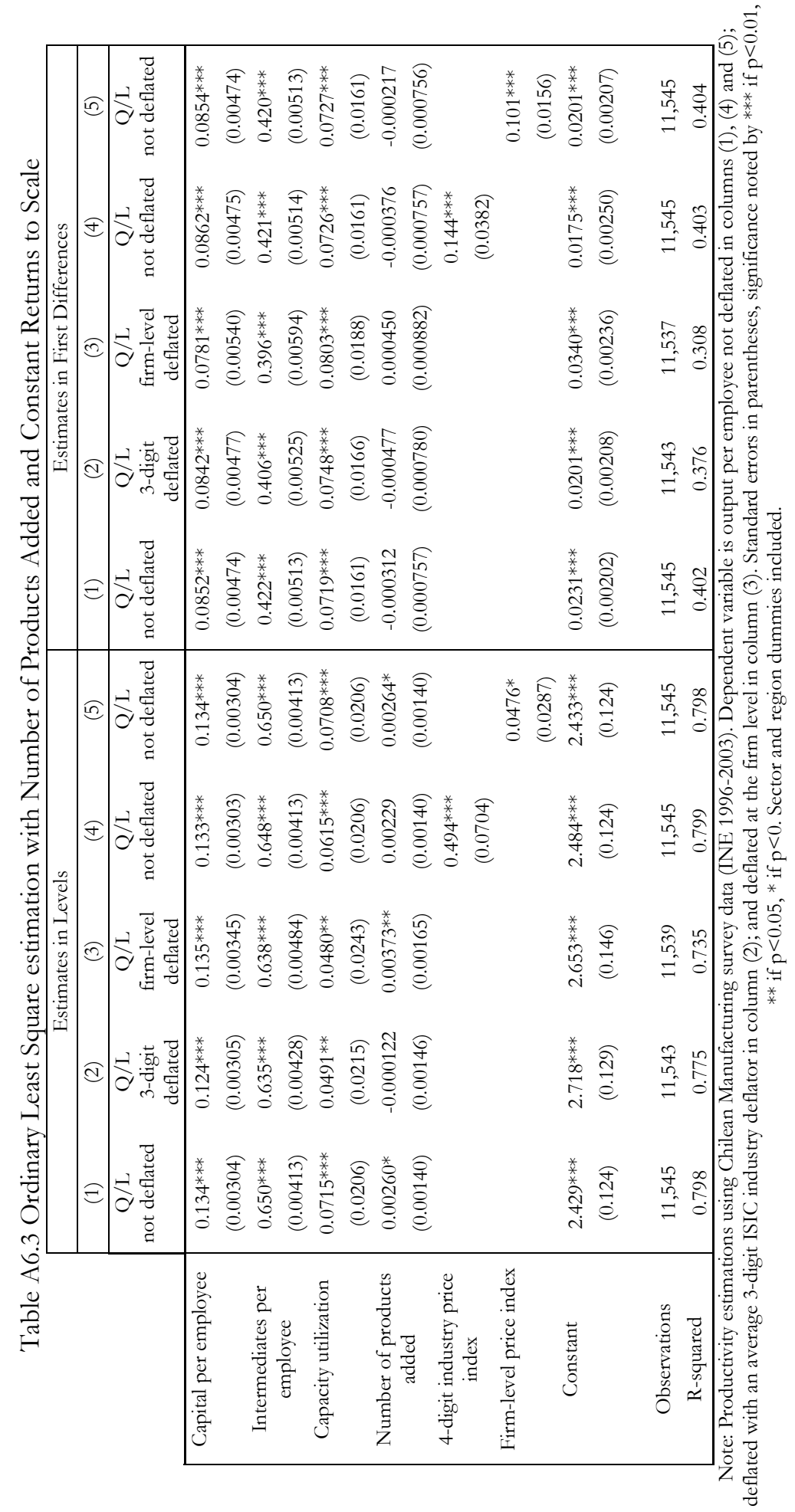




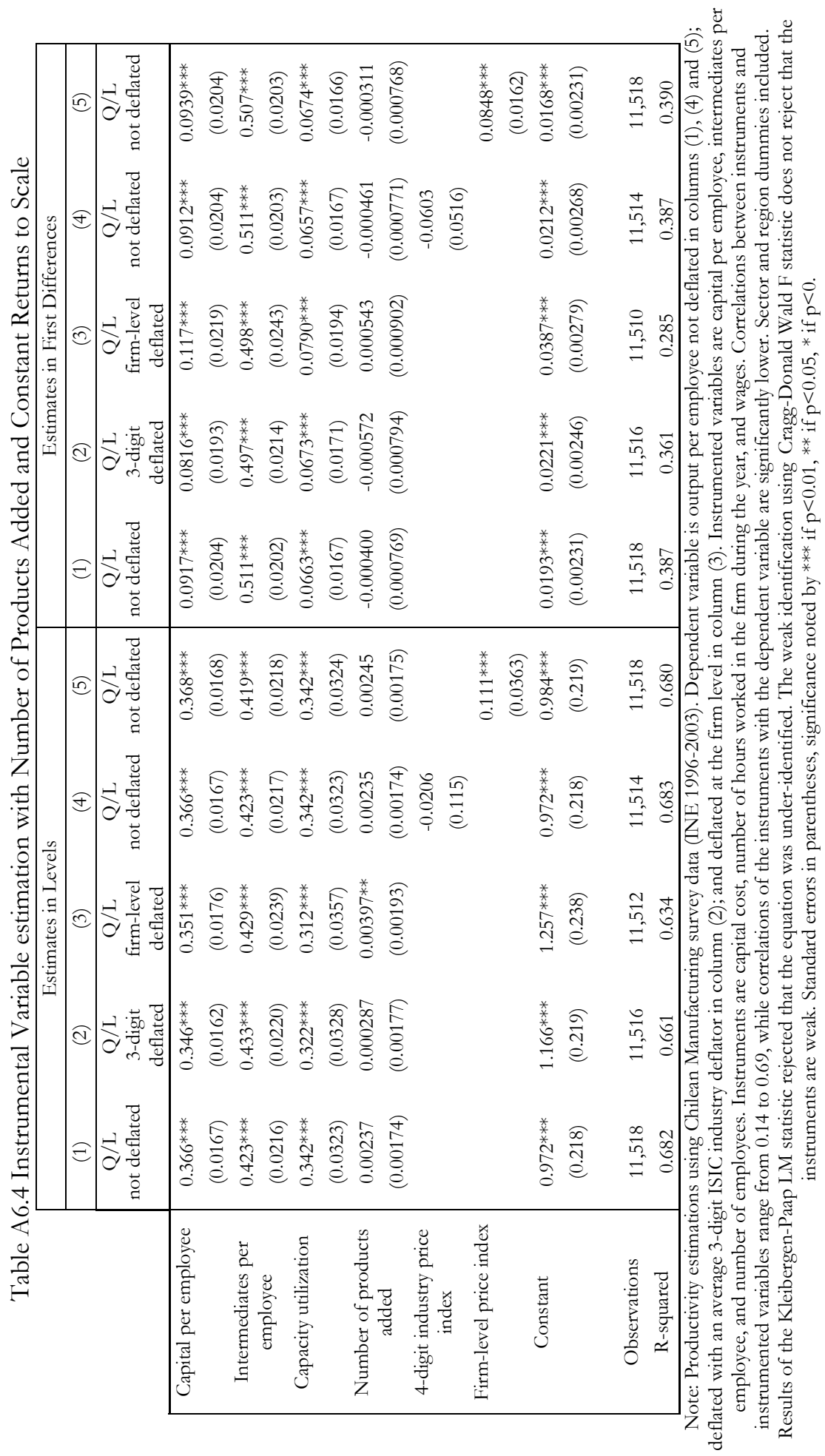




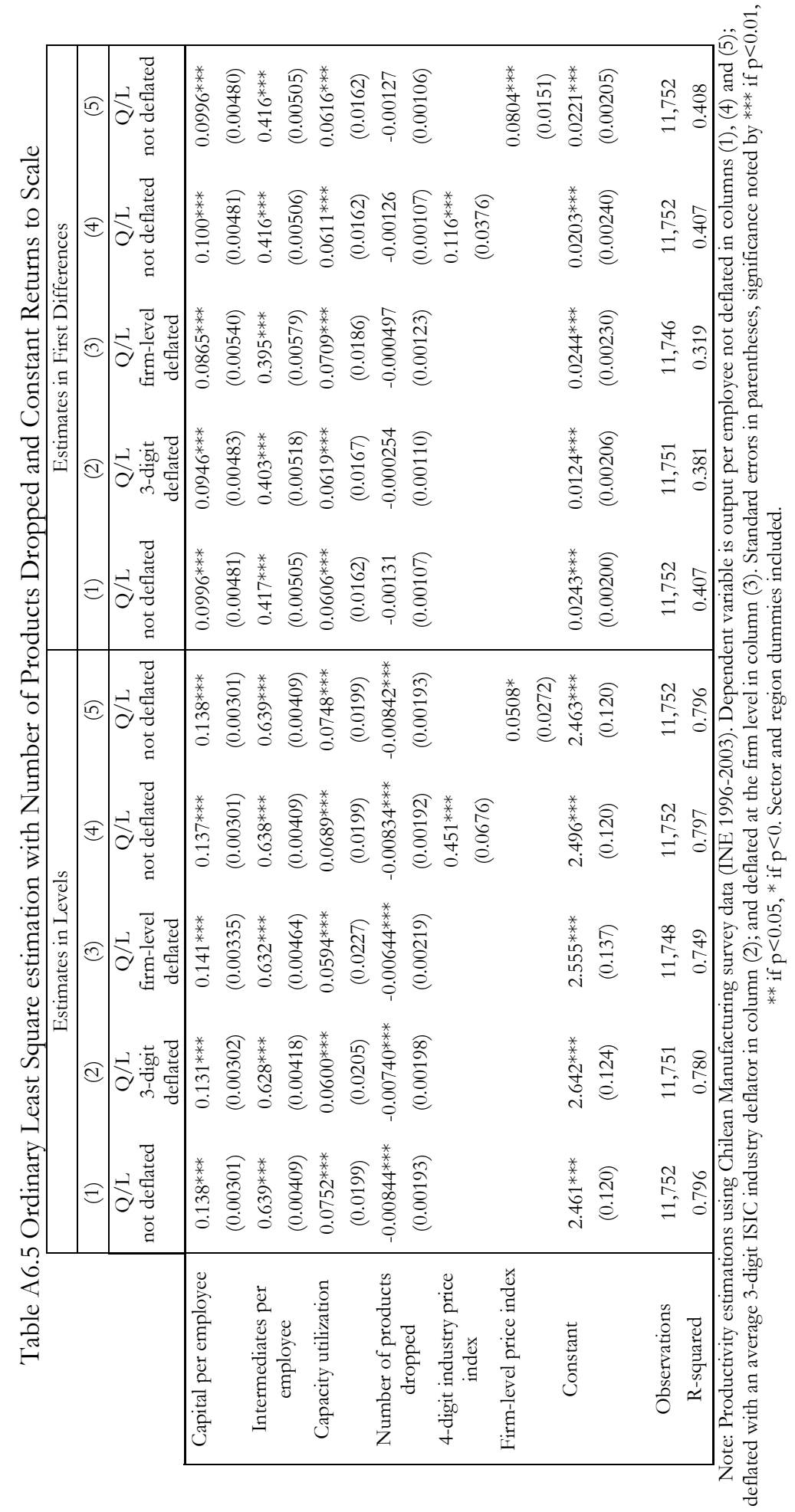




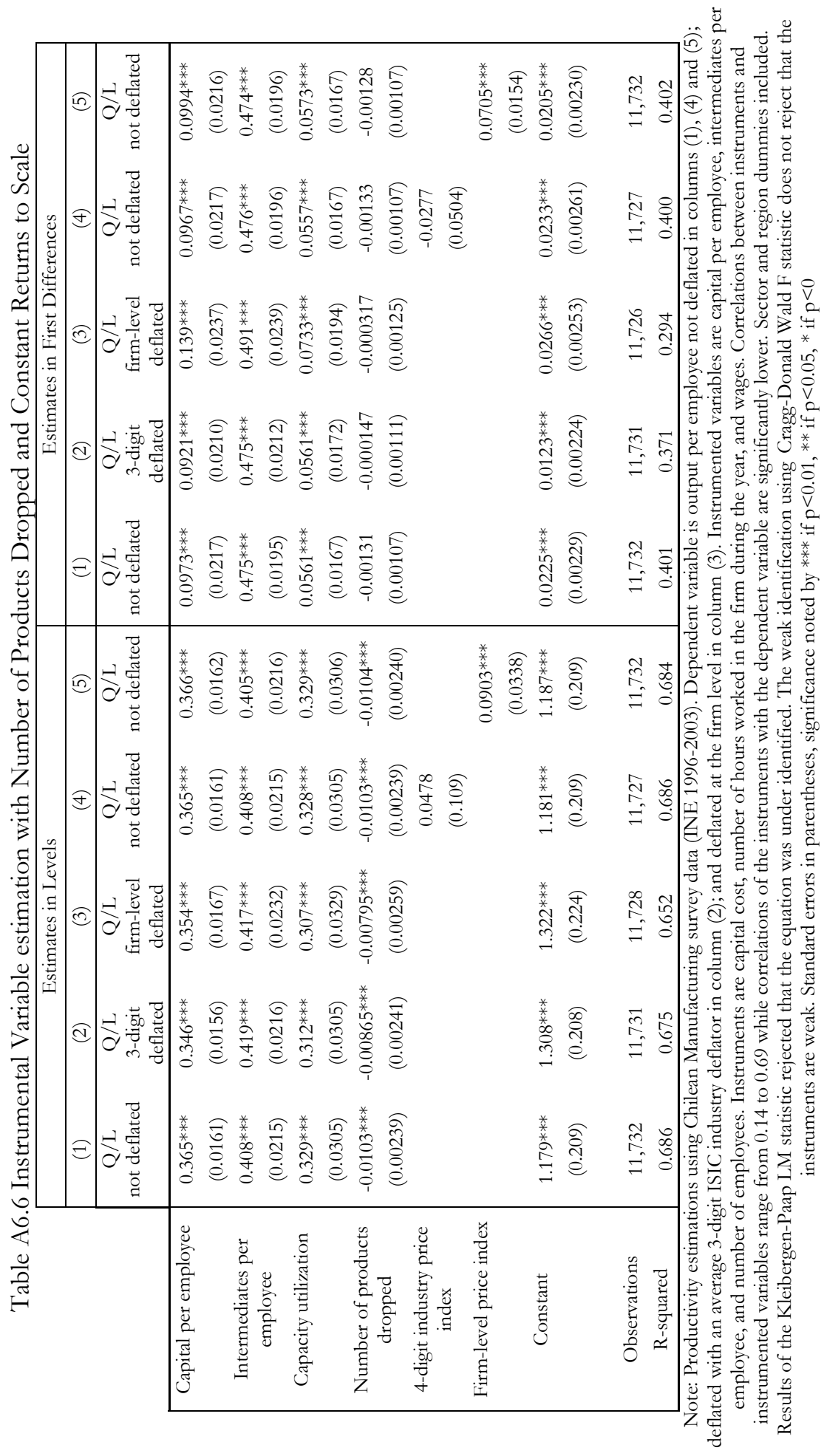





\section{CURRICULUM VITAE}

Rodolfo Lauterbach was born in Santiago, Chile in 1981. He studied Economics at the University of Chile where he obtained his undergraduate degree in 2006. He worked for two years as a researcher of INTELIS centre for Innovation and Entrepreneurial studies in Santiago. In 2007 he taught Applied Econometrics at the Engineering School of the Catholic University of Chile. During 2006 and 2007 he also worked as R.A and T.A. on Economic Development, Econometrics and International Finance courses. In June 2008 he published his undergraduate thesis together with J.M. Benavente, "Technological Innovation and Employment: Complements or Substitutes?" in The European Journal of Development Research (vol 20, issue 2).

Rodolfo joined the PhD program of Maastricht University and United Nations University at Maastricht Economic and Social Research and Training Centre on Innovation and Technology UNU-MERIT in September of 2008. During his PhD research he participated in several opportunities as a visiting researcher at CRESTINSEE in Paris. Part of his research was also conducted at the Economics Department of the University of California at Berkeley. His work in progress has been presented in several conferences including the MEIDE Conference 2007 in Maastricht, 2009 in Rio do Janeiro and 2010 in Tartu.

Rodolfo Lauterbach currently works as an Innovation Management Consulting Associate at the Scientific and Technological Research Directorate of the Catholic University of Chile, DICTUC. 



\section{UNU-MERIT DISSERTATION SERIES}

74. Kirsten Wiebe (2012), Quantitative Assessment of Sustainable Development and Growth in Sub-Saharan Africa.

73. Julio Miguel Rosa (2012), Organizational Strategies, Firms' Performance and Spatial Spillovers. The Canadian Case in Research and Development.

Johannes Wilhelmus Marie Boels

Joseph Schumpeter, honderd jaar economische ontwikkeling. Een historischtheoretische beschouwing.

72. Daniel Vertesy (2011), Interrupted Innovation: Emerging economies in the structure of the global aerospace industry.

71. Tina Saebi (2011), Successfully managing alliance portfolios: an alliance capability view.

70. Nora Engel (2011), Tuberculosis in India - A case of innovation and control.

69. Evans Mupela (2011), Connectivity and growth in Sub-Saharan Africa: The role of communication satellites

68. Nantawan Kwanjai (2011), Cross cultural intelligence amid intricate cultural webs A tale of the UnDutchables in the land of 1002 smiles

67. Lina Sonne (2011), Innovation in Finance to Finance Innovation: Supporting propoor entrepreneur-based innovation

66. Fernando Santiago Rodriguez (2010), Human Resources Management Practices and Learning for Innovation in Developing Countries: Pharmaceutical Firms in Mexico

65. Zakaria Babutsidze (2010), Essays on Economies with Heterogenous Interacting Consumers 
64. Bertha Vallejo (2010), Learning and Innovation Under Changing Market Conditions: The Auto Parts Industry in Mexico

63. Donatus Ayitey (2010), Technical Change, Competitiveness and Poverty Reduction: A Study of the Ghanaian Apparel Industry

62. Sergey Fillipov (2010), Multinational Subsidiary Evolution: Corporate Change in New EU Member States

61. Asel Doranova (2010), Technology Transfer and Learning under the Kyoto regime; Exploring the Technological Impact of CDM projects in developing countries

60. Alexis Habiyaremye (2009), From Primary Commodity Dependence to Diversification and Growth". "Absorptive Capacity and Technological Catch Up in Botswana and Mauritius".

59. Yoseph Getachew (2009), The Role of Public Capital in Economic Development

58. Sandra Leitner (2009), Embodied Technological Change and Patterns of Investment in Austrian Manufacturing

57. Semih Akçomak (2009), The Impact of Social Capital on Economic and Social Outcomes

56. Abraham Garcia (2009), The Role of Demand in Technical Change

55. Saurabh Arora (2009), Coherence in socio-technical systems: a network perspective on the innovation process

54. Rutger Daems (2008), Medicines for the developing world

53. Johannes Hanel (2008), Assessing Induced Technology - Sombart's Understanding of Technical Change in the History of Economics

52. Rifka Weehuizen (2008), Mental Capital: the economic significance of mental health

51. Danielle Cloodt (2008), The relationship between R\&D partnership formation, social embeddedness and innovative performance

50. Sabine Fuss (2008), Sustainable Energy Development under Uncertainty 
49. Tobias Kronenberg (2007), Reconciling Environmental Conservation with Economic Prosperity: The Feasibility of Double Dividends in the Short and Long Run

48. Viktoria Kravtsova (2007), Assessing the Impact of Foreign Direct Investment in Transition Economies

47. Suhail Sultan (2007), The Competitive Advantage of Small and Medium Sized Enterprises: The Case of Jordan's Natural Stone Industry

46. Bulat Sanditov (2006), Essays on Social Learning and Imitation

45. Mamata Parhi (2006), Dynamics of New Technology Diffusion: A Study of the Indian Automotive Industry

44. Andreas Reinstaller (2006), Social structures and the innovation process: Their role in the demand of firms and consumers

43. Rose Kiggundu (2006), Innovation systems and development : the journey of a Beleaguered Nile Perch Fishery in Uganda

42. Thomas Pogue (2006), The Evolution of Research Collaboration in South African Gold Mining: 1886-1933

41. Geoffrey Gachino (2006), Foreign Direct Investment, Spillovers and Innovation: The Case of Kenyan Manufacturing Industry

40. Önder Nomaler (2006), Technological Change, International Trade and Growth An Evolutionary, Multi-Agents-Based Modeling Approach

39. Samia Satti Osman Mohamed-Nour (2005), Change and Skill Development in the Arab Gulf Countries

38. Elad Harison (2005), Intellectual Property Rights: Economics and Policy Analysis

37. Daniel Dalohoun (2005), The relationship between R\&D partnership formation, social embeddedness and innovative performance: a multi-level approach of social embeddedness

36. Müge Ozman (2005), Networks, Organizations and Knowledge

35. Bas Straathof (2005), Product variety and economic growth - The counteracting effects of scale and idiosyncrasy 
34. Wilfred Schoenmakers (2005), Knowledge Flows between Multinational Companies: A Patent Data Analysis

33. Myriam Cloodt (2005), Mergers and Acquisitions (M\&As) in High-Tech Industries: Measuring the Post-M\&A Innovative Performance of Companies

32. Paola Criscuolo (2004), R\&D Internationalisation and Knowledge Transfer. Impact on MNEs and their Home Countries

31. Maarten Verkerk (2004), Trust and Power on the Shop Floor

30. Gottfried Leibbrandt (2004), Adoption, harmonization and succession of network technologies across countries

29. Mark Sanders (2004), Skill Biased Technical change - Its Origins, the Interaction with the Labour Market and Policy Implications

28. Nadine Roijakkers (2003), Inter-firm cooperation in high-tech industries: a study of $\mathrm{R} \& \mathrm{D}$ partnerships in pharmaceutical biotechnology

27. Viki Sonntag (2003), Speed, Scale and Sustainability

26. Masaru Yarime (2003), From End-of-Pipe Technology to Clean Technology

25. Stéphane Malo (2003), The combinatorial Chemistry Revolution - Sustaining a Superior Performance Position through Technological Learning

24. Annelies Hogenbirk (2002), Determinants of Inward Foreign Direct Investment: the Case of the Netherlands

23. John Adeoti (2001), Technology Investment in Pollution Control in Sub-Saharan Africa: The Case of the Nigerian Manufacturing Industry

22. Edward Huizenga (2001), Innovation Management: How Frontrunners Stay Ahead. An Empirical Study on Key Success Factors in the ICT sector

21. Machiel van Dijk (2000), Technological Change and the Dynamics of Industries. Theoretical Issues and Empirical evidence from Dutch Manufacturing

20. Jan Cobbenhagen (1999), Managing Innovation at the Company Level: A Study on Non-Sector-Specific Success Factors 
19. Marjolein Caniëls (1999), Regional Growth Differentials: The Impact of Locally Bounded Knowledge Spillovers

18. Aldo Geuna (1998), Resource allocation and knowledge production: Studies in the economics of university research

17. Reinoud Joosten (1996), Dynamics, Equilibria, and Values

16. Hugo Kruiniger (1996), Investment, R\&D, and the Financing Decisions of the Firm

15. Hans van Meijl (1995), Endogenous Technological Change: The Case of Information Technology. Theoretical Considerations and Empirical Results

14. René Kemp (1995), Environmental Policy and Technical Change. A Comparison of the Technological Impact of Policy Instruments

13. Rohini Acharya (1995), The Impact of New Technologies on Economic Growth and Trade. A Case Study of Biotechnology

12. Geert Duysters (1995), The Evolution of Complex Industrial Systems. The Dynamics of Major IT Sectors

11. Marjan Groen (1995), Technology, Work and Organisation, A Study of the Nursing Process in Intensive Care Units

10. Huub Meijers (1994), On the Diffusion of Technologies in a Vintage Framework; Theoretical Considerations and Empirical Results

9. Theon van Dijk (1994), The Limits of Patent Protection. Essays on the Economics of Intellectual Property Rights

8. Hans Voordijk (1994), Naar Integrale Logistiek in Bedrijfsketens, Ontwikkelingen in de Bouw

7. Paul Diederen (1993), Technological Progress in Enterprises and Diffusion of Innovations. Theoretical Reflections and Empirical Evidence.

6. Ben Dankbaar (1993), Economic Crisis and Institutional Change. The crisis of Fordism from the perspective of the automobile industry

5. Hanno Roberts (1993), Accountability and Responsibility: The Influence of Organisation Design on Management Accounting 
4. Bart Verspagen (1992), Uneven Growth Between Interdependent Economies. An Evolutionary View on Technology Gaps, Trade and Growth

3. Sjoerd Romme (1992), A Self-organization Perspective on Strategy Formation

2. John Spangenberg (1989), Economies of Scale, and Atmosphere in Research Organisations

1. John Hagedoorn (1988), Evolutionary and heterodox innovation analysis : a study of industrial and technological development in process control and information technology 